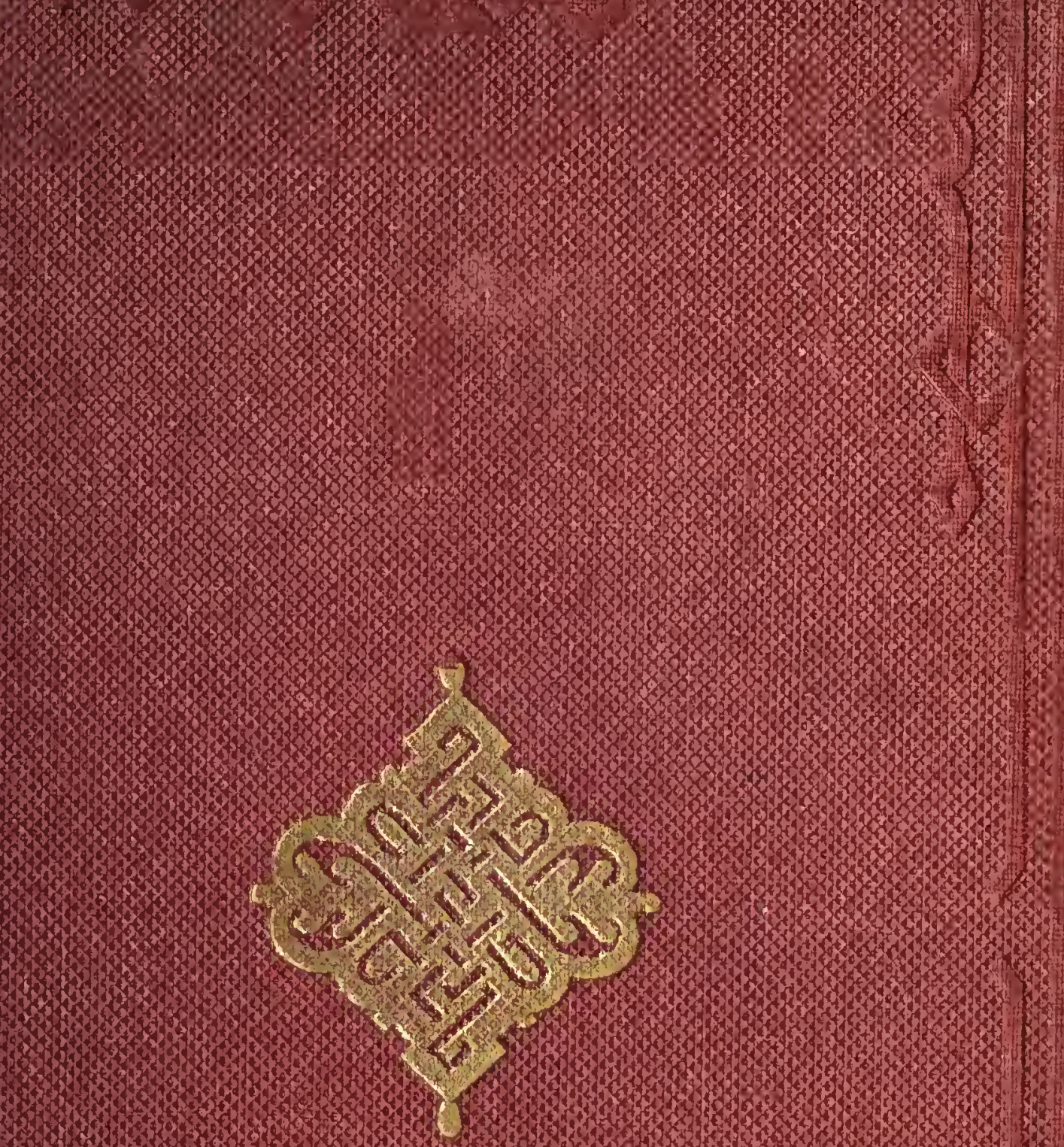

. 

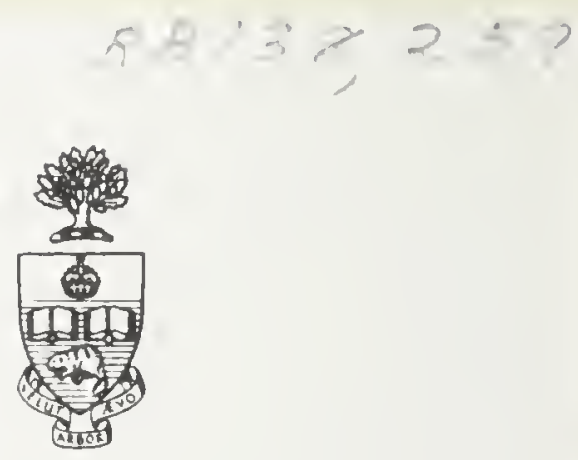

Presented to the

LIBRARY of the

UNIVERSITY OF TORONTO

by

Mrs. Andrew Kellogg 


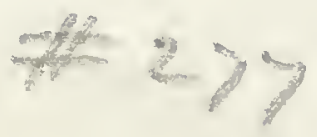


Digitized by the Internet Archive in 2018 with funding from University of Toronto

https://archive.org/details/introductiontoma00smit 


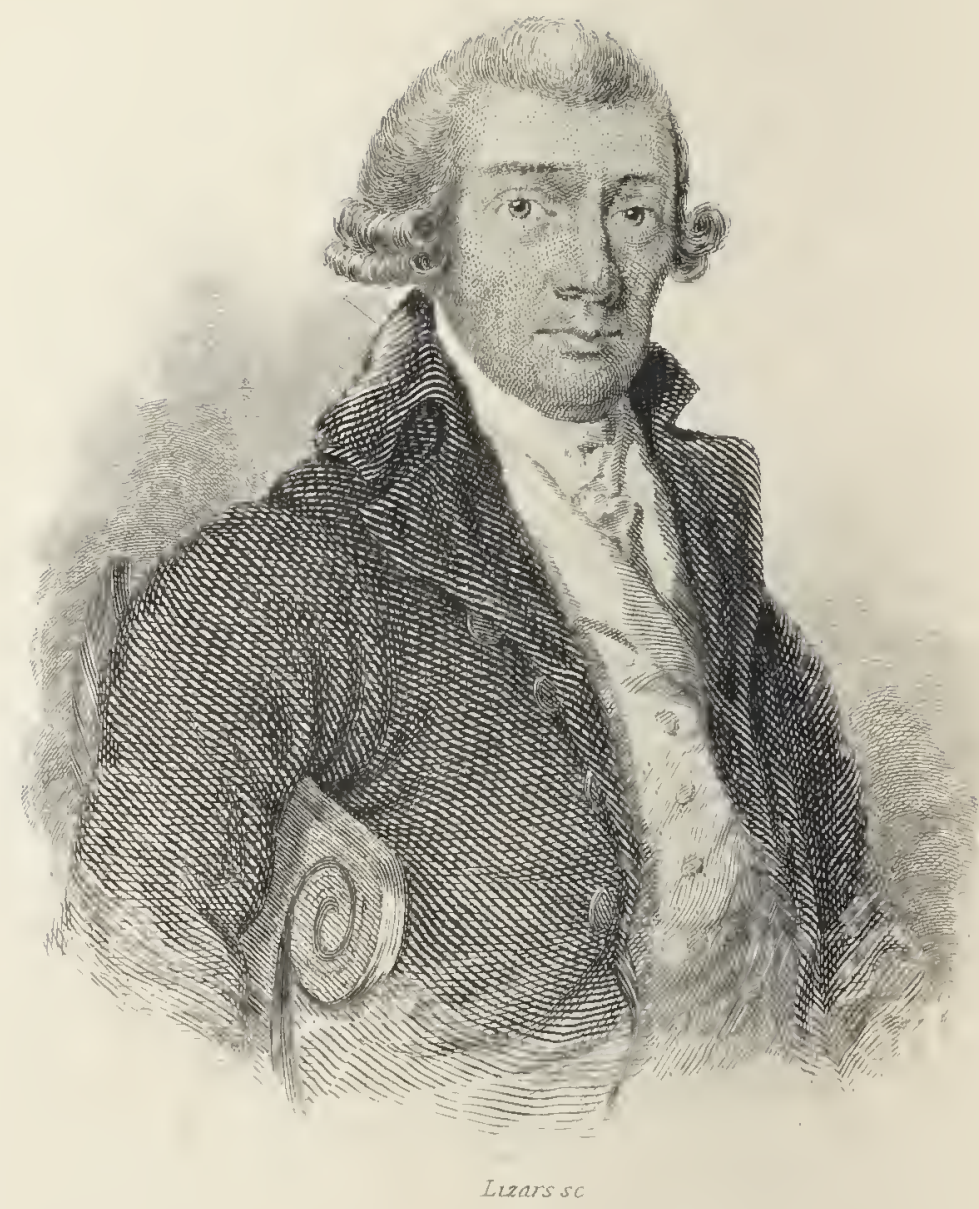

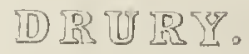


WA

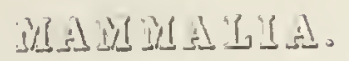

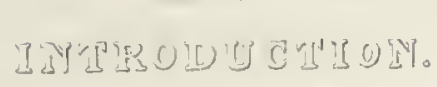

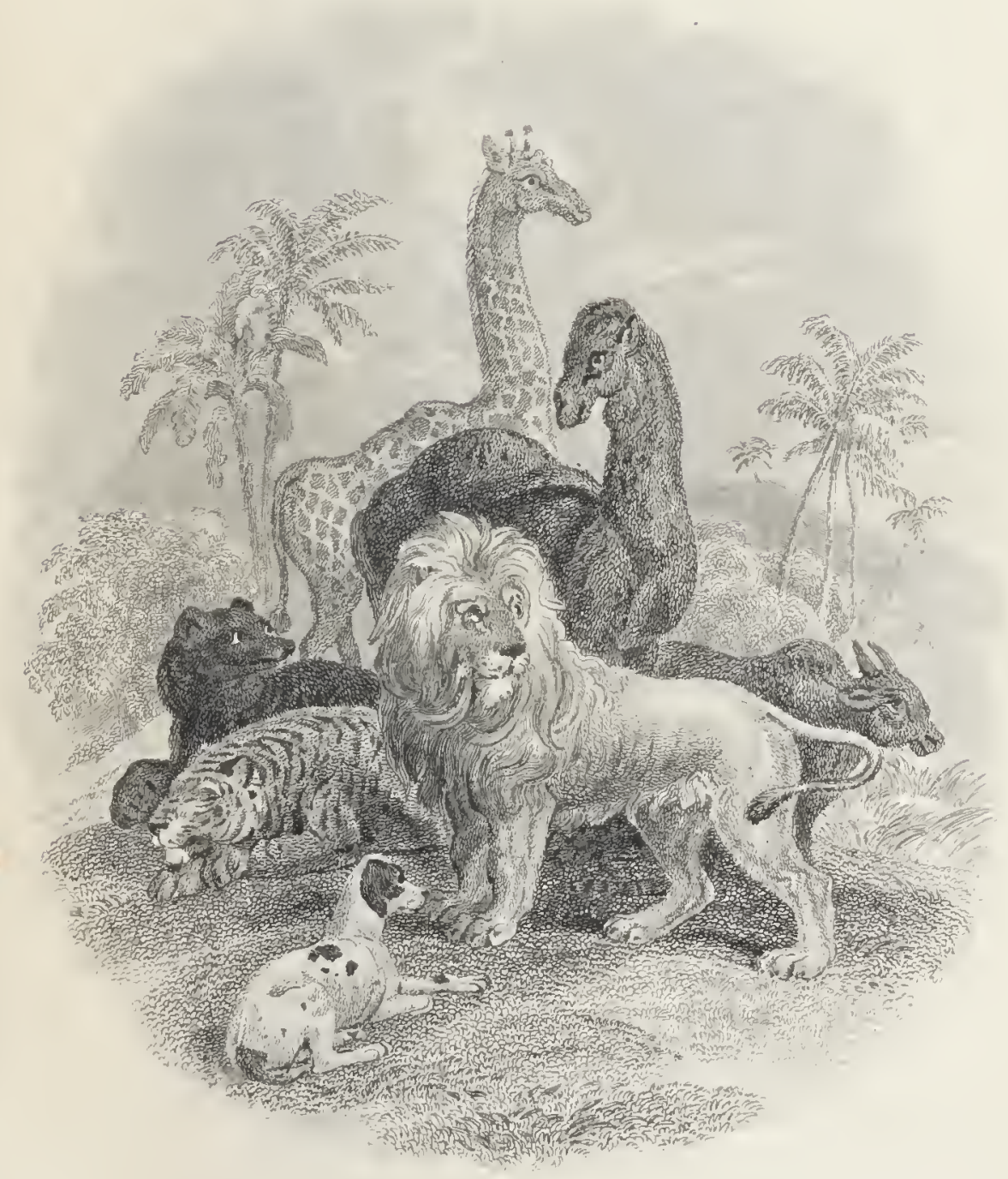





\section{THE}

\section{NATURALIST'S LIBRARY.}

EDITED BY

SIR WILLIAM JARDINE, BART.

F.R.S.E., F.L.S., ETC. ETC.

Vol. XV.

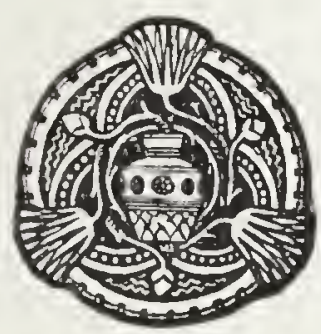

Ittammalia.

INTRODUCTION TO MAMMALIA.

BY LIEUT.-COL. CHARLES HAMILTON SMITH, K.H. AND K.W., F.R. AND L.S., PRESIDENT OF THE DEVON AND CORNWALL NAT. HIST. SOC., ETC. ETC.

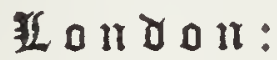

CHATTO \& WINDUS, PICCADILLY. 



\section{CONTENTS.}

PAGR

Memolr of Dru Drury, . $\quad$ - $\quad$ • $\quad$. 17

INTKODUCTION, . . . . 73

'I'he Mamalia, . . . . 80

Division of the Class Mammalia into Orders, . $\quad .9$

VERTEBRATA.-MAMMALIA.

I. Sub-Class._PLACENTALIA, - 93

ORDER I._BIMANA, • • • • 96

ORDER II.-THE QUADRUMANA, 99

White Maimon.

Macacus (Maimon) Rrosszurus. Plate I. . 103 ORDER III.-THE CHEIRUPTERA, . . 113

White Box-tailed Bat.

Diclidurus albus, or Freyreysii. $\quad$ Plate II. . $\quad 123$

Common Vampyre Bat.

Vampyrus spectrum. Plate II. . 126

ORDER IV._INSECTIVORA, . . . 138

ORDER V.-THE CARNIVORA, . . . 150

Greyhound Dhole.

Chryseus. Plate III. . . . 153

Meercat. Barrow.

Cynictis Steedmanni. Plate IV. . $\quad 157$

The Zebra Ichneumon.

Herpestes mungo. Plate V. . . 159

Paradomurus dubius. Plate VI. . . 162

Gwatkin's Galidictis.

Galidictis chrysogaster. Plate VII. . 167 
CONTENTS.

PAGB

Genetta tigrina. Plate VIII. . . . 173

Hemigalea zebra. Plate IX. . . 175

The Felide, . $\quad$. . . . ib.

Black Maned Lion.

Leo melanochaitus. Plate X. $\quad$. $\quad 177$

The Maneless Lion.

Felis leo gougeratensis. Plate XI. . . 178

Felis uncia. Plate XII. • . . 181

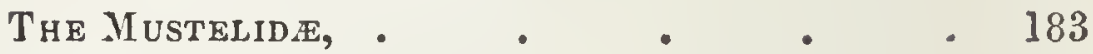

The Plantigrades, •

The Arctogalide, . . . . . j3

Chili Skunk.

- Meph. Chilensis. Plate XIII. . . 198

Banded Grison.

Galictis vittata, Plate XIV. • • . 200

Eira furriginea. Plate XVI. . . 204

Telagon or Stinkard.

Mydaus meliceps. Plate XV. . . 213

The URSIDe, . . . . . ib.

Shining Panda,

Ailurus fulyens. Plate XVII. . . 215

Nasua monachus. Plate XVIII. • . 220

Crab-eating Racoon.

Procyon cancrivorus. Plate XIX. . . 223

The Brown Bear.

Ursus Arctos. Plate XX. • • . • 235

The Pinnatipedes, • • • • 246

The Sea Otter.

Enhydra marina. Plate XX.* . . 254

ORDER VI.-THE CETACEA, • • . 265

CRDER VII.-THE PACHYDERMATA, • 268

ORDER VIII.-THE RUMINANTIA, • • 274

The Camrlide, . . . . 275

The Cervide, . . . . . . ib.

The Giraffide, . . . . . 278

The Capride, . . . . . . 279 


\section{CONTENTS.}

PAGE

Sub-genus Aigocerus.

Aigocerus Niger. Plate XXI. . . 281

THE BOVIDA, . • • • . 2838

ORDER IX._THE EDENTATA, . • 294

Chlamyphorus truncatus. Plate XXIII. • 298

The Tamandua or Great Anteater.

Myrmecophaga jubata. Plate XXII. . 300

ORDER X.-THE RODENTIA, • • . 302

Duvaucel's Squirrel.

Sciurus hypoleucus. Plate XXIV. . . 305

Long-toed Spinous Rat.

Echimys dactilinus. Plate XXV. • . 308

Chinchilla Diana, Viscachia? Plate XXVI. 309

The Cavide, . . . . . ib.

The Cabybara.

Hydrocharus Cabiai. Plate XXVII. . . 310

Lepus Braziliensis. The Tapeti. Plate XXVIII. ib.

II. Sub-Class.-IMPLACENTALIA.

ORDER XI.-THE MARSUPIALIA OR POUCH-

ED ANIMALS, • . • . 311

Halmaturus Rutilans. Plate XXIX. . . ib.

ORDER XII._MONOTREMATA, . . $3 \mathrm{I} 2$

Echidna setosa. Plate XXX. . . . . ib.

Portrait of Dru Drury, . . . . 2

Vignette Title-Page, . $\quad$ - $\quad$. 3

In all Thirty-one Plates in this Foume. 



\section{MEMOIR OF DRU DRUKY.}

To those who are acquainted with the history of Entomology, the name of Dru Drury is familiarly known, as one of the most zealous and successful collectors of insects that ever prosecuted the study in this country. The work entitled "Illustrations of Exotic Entomology," in which he made the most interesting objects of his collection known to the public, is also admitted to be of very high merit; it is still one of the most beautiful we possess on this subject, and at the time when it appeared, was almost unrivalled for the elegance and accuracy of its pictorial delineations. In both the capacities, therefore, of a collector and author, Drury has rendered most important services to Entomology, and is entitled to the respect and gratitude of all who cultivate the science,-a science which, according to the high authority of Baron Walckenaer, is at once the most difficult, the most extensive, and most philosophical, of all the departments of Natural History. In these circumstances it is gratifying 
to have it in our power to give some account, for the first time, of the most remarkable incidents of Drury's life, along with extracts from his voluminous correspondence, which was carried on with nearly all such of his cotemporaries as took an interest in the subject to which he was so warmlv attached.*

Dru Drury was born on the 4th February 1725, in Wood Street, Cheapside, London. His father, who was of the same name, was a manufacturer of silver spoons and knife and fork handles, in Love Lane, Wood Street; he also resided for some time at Hutton, in Essex. He was married four times. By his first wife, Mary Grundy, he had five children, all of whom died young. By his second wife, Mary Hesketh, he had eight children, all of whom died before attaining the age of puberty, except Dru, the subject of this memoir, who was the second. By his third and fourth wives, Mary Cholmeley and Mary Pedley, he had no children. His death took place on the 18th April 1763, at the age of seventy-five.

It appears from an account of the family of Drury, accompanied with a genealogical tree, in a work entitled the History and Antiquities of Hamstead,

* The materials from which this biographical notice is drawn up, as well as the painting from which the prefixed portrait is engraved, have been supplied to us by Messrs. Drury of London, grandsons of the subject of this Memoir, to whom we beg leave to offer our best thanks for tlieir courtesy and attention. 
in Suffolk, that the first of that name who settlepi in this country was a Norman gentleman, who came to England from Normandy with William the Conqueror in 1066. It is further stated, that in Normandy there is still a place called Drury, * and sundry persons of that surname. The manor of Hamstead, above alluded to, was in the possession of the Drury family one hundred and ninety years, but in $\mathbf{1 6 5 6}$ it passed into another family by marriage.

Of the early life of that member of the family with whom we are more immediately concerned, it is not in our power to furnish any account. In a brief sketch which he himself gives of his history to one of his correspondents, he commences with his marriage. It is probable that, after finishing his education, which seems to have been conducted with some care, he assisted his father in the business he carried on in Wood Street. However this may be, we find that, when he had attained the age of twenty-three, his father entirely resigned the business into his hands. About the same time he married Esther Pedley, the daughlter of his father's first wife by her former husband, John Pedley of Wood Street, soapmaker. The marriage took place on the Tth of June 1748, in Allhallow's Church, London Wall. In consequence of these marriages with the Pedleys, Dru Drury became possessed of some freehold houses in London, Essex, Hertford-

* It is possible that the well-known Drury Lane may have derived its name from the same source. 


\section{MEMOIR OF DRURY.}

shire, and Middlesex, which yielded an annual income of between $\mathscr{L} 250$ and $\mathfrak{E} 300$.

$\mathrm{He}$ carried on the business in Wood Street for many years, it would appear with considerable success at first, although it ultimately began to fall off, and he became desirous to effect some change. "When my father resigned his business to me," we find him writing to one of his correspondents, "it was sufficient for a man to live on, but not to lay up any great sum. The industry I constantly exercised enabled me to live for about eighteen years with much happiness and satisfaction, at which time, finding my trade gradually diminish, I was determined to embrace the first opportunity of engaging in some other that was more likely to reward my labour. I already mentioned that I have had seventeen children, besides nine miscarriages, the heavy expense of which, together with some severe blows of fortune, had prevented me acquiring that wealth I probably might otherwise have done, and therefore my resolution of pursuing some other trade every day increased. About that time Mr. Jeffreys, my predecessor, wanted to retire from business, and applying to me for a person to succeed him, I embraced the opportunity, and have the honour of being made Goldsmith to the Queen and also Cutler to the King; - a feather $\mathbf{I}$ would at any time resign, if no advantage arose from it, for I have lived long enough to be able to laugh most heartily at the fools that can think happiness dependent on titles, or content flourishing amidst 
pomp and distinctions." The business, however, in Wood Street enabled him to realise about $\mathfrak{E} 6000$, and likewise to keep a country-house at Enfield, in Middlesex, at which his family for the most part resided.

It was in February, 1771, that he purchased the stock in trade and good will of the business of Mr. Nathaniel Jeffreys, gold and silver smith and cutler, at No. 32 Strand, London, for the sum of \& 11,500 , paying him partly in cash, and the balance by instalments at stated periods. The business to which he had been brought up, he himself states, was that of a working silversmith, and the change to a goldsmith, he adds, was so considerable, that it was necessary for him to derote the whole of his time to it in order to become acquainted with the details of management. He appears to have conducted the business for several years with great success, realising an income of nearly $\mathfrak{E} 2000$ per annum. He made great efforts to extend his mercantile transactions, and formed extensive contracts for supplying several regiments with swords and other military accoutrements. Still, however, he had various difficulties to encounter, and a perusal of his letters about this period makes us aware that the business had not equalled his expectations, and the obligations he had contracted to obtain it threatened ultimately to become oppressive. It was in all probability this conviction that led him to enter the more readily into a speculation which promised at first to be highly adrantageous, but which 
in the end was attended with the most disastrous consequences.

In 1777 , he entered into an arrangement with certain parties to supply them with goods, principally plate and jewellery, to a large amount. For a time he accepted of their bills, but these he was soon informed by them they were unable to pay, accompanying this intelligence with a proposal which they thought likely to satisfy Drury for the whole sum they might become due to him. One of the parties represented himself as entitled to a very considerable estate in Yorkshire, which his father then enjoyed, but which must come to lim after his father's decease, it being entailed on the male heir, so that it was not in his father's power to deprive him of it. The estate was alleged to be worth between twenty and thirty thousand pounds, and to be let for about a thousand pounds per annum, and it was proposed to convey a mortgage of the reversion of the property to Drury as security. This proposal was urged with great plausibility, and Drury's desire to send a lawyer to examine the validity of the title to the estate at once acquiesced in, and every other facility offered for completing the arrangement. The attorney was absent for some time, and his report must have been "such as to satisfy Mr. Drury, for the necessary deeds were afterwards duly drawn up and signed. On the belief that the transaction was managed in good faith, and the parties men of honour and integrity, Drury advanced goods at various times, till they ultimately 
amounted to the value of upwards of $\mathbb{E} 10,060$. It unfortunately turned out, on future investigation, that the security for this large sum was of no value, the parties not having a legal right to the estate in question, and having concerted the scheme to plunder him of his property. To aggravate this evil, he had met with several severe losses in trade only a short time before, and his freehold property had previously been assigned over to Mr. Jeffreys as security for the balance of the purchase-money of the business. He thus felt himself stripped of all his property.

In these circumstances he had no alternative but to call a meeting of his creditors, and lay before them a statement of his affairs. He was thereupon declared bankrupt, and surrendered all his property under the commission.

A thorough conviction of the sterling worth of his character, distinguished, as it had always been, for integrity, honourable feeling, and great diligence in business, predisposed his creditors to treat him with the utmost lenity. By the assistance of his friends (among whom we find the names of Dr. Fothergill and Mr. Banks), he was enabled to repurchase his stock in trade, and resume his business in his former premises. He, appears to have borne this reverse of fortune with great fortitude, but his constitutional sensibility led him to feel deeply on the occasion. The state of his mind in some measure appears from the following extract from a letter addressed to a reverend friend at Warnham, near 
Horsham. It is dated 11th December, 1777."There was a time when the subjects that occupied my pen in writing to my worthy friend, were very different from those which now occasion the same employ. There was a time when those subjects were all of a gay and cheerful cast; when no dark and gloomy thoughts prevailed to cloud and tarnish the happy hours of my worthy friends at Warnham Place. There was also a time when, with a bold and open brow, I feared not to look each man in the face, well knowing none could ask me for debts I was not able to pay,- - a time when I was happy, pleased, and solvent. But now I am, what? a B-! though an honest man. I repeat the word an honest man, well knowing myself to be so. God forbid that I should make the terms incompatible with each other, for it is certainly true. 'Tis not in the power of mortals to command success, but it is in the power of every one to be just and honest, and that I have been so, witness, kind Heaven! No action of my life hangs heavy on my heart, no crime. to make me wretched or unhappy; but yet I drop a tear while I relate the mournful news. I beseech you do not think I rave. Men of sensibility cannot think like the common herd, and it has been my misfortune to be cursed with too great a portion of that ingredient. Cursed did I say? Forgive me Heaven! for thus arraigning the justice of thy dispensations. I hope I do not write amiss in saying so, but if I had possessed less sensibility, less credulity and fewer feelings, I had now been a 
wealthier man; I had now enjoyed the fortune I formerly possessed; but alas! who can tell what is reserved in store for him? The very misfortune that I now so heavily deplore, may turn out to be the happiest period of my life, and what I consider as the greatest evil, may, in the hand of Providence, be the greatest blessing. Shall I then distrust His gooduess? Shall I consider that Being whose works I have ever viewed with wonder and delight, whose infinite wisdom, goodness, and power have been so plainly manifested; shall I consider Him, I say, in such a light as to suppose $\mathrm{He}$ will not extend that goodness and power towards me which in thousands of instances I have experienced in my life? Certainly not. Believe me, my dear friend, when I tell you that $\mathrm{He}$ is my only support, my strongest prop and stay, and the only ground on which I build my future hopes. Do not think I rant when I tell you, in the full bitterness of soul, that these thoughts are my only comfort, and it is from the interposition of His Providence that I hope to be extricated from all my present troubles. I do not think I am wrong in my judgment, if $I$ get réinstated in my business, to say it is owing to His interference that I obtain that happiness; and although the goodness of my own character, the kindness of my friends, and the clemency of mankind, may be the medium by which that end is accomplished, yet the other is the primary and unseen Cause to whom all my thanks will be due, 
together with all the sacrifice of prayer and praise that a grateful heart can give."

Mr. Drury obtained from his creditors a certificate of discharge in April 1778. After recommencing business he proved most successful, his friends and former customers vying with each other in promoting his interests and testifying their respect for his character. In his letters of this date, we find many expressions of gratitude for the sympathy and support he was receiving: among others is the following: "I have got reinstated in my business, which I really think is much greater than it ever was; the civilities and kindness I have received from the public are beyond conception, and I have no doubt but a few years, if Providence allows me health, will place me in a much happier and better situation than I ever was. Would you believe it? The Queen herself, to whom I am goldsmith, lias been so very kind as to say that "She hoped I would do well again." Thus you see Providence never permits an evil to befall us but it also has some good in store, and in that liglit I now view my laté misfortunes." With these pleasing prospects, we leave, for a while, the consideration of Mr. Drury's commercial relations, to which indeed we shall have little occasion again to refer, as enough has been said to show the position he occupied in society; and proceed to view him in a capacity more appropriate to our purpose, and which aione has brought him under our notice on the present 
occasion, namely, as an intelligent and indefatigab:e cultivator of Natural History.

Entomology was the subject to which he was most ardently attached, although it is evident from his letters that he did not altogether neglect some of the other departments. It does not appear what first attracted his attention to this study, nor at what time he first began to prosecute it, but it was probably at an early period of his life. Writing to General Ranger, in 1778, he states that he had been employed thirty years in forming his collection of insects, so that he must have commenced about the time when he first engaged in business on his own account. Much of the earliest portion of his correspondence that has been preserved, consists of letters to individuals residing in foreign countries, soliciting them to transmit specimens to him. He seems to have neglected no opportunity that presented itself at all likely to promote his views, and the time and trouble he spent on the subject must have been great. The letters in question are generally of great length, written with much care, and giving detailed direction about the best mode of collecting, preserving, \&c. A specimen of them has already been published by Mr. Westwood in his recent edition of Drury's Illustrations of Natural History, from a great number now before us, equally long and elaborate, we select the following: it is addressed to Captain Mayle, of the Hound sloop of war, going to the coast of Africa. 


\section{"Dear Sir,}

"The promise you are so kind to make me of sending me some curiosities from the coast of Africa, I cannot help considering as the strongest instance of your friendship I ever was favoured with, nor have I the least doubt of your resolution of faithfully performing it when opportunities arise; but give me leave to mention what kind of curiosities will be most pleasing to me and what not. This I shall comprise in one single word, by assuring you my taste in these subjects is confined entirely to INSECTS; all the other parts of natural history put together do not afford me a quarter of the delight as this single class. Hence you perceive the most agreeable present you can possibly make me will be a collection of this kind, and as the method of obtaining and preserving them requires some instructions, I flatter myself these memoranda will not be unnecessary. For this purpose I shall divide insects into three several kinds: Ist, The farinaceous winged tribe; $2 \mathrm{dly}$, The hard scaly winged tribe; 3dly, The transparent winged tribe. The first includes butterflies and moths, whose variety is exceedingly great; the second takes in all the beetle kind, whose variety is not less; in the third is comprehended all kinds of bees, wasps, locusts, ants, water-flies, \&c., all which produce, in their respective genera, such a number of species as is really wonderful. For the taking of all sorts you will find the forcep-nets (of which I send two pair) exceeding useful, and the most convenient implement 
ever invented. Let me therefore entreat $\mathrm{ynu}_{\mathrm{a}} \mathrm{mv}$ dear friend, when you get to Africa, not to let them remain idle. Indeed, your own time, I am very sensible, will be too valuable for you to bestow in that manner, but I apprehend you may for a very trifle hire a boy or a man to collect them in the fields and woods, who at night can bring home to you what he has procured, which you may place in one of the green square boxes whose bottoms and tops are lined with green wax. For this purpose I send you three smaller boxes, with pieces of cork in the bottoms and tops; one or two of these may be taken by your agent into the fields when he goes collecting, and having caught an insect with the forcep-net, let him stick it through the body with a pin and fasten it in one of these boxes, where it will remain secure till it is removed to one of the square green boxes. If he catches a butterfly or moth, let him give the body a good squeeze, which will kill it, and then stick it in one of the boxes. Each of these, observe, is capable of containing a great number, if he sticks them close to each other; the pins for this purpese I have also sent, with pincushions to be used by the collector when he goes on this business. When you have got as many insects as you can well stow in one of the square boxes, I will get you to send it to England, enclosed in a packing-case, sending me advice by letter. But I must, previously to your packing it up, desire you to paste a slip of linen or paper outside round the joinings of the box, to prevent the ants, cockroaches, 
and other vermin from getting in and destroying the valuables. Before I proceed, I must inform your. that the most ugly, hideous, and disagreeable insects, as they would appear to the generality of mankind, are to me the most valuable, nor can the appearance of the gayest and brightest colours induce me to give them the preference. All that I desire is to have variety among the beetle kind, even those that are of the most dull and unstriking colours may perhaps be the most acceptable. May I therefore hope my good friend will indulge my appetite for these articles with a gratification? That, I must confess, I prefer to all the subjects of curiosity that that continent affords. Shall I tell you why I am so ardent for subjects of this kind? You must know that as my collection is pretty strong in insects from the West Indies, which I have procured with much trouble and some expense, I am determined to publish a History of Insects, if I can obtain a few more species than what I have already that have not been described by any author, and as the coast of Africa affords a great number of that sort, I only wait till I am so happy as to get some from those parts, when I should immediately begin; but as all my attempts, for ten years past, have proved fruitless, I am the more solicitous with you on that account. But if friendship, added to the little degree of duty owing to the public, should prove ineffectual, I shall let the whole scheme drop, because I shall conclude that if the difficulties are so great that I cannot procure them by means of a friend, it 
will be in vain to expect to get them by the assistance of a stranger. I am strongly inclined to think there are no species in Africa the same as those we have here (or, however, but a few); indeed, we are so little acquainted with the product of that part of the world, that our judgment in these cases is rather conjecture than founded on any knowledge or experience. Hence I take the liberty of saying, that whatever you will oblige me with from these climates will receive an addition to its intrinsic value from our ignorance of the insects found there, and for this reason, not only myself, but mankind in general, may be indebted to you for your endeavours this way, as I am very sensible it will be in your power to send me over many undescribed insects. (The writer then proceeds to describe the places where insects are most likely to be found, a portion of the letter which we think it unnecessary to insert here, as that matter is fully treated of in a paper given on a subsequent page). I think I have now gone through every kind, and mentioned every circumstance necessary to be known for procuring and preserving these creatures. Before I conclude, let me take the liberty of saying, that I shall ever consider myself so much indebted to you for any present of the above kind, that I shall take the first opportunity of manifesting my gratitude by a proportionate return. I would not shock your sensibility, for what expense you may be at in procuring them I do not know, but whatever it may be, it is but just I should return it. I shall only beg of you not 
to let any thing of that kind disappoint my exp tations, which I assure you are very sanguine.

"I am, with the utmost respect,

"Your most sincere Friend and

"Humble Servant, " D. Drury."

It was Drury's practice, whenever he became acquainted with any one about to visit a foreign country and willing to take some trouble in collecting insects, to supply him with a series of boxes similar to those alluded to in the above letter, forceps, nets, \&c. as well as written instructions how to proceed; promising at the same time to defray all the expense that might be incurred, and reward the collector in a manner proportionate to the value of his acquisitions. Such individual was generally em powered to engage others, after reaching the place of his destination, on similar terms. The number of those who were thus induced to offer their services was very great, and they were scattered over almost every country of the globe. Among Drury's papers we find a tabular list of the individuals who had collecting apparatus entrusted to them, the names of the vessels in which they sailed, their place of destination, and in many instances a notice of the returns made to him in insects; in very many cases, as may readily be supposed, he never received any. In the list for 1768 the names of between seventy and eighty vessels occur, and in several of these he had two or three different individuals engaged to col- 
lect. To save the trouble of furnishing written instructions to so many different parties, he drew up and printed "Directions for collecting Insects in F'oreign Countries." These were translated into several languages, and extensively distributed among the natives of different quarters of the globe, often accompanied by a series of coloured drawings of insects to show what kind of objects were required. These Directions we think it important to give here entire, as they afford many suggestions which will be of great advantage to the collector of the present day, being the result of a more extensive experience than perhaps was ever acquired in the same pursuit.

"The person that would collect insects must go into the fields or woods, taking with him the brass tongs, nets, \&c., the oval pocket-box, and the pincushion stocked with pins. The box is lined at top and bottom with cork, and is to receive what he takes. When he catches an insect of any kind, let him stick it through the body with a pin, and place it in the box; using small pins for small insects, and large pins for large ones. Large pins should not be stuck into small insects.

"If he catches a butterfly or moth, let him give the body a squeeze with his finger and thumb while it is in the net; which will prevent its fluttering, and will kill it. In doing this, he must take great care not to rub off the meal or down on its wings, for in that all their beauty consists. He mast not squeeze the body of any other kind of insect; oniy a butterfly or moth, because it wili do harm to the 
other sorts; and if he perceives the edges of the wings to be ragged or broken, appearing as if little peeces were torn out of them, he must throw such hutterfly or moth away; but as the wings of many of them are naturally scolloped, great care must be taken to distinguish one from the other. The ragged ones are imperfect and good for nothing; the porfect ones (whether they are scolloped or plain), if not torn or battered, are desirable; therefore, to know the difference, he must observe closely the wings, and if they are scolloped, he will perceive the same notches or indented edges on the right wing as on the left, the one answering very exactly and regularly to the other; whereas, in those that are ragged and imperfect, there is not any exactness or regularity, the edges of the wings being very uneven and unlike each other, having a notch here and there, as the wings happen to be more or less torn and wasted. The four butterflies placed in the oval box will readily discover the difference between those that are perfect and complete, and fit to be preserved, and those that are ragged and good f.r nothing. This account of the butterflies and moths is thus particularly mentioned, because, when they are caught, being ragged and bad, as described before, they are worth nothing; and the collector may, for that reason, spare himself the trouble of bringing such home; good ones being as easily to be caught and brought home as bad ones.

- Let him catch small insects as well as large, 
they being equally as valuable; * and let him take all the various sorts he possibly can.

"When he gets home let him take out all that are alive (except butterflies and moths), and stick-ing a few at a time on the end or edge of a piece of wood or stick; \&c. let him hold them to the fire (but not so close as to scorch or burn them), and he will find this will quickly kill them; or by throwing them into boiling hot water, they will be killed in a few moments, without injuring them, if they are taken out as soon as they are dead. Afterwards they must be stuck in the large square box, taking care not to move them after they are fixed there on any account, for fear of breaking off their horns or legs, which will much lessen their value; therefore be careful to preserve these parts, and don't place them in the large box till they are quite dead, because they will pull and tear one another to pieces with their claws, if they are alive and placed near each other. This box being lined at top and bottom with cork, like the small one, is to be considered as the repository or receptacle for all he catches.

"This method is much better than putting them

* Collectors of insects in foreign countries will do well to observe that, in the present day, the smaller species, and those least remarkable for brilliancy of colour or other peculiarities, are most likely to prove new, and therefore of greatest scientific interest. It is not to be supposed that very many of the most conspicuous species, except in certain regions, have escaped the diligent researches made for them: among the more minute and microscopic kinds, however, a rich harvest may yet be expected. 
in spirits, because the spirits will certainly destroy their colours.

"The insects placed in the oval box, and now sent, will serve to show what kinds of things are meant, and also the manner in which the pins are to be stuck through them, observing, that the insects of foreign countries are oftentimes much larger than any of these now sent, but are not less valuable on that account. These are only sent as examples, being all English, and of no value; therefore they may be thrown away when the person gets abroad, in order to make room for those that are to be caught.

"It is desired, if the ship touches at different places in _ to collect some at each of them, taking care to distinguish and separate them by a mark or line in the box denoting where they were taken, and keeping each parcel by itself.

"Remember to bring as great a variety as possible, not too many of one sort, but different ones; two or three being a sufficient number of any one kind, it not being so much the number as the different kinds that are wanted; and for this reason the collector is requested to bring various sorts of Butterflies or Moths, Beetles, Flies with transparent wings, Locusts or Grasshoppers, Wasps, Ants, Waterflies, Fireflies, or in short any other sort except Cockroaches, Centipedes, or Scorpions, which are in general so very common as not to be worth bringing, unless they are unusual sorts, and such as are seldom seen. 
"When the box is filled, he must cover it all over with a piece of linen dipped in tar or wax, or paste a slip of paper all round the edges, to prevent the small vermin getting in, who will certainly do mischief to the insects withinside; it being observed, that cockroaches and other vermin do not eat or gnaw any thing that is well impregnated with tar, therefore he must be careful to cover every crevice or opening exceedingly well, that nothing may get in.

"It is necessary to mention that insects are found in various places; some frequenting flowers, particularly butterflies and those with transparent wings; others, particularly beetles, are found in the dung of animals, and in stinking flesh or putrid carcasses of dead creatures; some hide themselves under the bark of trees, where it starts or separates from the body of the tree itself, and which by tearing it up, will discover many kinds; numbers also are found in rotten wood and rotten trees, living in holes in the wood. The billets and bavins likewise that are cut and brought on board ships for their necessary use, when they are in foreign countries, frequently contain many curious insects, and therefore should be examined when it is split, at which time large white worms like maggots, as big as a man's finger, are sometimes found in the wood, and very frequently worms that are of a small size. These should not be stuck with a pin or put in spirits, but should be preserved in the same cavity of the billet they were found in, by tying the split pieces to- 
gether with a string, for in process of time they will turn to beetles, many of which are very curious, and seldom to be met witl in any other way. And this is a matter that should be particularly observed, because the insects proceeding from such worms are generally very desirable. Many insects also are found under moss that grows on the ground, or at the roots of trees, which, by removing, are easily discovered. Likewise when ships lie at anchor, a great many insects are blown from the shore by the land-breezes in the night, which settling on various parts of the ship, may easily be taken in the morning with the brass tongs or forcep-nets, and therefore should be searched every day for that purpose. The different seasons or times of the year also will yield different sorts, insomuch that every week will produce new kinds that were not to be seen in the foregoing ones, so that by searching for them at different times he will be sure of finding different sorts.

"In this account it is not intended for the persons to bring any caterpillars or worms, except such as were mentioned before to be enclosed in the split billets, but chiefly insects with wings, unless it be curious ants, spiders, or crabs, \&c., and the most ugly disagreeable insects, as they seem to be, are generally the most acceptable.

"It is desired no insect may be thrown away on the person's passage home, even if it is mouldy, broken, \&c., because many desirable ones may be thrown away by that means; if there are any so 
bad as not to be worth keeping, they can at the worst be thrown away when they arrive in England.

"It is necessary to mention that butterflies should not, like other insects, be held to the fire to be killed, because the fire will crimple and shrivel up their wings and spoil them; neitlier should they be thrown into loot water, a pinch with the finger and thumb, as mentioned before, will be sufficient to kill them.

"Whatever quantity is collected (either little or great) is desired to be brought to Mr. Drury, at the corner of Love Lane, in Wood Street, near Cheapside, who will give sixpence a piece for them, either large or small."

But these means, however extensire the scale on which they were conducted, were not the only ones adopted by Drury to extend his collection, and render it (which was the great object of his ambition) one of the best at that time existing. He caused many advertisements to be inserted in foreign newspapers, soliciting specimens either by purchase or exchange. By the latter method he obtained many fine examples, particularly from Holland, where collectors were numerous, even at a time when the subject was little attended to in this country. Among his correspondents in that quarter may be mentioned Baron Ranger, chamberlain to the Prince of Orange, Dr. Gische, Sepp of Amsterdam, and Ammiral at the Hague. Pallas also, with whom he was on intimate terms, was of great service, both 
by sending specimens himself, and using his influence with other naturalists for the same purpose. But of all his contributors, perhaps the most valuable was Henry Smeathman. A long intimacy seems to havc subsisted between Drury and this gentleman, for we find that they were in correspondence with cach other at an early date, and in such terms as to imply a previous friendship of some standing. Smeathman had acquired considerable skill in natural history, and seems to have possessed the requisite powers of observation for successfully prosecuting that study, if we may judge from his excellent history of the Termites or white ants, which he was the first to illustrate. Being desirous of becoming a travelling naturalist, Drury and a few of his fricnds subscribed the requisite sum, and sent him to the coast of Africa, the productions of which were at that time comparatively little known. The principal subścribers, besides Drury, were Mr. Banks (afterwards Sir Joseph), Dr. Solander, Dr. Fothergill, and, at a later period, the Duchess dowager of Portland, who was a zealous collector of shells. Smeathman lcft this country in J771, and in the ensuing year we find the following amusing letter from his patron, addressed to lim at Sierra Leone.

"London, April 28, 1772.

"Dear Smeathman,

"I received both your letters, one of which (the principal one) without any date enclosed the other, 
and from several little circumstances in them, I cannot help concluding that you are hastening to become a $T$ ar, and I will be hanged if you have not even kept the captain's journal; else for what purpose need you have wrote at the top of the letter, Isles de Los, Lat. $9.36 \mathrm{~N}$., Wind $S$. $W$., instead of the date of the year, \&c. What was it to me, think you, where those isles were situated, or whether the wind blew north or south, that you must needs tell me those circumstances before every thing else? I wanted to hear of your health, and to that end with eagerness read first that letter and afterwards the enclosed, and behold, to my greatest disappointment, not a single word on that head, and except one passage, of your having got about fifty curious insects (which, by the bye, you don't say were large or small), I might as well have received a letter from some dull man of fortune on business. Indeed I wanted to know something about the country, your voyage, entertainment on board, and several other matters, but as you have amply superseded that by telling me you have only a few hours to write to your friends, I readily excuse the omission of a Tar; in which light I shall certainly in future consider you if you don't write more in the character of a philosopher and a man of letters. You will make a fine F. R. S. truly, to stuff your letters with the variations of the wind, the needle, latitudes, \&c. when you should be describing some of Nature's beauties out of the three kingdoms. In fine, therefore, "be a good boy, and do so no more." Now to 
be serious. I nrote to you the beginning of last month by means of Mr. T_, who was acquainted with a captain going from Bristol to Sierra Leone, which letter I hope you received; indeed, I shall not omit writing by every ship I can hear of, if I only mention in my letter that $\mathrm{I}$ am well, together with my family, a circumstance I hope will serve as an example for you to follow, especially as you can have no doubt what reception your letters will always meet. Nothing can be more vehement than the present desire of your friends in natural history to hear from you. All long to know something of a country that has yet been unexplored by any curious man, but patience must be the portion of every one, and must likewise be put in practice. Last Thursday I had the honour of a visit from the Duchess dowager of Portland to see my collection, with which she was greatly pleased. She has lately, by the means I fancy of Dr. Solander, become a staunch entomologist. We were deeply engaged for three hours, as you may well imagine, and in the course of our conversation she said that she hoped to become possessed of a collection of Africans by your means, for she had heard of your going on a physical inquiry; and, indeed, if the plan you established had not been confined to a particular science, I am confident she would have become one of your subscribers. I explained the nature of your voyage, also the whole of the plan, and assured her that after the subscribers had been repaid by the amount of the specimens, you would 
be at liberty to dispose of the remainder for your own advantage, and $I$ would undertake to engage that her Grace should have a fine collection in due time. She was mightily pleased with this declaration, and desired I would not forget it. I must here mention, lest I should hereafter neglect it, that she is more attracted by the beauties of the Lepidoptera than any of the others, and, as such, collects them with more avidity than any of the rest. This hint I think will not be unserviceable to you. It remains with you to improve it to the best advantage, wherein if I can be an actor,-but a word to the wise is enough.

"In my last I told you I had got two pictures to compose for one of the Queen's ladies, and hoped to improve that circumstance to the benefit of natural history. I have this view still in my head, and believe I shall accomplish it. The lady I speak of is Madame Scliwellenburg, keeper of the Queen's wardrobe, an exceeding worthy woman, and from her merit has great weight with the Queen. It is to her great interest, as I judge, that I am indebted for being appointed Goldsmith to her Majesty, in conjunction with Mr. J., an honour I received the 9th ult. When I carried her the pictures, she was charmed with them, though by the way they were not the best I could have composed, if I had been at liberty to have chose my own subjects, and in the fulness of her satisfaction, asked me what recompense she could make me, and took me into a closet of pictures to have my judgment about hang- 
ing them up. Does not this look well? Perhaps I may be able to transport, in due time, some insects from the African coast to the Queen's closet. I wish for the sake of H.S. I may be able to do it. Lord! how I should rejoice to see him made Butterfycatcher to the Queen! Risum teneatis? But softly, Dru; where are you rambling to? Get firm upon the first step before you attempt to mount the second. True; so I will, and therefore I will stop here." * * * *

A young man from Sweden was subsequently sent to assist Mr. Smeathman, fitted out entirely at the expense of Dr. Fothergill, who was desirous that he should principally occupy himself in collecting plants and seeds; but he proved of no use. Smeathman transmitted to his subscribers a great number of fine insects, many of which were new; and, in fact, his contributions form by far the most valuable part of Drury's third volume of Illustra-. tions, not a few of the species continuing unique even to the present day. The sense that Drury entertained of their value may be inferred from the following note to the Duchess of Portland.

\section{"To the Dowager Duchess of Portland.}

"May it please your Grace,

" The last time you did me the honour of a visit, you seemed desirous of being a subscriber to Mr. Smeathman, who is now on the coast of Africa collecting the Naturalia of that country. I take the 
liberty of informing your Grace that a ship is now going to that part, and as I am to send some things to him, will with pleasure receive your subscription on his account. I must also beg leave to inform you that $I$ have just received an exceeding fine collection of insects from him, which are in the finest condition I ever saw come from abroad. His collection of shells, birds, plants, \&c. are now on the sea, under the care of a gentleman coming from that part; and as Mr. Banks and Dr. Fothergill are out of town, they will not be shared these two months. Therefore, if your Grace pleases to advance the money for your subscription, you will have the opportunity of sharing the first of his collection in those branches, as well as the insects now arrived; and I am strongly inclined to think there will not be a second collection come from him in such fine order as these.

"I am, with the utmost respect,

"Your Grace's most obedient and

"Humble Servant, "D. Drury.

The Duchess subscribed $\mathscr{E} 100$, and thus became a sharer in the treasures transmitted by Smeathman. A proposal was at one time made by Dr. Fothergill and some other gentlemen to fit out a vessel for Smeathman; to provide him with a number of assistants; and send him to the coast of Africa to collect whatever objects in natural history he could obtain: but this munificent scheme was never car- 
ried into effect. He returned home by the West Indies after an absence of some years.

An individual to whom Drury showed much kindness, in the hope of being supplied through his means with the insects of New South Wales, was J. W. Lewin, author of a small, but original, and really valuable work, entitled "A Natural History of thie Lepidopterous Insects of New South Wales." It appears from Lewin's letters that he was in a great measure illiterate, and had been subjected to many difficulties, so that it was a good while before he could do much towards the fulfilment of Drury's wishes. They continued, however, to communicate with each other for a considerable time; Drury supplying goods to no small amount, which were to be repaid in insects. In his necessities, Lewin is not backward in his demands on the liberality of his friend, who supplied him, among many other miscellaneous articles, with the copperplates on which he engraved his insects and birds, and even with the paper for printing them. Thomas Marsham, author of the Entomologia Britannica, and Alexander Macleay, afterwards united with Drury in advancing money to Lewin while he was at Botany Bay, expecting the value to be returned to them in insects.

It will readily be supposed that with such numerous contributors, and liberal outlay in procuring insects, Drury's collection had become of great extent; and it was not more remarkable on that account than it was for the perfection and rarity 
of the specimens. A particular specification of its contents will be given hereafter. When he found objects of great interest begin to accumulate, and many of them to prove altogether new, he thought it incumbent on lim to adopt some means of making them known to the public for the advancement of natural history. He seems to have conceived the plan of publishing his "Illustrations" at an early period, but it was his original intention that they should be confined to English insects, foreign ones being referred to only for the sake of comparison and illustration. This design, however, was soon abandoned, and a work undertaken to embody the most valuable objects of his cabinet from foreign parts. The first volume appeared in 1770 , forming a handsome quarto, containing fifty plates, on which were exhibited upwards of two hundred and forty figures. The drawings were made, the plates engraved, and in the best copies coloured likewise, by Moses Harris, who is admitted by all to have been one of the best, if not the very best, entomological artists of his day. His employer also exercised a vigilant superintendence over his proceedings, so that the utmost confidence may be placed in the general accuracy of the delineations, both in regard to engraving and colouring. Indeed, the care with which they were got up, seems occasionally to have led to such delay as nearly to exhaust the patience of the placable author and disturb his habitual equanimity. Hence the following scolding note to the artist:- 
"London, April $5 t F_{\text {, }}, i \because$.

"Dear Harris,

"I have at last got my work entirely printed, and shall have it home tomorrow or next day. I have also agreed with Mr. White, bookseller in Fleet Street, for the necessary business to be done in publishing it, \&c.; but as I have only two sets of prints coloured in your best manner, and one of these, if not both, bespoke, I cannot with propriety advertise it till $I$ have some more of them ready. I am at the greatest loss imaginable to know what can be the occasion of your keeping those sets so long in hand. Your son took them away the 8th of February, therefore you have had them eight weeks, and you often told me you could finish a set in a week. If so, how can I account for your delay, and that at a time when you cannot but be sensible it is of the greatest consequence to me. I wish to Heaven you was removed from the place where you are now buried, and come to London, for then I could scold you by word of mouth, and am now forced to employ a great deal of time in doing it by letter, which I can but ill spare. I beseech you, if you have not heard of a house in London, put an advertisement in the newspapers for one, that I may not be compelled to put you and myself to the trouble of reading and writing these letters. It is now three weeks since I wrote ny last, and am afraid that my prints are but a very little forwarder than they were at that time; indeed, I fully expected that they would have been 
finished by this time, but, I an sorry to say it, I cannot depend on you. I am perplexed to the last degree. If I advertise the work and not mention the best prints, it will be using some persons ill, as they will with reason think; and if I mention them without having a sufficient stock, I shall appear in a most ridiculous light. In short, it has fallen out exactly as I foresaw it would, and as I told you some time ago, and I am much afraid your neglect will prove very injurious to me. In fine, write me word when I may expect the prints, that I may give an answer to those who inquire, and you will oblige,

"Yours, \&c.

"D. Drury."

Besides describing the species, Drury endearours to give their natural history as far as known to him; but in this respect the work was necessarily very meagre, as in most instances his contributors were contented with transmitting specimens of the perfect insects without furnishing any account of their previous states or general habits. This we find him often lamenting in his letters, but it was an evil which he had no means of remedying. "Let me assure you," he says, writing to a correspondent at Quebec, "that next to receiving the insects themselves, nothing could be more agreeable to me than to know their history, manner of life, what they feed upon, where they live, what enemies they have, how they secure themselves from the power of those 
enemies, what time of the year they make their appearance, how often in the year they breed, and in short many otier circumstances that it is impossible for me to have any idea of, and which only being familiar with the subjects, and seeing them alive, can possibly furnish. Hence you perceive the most trifling incidents attending the various species will always be received with pleasure, and as it is impossible you should be acquainted with the above properties belonging to every insect, let me conjure you not to neglect sending me those you do know, a piece of knowledge that will enhance the value of every insect you shall oblige me with." This extract (and many others of a similar tendency could be giren) showiws that Drury had a much higher aim than merely to be a collector of specimens; and his work itself hears ample testimony to the same effect. To facilitate the circulation of the Illustrations on the continent, a French translation of the text was given in a parallel column. * The descriptions are not very minute, and too vague to be of much use; indeed, he expressly affirms that they are only intended to assist the reader in ascertaining the different species; and are not so complete as to give a perfect idea of the animal without the help of the figure. $\downarrow$ The reception the work

* The translation was executed by M. Da Costa, the conchologist.

+ For further remarks on the general nature of his design, and mode of exeeuting it, reference may be made to the Introduetion to the first volume of his work. 
met with was highly favourable, and its sale consiuerable. The author presented a copy to Linnæus, accompanied with the following letter, which is well worthy of being transcribed.

\section{"To Dr. Linnæus.}

"Address . . . . . Regiæ Scientiarum Societati Upsaliensi Upsala.

"Most excellent Sir,

"Lordon, Aug. 30, 1770.

"I cannot better express the strong inclination I have of testifying my respect to you as the greatest Master of Natural History now existing, than by presenting you a copy of a work I have just published here.

"Believe me, Sir, it is not from vanity I take the liberty of making you this offering, nor, poor as it is (for I am truly sensible of its defects), would I make it to any person that is inferior to Linnæus in the study of Nature. But to whom sloould I. pay my acknowledgments of this sort, but to the Father of Natural History? You, Sir, I consider as that father, and therefore I beseech your kind acceptance hereof, a circumstance that will do me great honour and favour, and at the same time countenance my weak endeavours to promote a study that, I must confess, I prefer to every other.

"Permit me also to take this opportunity of congratulating you on the effects which your Systema 
has had among the followers of Natural History here in London, the numbers of whom, although not equal to those found in many other countries, are yet every day increasing, to such a degree as could not have been anticipated a little time ago by its most sanguine wellwishers.

"That it may still increase and flourish, and that you may live, with health, to see its study carried to the furthest ends of the earth, is the hearty wish of,

$$
\text { "Sir, }
$$

"Your sincere Admirer, and

"Most obedient humble Servant, "D. Drury."

In the Preface to his first volume, Mr. Drury announced that the continuance of the work would entirely depend on the reception the public should be pleased to give to it. Being thoroughly satisfied on that head, he immediately began to prepare a second, and both the descriptions and engravings were finished about the beginning of the year 1771; but it was not published till 1773. In his own opinion (as expressed in a letter to a friend in Halifax) this volume was preferable to the first, because containing a great many more uncommon insects, all of them (as he then supposed) being nondescripts. "I am only sorry," he adds, "I have it not in my power to give the natural history of every one of them; how happy I should be to be able to do that! but so long as distant countries 
afford few or no new speculations, we must not expect it. A Banks and Solander are to be found only in an age; and the wonders of creation must not be expected to be opened and displayed but by slow and gradual means."

He had resolved not to publish a third volume; not because he was less anxious than formerly to do every thing in his power to promote his favourite study, or that he was dissatisfied with the success of the two first, but because the pressure of business denied him the requisite leisure for such an undertaking. From this cause we find him proposing to devolve the task on Smeathman, as it was to him that he was indebted for most of the subjects of which it was to be composed. "Could you not," he asks, in a letter dated 28th January, 1773 , " do this business for me? How? you will say. I will tell you. I can from time to time send you the insects I would compose it of, which you might describe, and if you would write the natural history of some of those you find, they might be inserted, and embellish it so much as to make it sell with avidity. I would be at all the expense of engraving, colouring, \&c. The advantage of it you would share jointly with me, or I would pay you for the whole at a stated sum. The duty I owe mankind makes me wish I could bring this about, for I really know nobody so capable to give the natural history of these animals as yourself, both from your situation and abilities. If I cannot get it done by some such means, I shall certainly never publish any 
thing more." The volume in question did not appear till 1782 , the delay being no doubt occasioned by Drury's mercantile embarassments; but the text, as usual, was written by himself, with the aid of Smeathman's notes. The greater number, and by far the most interesting, of the insects figured, were obtained by that collector at Sierra Leone and other places on the western coast of Africa. Some of these, such as the large and elegant Papilio Antimachus and the equally conspicuous Saturnia lucina, continue unique even to the present day. A large proportion of the plates in this volume were executed by Moses Harris, but in a few instances other artists were employed.

Writing to Pallas in 1775 , our author states that he had ample materials in his collection to furnish three other volumes; and that if he had time he would continue the work with infinite pleasure, "for surely," he adds, "Heaven gave me a relish for these subjects to sweeten and allay the numerous plagues and troubles I have lately been surrounded with; but I must give up all thoughts (notwith. standing the solicitations of my friends) of ever engaging again in that employment." Notwithstanding this determination, Mr. Haworth * assures us that Drury, a short time before his decease, meditated the publication of another volume, with a view to embrace the gigantic and extraordinary insects of Demerara; this design, it is scarcely necessary to add, was never accomplished. The work, as

* See Trans, Ent. Soc, 1807, vol, i. p. 34. 
it now stands, must be regarded as one that has been of important service to entomology, and the first ever executed in this country in such a high style of art. The figures are in general extremely accurate, and the colouring faithful to nature. It is proper, however, to add, that two series were issued at different prices, one of them wholly coloured by Harris's own hand, the other by ordinary culourists under that artist's superintendence. The work acquires additional importance from the fact, that the figures are often cited by the best descriptive and systematic writers, so that it has obtained a kind of classical value as a book of reference. ${ }^{*}$ It is likewise remarkable as being the first work published in this country in which an attempt was made to apply the Linnean trivial names.

We must now say a few words respecting the Collection itself. During the temporary reverse of

* A fer years ago, a new edition, witl impressions from the original plates, was published, under the editorial eare of Mr. Westwood, by Mr. Henry Bohn the bookseller.

It is not easy to speak of this edition in terms of too high commendation. The colouring, executed from the original drawings, under the superintendence of one of the ablest entomological artists of the day, is faithful to nature, and owing to the fineness of the paper and a particular process to which it has been subjected, possesses a lustre and beauty which were unattainable at the time when the original edition appeared. The text has been in a great measure re-written; ample and accurate descriptions introduced; the modem nomenclature applied, and the intricacies of synonymy unravelled; Indexes and much original matter added, and the whole work adapted to the present advanced statc of the science. 
fortune to which Drury was subjected in 1777 , he thought it his duty to offer it for sale, and with this view drew up a detailed statement of its contents. In the beginning of the year 1778 , these were as follows :-

Coleoptera 1946 subjeets, of 1680 different speeies.

Lepidoptera 1910 ditto 1635 ditto.

Hemiptera 736 ditto 664 ditto.

Neuroptera 123 ditto 109 ditto.

Hymenoptera 508 ditto 485 ditto.

Diptera 253 ditto 241 ditto.

Aptera 29 ditto 29 ditto.

Total Number 5505 Insects of 4843 different species.

Two years after, they had increased to 5778 insects, of 5066 different species; and in 1788, at which period not less than $\mathfrak{E} 4000$ had been expended on the collection, it stood as follows:-

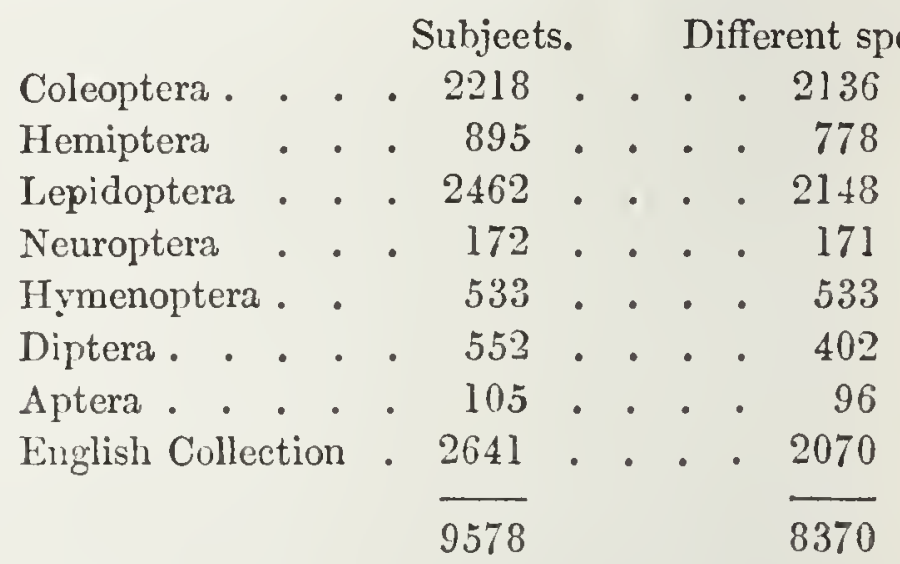

To this number very large additions were afterwards made, for he continued to collect with almost unabated zeal till near his death. When it consisted of the smaller or first mentioned number of specimens, 
the value he set upon the collection was $£ 1000$, and he considered it, even at that time, as the first in the world. In writing to Dr. Pallas, and asking him to endeavour to find a purchaser, he speaks of it as follows. "I don't know whether the Empress of Russia has any collection of Natural History; if she has, her munificence and bounty may induce her to accept the offer I make of the disposal of mine. Do not think me vain when I tell you that I look upon it as the first in the world. The great number of specimens procured from Africa (I mean that part near Sierra Leone) and the Brazils, I think cannot fail to render it superior to any yet known. The incredible pains and trouble I have taken to procure so vast a variety, I do not urge as a circumstance in its favour; it best speaks its own value; but believe me, I would not go through the same trouble again for a thousand pounds. My third and last volume, likewise, which I am now preparing, will inform you what amazing additions have been made to it since the publication of the two first, the great expense of procuring which I am pretty certain will not be repaid me by the price I set on it. I also intend to dispose of all the original drawings from which the engravings have been taken. These, I must inform you, are wonderfully fine: Mr. Harris, the painter, who executed them, and also engraved and coloured my work, having exerted his utmost skill in making these drawings. The latter I value at $\mathfrak{E} 325$." * He likewise wrote * These drawings, we are informed, are now in possession 
on the same subject to Mr. Ashton Lever (afterwards Sir Ashton), one of the most extensive collectors of natural curiosities that ever lived, as well as to General Rengers and other individuals; but it would seem to be as difficult to dispose of a collection of this kind as it is to make it; no one offered an adequate sum, and Drury retained the objects which he had amassed with so much care and labour, beside him to the last, never relaxing in his endeavours to augment their number and obtain more perfect specimens. Every foreign entomologist of note, who visited this country, took the opportunity of examining Mr. Drury's Collection, and permission was given with a degree of frankness and liberality, which on some occasions were turned to the owner's disadvantage. Several unique specimens, for example, were clandestinely figured by other authors, at the very time Drury's own work was in progress. * Fabricius studied the Col-

of Mrs. Allan of Glen, in Peebles-shire, who obtained them at a price very little inferior to that here set on them.

* Drury complains of General Rengers for allowing Cramer to figure several new spccies which he had scnt to him, and designed to make public in his own work. "This, I confess, appears a little hard on my side, and puts me in mind of a man's putting a knife into the hands of another in order to cut his own throat. I must entreat you not to let him figure any more that have been in my collcction. He cannot want subjects among so many grand collections as Holland abounds with; therefore I would wish not to receive any further injury from him." Stoll retorts this charge on the part of Cramer, in lus Supplement (Preface, p. v.). Neither party appcars de- 
lection with great care, and often refers to it. "I think," says Drury to one of his correspondents, in a letter dated June 24th, 1773, "you remember M. Fabricius. He is now in London, and very busy in making descriptions from Mr. Banks' and my Collections, where he will have employment for some months; a pleasure he seems to enjoy with as much glee as a lover of wine does the sight of his cellar when well stored with full casks and bottles, enjoying by anticipation the pleasure he is to receive in emptying them." It seems to be the general fate of extensive collections of this kind, to undergo dispersion on the death of their original owners. It often happens that a love for the study is not hereditary, although the objects themselves may be so; hence they frequently fall into the hands of those who are indifferent to their preservation. It is usually the case, also, in estimating the value of such collections, that more regard is had to the money and labour that have been expended on their acquisition, than their intrinsic value at the time when they are exposed to sale. It is not considered that they have already in a great measure repaid their original cost, by the pleasure and instruction they have afforded their owner; and that the kind of factitious value they may have acquired in his eyes, cannot be expected to exercise any influence on another. For a long period, moreover, the supply of such objects from foreign countries serving of blame, each having acted in ignorance of the other's intentions. 
has exceeded the demand, and their value, in a commercial point of view, has therefore been gradually deteriorating.

Drury fortunately was not subjected to the pain of witnessing the dispersion of the objects he had laboured with such unwearied zeal to assemble, and from the examination of which he had derived so much rational enjoyment. The collection was not disposed of for upwards of a year after his death: and no purchaser having been found for it in an entire state, it was sold in separate lots by auction. The sale commenced on Thursday, May 23, 1805, lasting for three days, and realising no larger sum than $£ 614$ 8s. 6 d. for the insects, and about $£ 300$ more for the cabinets and copperplates of the Illustrations. A few of the more interesting lots, with the prices obtained for them, as well as the names of the purchasers, have been given by Mr. Westwood as an interesting record ; and as such we here subjoin it, from his edition of Drury's work.

Lst 3. Phalæna Aprilina, Graminis, and 22 others

$26 £ 712 \quad 0$ G. Humphrey

8. Sphinx Convolvuli, and 8 others

$\begin{array}{lllll}9 & 4 & 1 & 0 & \text { Donovan }\end{array}$

46. Papilio Priamus

14146 Gen. Davieg

64. others .

Claviger, and 5 )

$6710 \quad 0$ Macleay

69. A variety of curious Spiders, chiefly from $110 \quad 4 \quad 4 \quad 0$ Donovan Georgia

90. Pap. Iris, Edusa, Hyale, ? and various .

410 ن̀ Humpinrey 
Lot 95. Scarabæus Goliathus, var. $\quad 1 £ 12 \quad 1 \quad 6$ Humphrey

100. Cerambyx Gigas, and 2 \} others .

104. Thirteen species of the Bupestris genus .

105. Elater flabellicornis, vi- ) rens, and 8 others

112. Cetonia hamata, nitens, grandis, Scarabæus festivus, and 12 others

123. A variety of small insects of the Mordella, Forficula, and other genera, among which are Diopsis Ichneumonia, and also a species of Paussus

201. Mutilla bimaculata, thoracica, Scolia signata, and 24 others $\begin{array}{llll}3 & 4 & 8 & 0\end{array}$ Haworth

$13 \quad 8 \quad 0 \quad 0$ Macleay

$1046 \quad 0$ Latham

$\begin{array}{lllll}16 & 17 & 0 & 0 & \text { Macleay }\end{array}$

$\begin{array}{lllll}27 & 3 & 5 & 0 & \text { Kirbs }\end{array}$

$6 \quad 6 \quad 0$ Ditto.

269. Sphex tropica, frontalis, Africana, \&c. .

In the year 1787 Drury lost his wife, by whom he had seventeen children; all of these, however, died young, excepting three who survived him. In the spring of 1789 he retired from trade, relinquishing his share of the business to his son, who paid him a sum of money in hand, and allowed him an annuity for the rest of his life.

He then took a house at Broxbourne, in Hertfordshire, at which he went to reside, but occasionally came to London to visit his son, remaining for a few weeks at a time. While at Broxbourne he continued to collect insects as formerly, and spent much of the leisure time he now enjoyed in arranging and improving his cabinet. He became very fond 
of gardening; and amused himself by fishing in the river Lea, and the adjoining New River. But his favourite amusement for some years consisted of making wines from various kinds of fruits, and attempting experiments in distillation. An entire memorandum book is filled with notices of the qualities of his different wines, and some of them are not a little amusing. His taste seems to have been somewhat fastidious, a quality it probably owed to his being a member of the worshipful corporation of Goldsmiths, and not unacquainted with the festivities of Guildhall and the Mansion House. The following entry will suffice as an exaraple. "October 1. Memorandum.-Examined the wines. Those made this year are very good, both white and red. The white which is in the nine gallon cask, to which I put four pounds and a half of sugar (see Sept. 15), is very good, but I think is tending to have the flat twang. Time will show whether it will increase. The same wine in the small five gallon rundlet has lost its sweetness considerably. It is therefore evident that two pounds and a half of sugar to the gallon is not enough; it should be three pounds. The red currant wine is also very good. That in the ten gallon cask will be exceeding good. It wants nothing but age. The same wine in the five gallon rundlet is also very nice and good: therefore all these wines I stopped down very close, and intend to let them remain so till I bottle them off. I fully intended to day to have put some pulverised clay in order to fine them, but upon tasting 
them, I afterwards declined it. I examined the cask of mixed wine on the left hand at the further end of the cellar. It is not fine, and has the flat twang. The wine on the right hand in a fifteen gallon cask has lost all its sweetness. It is not bad, but it is not pleasant, and I think is easily recoverable. I think therefore to put fifteen pounds of Malaga raisins to it and try if they will not bring it to rights. If they will not, I must e'en distil it." A multitude of similar notices show in how complete a spirit of amateurship he entered upon this occupation, one to which so many good people are addicted, and which might be considered as harmless as it seems to be amusing, if they did not expect their friends to be as well pleased with the fruits of their labours as they invariably are themselves, and not only to drink their "brewed enchantments," but to do it in the same manner as the historian informs us a Grecian sage exhibited when a similar potion was forced on him, "with a pleased expression of countenance."

There was another matter which occupied such a considerable portion of the latter years of Mr. Drury's life, that it must not be passed over unnoticed. He had long been of opinion that a careful examination of the beds of rivers in many foreign countries, would lead to the discovery of considerable quantities of gold and silver; believing that the little usually obtained that way, was rather owing to the indifference and want of skill in travellers, than the absence of these metals. It was 
his wish, when the sand or gravcl appeared metaliferous, that large quantities should be brought home as ballast or otherwise, in order that he might subject it to a careful examination, being, as he himself expresses it, well experienced in the trade and mystery of smelting, refining, washing, and manufacturing gold and silver metals. Should the product prove sufficiently rich to repay the labour, it was his design to conduct the operations on a large scale, as will appear from the following extract from a written agreement between himself and a Captain Wilson: "And further it is mutually agreed between the parties above said, that if in future times it shall and may be thought proper to bring over so large a quantity of the above named sand or ballast, \&c. so that the smelting, pounding, and washing the same may require extensive room for the erecting of furnaces, mills, or other implements, so as to occasion considerable expenses in obtaining the said metals from the said ballast, \&c. It is further mutually agreed by the aforesaid parties, that the said Dru Drury shall and will direct the management thereof, and also build and conduct such buildings and erections as his experience and knowledge shall enable him to judge necessary and proper for the carrying on such a business. * * * And further it is mutually agreed, that the said Dru Drury, so long as he shall live and be capable of doing so, shall have the managing, superintending, and conducting the said manufacture and business; and it is further agreed, that, if it shall please 
God to take away the said Dru Drury, and the business or work by that circumstance should be at a stand for want of a legal successor or proper person already nominated or provided for in this agreement, in that case the said Captain Wilson, doth agree that the half of the profit, or advantage, that the said Dru Drury did enjoy in his lifetime shall be continued to his son William Drury, of the Strand, Goldsmith, \&c. \&c."

Many similar agreenients, formally drawn up, written on stamp-paper, and signed in the presence of witnesses, were entered into with commanders of vessels proceeding to various quarters of the globe; and those whom Drury used to employ in collecting insects, were often enjoined to turn their attention at the same time to this subject. As might have been expected, the hopes of sudden wealth, with which some of them were thus inspired, were generally, if not in every instance, disappointed. We find poor Lewin, to whom the discovery of a treasure of this kind would have been even more than usually acceptable, writing in the following terms (which we give nearly verbatim, but not nearly literatim) to his patron, in a letter from Sidney, dated 7th March, 1803:- "I hope you will never mention any more in your letters about gold; and sorry enough I am that ever such a thought entered into my head; but enough of that subject, for I am really sick of it; for had it not been for those ideas, or rather dreams, I never should have gone to Otaheite in search of pearls, where I very nigh lost 
my life; for the ressel that I went in was stranded on the beach, on Point Venus, where she was entirely lost in a heavy gale of wind which lasted five days; and that was not the only misfortune, for after we got on shore we had the natives to fight, for they were at war with the party who were our friends. So that for the nine months that we were on the island, we were continually alarmed with the dreadful ideas of our having our throats cut; and I have not the least doubt but we should have been all massacred, and the mission entirely destroyed, or at least forced to fly to the other island at the risk of being drowned, only for a few of us who well knew the use of fire-arms. As for those dastards called missionaries, they would have run and hid themselves rather than fight and protect their property, wives, \&c." It is very likely that in this matter Drury himself, who had evidently formed high expectations, was as much disappointed as any of his agents; at all events, we find no intimation in his books and memoranda of any success resulting from his exertions. The attention he paid to the subject led him to draw up and publish a pamphlet containing instructions for collecting minerals and precious stones, describing their various appearances in a rough state, the places where they are most likely to be found, \&c., which furnishes a number of very useful suggestions.

In 1797, Drury removed from Broxbourne to Turnham Green, near Brentford, Middlesex, where he continued to reside until near the time of his 
death. During many of the latter years of his life, he was much aftlicted with stone in the bladder, and was obliged to have recourse to the frequent use of laudanum as an anodyne. ${ }^{*}$ Other disorders also began to assail him, indicating that the powers of his constitution were beginning to decay. He still, however, continued to make frequent visits to London, and even to take part occasionally in matters of a public nature. Thus we find the following notice in his memorandum book: "Attended Mr. Rawlins, upholsterer, and Mr. Cox, goldsmith, being the sheriffs elect, to the London Tavern, where the company breakfasted and proceeded to Guildhall, where they gave bond to serve the office, and returned to the Tavern to an elegant entertainment. On Wednesday $\mathbf{I}$ attended them again to Goldsmiths' Hall, where we breakfasted, and proceeded in the goldsmitls' barge to Westminster, where they were sworn into their office before one of the Barons of Exchequer, and afterwards returned in the barge to dinner at Goldsmiths' Hall." The very last entries in his pocket book, written in such an unsteady hand as to be scarcely legible, chiefly refer to what may truly be called his ruling passion, consisting of the names of vessels by which he expected consignments of what he was in the habit of call. ing Naturalia, of individuals to whom he had sent

* After his death his body was opened, and three flattish oval stones taken out of the bladder, weighing upwards of six oumees, each of them being about two inches long, by one and three-quarters wide, and an inch thick. 
collecting instruments, or the addresses of his correspondents, who continued to be numerous even to the last. He died in London, in the house of his son, William Drury, in the Strand, on the 15th January, 1804, having nearly attained lis seventyninth year. He was buried in the vault under the church of St. Martin's in the Fields, London.

In every respect Drury's character was highly estimable. His conduct in the various relations of life seems always to liave been most exemplary. His correspondence furnishes abundant proofs of the warmth of his affections, the sincerity of his friendship, and disinterested desire to promote the welfare of others. He displayed the greatest liberality to those who exerted themselves to do him a favour, particularly in collecting objects in natural history; nor was his benevolence withheld from a necessitous individual, even when the latter had proved ungrateful for former kindnesses. Of the strictest honour and integrity himself, his natural generosity often led him to believe too readily in the existence of the like qualities in others; hence he became at times the victim of the designing, as in the transac. tions which caused the greatest commercial misfortune of his life. He was singularly exact and methodical in all matters of business, and of the most regular habits.

The love of natural history was deeply implanted in his mind. We find him thus writing to General Rengers, at the time when he had other matters of pressing urgency to engross his attention: "There 
was a time when natural history had charms for me superior to every other delight the world could bestow. All the enjoyments and gratifications of sense were not in my opinion to be placed in competition with it; and if any thing on earth could convey a faint or distant idea of heavenly pleasure, I think it must be that." Hence his ardent prosecution of the study, even when his circumstances were least favourable to such an indulgence; and it is easy to imagine with what gratification a mind so constituted would exchange for a time, and when a due and conscientious regard to his own interests and those of his family permitted, the bustle and anxieties of trade-the turmoil and effervescence of a great city-the

"Fumum et opes strepitumque Romæ,"-

for a tranquil retreat where he could give himself up without restraint to pursuits so congenial to his disposition. Moments such as these, snatched from his usual occupation, he regarded as in a great measure repaying him for the care and trouble to which the latter not unfrequently subjected him.

Honourable testimony has been often borne by the master spirits of the science, to the value of I)rury's exertions in its behalf, and the excellence of the work to which so high a character has already been assigned. Linnæus dedicated a species of Cimex to Drury; Fabricius, an American species of Stenocorus, as well as a Danish Tinea; and our own Kirby, in his Monograph of English Bees, after 
naming a rare species Apis Drurella, adds the re. mark: "In honorem D. Drury, operis entomologici splendidissimi auctoris, cujus museum insectorum rarissimorum undique conquisitorum gazophylacium ditissimum, hanc apem ab illo acceptam nominavi."* The younger Linnæus, when about to edit a new edition of his father's Syst. Nat., appreciating the value of Drury's work, wrote to him the following letter regarding it, which will be perused with interest, not only for the writer's sake, but on account of the information it conveys.
"Celeberrimo viro
"S. pl. d.
"D. Drury.
"Carolus a Linné.

"Dum post mortem dilectissimi parentis occupatus fui in redigendo naturalia ab illo in Syst. Nat. nondum determinata, et ut his nomenclaturam pro scientia naturali maxime necessariam continuarem, maxime sollicitus fui illa, quantum mihi possibile foret, synonymis ex præstantioribus auctoribus Scientiæ illustrare, imprimis illorum qui pulcherrimis individuorum figuris sint ornati. Tu, Vir Celeberrime, es ex illis qui in insectis pulcherrima præstitisti; ex tuo opere volumina habeo duo, quæ in heriditario cum reliqua Bibliotheca Parentis habeo: sed an Tertius Tomus s. plures post secundum prodiere, est quod ignoro, et de qua re rogarem tuam informationem? et si prodiere, ubi inveniuntur? et quo prætio? amicitiam quam erga Parentem habuisti, spero hanc filiolo permittere licentiam.

* Monog. Ap. Angl., ii. p. 286. 
Optandum esset a te in his majorem videre augmentum; requirunt insecta figuras; nam vix differentiis determinanda sunt. Insecta australioris plaga mundi a Banksio et Forsteriis indagata, pulcherrime et utilissime pro scientia methodo tua illustrari possent. Utinam facere velles; immortalitatem tuam conservaret scientia hæc!

"Ego qui nunc novam paro editionem Zoologicam Syst. Nat. summam in insectis sentio difficultatem ita exprimere, ut aliis intelligas, quod tam facile figuris lævatur. Multa præstitit noster De Geer de insectis, sed majora adhuc præstitisset, si figuræ vivis coloribus ornatæ fuissent. Quis Entomologus est alius apud nos, qui collectionem insectorum possidet ex India occidentali? Si quis esset qui desideraret insecta Suecica, lubenter illi ea præstare vellem.

"Nuper litteras habui ex America meridionali, ubi morbus endemius est. Homines etiam Europeos aggredit illuc venientes, qui causatur a larva Æstri, quæ intra cutem per integrum annum colatus, et nullo remedio expelli potest nisi periculo vitæ; est nova species \#stri.

"Sed hic vale et mihi fave.

“Dabam Upsaliæ, d. 10 Mart. 1780." 



\section{INTRODUCTION.}

As inquiry into the animate creation excites the interest of mankind in many points of view, sometimes on account of some striking peculiarity in a particular species of animals, at others, from the dread or the pleasure they inspire. That interest is, in some measure, regulated by their size, even more than by the proximity in station which they hold to us. We think but transitorily of bees, though they supply us with honey; or of silkworms, notwithstanding that they spin raiment for us; still less of locusts, albeit they commit enormous devastations, and gather together in armies, that have been considered sufficiently numerous to form a continuous circle round the globe. Fishes share somewhat more in our regard, on account of the food we derive from them, and of the multitudes who subsist entirely on taking, curing, and carrying this produce to distant lands. With birds, our affections first begin to be excited; the elegance of their form, the beauty of their plumage, the faculty of 
soaring high on the wing, the charm of song, and their companionable qualities all attract us, independently of the numerous advantages we derive from them as a nutritious and delicate article of food. But wher we turn our attention to Mammalia, to "the beasts of the field," we find some startling us by forms and actions so much resembling our own, as to excite unpleasant comparisons : others, causing just apprehensions, from their evident powers of mischief, our astonishment by their bulk, or doubt, by the questionable intention of their locomotive organs; while others, again, are companions of our sports, assistants in our toils, or supply us with food and clothing.

Reluctant though we may be to admit the relationship, it is in this class that man must confess his physical structure points out his own location: furnished with capacities, indeed, which place him at the head of the scale, he is only distinguished from those next in succession by slight external differences, and surpassed by many of the lower animals in the acuteness of one or more of the senses; not sufficiently pre-eminent to be altogether independent of other creatures, yet endowed with the prerogative of reason, he is enabled to render all subservient to his wants, and is distinguished as a being intended for higher duties, and a more exalted destiny. It is by the exercise of this faculty, that man is enabled to comprehend his relation to the various objects around him, and duly to appre- 
ciate the station which he holds in the great scale of nature.

Now, although this study imposed upon man somewhat of a duty, the science of natural history was comparatively unknown to the ancients; nor was its interest and importance recognised in their systems of knowledge. With the exception of Aristotle, neither the philosophers of antiquity, nor those of the ages succeeding the revival of learning, prosecuted the study of living nature with that accuracy of observation, and reference to organic structure, so indispensably necessary for distinguishing by just analogy, and determining by definite characters, the classes, orders, genera, and species, of the vast assemblage of animated beings.

Within the first quarter of the last century, there were still writers, and there were religious institutions in force, classing otters, seals, whales, herons, and ducks, with fish; and in law we even now admit whales by that name; while, in our markets, oysters, limpets, lobsters, and crabs, continue to be called shell-fish. In this respect, notwithstanding the valuable example placed before him by the mighty Stagyrite, we find the great Buffon viewed nature, and in particular zoology, more in the manner of a rhetorician, who had discovered a new field of eloquence, than as a true naturalist, who sees the connecting links of affinity, and by them demonstrates the relations organised bodies have to each other. In his magnificent descriptions of animals, he long persisted to disregard all classifi- 
cation, although Ray had pointed out the way so early as 1683; and Artedi, and in particular Linnæus, had called the attention of all scientific men to the system of arrangement known by his name. To the illustrious Swede, then, we are indebted for that lucid order, by him first established, in natural history, which, though it be artificial, has served mainly to unravel the apparent confusion observed in taking a general view of nature. From his time, the principles of investigation being clearly marked, it has been the constant aim of every writer, to introduce new observations and improvements in the descriptions and systematic locations, till, with the enormous accumulation of new and aberrant objects, the characteristics have not remained strictly applicable to many of the sections, and species in his system have imperatively risen into types of new genera; so that, by the progress of science, the labours of Linnæus have, at length, in a great measure, become confused and inapplicable. This was the natural result in a science based entirely on facts : as their number multiplied, modifications in what were at first deemed general conclusions, became more and more frequent and necessary, and the numerous attempts at transpositions of the groups of animals upon the artificial Linnæan model, depending alone on generalised notions of dentition, or on the form of the feet, though they often added something to the general stock of knowledge; and some had a temporary success, led. nevertheless, to a general acquiescence 
in the necessity of attempting the classification of organised nature upon the plan of natural affinities, such as had already been introduced in Botany. The first attempts were only approximations, until Baron Cuvier, the ablest observer, and the profoundest physiologist, since the days of Aristotle, " after," according to his own words, "forming several systems himself, which, however, he did not make known, because he ascertained that they were false, like all those that had been published to the period when he wrote," concluded, "that in the present state of science, it was impossible to discover any, and that that was the reason why he continued his researches, and why he openly proclaimed his observations."

But although Cuvier renounced making a system, he did not decline to form a great classified arrangement of the Animal Kingdom, wherein the whole is distributed according to its organisation. This mighty work, as happened to Linnæus, likewise at first met with opponents and dissentients; but, with the exception of gradual advances in separate branches, in orders, in new families, genera, and species, which the progress of science naturally calls for, and the author was always happy to adopt, when fully examined, there is not, at present, a general work more universally worthy to serve as a guide, than the second and last edition of his "Regne Animal d'apres son Organisation." It forms an abstract of all the important observations, from Aristotle down to Daubenton, Camper, Pennant, Pallas, Hunter, 
Buffon, and the great school of French naturalists, along with thirty years of his own researches, generalised into a natural order that forms its essence: and it is from this source we mean to draw the principal data of the present volume.

Cuvier did not stop here, he instituted the first regular system of fossil organic remains, which, from the unerring proofs drawn, by comparing the bones of lost species with those of animals now existing, is scrupulously exact in results. He enumerated, by this method, a great number of species of mammalia that lived in former zoologies, and fixed the laws, whereby a still greater number have since been detected by other naturalists. Of these also we wish to take a cursory notice.

But although the Baron had achieved such important improvements in zoology, at the time, even so late as when he revised his second edition of the "Animal Kingdom," physiologists had not yet been able to accumulate sufficient observations on the structure and generation of the pouched and monotreme animals, to justify placing them in a systematic order, where it has since appeared to be their most appropriate station. It is true, with every systematist, desirous of classing organic objects, by their affinities, into a natural concatenation; and, in particular, with mammologists, who begin with man, that although the physical approximations of species form, in general, a continuous chain of successive modifications from a primal type, taken either in an ascending or descending scale, there are also 
sudden transitions to new combinations, as in ruminants, seals, and whales; also solitary groups, like the equine, and elephantine, and divergences in most families, which tend, some towards one, others towards another, and even to a third order, by means whereof they osculate, more or less, in circles of seeming affinities with surrounding families of other forms, which, in their turn, have similar tendencies; * hence a succession of orders, families, genera, and species, in a written system, necessarily following each other seriatim, some are constantly found in the list, which would better approximate a group, not the next in the writer's system; and, as his object will naturally be, to terminate the series of mammalia, where they obviously assume characters of other classes; - that is, of birds, reptiles, or fishes, he is forced to conduct his links of successive connection, so as to end with whales, who already have the form of fishes; or by some other arrangement of affinities, lead his series towards the birds or reptiles. While the opossums were confined to a few species,

* Suclı, for example, as the genus Paradoxurus, which is plantigrade, and therefore assimilates in that and other respects with Nasua, in the family of bears; while, by the dentition, \&c., it is retained in the digitigrade viverrine series, which, in latc classification, terminating with Crosarchus, precedcs the Hyænas. It was from the frequent recurrence of these tendencies, that in England an attcmpt was made to form the winole animal kingdom into quinary sets of orders, each order again making five families, and these fanilics osculating similarly with one of the otlıcr, and forming a continual serics, cach returning into itself ; and, finally, each of the mammalian ordcrs having one corresponding in the birds. 
still comparatively unknown, authors had agreed to terminate the mammals by cetacea, because these approached the class of fishes as just mentioned. But there being extant, along with true mammalia, that second series, small indeed, and almost isolated in Australia, known by the name of marsupial or pouched animals; a series organised, in many respects, upon a different typical plan, and lower in the scale of nature, but with dentitions and aptitudes running parallel to several orders of true mammals ; and a still smaller group, which, though quadruped and warm blooded, is monotremous, and in many respects organised like reptiles; it followed, that when duly investigated in a natural system, this series could no longer find a proper place between families of true mammalia, but required to be located at the termination of the set of links, which led from man downwards to that order, and was possessed of families most naturally connecting itself with them.

We now beg to proceed with a few preliminary observations by way of introduction.

\section{THE MAMMALIA.}

Tire mammalia, that is, all animals that are provided with organs to suckle their young, are placed at the head of the vertebrated series in the animal kingdom. For, even excluding man, we find among them the greatest number of faculties, the most delicate sensations, the most varied action, and an aggregate of properties for the production of intelli- 
gence: they are the most fruitful in resources, least subject to mere instinct, and most susceptible of progressive improvement. With but a moderate quantity of respiration, they are, in general, intended for locomotion, by walking with strength and continuity, and hence, all the articulations of their skeletons have the forms very exact; thereby determining, with equal precision, the nature of their movements. Though the typical form is intended for walking on the earth, some fly through the air, by means of membranes attached to their limbs, and a supplementary structure fitting for that purpose; while ethers have the extremities so short, that they move with ease only in water: but both retain, in every other respects, all the general characters of the class.

All mammalia are endowed with warm blood, which results from the great development of the respiratory apparatus; the heart is double, and contains four cavities, viz. - an auricle and a ventricle on the right side, and the same on the left. The veinous blood passes through the cavities in the right side, and is distributed through the lungs, where it combines with the oxygen or vivifying principle of the air ; it is then conveyed by the pulmonary veins to the left auricle, from whence it flows into the ventricle, and is propelled through the arterial system. The females, suckling their young with milk, secreted in breasts or mammæ, are viviparous or ovo-viviparous, therefore placental or implacental; the placental incluaing all the highest organised mammals, from man to thite 
last true rodent; and the implacental, the marsupialia, and monotremata. They have all the upper faw fixed to the skull, and the lower, formed of only two pieces, is articulated to the temporal bones. The neck is composed of seven vertebræ; * those of the back and loins vary occasionally in the same species; the anterior ribs are secured to the sternum, or breast bone, by cartilaginous processes ; the anterior extremities commence with a shoulder blade, not articulated, but suspended between the muscles, and often resting on the sternum, by means of the clavicle on each side: it is continued by an arm, forearm, and a hand; the hand is formed of two rows of bones, (the carpus), of another row (the metacarpus), and of fingers, each consisting of two or three joints, called phalanges. $\dagger$

If we except cetacea, or the whale tribe, all mammalia have the basin or pelvis attached to the spine, the pubes forming the anterior, and the ilia, ischia, sacrum, and coccyx; the lateral and posterior parts, where the three first-named bones of the pelvis unite on each side, is the cavity wherein the femur or thigh bone is articulated: to the former are attached the leg bones (tibia and fibula), in most cases distinct, succeeded by those composing the foot, which correspond to the bones of the hand; namely, a tarsus,

* With the exception of the three-toed sloth, which has nine. In cetacea, though seven, they are united into one by anchilosis.

+ Several of these bones are, in different tribes of animals, sol.]ered together, or wanting. 
metatarsus, and toes. The extremities are greatly liable to vary in different orders and genera; in some, those of the fore parts being lengthened, so as to form the supporters of a wing, as in bats ; in others, shortened, as in jerboa and kangaroo; while, in both the last mentioned, the posterior extremities are enlarged to an apparent disproportion. Cetacea and analogous animals have not only no pelvis, but their hinder extremities are likewise wanting, having in their stead, at the end of the vertebral column or spine, cartilaginous bodies, forming a kind of feet, or the flukes of the tail, which, with them, is always horizontal.

The head of mammalia is, in all cases, articulated by two condyles upon their atlas or first vertebra: As the seat of intelligence, it has excited the greatest interest in all ages; and it has been remarked, that the approach to reason, observed in animals, bore some relation to the size and configuration of the head. As the brain is the centre, or origin of the nervous system, it may be proper to enter into a general anatomical detail of its structure. The brain proper, or cerebrum, consists of two large lateral lobes or hemispheres, and of the anterior and middle lobes. It is divided by a strong membrane from the cerebellum, or smaller brain, which occupies the lower and posterior part of the cranium. The surface of the brain presents a convoluted appearance, and is of a pale reddish-grey colour; but this is only superficial; and if a portion be removed, the interior is white: the lateral hemispheres are deeriy 
separated longitudinally, by a strong membrane called the falx, which is a prolongation of the dura mater, or lining membrane of the skull ; but beneath the lobes, are united by a white medullary mass, cailed the corpus callosum; nearly on a level with this substance, and on each side of it, we find the lateral ventricles, consisting of three sinuses, one anterior, one inferior or middle, and the other posterior; the walls, or sides of these cavities, are in contact, unless separated by a small quantity of limpid fluid, which is not unfrequent: in the centre of each we find a rounded tubercular-like elevation, termed the corpus strictum, and attached to it posteriorly the optic thalamus, or origin of the optic nerve: the ventricles are divided from each other by the septun! lucidum, or their medullary partition, which descends from the under surface of the corpus callosum, and is united to the fornix ; this partition, on being torn, is found to consist of two layers; and the cavity between has been called the fifth ventricle: the fornix is a white medullary band, connected at each extremity to the anterior and middle lobes, by two cords or crura: under the anterior crura there is a small aperture, which forms a communication between the ventricles; between the fornix and corpora striata, is the plexus choroides, consisting of a fasciculus of minute blood vessels, extending into the inferior and posterior corners of the ventricles, and communicating with the blood ressels of the membrane which covers the base of the brain. On separating the optic thalami, we see a white cord, terme? 
the anterior and posterior commisure connecting them, and the intervening cavity is the third ventricle: under the posterior part of this cavity, and in the passage leading to the fourth, we find the pineal gland, and, still lower, the four small eminences called the tubercula quadrigemina. The cavity to which the name of the fourth ventricle has been given, lies between the cerebellum and medulla oblongata, and is, properly speaking, exterior to the brain, being merely formed by its investing membrane. It was before remarked, that the cerebrum and cerebellum were separated from each other by a membrane ; in the centre of this, however, there is an opening through which the cerebrum sends off two crura; these unite with two others, from the cerebellum to form the tuber annulare, of which the medulla oblongata is merely a prolongation, and forms the commencement of the spinal marrow. The nerves, which have their origin in the brain and beginning of the spinal marrow, consist of medullary matter, enveloped in a fibrous structure, and pass through various apertures in the base of the cranium, to be distributed in the various organs of sense and motion.

In the proportions of the size of the brain relative to the whole body, there are great differences in mammalia, man being among those most abundantly provided; so, also, in the proportion between the cerebrum and the cerebellum, man is, with the exception of one (callitrix sciurea) again the first. "But 
it is in the development of the cerebral hemispheres, the complexity and volume of the apparatus (especially of the corpus callosum), by which its several parts are brought into communication, and the increased extent given to the surface of the hemispheres, by means of the convolutions, that the brain of man rises above that of other mammalia."* The size of the nerves, relatively to the brain, is very various; those animals with large jaws, and powerful muscles, having them considerably larger than others, but only in proportion to the supply of nervous energy required for their mode of life.

The eyes of mammalia are invariably placed in their orbits, and are preserved by two eyelids, and in some with a kind of third, or nictitating membrane. In the ear a cavity is always found called the tympanum or ear-drum, which communicates with the hinder part of the mouth by a canal, called the Eustachian tube: this cavity is closed externally by a membrane, termed the membrana tympani, and contains within it a chain of four bones, called the malleus or hammer bone, the incus or anvil, the os orbiculare or lenticular bone, and the stapes or stirrup : the stapes rests upon a vestibulum or central porch, which communicates with three semicircular canals; and, on the other side, to a cochlea or spiral canal, communicating by one extremity with

* Martin's Introduction to the Nat. Hist. of Quadrupeds, p. 14, a work which, it is greatly to be regretted, that the public has not supported adequately to its high merit. 
the vestibulum, and by the other with the tympanum. The cranium, or skull, may be sub-divided into three compartments, the anterior containing the two frontal bones and the rthmoid; the central portion being the parietal bones and sphenoid, and the hinder part composed of the occipital bone; between the occipital, the parietals and the sphenoid are placed the temporal bones, of which a part belongs to the face.

The face is essentially composed of the two maxillary bones, containing betwixt them the canal of the nostrils: upon these are the two intermaxillaries, and behind the two palate bones; between them descends the single blade of the æthmoid, named vomer, and upon the entrances of the nasal canal are placed the bones, properly termed nasal. To the external parts of the entrance adhere the inferior turbinated bones, but the superior turbinated bones belong to the æthmoid, and are placed behind and above. This general structure of the nasal apparatus is not found in cetacea; the two canals corresponding to the nostrils pierce the head vertically, admitting the air to and from the lungs when the head is nearly entirely immersed in water, and expelling the liquid which may come in at the mouth.

The jugal, or cheek bones, unite on each side the maxillary, to the temporal bones, and often to the frontal, and the lachrymals occupy the internal angle of the orbits, extending sometimes over a part of the cheeks. 
The tongue of mammalia is always fleshy, and attached to a bone named hyoid (os hyoides), which is composed of several pieces, and suspended to the cranium by ligaments.

Their lungs are two in number, divided into lobes, and composed of an immense multitude of small cells; they are invariably suspended, without adhesion, in a cavity formed by the ribs and diaphragm, and lined by the pleura. Their organ of voice is always at the superior extremity of the trachea or windpipe ; and a fleshy prolongation, called the curtain of the palate (velum palati), establishes a direct communication with the back part of the nostrils. As mammalia reside in general on the surface of the earth, they are less exposed to alternations of heat and cold, and, therefore, the covering given them is only of moderate density; yet varying from a close fur, in high latitudes, to a very scanty spread of hair in the tropics; and cetacea, entirely confined to the waters, are alone deprived of every excressent protection. *

* We think this abbreviated review of Baron Cuvier's generalities on this subject, together with an occasional glance at the excellent Introduction to a Version of the Animal Kingdom, commenced, we believe, by William Macgillivray, A. M., with copious additional observations, sufficient for our popular series, referring those, who are desirous of more complete information, to the two works here mentioned, to Griffith's Animal Kingdom, and to Professor Owen's papers before noticed. We refer also to the exccllent description of Mr. Martin, in his Nat. Hist. of Quadrupeds. 


\section{Division of the Class Mammalia into Orders.}

Naturalists have distributed the whole animal creation into classes and orders, and, without even excepting man, into families, according to affinities they bear with others more or less consimilar: the further divisions are into genera, and these into species and varieties; but it has been found convenient to sub-divide occasionally the classes into sub-classes, the families into sub-families or tribes, genera into sub-genera or groups, and in these there have been recognised forms, where, apparently, one typical species is surrounded by others so nearly alike, that the question of variety, or of difference, cannot be completely decided.

The characters of mammalia, by which Cuvier chiefly distinguished one from another, are derived from the organs of touch, which indicate their degree of dexterity, and from the organs of mastication, which determine the nature of their food, and necessarily point out the form and functions of the organs connected with digestion, and a variety of other circumstances, even such as relate to their intelligence. The perfection of the organs of touch is estimated by the number and mobility of the digits, according as they may be more or less inclosed in claws or hoofs. A digit, which has a great part of the extremity sunk into a hoof, is denied the exercise of feeling and of prehension; the opposite extreme shows a nail, composed of a single lamina, 
covering only one side of the end of a digit, leaving the other completely bare for the functions of tact.

The kind of food is manifested by the form of the molar teeth, which always indicate the same kind of action as the articulation of their jaws. For cutting flesh, the molars are always serrated, or toothed like a saw, and the jaws are hung close, so that they only open and shut like shears. The molar teeth, destined for bruising grain and roots, have flat crowns, and the jaws have a power of motion in an horizontal direction, that is, of grinding; and, in order to produce the same ridgy property which we give to millstones, the crown of the molars is composed of two different substances, the one harder than the other, and, therefore, unequal in wearing down.

The ungulate quadrupeds are necessarily all herbivorous, or with flat-crowned molars, because their feet are not constructed to seize a living prey.

Animals with unguiculated feet, being susceptible of more variety, offer greater differences in the form of their molars, and in the mobility and sensibility of their digits: there is, moreover, a characteristic which affords immense sway over their dexterity and mode of action; it is the faculty of opposing the thumb to the other fingers, so as to seize the smallest objects, which constitutes a hand properly so called. This power is carried to the highest perfection in man, who possesses the whole anterior extremity free, and can employ it exclusively for prehension.

After the order which is solely occupied by man, 
Baron Cuvier classed the quadrumana, then carnivora, rodentia, edentata, marsupialia, pachydermata, ruminantia, and cetacea. This arrangement is open to the objection, that the singular form of winged quadrupeds, with very varying dentitions, and with some important organs in their structure, assimilating them to quadrumana; and again, others, destined to live without, or with little vision, and with organisations very distinct, both being chiefly insectivorous, should be grouped with carnivora, strictly so called. Next we find the marsupialia placed in the centre of the series; an order in itself peremptorily demanding sub-division into two; the first of them, even there, comprehending animals, by their dentition and diet, corresponding to carnivora, rodentia, and edentata, but all assimilated by the still more important condition of the phenomena of their progeniture, and the construction in the females of a pouch, to bear their immature offspring. In short, the marsupialia and monotremata differ from all other mammals, by being ovo-vivaporous or implacental. For these reasons, in the time of Cuvier, not as yet fully ascertained, Monsieur de Blainville, and after him the Prince of Canino, pointed out the propriety of modifying this part of the mammalian system; but Mr. Waterhouse first formed the present arrangement, and Professor Owen first completely demonstrated the necessity of removing the whole to a second series, independent of the placental. He perceived the necessity of adding to the general considcrations, applicable to the classification 
of mammalia, the conditions of the brain, and showed, in the descending scale of its complexity towards the lower organised reptilia, that the marsupials should come last, succeeding the rodentia, which terminate the plancentals, and ending themselves with monotremata, who approximate to the class birds in one particular, and reptilia in others. * This removal from the middle of the chain, necessitated other modifications, which, instead of leaving the cetacea to the last, connects them to the carnivorous seals and morses, and passes by the herbivorous dugongs, to the giants of the fresh waters and the land, or the pachydermous order, erding in the horse, and conducting us to the ruminantia, and thence to the edentata and rodentia, the lowest in cerebral organization, have genera which present forms not unlike kangaroos. Among the marsupials some have the characters of rodents, and might connect the two sub-classes, but that it appears preferable to recommence by a second series of animals, from the higher organized towards the lower. Thus, the first of implacentals forms the marsupialia, and the second and last order the monotremata. But as there is every probability that all the variety of forms to be found in the marsupialia are by no means as yet known to naturalists, and,

* Mr. Waterhouse, however, makes edentata the last of placentals; but Professor Owen may have had in view also the condition of several rodents, who assimilate with kangaroos by the conformation of their hinder extremities, and the structure of their claws. 
perhaps, not even in the monotremata,--both orders being almost exclusively from Australia, barely half explored,--it follows, that their classification into a regular series of families, genera, and species, must still be only provisional. These modifications, we think, Baron Cuvier would have himself adopted, had he lived to acquire the additional information the science has since obtained. We have, therefore, with his distribution and dismemberments, the transpositions rendered necessary by an appropriate location of the implacentals, according to Professor Owen, a system which produces the following order:-

\section{VERTEBRATA.}

MAMMALIA.

\section{Sub-class.-Placentalia.}

Order I. Bimana (Rationalia.) MaN ! privileged in every other aspect, is zoologically distinguished by possessing hands on the anterior extremities alone; while the hinder extremities are destined solely to sustain him in walking.

The order which comes nearest to him is

Order II. That of Quadrumana, having hands on the four extremities, with thumbs free, and opposable on all. Monkeys and lemurs.

Order III. Next is the aberrant order of Cheiroptera, with pectoral mammæ, \&c., like the former, but having a fold of the skin connecting the sides of the neck, with all the limios and 
the fingers of the anterior pair ; therefore, without the thumbs free and opposable. Cuvier had placed this order as a family of carnassiers, to which it and the next are more or less allied. Bats and fying cats.

Order IV. Another dismemberment from carnassiers, the Insectivora, with the crowns of the molar teeth conical; mostly with subterrene habits, and therefore with small, indifferent, or no sight. Moles, hedgehogs, and shrews.

Order V. The Carnivora proper, feeding on flesh, show molar teeth without conical crowns, no opposable thumbs; but plantigrade, like bears and badgers; digitigrade, like neasels, dogs, and cats; web-footed, or pinnigrade, like seals and valrus.

Order. VI. The Cetacea (aberrant) without posterior extremities, but furnished in lieu with an zontal cartilaginous tail, fit for swimming; divided into Cetacea proper, with spiracles on the head, like dolphins and whales, and Herbivora without spiracles, such as the Dugong manatee. These are so fish-like in form, that they might be regarded as a separate class, if their economy was not, in every other respect, the same as in the other orders of placental mammalia. They are the warm blooded fishes of the ancients, and residing in an element which easily sustains their mass, include the most gigantic forms that are to be found in the whole animal creation. 
Order VII. Here are placed the Pachydermata, or thick-skinned mammals, containing among them the largest terrestrial animals, several of which, by their habits, are almost amphibious. Hippopotamus, tapir; one of the proboscidean family, or the elephants, might form an order by itself, as well as the solipeda or horses; they are, however, normally multungular, and seem to be the chief residue of a former zoology. Order VIII. Already, in the last order, the animals had their digits much cramped by being sunk into deep hoofs; in the present, or Ruminantia, there is, moreover, a complicated stomach, a want of upper incisor teeth, in most even of laniaries, and their feet are bifid. Camels, deer, sheep, and oxen.

Crder IX. In the Edentata, we have the digits no less sunk into horny claws than in the preceding; they are altogether destitute of incisor teeth, and more or less deficient in laniaries and molars. They are divided into two tribes, tardigrada, comprehending the sloths; and Edentata proper; the anteaters and armadillos. Grder X. The Rodentia have again digits little different from the carnivora, but they want laniary teeth, and have the incisors of a form and disposition peculiar to themselves, being fitted for gnawing. Hares, squirrels, rats, \&c. Though they are of higher organisation than the last mentioned, and of social habits, they seem to approximate most to the 


\section{Sub-class.-Implacentalia.}

Drder XI. The Marsupialia or pouched mammals, approaching to rodentia in the structure and permanent separation of some of the bones of their skulls; having, in general, a more abundant incisal dentition than placental mammals, and always marsupial bones, performing important functions in their vital economy.

Order XII. The Monotremata, provided with marsupial bones, though destitute of pouch and teeth; armed with spurs on the hinder feet, and approaching towards the class reptilia in many anatomical characters, constitute the lowest, and, therefore, the last form in the orders of mammalia.

It would be easy to form a diagram, showing in what manner these twelve orders are linked together seriatim; osculate among each other, or point to the classes of vertebrata of different and lower organisation; but, in a volume of small dimensions, the above general view will, we trust, be sufficient, and as it is not intended to enter into the natural history of man in this introduction, we shall merely state that we do not admit more typical races than Cuvier has pointed out; all the other apparent varieties being referable to intermixture of two or even three, modified still more by climate, food, and 
other influential causes.* But, before we proseed further with the orders of mammalia, it may be proper to take a slight review of the organic remains of this class, which attest former zoological eras, apparently terminated, by mighty convulsions of the earth, totally or partially, according to the evidence of different epochs, and replaced by a new creation, not based upon organisations different in principle from the former, but almost universally distinct in species, often in genera, and sometimes apparently in the whole order. The widest differences appear to belong to the remotest periods, and approximations gradually assimilating with the present zoology, increasing as the epochs are comparatively recent.

Thus, the first traces of mammalia occur in the lower oolite series (the Oxford), where marsupial remains have been detected. Excepting some doubtful cetacean, no others have been observed of a later period, until the lower tertiary deposit is examined. This is now commonly called the eocine period, as observed in the London and Paris basins : it contains many genera of now extinct forms of quadrumana, cheiroptera, rodentia, and marsupialia; but it is chiefly in the numerous pachydermata that it abounds, while carnivora seem to have been wanting, their offce being supplied by huge sau-

* In a future work, we may revert to the history of man, and trace the existing races from their most ancient locations, by the routes which geographical necessity must have imposed, to rcach their later and present liahitations. 
rians, offering an indication that the soil at that period was in general swampy, and adapted for their residence, as well as convenient to the greater number of the colossal quadrupeds, to wallow, to feed, and to be fed upon. In the next stage, with a surface risen into upland, the more recent tertiary age, or newer pliocene, another condition of the atmosphere seems to have prevailed. The crocodile saurians have disappeared, or are few, and great carnivora commence to keep in balance the superabundant productiveness of the remaining pachydermata, of huge ruminants, of equine species, \&c. The geographical surface of the earth seems, in general, not to have been unlike the present, and each great portion of the globe bears evidence of having sustained a fauna, similar in character, though not identical with the present. During that period, the contents of innumerable caverns attest to a similar activity in the carnivorous scavengers, which we still observe in wild, and, in particular, in tropical countries, where hyenas, wolves, and jackals, seldom leave until morning any animal matter they can devour or carry off. Whether the bones of man, in this later fossil state, have or have not been found, is a question in dispute; but there is an evident accumulation of affirmative facts, which are not satisfactorily explained away by the arguments hitherto advanced for that purpose.

We pass now to 
ORDHR I .

THE QUADRUMANA.

Tuis order has already been in part the subject of a volume of the Naturalists' Library; we, therefore. propose on this, as well as on other similar occasions, to notice more lightly the subjects that have have been handled, in order to secure increased space for those which have not been similarly investigated, reserving to ourselves the means of pointing out new and important facts that may have been obtained since the volumes were written, and of modifying the classification according to our own views.

The Quadrumana, so called because they possess organs of prehension very similar to human hands, both on the anterior and posterior extremities, though with thumbs not invariably capable of opposition to the fingers, are, in the whole of their structure, essentially arboreal. They have teeth of three kinds, incisors, canines, and molars, with proper tubercles, more or less blunt; and, accordingly, feed on insects, reptiles, eggs, roots, mollusca, flesh, and even crustacea; but chiefly on fruits and nuts. They have been divided into three families, the Catarrhini, or with the nose slit downwards, which applies to the apes of the Old Continent; Platurhini, or wide noses, containing the monkeys of the $\mathrm{New}$ World; and Strepsirhini, or turned nose, wherein the lemurs and allied species are arranged. But 
Mr. Martin, we believe, proposed in lieu of terms rather harsh, though to a certain extent truly explanatory, to substitute names with a patronymic form more readly retained; and, therefore, gave those of Simiadoe to the first, and Cetidoe and Lemuridoe to the second and third. In a fossil state, quadrumana nearly allied to existing species, have lately been detected.

Simiada, or apes of the Old World. The thumb antagonising with the fingers, except where rudimental.

Dentition incisors $\frac{4}{4}$ can. $\frac{1}{1} \frac{1}{1}$
pr. mol. $\frac{2}{2} \frac{2}{2}$ molars $\frac{3}{3} \frac{3}{5}=32$.

Nostrils divided by narrow septum opening downwards; cheek-pouches, and membranous laryngal saculi, not constant characters.

The great Indian islands seem to be the centre of this form of animals, because there they are in the highest condition of organization and stature, and in the greatest number of species. In the hotter regions of Continental Asia, and in the whole of Africa, the genera are local to each; in Madagascar their presence is supplied by lemurs; in the island of Mauritius they have been imported; and perhaps also, though at a remote period, to Gibraltar.

The larger species, and some others, may congregate only in families; but the greater number of simiadce are gregarious, with more intelligence and aptitude than their indocility and petulance allows them fully to use. They are not so diurnal in habit, but that some species will rob by night, or at least 
before dawn, posting sentinels for their security at all times. In captivity they are scarcely corrigible, never truly domesticated, and if they be occasionally tolerated by mankind, they are generally viewed with suspicion, and often with disgust. We place at their head the great apes, or men of the woods, now divided into two genera. Of these the genus Troglodytes, the Chimpanzees, are lately placed foremost, although they are nearly destitute of forehead, and have callosities on the buttocks; but in that incipient form which may result from constant pressure. When adult, they are little, if at all, inferior to man in size, and vastly superior to him in strength; their hands reach only to the knees, and their hair is black. They live in families, which construct a kind of shelter, whither the females retire, or occupy ancient and decayed Adansonia trees, the adult males always residing outside. They are fond of clothes, and use sticks for weapons. These, and other notices of their manners recently made known, render several of the accounts of the older writers respecting them much less incredible. The next in order, is

Pitnecus.-The Orangs, or Men of the Woods, whereof the Jocko, or Pongo, Baron Wurmb's Orang-Ootang, were assumed to be synonyms. It now appears, however, that there are two species, both inhabitants of Borneo, and perhaps of Sumatra. Both are destitute of callosities and tail, and have very long arms.

Pithecus satyrus. - Adult, with muzzle very 
prominent, powerful laniary teeth, and very broad middle incisors; large protuberances on each cheek of the male, forehead much depressed, voluminous beard, and chestnut-brown hair; no eyelashes. And

P. Abelii, or Red Orang, with long red hair, that of the head extending upon the forehead in the form of a periwig; the eyelashes long; muzzle of the young short; the adult as yet unknown. It is, however, remarkable, that the very large, almost colossal, male orang, whose skin, hands, feet, and head were submitted to Dr. Abel's inspection, should not have exhibited the fleshy protuberances of the former species; and, in the profile, it offered a much more elevated forehead. Next we have the

Hylobates gibbons, or Long-armed Apes, resembling Pithecus in the length of arms, want of tail and cheek pouches, but having a short muzzle and decided callosities; several are likewise of considerable size. Then follow the genera,

Semnopithecus, or Solemn Apes, with very long tails, and laryngeal saculi, but possessed of no, or of small cheek pouches, and slender bodies; last molar of lower jaw with five tubercles.

Calobus, or Thumbless Apes, being destitute of thumbs on the forehands: they have short muzzles; tail long and slender; callosities and cheek pouches always present; last molar with five tubercles.

Cercopithecus, Guenons, with muzzle slightly elongated; tail long; have always callosities and cheek pouches; last molar of the lower jaw with four tubercles only. 

By some naturalists the long-nosed monkeys or Nasalis are separated; but a more distinct genus is,

Macacus, Macacos, have the muzzle rather elongated; limbs and bodies robust; cheek pouches and callosities; the last molar of upper jaw with five, and of lower jaw with six tubercles; tail varying from middle length to almost none, or a simple tubercle. Those with tails of some length, resembling Cercopithecus, have been formed into a distinct group, Cerexebes; the short-tailed into another, Maimon. We here figure

\section{WHITE MA IMON.}

\section{PLATE I.}

Macacus (Maimon) Brachyurus, Temм.

From a specimen in the collection of M. Temminck, it is nearly destitute of tail, about two feet high, covered entirely with close white fur, with the muzzle, ears, and callosities flesh coloured; upper surface of the four hands pale buff. We were informed that India was its native abode. The third group is the tailless Macacus magots, or Inuus, exemplified in the Barbary Ape.

* Macacus is a Latinisation of M. Lacépède, who, we think, was peculiarly unfortunate in the selection of his names, and often chose barbarous terms when classical appellations were before him unapplied. 
The Cynocephalus, or Baboons, have the head still more elongated and truncated; nostrils terminal; limbs robust, and of equal length; cheek pouches, and callosities, the hair wanting around the last mentioned; the last molar of the upper jaw with five, and the lower with six tubercles; tail varying in length.

This section includes the group of Cynocephalus, or Baboons, and that of Papio, or Mandrills.

In the second family, the Platyrhini, or Celide, we have the Monkeys of the New World, whose dental formula is incis. $\frac{4}{4}$, can. $\frac{1}{1}-\frac{1}{1}$, mol. $\frac{6}{6}-\frac{6}{6}=36$; nostrils separated by a broad partition opening on the sides of the nose, the genus Eriodes excepted; tail long, often prehensile, and callosities and pouches always absent.

In the first sub-tribe, distinguished by the name of Cathechura, or prehensile tails, commonly called Sapajous, we have the

Mycetes, or Howlers, more distinctly marked by the cavernous form of the hyoid bone, externally observable, and by the under surface of the terminal part of the tail being hairless. They have five fingers on all the hands, and are noisy inactive animals. After them follow the

Ateles, or Spider Monkeys, wanting the anterior thumbs, and remarkable for their elongated slender form. These pass into the genus

Eriodes, or Woolly Monkeys, with soft hair, thumbs on the forehands in a rudimental or semi- 
perfect state, but distinctiy marked, by their nostrils being separated by a narrow partition, and opening nearly beneath the nose. After these we find

Lagothrix, or Gluttonous Monkeys, having the head round like Ateles, the thumbs as in the Howlers, and the tail partly marked as before; the limbs are moderately long, and the hair is rather woolly. Then comes the genus

Cebus, Sajous, or Weepers, properly so called, with rounded heads, but their tails entirely hairy, though still prehensile. A group of these animals liave the hair of the forehead disposed in tufts, and, therefore, are known as the horned weepers.

In the second sub-tribe (Chalanura) or with tails depressed, imperfectly prehensile, or absolutely lax and bushy; the hands always pentadactylous: we first meet with the genus

Calliturix, or Squirrel Monkeys, with round heads; eyes and ears large; tail longer than the body, covered with short hair; nails flat on the thumbs, long and narrow on the fingers. And next to these,

Fithecia, or Fox Tails, with eye and ears resembling those of man; strong canines, and tails usually long and brush-like. A sub-division of this group have, by Spix, been formed into another genus, under the name of

Brachyurus, because they have tails in length less than the body. These genera begin to be nocturnal, or at least crepuscular; they reside in the deepest forests, and we have olserved them at the dawn of day, in the summits of the highest trees, 
watching our camp and night fires. The next genus of this sub-division, is that of

Nyctipithecus, or Night Monkeys, improperly named Aotus, or Earless, by Illiger, those organs being only concealed in the hair; they have round heads, and very large nocturnal eyes, approximating, by these characters, the Loris of the Old Continent.

Humboldt first introduced a species to the notice of naturalists, named Douroucouli, and others have since been added by Spir.

The last genus is by some raised to a family, and named Hapale and Hapalida, because it has, like the apes of the Old Continent, only thirty-two teeth, and, unlike any of the Simiada, claws on the fingers and thumbs of the forehands, and nails only on the thumbs of the hinder hands. They form two subgenera:-

The Hapale proper, or Jacchus marmousets, and Midas, or Tamarin marmousets; the former having a more bushy tail, and with the lower incisor teeth in a curved line; and the latter with the tail more slender, and the lower incisors in a straighter line: both are known by the name of Wistitis, and all are beautiful little animals.

In the last family of Quadrumana, are placed

The Lemuride or Makis, whose form approaches more nearly to quadrupeds, with a more pointed snout, a rather woolly fur, and claws on the first finger of the hinder hand, sometimes on the second finger; flat nails on all the others, and thumbs per- 
fectly opposable; teeth tuberculous, approximating the form of insectivoræ. The first genus contains

Lemur, the Lemurs, properly so called. Dental formula, in. $\frac{4}{6}$, lan. $\frac{1}{1}-\frac{1}{1}$, mol. $\frac{6}{6}-\frac{6}{6}=38$. The form of the head and tail gives them a mixed aspect, as if they were quadrumanous foxes; they are of the size of a domestic cat, or smaller, very active, cleanly, and tameable; the voice is a shrill whistling, or a guttural grunting. They are exclusively found in Madagascar; but we have had occasion to observe many domesticated in the tropics, and found them never asleep in the night; the pupils of the eyes expanding and contracting most rapidly with the changes of the light, or the excitement of passions; ever watchful after insects, but greedy of fruit, and, therefore, very jealous of children, while they were gentle and playful with grown persons.

L. catta._Ring-tailed Lemur, Mococo of Edwards. -Blue-grey, with a rosy tint on the back; pure white beneath; tail ringed with black and white; with the arms stretched, the forefingers involuntarily close. They are harmless and active.

L. macaco.-The Vari or Ruffed Lemur. - Pied with large spaces of black and white. The Black Lemur of Edwards is only an individual entirely of that colour. The Vari is the largest and fiercest of the genus, capable of making excessively loud noises. M. F. Cuvier mentions one which, in the night, killed and devoured another that was kept in the same cage with him, leaving only the skin.

L. ruber, Geoff.-_Red Lemur. - Bright reddish 
chestnut; below, face, hands, and tail, black; broad white spot on the nape of the neck.

L. albimanus, Geoff.-White-handed Lemur. Greyish-brown above, belly and hands white.

L. allifrons, Geoff. - White-fronted Lemur. Chestnut-brown above; olive-grey beneath; white band round head; hands yellowish.

L. mongoz, Linn.-Mongoos Lemur. - Brownish-fawn above, with an olive shade; end of tail black; face grey; top of head black; cheeks bright orange-brown: in the female, the top of the head is grey.

L. nigrifrons. - Dark-fronted Lemur, Geoff. Greyish-brown above; ash-grey beneath; forehead and face dark brown; hands ash colour; larger than Mongoos. We have seen a male of this species spring the whole length of his chain after a negro child, lay open its neck with a deep long scratch, making the blood flow profusely, and carry off an orange, the object for which the attack was made. This animal would always snatch lighted cigars out of the mouths of bystanders, and often scorch itself by rubbing the ignited part against his abdomen, blinking and grunting all the while it remained smoking.

There are, besides these, the Diadem lemur, Propithecus diadema of Bennet; the Anguan lemur, the Red-fronted lemur, and probably several others; all, as far as is yet known, inhabiting Madagascar.

Genus Lichanotus.-The Indris.-The head tri- 
angular; ears short and rounded; teeth similar to the former, excepting that there are only four incisors in the lower jaw; but it seems that the whole formula is as yet not well known; mammæ two, pectoral. There is only one species known.

L. brevicaudatus. - Short-tailed Indri. - Almost without a tail ; three feet and a-half high; brownish-black, with a grey face; crupper and tail white; the voice like that of a weeping child. It is said that the natives of Madagascar train the animal, like a dog, for sporting; but vegetable-eating, harmless, scansorial, and destitute of speed; it remains to be explained in what manner it can be rendered serviceable.

- Genus Stenops. - The Lorises, or Slow Lemurs. - Have the dentition of lemurs, but with the points of the molars sharper; the muzzle short; the eyes very large and approximating; the body slender; the tongue rough; no tail. They are nocturnal, feeding on insects, and perhaps on small birds, but mostly on fruit; they move very slowly. Sir A. Carlisle discovered that the arteries of their limbs are sub-divided at the base into small branches, in the same manner as in the True Sloths.

S. tardigradus. - The Sloth Loris. - Reddishbrown; dark brown line along the back; a white spot on the forehead. Inhabits Bengal. This species is described from the living animal by the classical pen of Sir William Jones. There is a larger grey variety in India, with a black dorsal stripe. 
S. gracilis, or Slender Loris of Ceylon.-With a more elevated nose and red circle round the eyes.

Genus Perodicticus. - Incis. $\frac{4}{6}$, can. $\frac{1}{1}-\frac{1}{1}$, mol. $\frac{4}{5}$ or $\frac{4}{4}$. All the cheek teeth assuming tubercular forms; tail of middle length; index very short; one phalanx alone excerted.

P. Geoffroyi.-The Potto of Bosman.-Chestnut; below paler with greyish hairs intermixed; hair woolly. Resides in Western Africa, Sierra Leone. We might add here, the

Genus Mrcrocebus of Geoff.-Differing from the former in several particulars. The arteries of the posterior limbs simple, and branching off in the usual manner.

M. murinus._-Buff coloured; from nose to tail five inches, tail six inches; ears large, naked; head rounded; muzzle short, pointed: eyes not so large as in Stenops, but brilliant. Habits nocturnal.

Genus Otolicnus, Illig.-The Gallagoes.-Dent. form ; incis. $\frac{2}{6}$ or $\frac{4}{6}$, can. $\frac{1}{1}-\frac{1}{1}$, pr. mol. $\frac{2}{1}-\frac{2}{1}$, mol. $\frac{4}{4}-\frac{4}{4}$ $=\frac{1}{1} \frac{8}{8}=36$. They have the the teeth frugiverous and insectivorous; diet of the lorises; their tarsi are very long; the tail long and bushy; ears open, naked, capable of being folded and closed; eyes large, nocturnal. They are all most active arboreal animals; natives of Africa and Madagascar; in their manners very like monkeys.

O. crassicaudatus. - Great Gallago. - Size of a rabbit; ears two-thirds of the length of the head; colour reddish-grey; tail bushy. 
O. Senegalensis.—Senegal Gallago. - The ears as long as the head; colour yellowish-grey above, yellowish-white beneath.

O. Madagascariensis, is the Marine Lemur of Pennant.-The size of a rat, and in general form very like a Maki; the colour is uniform fawn grey above, below white.

Genus Tarsius. - The Tarsiers.-Have the head round, the muzzle short and pointed; the eyes very large, approximated, nocturnal; ears large, naked. Dental formula in. $\frac{4}{2}$, can. $\frac{1}{1}-\frac{1}{1}$, p. mol. $\frac{6}{6}$, mol. $\frac{6}{6}=$ $\frac{1}{1} \frac{8}{6}=34$; tail long; mammæ two, ventral. Inhabit the East Indian Archipelago.

T. spectrum. - Podje Tarsier. - Size of a rat; light greyish-brown.

Here systematists place a genus named CnirogaLEUS, entirely depending upon several drawings left by Commerson, and engraved by Geoffroy under the above name. They seem to indicate a new genus, somewhat like quadrumanous cats, but with straight awl-shaped claws on the fingers, and flat nails on the thumbs. The largest of three supposed species is little more than twelve inches in length.

We place, with Mr. Waterhouse, at the end of this order, the

Genus Galeopithecus or Flying Lemurs.-Dent. form. incis. $\frac{2}{4}-^{2}$, can. $\frac{0}{1}-\frac{0}{1}$, false molars, $\frac{2}{2}-\frac{\frac{9}{2}}{2}$, molars $\frac{4}{4}-\frac{4}{4}=34$. They are remarkable for the expanded skin from the fore to the hind legs and tail, which gives them the same and superior means of sailing downwards, possessed by flying squirrels; their legs 
are nearly of equal length; the fingers armed with sharp claws. A peculiarity found in this genus alone is, that their canines are curiously indented, and short, like the molars; only two indented incisors above, very wide asunder, and below six, cleft with narrow pectinated grooves. They are arboreal, living in the Indian Archipelago. Until lately, only one species was known.

G. Temminckii, Waterh. - Calugo, or Olek. Temminck's Flying Lemur, or Lemur Volans of Linn.-Grey rust colour above, pale rufous beneath. Found in the Moluccas, Penang, \&c. And a second,

G. Philippinensis, Waterh. - Philippine Flying Lemur. - Brought from the Isle of Bohal. The variegated specimens are merely the young of $\mathrm{Co}$ lugo, or of both.

Fossil quadrumana were long undiscovered; more lately, however, in the lower tertiary (Eocene), remains of a Baboon, or rather Macacus, have been found in the Isle of Sheppy, London clay, and in the newer pliocene deposits of Asia. Among the Sewalek Hills, a Semnopithecus, allied to S. Entillus, but larger; and bones of the face of another species, still larger, were discovered. Cavern deposits have likewise produced fragments of quadrumana. 
ORDER III.

THE CHEIROPTERA.

TIE Cheiroptera are mammals, with four distinct unguiculated limbs; three kinds of teeth; all the phalanges much prolonged, and united by a membrane to the hind legs, and generally beyond them, forming true wings; the thumbs free, not opposable, and armed with a claw; a kind of patella behind the articulation of the arm, with the fore-arm analogous to the olecranon process, believed to be found in this order only; the posterior extremities are weak, furnished with five equal toes and strong claws. Like the later quadrumana, the Cheiroptera stand between the frugivora and carnivora, feeding partly on fruit, but not totally without animal food, and that chiefly consisting of insects. 'They are all nocturnal or crepuscular. Hibernating in our latitudes, they hang by the hind feet, when in a state of repose, from branches of umbrageous trees, or more commonly from the rocky sides of caverns, the interior of hollow trees, and in the roofs of barns and unfrequented houses. The sense of hearing they have in an exceeding degree of acuteness, and, moreover, a perception of the vicinity of strange bodies, which 
permits them to fly about when totally blinded, at if they had their complete sight. This power enables them to penetrate into the deepest caves and conduits, no matter how far remote from the light; nor do they suffer from the want of air, or from its mephitic state. In these retreats they are found in flocks, but the species never are mixed, nor the males with the females, nor the young with either, when they are capable of flying. It is in the pairing seasons that they are for some time associated. Late observations tend to prove, that some, if not all, reproduce their species only when nearly adult, and never after they are grown.

Many species fly with great vigour, but none ever raise themselves to a great altitude in the air; nor is it likely that any can sustain their flight for the same length of time which we know many species of birds are wont to perform.

The bats were placed in one genus by Linnæus; afterwards, they formed almost exclusively the family of Cheiroptera, in the order Carnassier of the French naturalists, and of Cuvier; then the family of Vespertilionidce of Gray and Lesson; and last, the Cheiroptera,-excluding the genus GaleoPITHECUS, consisting of the bats alone,-forms the third order of Professor Owen; and, in this arrangement, it still contains a great number of species demanding much sub-division, and of all mammalia is that which is most rapidly increasing in numbers, by the constant discovery of new forms, and of new species. 
The best arrangement of the Cheiroptera, appears to be that of Mr. Macgillivray, which combines all the essential information found in Temminck's monograph, with certain modifications of Isid. Geoffroy, Spix, Gray, and Lesson. The bats not being an order commanding sufficient interest with the general reader, we shall review it with some brevity, dwelling only on a few of the species which have claims to a particular notice, while, for the rest, we expose only the characters distinguishing the tribes and genera. We name,

Family I. Harpyidae. - The Frugivorous Bats, or Meganycteres of Latreille. - They have molar teeth, with flat or slightly crested crowns; the index or first finger of the wing with three phalanges, usually with a nail. They reside in China, Japan, Southern Asia, the East Indies, the Indian Archipelago, New Holland, the Mauritius, Madagascar, and Africa; but are not found in America or Europe. The species are, in general, larger than the insect eating bats, and proportionally less supplied with membranous surface for flying; still some are also sufficiently diurnal to have been shot on the wing, in open day, several miles from the land, in the straits of Malacca and Banca. Some of the Egyptian species may have extended anciently along the coast of Syria and Asia Minor, and similarly others from Morocco to the south of Spain, for either directly or indirectly, that tribe especially, which is destitute of tail, was the type which served the 
classical poets of antiquity with their marrellous tales of harpies.

In A, the first section of Goblins or Rousettes* is tailless, embracing the

Gerius Pteropus, or Ghole.-With a prolonged, straight, conical head; slender muzzle; vertical incisors; slight interfemoral membrane; fore-finger generally with a claw; wing membranes attached more towards the back. Dent. form. in. $\frac{4}{4}$, can. $\frac{1}{1}-\frac{1}{1}$, p. mol. $\frac{2}{2}, \mathrm{~mol} \cdot \frac{8}{10}$ or $\frac{1}{1} \frac{0}{0}, \frac{1}{1} \frac{6}{8}$ or $\frac{1}{1} \frac{8}{8},=34$ or 36 . They devour a great quantity of fruit, and yet are eager after birds and small quadrupeds. Among these the

P. edulis. - The Kalong, or Edible Ghole.Dark brown, with the neck and upper part of the head bright rust colour, and a transverse reddish band, and another black between the shoulders, is the largest known species : some extend their wings t,o ahove five feet English measure. They are often by seamen called Flying Dogs; abound in the Sunda Islands, Java, the Moluccas, \&c., where they hang in the day time suspended in the largest trees, and fly out at dusk, destroying the fruit trees that are not protected with nets, devouring birds, quadrupeds, and probably reptiles; the females with one or two proportionably bulky young hanging at their breasts, making strong goose-like cries, and though

* A name which we think applies better to the family than the single species, where Illiger has bestowed it; it is that which in English might be rendered by Ghole or Goblin, both understood, and more expressive than the French word Roussette. We have too many Gallicisms already in the language. 
flying singly, never at a distance from many others. We perceive at once, that the ancients had before them all the materials for their filthy monsters, and yet the natives of their present country find them palateable food, taking great care at the same time, when hunting them with net bags suspended from poles, that the falling or taken animal does not get entangled with his unmanageable hind claws, in the bushy matted heads of the hunters, such as those of Papoos and Haraforos usually are; for, even on the continent of Europe, the peasantry dread the claws of common bats becoming entangled in their hair.

Of this section there are enumerated twenty-one species, most, if not all, edible, and some reported to have the flesh white, tender, well flavoured, and entirely destitute of the musky smell which pervades that of others.

In B, the second section of Goblin Bats, or Gholes with tails, we find the

P. Egyptiacus, or Geoffroy.-Egyptian Ghole.Found by Mr. Geoffroy, hanging from the ceiling of one of the chambers of the great pyramid; but since discovered also in Senegal, and, therefore, resident across the whole breadth of Northern Africa. It is of a dull greyish-brown, with a very short tail. In this section is likewise included the group which Mr. Gray, perhaps prematurely, has separated into a genus, by the name of Epomophorus, on account of a lengthened spot on each side of the neck, at the anterior insertion of the wings, covering with length- 
ened white hairs an odoriferous gland, the use of which is not as yet determined. Of these, all from Western Africa, he enumerates three species, making, with the rest of the second section, nine, exclusive of several others said to be identical with established ones.

Mr. Isid. Geoffroy St. Hilaire, finding several species of Pteropus with four molars less, and their zygomatic arches more prominent than in the former, detached them, and in his monograph of Pteropus (dict. class. d'hist. nat.), formed them into another by the name of Pachysoma.

The genus $\mathbf{P}_{\text {ACn }}$ rsonra. - Stout Gholes. - Have the head spheroidal, large; muzzle large; the zygomatic arches prominent; half the thumb inserted in the membrane; mammæ before the armpits. Dent. form. in. $\frac{4}{4}$, can. $\frac{1}{1}-\frac{1}{1}$, p. mol. $\frac{2}{2}$, mol. $\frac{6}{8}=\frac{1}{16}=30$. They are of small size, with nocturnal habits, retiring to hollow trees or cavities; their fight rapid, but irregular; their cry piercing, and bite painful; the best known is

P. titthwecheilum. - Wart-lipped Pachysoma. First described by Temminck under the name of Pteropus titthcecheilus. Russet-brown above; grey beneath; on the neck, nape, and sides of chest, bright rose colour (in the males only); the upper lip with two large warts separated by a furrow; the tail enveloped, the point only free; the interfemoral membrane naked beneath, deeply cavitied. Found in Java, \&c.

There are four or five more species, with tails 
wanting, short, or even long; but passing to another species, separated from Pteropus by Isidore Geoffroy, we have the

Genus MaCroglossus.-Kiodote or Great-tongued Goblins.-With an elongated head; muzzle almost cylindrical, slender; tongue long, excertile, cylindrical; alar membranes attached to the sides of the back. Dent. form. in. $\frac{4}{4}$, can. $\frac{1}{1}-\frac{1}{1}$, p. mol. $\frac{2}{2}$, mol. $\frac{8}{10}$ $=\frac{1}{1} \frac{6}{8}=34$. In this genus, the intermaxillary bones form a prolonged obtuse cone, supporting the muzzle, which is of very different lengths in the animals of different islands of the Indian Archipelago, though they are considered to be only one species, known by the name of

M. minimus, Kiodote Goblin Bat. - Pteropus rostratus of Horsf.-It is of a light red colour, tinted with yellow above, light russet beneath; the interfemoral membrane very narrow, hairy above ; tail rudimentary. It is the Lowo apu, or Dog Bat of Java, and feeds in preference on the Jambu or Eugenia, cultivated in the gardens of Java and Timor.

Genus Harpyia, Illig.-Tube Nosed Goblin, or True Harpy.-Head large and broad ; muzzle thick, very short; nose prolonged into two diverging tubes, cleft externally, and margined at termination; alar membrane attached to sides of back; thumb partly covered by membrane; index with third phalanx and claw. Middle age, dent. form. incis. $\frac{2}{2}$, can. $\frac{1}{1}-\frac{1}{1}$, p. mol. $\frac{2}{2}$, mol. $\frac{6}{8}=\frac{1}{1} \frac{2}{4}=26$. In old specimens, the lower incisors appear to be often wanting, as well as a molar on each side. 


\section{H. Pallasii. - Pallas' Tube Nosed Goblin. -} Vespertilio cephalotis, Linn. - Cephalotis Pallasii, Geoff.-Colour clear ashy-brown; whitish beneath; the tubes of the nose, ears, and tail, bright yellowish brown; membrane yellowish-red, with irregular whitish spots; the interfemoral cleft in the middle, partly covering the tail; tail short: size of the Common Bat of Europe. Inhabits Amboyna.

Genus Cephalotes, Geoff.-Cephalotes.-The head very thick; muzzle short, truncated; nostrils slightly tubular, large; upper lip cleft by a furrow ; alar membrane adhering to the spine only by a transparent membrane; thumb nail partly covered by the membrane; index with third phalanx out; no claw. Dental formula varying with age, is in the adult incis. $\frac{2}{2}$, can. $\frac{1}{1}-\frac{1}{1}$, mol. $\frac{8}{12}=\frac{1}{1} \frac{2}{6}=28$. The interinaxillary bears, on each side, a small tooth, capable of acting backwards and forwards, by means of a set of muscles, which thus make the incisors moveable.

C. Peronii._-The hair brownish or reddish; tail partly engaged in the interfemoral membrane; ears broad, pointed; its wings expand two feet. Inhabits Amboyna, Timor, \&c.

Family II. Vespertilionidce.-Insectivorous Bats. -Vespertilionidæ.- These constitute the true bats, with molars having conical points; the index with one or two phalanges only, always without a nail: their molar teeth, three in number in each jaw, are preceded by a variable number of premolars; and, with the exception of one sub-genus, the membrane always 
extends between the thighs. They inhabit the tropical and temperate parts of the whole earth.

The insectivorous bats may be divided into two principal tribes; the first having the middle finger in the membrane, with three ossified phalanges, while the others, including the index, possess only two; the second, with only one ossified phalanx for the index, and the other fingers two or three.

Tribe I. Diphalangia anistiophora.-Two-jointed Leafless Bats.-Having the index with two ossified phalanges, a nose simple, destitute of a leafy appendage.

Genus Dysopes, Illig. - Bull Dog Bats.-The head thick; muzzle broad and flat; ears very large, approximated, recumbent over the eyes, and arising from the commissure of the lips; upper lip large and wrinkled. Dental formula varying according to age, incis. $\frac{2}{2}$, can. $\frac{1}{1}-\frac{1}{1}$, mol. $\frac{8}{10}=\frac{1}{3} \frac{2}{4}=26$. But the incisors are very variable, at first $\frac{4}{6}$, then $\frac{2}{6}$, later $\frac{2}{4}$, adult $\frac{2}{2}$, old $\frac{2}{0}$. The toes are covered with bristles; the hinder thumbs free, sometimes opposable; the wing membrane narrow; tail long, partly engaged in the interfemoral membrane. They inhabit the tropics, and warmest parts of the earth.

It is from this genus, Dysopes cestonii, that Professor Savi formed his genus Dinops, because his specimens had the six incisors of extreme youth. M. Geoffroy made his genus Nyctinomus from young animals, which had four incisors in the lower jaw; Dr. Horsfield, his Cinerromeles from a species which had the character of an opposable thumb on 
hind feet distinctly marked ; finally, Mr. Macgillivray thinks it probable, that the genus THYRoptera of Spix, as yet imperfectly described, may be referred to the present. All these animals have the body heavy in proportion to the narrowness of their wings; hence they live more in caves and hollows, where, by their superior apparatus for scaling walls, they subsist on larvæ, \&c. They are found in America, the Old Continent, and New Holland.

There are fifteen admitted species, besides eleven doubtful, and some doubly denominated.

Genus Stenoderma, Geoff. - Narrow Banded Bats. - Ears small, lateral, isolated, with an auricular operculum; interfemoral membrane rudimentary, lining the thighs like a band; no tail. Dental formula of adult, incis. $\frac{2}{4}$, can. $\frac{1}{1}-\frac{1}{1}, \mathrm{~mol} \cdot \frac{8}{10}$ $=\frac{1}{1} \frac{2}{4}=26$ (G. Cuv.). Little is as yet known of this genus; but the

Genus Diclidurus, P. of Wied, or Box-tailed Bats, is very remarkable, having a broad head; pointed muzzle; broad ears inserted over the eyes; and the tail consisting of two corneous valves, moveable and hollow; the coccyx entering the upper valve; the interfemoral membrane extending beneath and beyond the caudal valves. Dental formula, as far as yet known, incis. $\frac{2}{6}$, can $\frac{1}{1}-\frac{1}{1}, m_{0}$. $\frac{1}{1} \frac{0}{0}$ $=\frac{14}{18}=32$. There is only one species as yet known of this animal, first described by the indefatigable naturalist, Prince Maximilian of Wied; it is the 
WHITE BOX-TAILED BAT.

PLATE II. Fig. 1.

Diclidurus allus, or Freyreysii of P. MAX.

ON this species, of which we here give a figure, the genus was established; offering a structure, in the form and composition of the parts of the tail, without example in any other class of mammalia, and perhaps not in the animal kingdom; the coccygeal bones running out jointed into two horny pieces, covered by the skin of the body, forming a kind of box of two valves, applied horizontally, and capable of separate motion. It was found by Mr. Freyreise upon cocoa trees, near Rio Pardo, in Brazil.

Genus Noctilio, Cuv. and Geoff.-Hare-lipped Bats.-Head broad; muzzle short, swelling cleft, furnished with warts or tubercles; nose confounded with the cleft lips; nostrils almost tubular, prominent; ears small, isolated, with auricular operculum internal. Dent. form. incis. $\frac{4}{2}$, can. $\frac{1}{1}-\frac{1}{1}$, mol. $\frac{8}{10}=$ $\frac{1}{1} \frac{4}{4}=28$. The interfemoral membrane very broad, projecting with two obtuse angles; tail mostly enveloped, but free at tip. Inhabits South America. There are two species known of this genus.

The genus Aello of Leach., Linn. Trası. xiii., 
depends upon a specimen in the Museum of University College, London; with a conical head; flat forehead; ears large, separate, apparently truncated; tail with membranous band, prolonged to the point of the interfemoral membrane; alar membrane darkbrown; body rusty-brown. Dent. form. incis. $\frac{2}{4}$, can. $\frac{1}{1}-\frac{1}{1}$, mol. $\frac{8}{10}=\frac{1}{1} \frac{2}{8}=30$. Habitat unknown. Another more questionable genus of the same authors, is that called CeLeno, which, according to Mr. Gray, is a Noctilio, without the bones of the tail present in the skin.

The genus Pteronotus of Mr. Gray, proposed from a specimen in the Museum of Fort Pitt, at Chatham, is not figured that we know of; and the

Genus Mropteris of Geoffroy contains the Rat Volant of Daubenton. - The nose is simple; the ears broad, separate, lateral, with internal operculum; tail long, one half engaged in the membrane; muzzle short and thick; colour brown, beneath lighter. Dent. form. incis. $\frac{2}{2}$, can. $\frac{1}{1}-\frac{1}{1}, \mathrm{~mol} \cdot \frac{8}{10}=$ $\frac{1}{1} \frac{2}{4}=26$.

Tribe II. Diphalangia istiophora. - Two-jointed Leaf-nosed Bats.-Having the index with two ossified phalanges, the middle finger with three, and nose with one or two leafy appendages.

In the groups of this tribe, the cutaneous system is in the extreme of developement, both with respect to the extent of membrane between the digits, and in the horse shoe forms and tubes about the nostrils, leaf-like appendages on the nose, the expansion of the ears, and the extent of the interfemoral mem- 
brane. Large as the external ear is found to be in some of the preceding genera, it is still increased, often double, with an internal concha, which surrounds the auditory foramen; and all these membranes appear endowed with so exquisite a feeling, as to afford the animals a kind of sixth sense, which has the effect of seeing and touching both combined. This exquisite sensibility of their organs, moreover, they have the power in a great measure to control, the nasal tubes and auricular conchs being capable of closing at the will of the animals. The foremost of these is, the

Genus Vampyrus, Leach. - Vampyre Bats, which have the head long and narrow; the muzzle lengthened; the ears middle sized, separate; the auricular operculum notched, placed interiorly; the tongue extensile, with the point formed for suction; the papillre directed backwards; the nose with two appendages, one horizontal, in the form of a horse shoe, the other erect, like the blade of a javelin. Dent form. incis. $\frac{4}{4}$, can. $\frac{1}{1}-\frac{1}{1}, \mathrm{~mol}$. $\frac{1}{1} \frac{0}{2}=\frac{1}{1} \frac{6}{8}=34$. The Vampyre genus was detached from Phyllostoma of Geoffroy and Cuvier, on account of the cranium being longer and narrower, and the presence of two more premolars in the lower jaw. It is likewise preeminently distinguished as a blood sucker, though by no means the only one. This habit was long doubted, and although the effect of their bite on man is not of that fearful kind which the planters of Guiana used to assert, yet it is still sufficiently serious to excite alarm, and, in some cases, is dan- 
gerous. They seldom appear to attack large animals; and never man, unless while he is sleeping, and then they invariably inflict a small wound in the great toe, without causing him to awake, and suck the blood in such a way, that when the Bat withdraws, the wound remains open, and may still bleed freely. The celebrated Azara was bitten no less than four times, though probably not by this, but by one of the next genus. Mr. Waterton witnessed its attack upon a planter, who was his companion.

COMMON VAMPYRE BAT.

PLATE II. Fig. 2.

Vampyrus spectrum, LEACH.

Is the Andira guaçu of Brazil ; the size of a magpie; reddish-brown above, more yellowish beneath. Mr. Waterton killed one that measured thirty-two inches across the wings. This species is the great blood-sucker, and a still greater destroyer of fruit, although the principal part of its food consists of insects. It inhabits the deep woods, and also ruined plantations in Brazil and Guiana, and, perhaps, the north coast of South America, but we have not found or heard of it north of the isthmus of Darien.

There are two or three other and smaller species, according to Spix, in Brazil. 

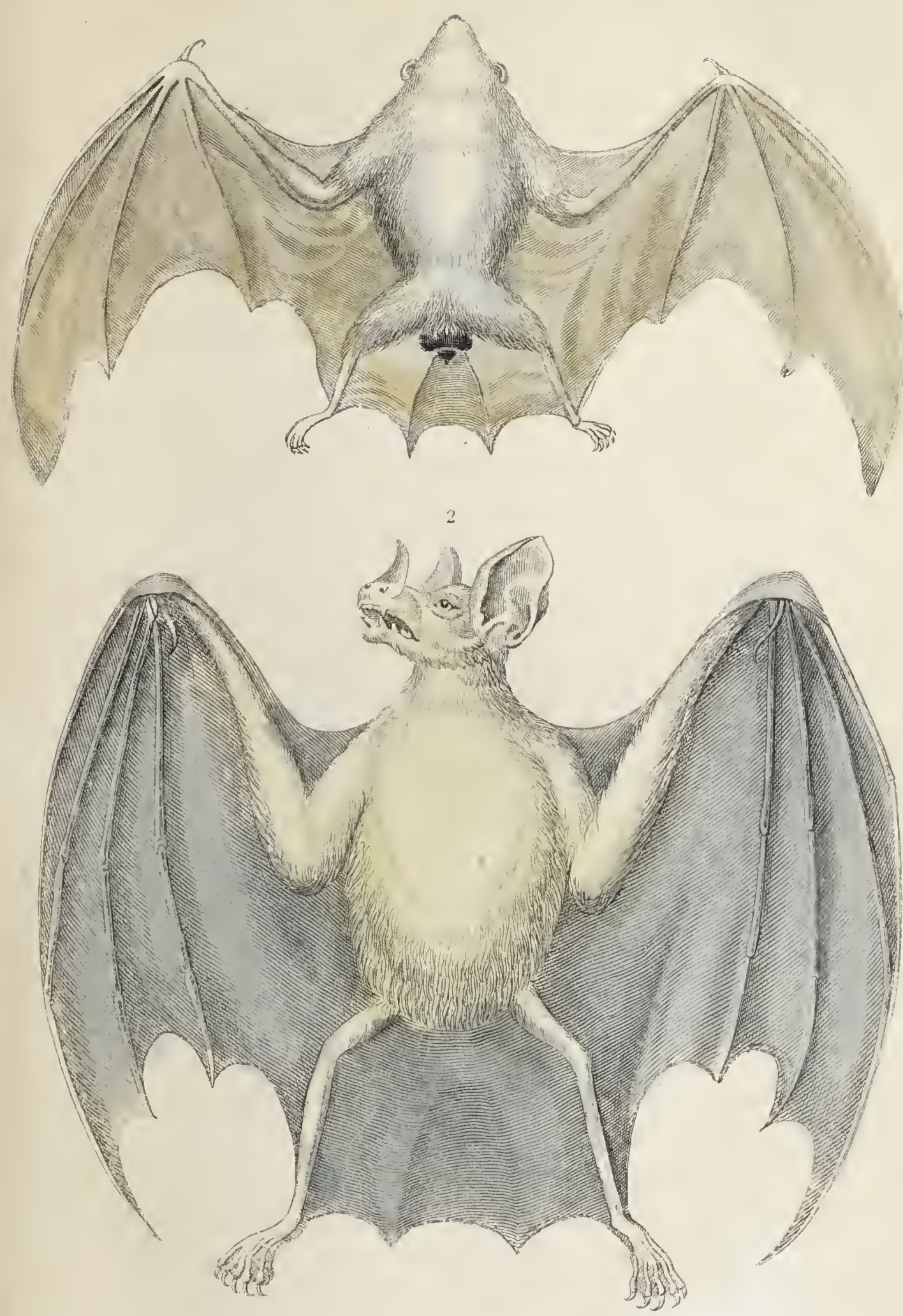

CIEIROPTERA

1 WUITHLRUS ALPUS. 2. WAMHYUS SPECTKUM

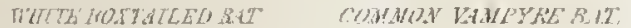

$$
\text { Then Brazid. }
$$



Genus Phyllostoma, Geoff.-Javelin Bats, with the head and muzzle short, thick, and broad. Dent. form. incis. $\frac{4}{4}$, can. $\frac{1}{1}-\frac{1}{1}$, mol. $\frac{1}{1} \frac{0}{0}=\frac{1}{1} \frac{6}{6}=32$. The normal number of their incisors is four in each jaw, but some of these in the lower are often dislodged by the growth of the canines: the leaf-like membrane is turned up across the nose; the operculum of the ear appears like a small dentated leaf; the tongue very extensile, terminally papillated, and used in the same manner as the Vampyres. They belong exclusively to America, and have the faculty of running on the ground with more facility than other bats. Their wings are large, and the interfemoral membrane unites the two thighs; some are without tails; where these occur they are short, and pierce the membrane either above or below. These distinctions form the groups;-

A, Tailless Javelin Bats; and B, Tailed Javelin Bats.

$P$. perspecillatum, Geoff. - Spectailed Javelin Bat.-About five inches long; dark brown, lighter beneath, and a white band from the nose to the ear. It is the Grand fer de lance of Buffon, and common to northern South America, and the great West India Islands, where it is said to destroy great quantities of fruit; but neither this, nor P. Jamaicense, are considered in Jamaica either as bleeders or robbers, so far as personal observation or report could inform us.

There are enumerated ten other species, and several that are doubtful; and Dr. Leach indicated, in 
the Linn. Trans. xiii. p. 75, a species which he considered to require a distinct generic, appellation, because there were no incisors in the lower jaw; had an erect nose-leaf, and a short tail: it is descibed by the name of Monophyllus Redmanni.

Genus Glossopmaga. - Long-tongued Bats, with broad head and produced narrow muzzle; small ears, with an operculum; double nasal rnembrane, one hastate, the other blended in the upper lip; tongue very long, extensile, channelled, and with reversed papillæ; small, or no interfemoral membrane or tail. Dent. form. incis. $\frac{4}{4}$, can. $\frac{1}{1}-\frac{1}{1}$, mol. $\frac{1}{1} \frac{2}{2}=\frac{1}{1} \frac{8}{8}=36$. These bats, chiefly characterized by their extensile tongue, form the third genus of blood suckers; the four known, and the three doubtful species, including the Diphylla of Spix, Brachyphylla of Gray, and Madatceus Levisii of Leach., Linn. Trans. ut supra, are all natives of America.

Tribe III. Monophalangia istiophora, have the index with only one ossified phalanx, the other fingers with two; the nose with one or more leaf-like membranes.

Genus Megaderma, Geoff.-Broad-winged Bats. -Dent. form. incis. $\frac{0}{4}$, can. $\frac{1}{1}-\frac{1}{1}$, mol. $\frac{8}{10}=\frac{1}{1} \frac{0}{6}=26$. Nose with three appendages, the upper vertical, the second horizontal, and the lowest resembling a horse shoe; ears very large, united over the forehead; the opercula prominent; tongue short, slender ; no tail Habitat, the East Indies and Africa.

They form the connecting link between the Phyl- 
lostoma and Rhinolophi, have no intermaxillary bones, there being, instead, a mere membrane, and, consequently, have no upper incisors.

Megaderma spasma, Cuv. - Cordated Bat, or Meg. trifolium, - is a species from Ternate and Java, with an oval or cordate nasal appendage resembling the horizontal, and the opercula bi or trilobate; it is mouse colour or russet, and about four inches long.

$M$. lyra and $M$. frons are two other species, described from India and from the Gambia.

Genus Rhinolophus.-Horse Shoe Bats.-Dent. form. incis. $\frac{2}{4}$, can $\frac{1}{1}-\frac{1}{1}, \mathrm{~mol} \cdot \frac{1}{1} \frac{0}{0}=\frac{14}{1} \frac{4}{6}=30$. Sometimes there are no upper incisors, but there is occasionally a third premolar in the lower jaw, and in other cases only one on each side in the upper; the ears are large without opercula; nose complicated with membranes; two inguinal glands ; interfemoral membrane entire, including the tail.

These are the common Horse Shoe Bats; they have no fibula, or small leg bone; their great toe is not opposable like the hinder thumb of other species.

They are divided into Rhinolophi $\mathbf{A}$, with a simple nose-leaf, transversal, and more or less circular (Hipposideros of Gray), which comprehends species belonging to Southern Asia, such as $R$. nobilis, or Klebeck of Java ; R. diadema, or Diadem Horse Shoe Bat of Timor; the R. insignis, $R$. speoris, \&c.

$\mathrm{S}$, section $\mathrm{B}$, with nose-leaf more or less complicated, the posterior leaflet being.spear-shaped, and 
a foot stalk rising from the centre of the horse shoe (Phyllorhine of Bonap.), contains species found in Europe and Africa, spreading over temperate Asia, and extends to the great islands of Australasia. Among them, the best known is,

Rhinolophus unihastatus, Geoff.; Vesp. Ferrum Equinum of Linn. ; and Horse Shoe Bat of Penn.Is mouse-grey in the male, and russet in the female, with a lanceolate complicated nasal appendage; ears notched on the outer margin: resides in Europe (Great Britain) and Northern Africa, where it hangs by the feet in quarries, with the body entirely wrapped within its wings. This bat hibernates for a few days; but can resist winter temperatures, which would be fatal to others. Found as far north as the forests of Thuringia.

R. bihastatus, Geoff.-Little Horse Shoe Bat.Was confounded with the former by Linnæus; is white, with the tips of the hair reddish; the nasal appendage lanceolate, erect, reddish; a second lance shaped membrane in the centre. It is rare in Germany and France, where the most inaccessible nooks of caverns are its haunts; is about three inches in length, and ten inches over the wings. There are enumerated seventeen other species, all foreign, and several more are doubtful.

Genus Nyctophilus, Leach._-South Sea Bats.Dent. form. incis. $\frac{2}{4}$, can. $\frac{1}{1}-\frac{1}{1}$, mol. $\frac{8}{8}=\frac{1}{1} \frac{2}{4}=26$. The ears large, united over the forehead; the tragus lanceolate; tail not terminated by forked cartilage; membranes less developed than in Nycteris; the 
upper incisors, by their length and position, appear like a second pair of canines.

There is as yet only one species known, namely, Nyctophilus Geoffroyi, with hair black at the root, and pale ash at tip; it is three inches long, and nine across the wings.

Genus Nycteris, Cuv. - Cheek-pouch Bats. Dent. form. incis. $\frac{1}{6}$, can. $\frac{1}{1}-\frac{1}{1}$, mol. $\frac{8}{10}=\frac{14}{1} \frac{4}{8}=32$. Upper incisors very small, continuous, and bilobed; the lower trilobed or bilobed; nostrils simple, the cartilage forming a moveable operculum; the chaffron with a deep longitudinal furrow; interfemoral membrane longer and wider than the body; tail bifurcated at tip. This genus, according to Geoffroy, has the power of inflating the tissues of the skin, by means of two passages communicating with the mouth, thereby rendering itself, like birds, specifically lighter. The different species are found in the warm regions of the Old World, where they frequent dark and nauseous caverns.

Nycteris hispida was known to Buffon, and is the Campagnol volant of Daubenton. There are enumerated five other species.

Genus Desmodus, P. Max. of Wied. - Curved Tooth Bats.-Dent. form. incis. $\frac{2}{4}$, can. $\frac{1}{1}-\frac{1}{1}$, mol. $\frac{4}{6}$ $=\frac{8}{1}=20$. Head small; muzzle obtuse; ears with opercula; nose with complicated membranes; thumbs very long and strong; interfemoral membrane narrow; tail none. This genus is still one of the blood-suckers, for it was an individual of the Desmodus d'Orbignyi that Mr. Darwin's servant 
caught on the withers of a horse, in the act of bleeding it. This species does not exceed three inches three lines, and the extreme breadth twelve inches eight lines. Mr. Waterhouse observed it to be without true molars, and, therefore, unable to masticate its food: the canines and incisors were perfectly fitted for inflicting a wound, and the small interfemoral membrane allowing more freedom to the legs, together with the large thumb and claw, enable the bat to fasten with security on its victims. There are two other species known, all inhabitants of South America.

Genus Rminopoma, Cuv. - Lid-nose Bats. Dent form. incis. $\frac{2}{4}$, can. $\frac{1}{1}-\frac{1}{1}, \mathrm{~mol} \cdot \frac{8}{10}=\frac{1}{1} \frac{2}{6}=28$. Nose long, conical, truncated ; nose-leaf small ; nos. trils narrow, transversal, covered with a lid; chaffron broad, concave ; ears large, united, connected with face; tragus external ; interfemoral membrane narrow, truncated; tail long.

R. microphyllum, inhabiting Egypt, is the only well known species.

Mr. Gray mentions one, R. Hardroickii, from Bengal.

Genus Taphozous, Geoff.-Wing-pouched Bats, or Taphians. Dent. form. incis. $\frac{0}{4}$, can. $\frac{1}{1}-\frac{1}{1}, \mathrm{~mol}$. $\frac{1}{1} \frac{0}{0}=\frac{12}{16}=28$. The chaffron furrowed, without over-lapping edges; nose-leaf none; upper lip thick ; muzzle produced; ears moderate ; operculum internal; interfemoral membrane large, salient; tail having six vertebræ; a slight prolongation of the alar membrane forms a kind of pouch near the carpus. 
Mr. Geoffroy detected one, Taphazous perforatus, in the catacombs of Egypt, and they are found in the warmer regions of the Old Continent; but one also occurs in North America, making, in all, seven species.

Genus Mormoops, Leach. - Mormoop Bats. The dental formula differs materially as given by Dr. Leach and F. Cuvier, the first being, incis. $\frac{4}{4}$, can. $\frac{0}{0}-\frac{0}{0}, \mathrm{~mol} \cdot \frac{1}{1} \frac{0}{2}=\frac{1}{1} \frac{4}{6}=30$, and the second, incis. $\frac{4}{4}$, can. $\frac{1}{1}-\frac{1}{1}, \mathrm{~mol} \cdot \frac{1}{1} \frac{2}{2}=\frac{1}{1} \frac{8}{8}=36$. The cranium is elevated pyramidally; on each side the nose a triangular membrane; the ears large and coalescing; tragus conspicuous; nose-leaf erect, conjoined to the ears ; tail extending to two-thirds of the interfemoral membrane. One species only known, inhabits Jamaica and Cuba, is denominated M. Blainvillii.

Tribe IV. Monophalangia anistiophora. Vespertilionina of Gray, have the index with only one ossified phalanx, the other fingers with two; nose without leafy appendage.

Genus Emballonura, Kühl.-Long-nosed Bats. -Dent. form. incis. $\frac{4}{6}$, can. $\frac{1}{1}-\frac{1}{1}$, mol. $\frac{1}{1} \frac{0}{0}=\frac{1}{1} \frac{6}{8}=$ 34. With long conical head; flat forehead; long muzzle; upper jaw longest ; tail partially involved in the membrane. Inhabits Brazil and the Indian Archipelago in general; noticed by P. Max. of Wied; five species enumerated.

Genus Urocryptos Temm. - Concealed Tail Bats. - A genus established, but not yet described by M. Temminck, who states merely that Emballo- 
nura and Urocryptus form two small groups between Taphozous and the true bats.

Genus Nycticejus, Rafin.--Roquet-dog Bats.Dent. form. incis. $\frac{2}{6}$, can. $\frac{1}{1}-\frac{1}{1}$, mol. $\frac{8}{10}=\frac{1}{1} \frac{2}{8}=30$. But there are sometimes two incisors and two premolars more above, making the dentition vary to thirty-two and even to thirty-four; the ears are small; muzzle simple; chaffron very broad; forehead narrow; occiput elevated; interfemoral membrane pierced by the tail, which is usually long. Is found on all the continents, Europe excepted. They form two groups, one belonging to the Old World, the other to the New; the first with close smooth fur, some species partially naked, more especially on the abdomen, croup, and thighs. Form A, section 1, contains seven species from Africa, India, the Islands, and Bourbon.

$B$, section 2, forming the American group, have the fur usually longer, and the interfemoral membrane clad more or less with hair: among these is the New York Bat of Penn., Nyct. Noreboracensis, and three others, besides some species of the interior of the United States described by Rafinesque, and his genus Atalapua depends solely upon an old Nycticejus without its incisors.

Genus Vespertilio, Linn.-Bats Proper.-Dent. form. incis. $\frac{4}{6}$, can. $\frac{1}{1}-\frac{1}{1}$, mol. $\frac{8}{10}=\frac{1}{1} \frac{4}{8}=32$. But, according to the number of premolars, 34,36 , and even 38 ; the tail is invariably included within the membrane; nose without leaf, ridges, or tubes; the 
index with one, middle finger with three phalanges, two last each with two. They prey solely on insects, and inhabit every region except Australia. At all periods of their lives, they have four incisors above and six below: all the species have about the head odoriferous glands in both sexes.

The European Bats associate together about the period of hybernation, which often continues through the winter, where they link themselves together in great masses of individuals, in the retreats in which they are protected from cold.

According to M. Temminck, some species bear one, others two young, periodically or accidentally; all produce sometimes the former number, at others the latter. This is particularly the case with the common Vespertilio noctula: when rearing their offspring, the females fix their arm hook, and bend the tail under the abdomen, thus converting the interfemoral membrane into a sack, forming a nest for the young, in which it is conveyed while the mother is on the wing.

Bats Proper, and Rhinolophi, perhaps all the long-tailed insectivorous Cheiroptera, use that member as a finger, to introduce their prey into the mouth, or rather throat, when it is of larger dimensions than usual; they approximate it to the head, bend the neck, and thus master their insect victim; hence the tail must have considerable influence on. the habits of the different groups, and in true bats it is always formed upon one model.

The number of species in this genus, expunging 
Plecotus, is very great, and, contrary to a law of zoological geography, spreads over the whole earth, with the exception (hitherto) of New Holland. There are now seventy-eight species fully ascertained: twenty-eight belonging to Europe, nine to Africa, with two common to both, twenty-four to Asia and India, two of which likewise occur in Europe, and seventeen are known in America: there are many more not satisfactorily described, the whole amounting to at least one hundred and eight species.

In England, alone, we have thirteen species:$V$. noctilio, or Noctule Bat;. V. Leislerii; $V$. discolor; $V$. serotinus; $V$. auritus, or Long-eared Bat; $V$. Nattereri; $V$. Daubentonii; $V$. nystacinus; $V$. emarginatus; $V$. pipistrellus, or Common Bat; V.barbastellus; V. Bechsteinii; and V.murinus, or Mouse-eared Bat. The common species is well known, and the others afford, in general, not sufficient interest to demand even a nominal notice in a work of such small dimensions as our present volume; we will, therefore, close our abstract account of this order, by naming the twenty-fifth and last of our catalogue, namely, the

Genus Furia, F. Cuv., or Fury Bats.-Dent. form. incis. $\frac{4}{6}$, can. $\frac{x}{1}-\frac{1}{1}$, mal. $\frac{1}{1} \frac{0}{2}=\frac{1}{2} \frac{6}{0}=36$. Cranium rising almost vertically from the face; upper jaw much depressed; flat nosed with hairy bristles; nail, only of the thumb, projecting from the membrane. Only one species of South America is known. F. horreus. - Rugged Bat. - Entirely black; 
large ears and large eyes; length $1 \frac{1}{2}$ inch; expanse 6 inches. This genus forms the last of the orders with pectoral nammæa and other anatomical characters, which caused them to be classed collectively by Linnæus in his order Primates.

Fossil Cheiroptera of species, said not to be distinguishable from the recent, have been found in the (Eocene) Paris Basin; such as Vesp. murinus, pipistrellus, ferugineus, plecotus, \&c., found also in the intermediate periods of that era and the present, and equally undeterminable. Bones and teeth of Bats in the cavern deposits of Kirkdale (Newer Pliocene), Banwell, Torquay, \&c., in Germany and America; lastly they are found in gravels, \&c. Siee Bartlets Chart. 
WE now proceed to those families which are considered to be still more truly insectivorous, although even among them, many have occasional habits of a frugivorous regimen. They have, like the Cheiroptera, the molar teeth entirely covered with conical points, but their teats are invariably ventrai; the mode of life is mostly nocturnal, or under the earth, pursuing worms, insects, and larvæ; and. in higher latitudes, commonly hibernating in a lethargic state. Although they have no lateral membranes, they are never destitute of clavicles; the feet are short, mostly plantigrade, with but little rapidity in their movements. They vary in the position and relative proportion of the incisors and canines, some having long incisors forward, followed by others, and by canines, all lower than the molars; a kind of dentition which we have already noticed among the Quadrumana in the genus Tarsius, and which slightly approximates the Rodentia: others have large canines separated by small incisors, in which arrangement they resemble the ordinary Quadrumana and Carnassiers, but these two kinds of dental disposition occur in genera otherwise very 
much alike in integuments, the forms of their limbs, and habits of life.

They may be divided into two tribes; one with the anterior extremities strong, formed for digging the earth, and the other with the same extremities more delicate, and made simply for walking or swimming, and with several incisors, smaller than the canines, like the Quadrumana.

I. Talpida, or Moles, are known for their subterrene life and structure, so eminently appropriate for that state of existence. They have very short arms, attached to long shoulder blades, sustained by strong clavicles, furnished with most powerful muscles, and terminated by broad hands, with the palms turned outwards and towards the rear; these hands have a sharp edged lower border, very short fingers, tipt with powerful, long, flat, and cutting claws; these are the instruments used by the animal to tear the earth, and work it behind him. The sternum is strengthened as with birds and bats, having a keel which enables the pectoral muscles to have the increased developement necessary for their functions. In order to penetrate into the earth, the Talpidoe use their long pointed head, with a snout possessing a particular bone, having vigorous cervical muscles; there occurs even a peculiar bone in the cervical ligament. The hinder extremities are feeble, and, on the surface of the earth they move comparatively with more trouble than beneath it. Moles have a delicate sense of hearing, the tympanum being very large, although 
there is no external ear; but the eyes are very small, or even wanting.

Genus Talpa, Linn. - Moles Proper. - Dent. form. incis. $\frac{6}{8}$, can. $\frac{1}{1}-\frac{1}{1}, \mathrm{~mol} \cdot \frac{1}{1} \frac{4}{2},=\frac{2}{2} \frac{2}{2}=44$. The canines have two roots like premolars, and these are four above and three below on each side, beside the three true molars on each side in both jaws. The females have six mammæ. The jaws are not robust, and subsistence depends on insects and a few tender roots, which is the cause of the devastations it is accused of in our fields and gardens.

T. Europoca. - The Common Mole, - well known with his pointed snout, scarcely perceptible eyes, cylindrical form, velvety-black fur, and short hairy tail; it measures nearly six inches in length, exclusive of the tail; has a small shrill voice; is domestic and peaceful with its family in the burrow, but fierce when meeting others above ground. In captivity, moles will tear and eat one another; and, according to Sir Thomas Brown, a mole kept in a large glass case, with a viper and a toad, killed and partly devoured both. They swim remarkably well, although often drowned during inundation. The females bring forth four or five young, which are carefully nestled in the burrow, and well supplied with dried roots; and it is asserted, that they feed on those of Colchicum, or meadow saffron, a plant which even in very small quantities, produces on man the most violent and even dangerous effects.

It is probable, that the mole in higher latitudes hibernates, although it is not known to become 
torpid in winter in this country or France. In Siberia, the species, if the same, grows to larger dimensions. None are said to exist in Ireland, or in Guernsey. There are occasionally white, and sometimes pied moles among the European species. According to Professor Harlan, it is found likewise in the United States of America; but the

Talpa purpurescens, or Purple Mole, originally described by Seba, may be distinct, being marked by a white tail, and a purple gloss on the black fur. It is found in Virginia.

Talpa coeca. - Italian Mole. - Noticed by Professor Savi, and found by him in the Appennines, though exactly similar to the common mole, is nevertheless totally destitute of eyes.

Genus Scalops, Cuv. - Shrew Moles. - Dent. form. incis. $\frac{2}{4}$, cones or p. mol. $\frac{3}{3}-\frac{3}{3}$, mol. $\frac{8}{6}=\frac{1}{1} \frac{4}{6}=$ 30. Intermediate incisors very strong; muzzle very long, with cartilaginous snout; eyes very small; no external ears; hands broad, pentadactylous like those of the mole; tail short.

Scalops Canadensis, the only species known, is very like the common mole in external appearance, but in habit more a water shrew. The species is found from Canada to Virginia, and westwards to California.

Genus Chrysochloris, Lacep. Chrysochlore, or Shining Moles. - Dent. form. incis. $\frac{2}{4}$, cones $\frac{3}{5}-\frac{3}{5}$, mol. $\frac{1}{1} \frac{2}{0}=\frac{2}{2} \frac{0}{0}=40$. Muzzle rather short, truncated, cartilaginous; eyes very small; no external ear; anterior feet three-toed, armed with strong fur- 
rowed claws; hind feet five-toed. Manners like those of the mole.

Chrysoc Capensis._Cape Chrysochlore.-Smaller than the European mole, and easily distinguished by the golden green irridescence of its fur, which, at the Cape of Good Hope, was formerly used in the manner of velvet to cover seats with; beneath, the colour is brownish-grey.

C. rufa and Hottentota, Smith.-Rufous Chrysochlore.-Has only four toes on the hind feet, but exceeds the European mole in size; the colour is rufous grey; tail short. In this species the external claw of the fore toes is longest; it has small rounded external ears, and is likewise a native of the Cape.

Genus Condylura, Illig. - Radiated Moles.Dent. form. incis. $\frac{6}{4}$, cones or premolars $\frac{6}{10}$, mol. $\frac{8}{6}$ $=\frac{2}{2} \frac{0}{3}=40$. - In the shape of their paws, and the whole exterior, they resemble moles; but the tail is longer, and a marked distinction occurs in the snout, the nostrils being surrounded by twenty-two small cartilaginous and moveable points, forming a kind of double star when expanded circularly. A remarkable species is,

Condyl. cristata. - Radiated Mole of North America. - Is little more than four inches long, with eleven points round each nostril, forming the double star. The fur is black, the feet white, and the snout rose colour. A second species is, the

C. longicaudala.-Long-tailed Radiated Mole.Somewhat larger than the former, with pentadac- 
tylous feet, the hinder pair squamous; the colour rusty-brown; and the radiated apparatus on the snout is small. This animal likewise resides in North America, and seems to extend to a higher latitude than the former. A third species is the Thick-tailed Radiated Mole, C. macroura of Professor Harlan.

Tribe II. Insectivora, with two long canines in front, followed by other lateral incisors or false canines, not longer than molars; feet formed for walking or swimming.

Genus Mrgale, Cur., Desman.-Dent. form. incis. $\frac{6}{8}$, can. $\frac{1}{1}-\frac{1}{1}, \mathrm{~mol} \cdot \frac{7}{6}-\frac{7}{6}=\frac{2}{2}=44$; but according to Pallas, the Russian species incis. $\frac{2}{4}$, cones $\frac{6}{6}-\frac{6}{6}, \mathrm{~mol}$. $\frac{4}{3}-\frac{4}{5}=44$. - They have the nostrils placed within two prolonged tubes, forming a kind of proboscis, exceedingly sensitive and moveable; small eyes; no external ears; feet five-toed, those of the hinder extremities, in particular, webbed; claws long and curved; tail naked, compressed. These animals reside about watery places, dig subterranean galleries, opening out beneath the surface of the water, but rising further on, so as never to fill entirely. They swim with the greatest ease, remain long below, or raise only the extremity of their tubed nostrils to the surface. They smell of musk, and feed on aquatic insects, leeches, \&c.

M. moscovitica.-Moscovite Desman.-With all the feet webbed is the Sorex moschatus of Linn., and was known even to Clusius; is the size of a rat, or larger; burrows in galleries of great length; 
the eyes are extremely small; it swims with great facility, but is slow on land. The colour is brown, white beneath. According to Pallas, the Desman does not occur in Russia proper, but is abundant to the south in the Volga, at about Woronetch. There is a species in Europe, the

M. pyrenaica.-Pyrenean Desman:-With the tail longer, hairy, cylindrical, excepting towards the tip, where it is compressed; fur brown above, grey beneath; claws much more powerful. Of this species, found near Tarbes in France, the manners are wholly unknown.

Genus Sorex, Linn.-The Shrews.-The shrews are, in general, small, some even are among the smallest of mammalia; on each flank, beneath the fur, they have a narrow band of bristly hairs, stiff and close, from among which, in the pairing season, exudes from a particular gland an odorous humour. They live in holes dug by themselves, seldom appearing abroad except towards night, feeding on worms and insects. Dent. form. incis. interm. $\frac{2}{2}$, false canines or lateral incis. $\frac{3}{2}-\frac{3}{2}$ or $\frac{4}{2}-\frac{4}{2}$, true molars. $\frac{4}{3}-\frac{4}{3}$ $=28$ or 30 . - The ears are short and rounded; eyes very small; toes weak; mammæ six; tail sometimes tetragonal, at others compressed towards the end.*

* Mr. Gray arranges the Sorices in the following order:-

A, LAND SHREWS.-Tail simple; feet not ciliated on the sides.

1. Corsira.-Front lower cutting teeth sharp edged, toothed above; tail with short close pressed hairs. 
jorex tetragonurus, Herm.-Common Shrew.Is about two inches in length, and with the tail $3^{\prime \prime} 8^{\prime \prime \prime}$; fur grey, and paler below; tail squared, shorter than the body. Resides in Europe. In Great Britain they occupy holes in the summer, and nestle under hay stacks in winter, feeding on insects. They are not detrimental to cattle. We have, also,

S. remifer.-The Oared Shrew.-The largest of those found in Europe being four inches, and the tail $2^{\prime \prime} 9^{\prime \prime \prime}$ in length; dark brown, paler beneath.

S. fodiens. - The Water Shrew. - Somewhat larger than the square-tailed; black above; white beneath. In England they frequent ditches and ponls, sometimes in numbers, swim about with great activity, penetrate between aquatic plants, and utter a shrill squeak; they dive, swim with great ease below the surface, and assume a silvery appearance from the bubbles of air which hang upon their fur. On shore they form extensive and intri-

2. Myro-sorex. - Front lower cutting teeth sharp edged, entire above; tail with short close pressed hairs.

3. Sorex proper.-Front lower cutting teeth rounded, and simple above; tail with short hairs, and longer scattered bristles.

B, W A TER Shrews. - Tail with a series of bristles beneatlı; feet and toes ciliated on the sides.

4. Amphisorex. - Front lower cutting teeth simple; four hinder cutting teeth gradually smaller; hinder very small.

5. Crossopus.-Front lower cutting teeth sharp edged, and toothed above; hinder cutting teeth rapidly smaller.-See Proceedings Zool. Soc., 1836, p. 123. 
cate galleries, generally beneath some overhanging bank, from whence an aditum is contrived, free from obstacles and leading direct to the water.

The Sorex araneus, or Continental Shrew.-Does not seem to inhabit Great Britain; and, among the very small species, may be enumerated $S$. etruscus of Savi ; S.parvus, or small shrew of Richardson; $S$. minimus of Pallas; $S$. exilis of Pennant, found in Siberia, and probably the smallest of all ; and one species, the giant among shrews, is the East Indian, S. giganteus of Isid. Geoffroy, above six inches long, exclusive of tail, which is nearly four inches. Mr. Pennant mentions a tailless shrew, S. minutus, which seems to belong to the new genus MacroceLIDES, or long-snouted shrews, of which there are two species, * both from Barbary, and lead to the Tenrecs. Here may be placed the new

Genus Solenodon of Brandt.-Formed upon the Sol. paradoxus, brought from Hayti, but not as yet distinctly characterized.

In the next, we find the fur gradually passing from a bristly to a spinous character, forming a small group of animals, which have a kind of counterpart in a similar group of rodents.

Genus Centenes, Illig.-The Tenrecs.-Dent.

* There existed besides, in antiquity, a species of Sorex, no doubt held sacred by the Egyptians, since Mr. Olivier discovered their remains preserved, or mummified, like those of the Ibis, in the catacombs of Sakkara; but the species is not at present known to science; the head alone being above an inch in length, and the fur rufous. 
form. incis. $\frac{6}{6}$ or $\frac{6}{4}$, can. $\frac{1}{1}-\frac{1}{1}$, mol. $\frac{6}{6}-\frac{6}{6}=34$ or 38 . They have the body more or less covered with spines, but are unable, like hedgehogs, to roll themselves into a ball; the snout is very pointed; five toes to all the feet; no tail. They are nocturnal; and, although natives of the Tropics, they pass three months of the year in a lethargic state. Seve ral species belong to Madagascar: such are,

Centenes setosus, or Bristly Tenrec.*-Of a brown colour; has six incisors hollowed out in each jaw, and is larger than a hedgehog.

C. armatus. - The Armed Tenrec. - Has the head shorter, thicker; ears larger; is of a light colour, and wholly covered with short spines.

C. semispinosus, or Half-spined Tenrec. - Size of a mole; striped yellow and black; very long snout, having spines mixed with the hair. Incisors and molars are all crooked, slender, and pointed.

Mr. Macgillivray, we believe, has separated from them, and formed a minor group of the Tendracs, under the name of Ericulus; $\uparrow$ but we know not by what diagnosis, unless the lower incisors, amounting to only four, constitute the character. It includes Ericulus nigrescens, or swarthy tendrac, in form very like a hedgehog, and a more doubtful small species, $E$. spinosus, with a long white head,

* Mr. Gray remarks, that Cuvier has, by mistake, misplaced his characters of the Tenrec and Tendrac, which last is $C$. setosus.

+ Telfairs echinops from Madagascar, described by Martin. —See Proceedings Zool. Soc. for 1838. 
and dark back, closely beset with slender spines. These bring us to the

Genus Erinaceds, or the Hedgehogs. - Dent. form. incis. $\frac{6}{6}$, can. $\frac{1}{1}-\frac{1}{1}$, mol. $\frac{5}{4}-\frac{5}{4}=34$ Desm. Body corered with spines; the skin of the back provided with muscles, which enable the animal to roll itself into the form of a ball, offering the points of the spines in every direction; the tail is very short; the middle incisors very long. They are nocturnal, live on larvæ, snails, and grubs, but also eggs and fruit; they can devour quantities of cantharides, without causing the least uneasiness, while a single one is sufficient to injure if not to kill a dog or cat. They are torpid in winter. Hedgehogs belong to the Old Continent. Beside the

Erinaceus Europoeus, or Common Hedgehog,generally known, there is a second, but rarely found in Europe, and distinguished from the other by a vivid, rufous, coarse fur; the spines on the back not extending so low on each side, and the muzzle shorter : it might be denominated $E$. caniceps. We have met with this animal on the edge of the forest of Soignies, near Brussels.

There are enumerated besides, $\boldsymbol{E}$. auritus, or Long-eared Hedgehog; E. frontalis, White Fronted; E. spatangus, Himalayan; E. concolor, Trebisond; E. Grayii, \&c. - See History of British Quadrupeds, Vol. III. Naturalist's Library, where the British species is described.

Genus Grmnura._-Oriental Hedgehogs.-Have a long unarmed tail, and plantigrade feet; the snout 
very long; ears round. Dent. form. incis. $\frac{2}{6}$, can. $\frac{0}{0}-\frac{0}{0}$, p. mol. $\frac{2}{1}-\frac{2}{1}, \mathrm{~mol} \cdot \frac{8}{8}-\frac{8}{2}=44$.

G. Rafflesii. - Raffles Gymnura. - Black, with head and neck whitish, a black streak passing on each side from the nose through the eyes; terminal part of the tail white.

Genus Cradobates. - The Tupaias.- Have teeth similar to the hedgehogs, though the intermedial incisors are shorter in proportion; they have four long ones in the lower jaw, and have no back tubercular tooth. They are climbing and active little animals, which might be mistaken for squirrels; but that their long sharp shrew-like snout distinguishes them even at a distance. The species, hitherto observed, were first made known by Sir Stamford Raffles and Dr. Horsfield, and belong to the great Australian Islands; such are the Tupaia of Java, or Banxring, T. Tana, and T. ferrugnea.

With regard to the fossil remains of the insectivorous order, there have been found, in caverns of the recent tertiary, and in peat bogs of a post tertiary era, bones of species of Talpa, and of Erinaceus. 
WE now come to the fifth order, including sereral families; but all exclusively, or partially, feeding on Hiesh. They are unguiculate, and have three kinds of teeth. The two last orders were, by their want of bulk and power, and by the conical tuberculous form of the teeth, nearly all, in their appetite for animal substances, reduced to grubs and insects; but in those we are about to consider, there is imparted more or less of strength to satisfy the lust for slaughter. In this order, we always find four great laniary or canine teeth, having between them, in each jaw, six incisors; the molars are either entirely formed for cutting, or are mixed with parts that have low tubercles, but no conical points.

Their carnivorous propensity is greater in proportion as the teeth are more exclusively trenchant; and, by comparing their tubercular surface to that which is shaped for cutting, what the degree of their appetite for blood in the choice of food is, may be indicated almost with unerring precision. The anterior molars are always the most trenchant, upon them follows a molar more voluminous than the 
others, commonly furnished with a tuberculous heel, more or less extensive, and behind this tooth there are one or two smaller, entirely flat. It is with these last that dogs masticate herbs, which they sometimes swallow. The great molar here mentioned, both in the upper and lower jaws, is called the carnassial ; those before it with points, premolars, or false molars, and those behind it tubercular teeth.

Those genera which are least provided with false or premolar teeth, and whose jaws are the shortest, have naturally the greatest power in biting; this offers the most certain indication for establishing the genera; but it is further necessary to take notice of the hind foot. Several, like in the last described orders, rest the sole of the whole hind foot upon the ground while walking, or when sitting up, which habit is readily ascertained by the absence of fur on the surface so applied: other, and more numerous genera, walk entirely on toes, keeping the tarsus elevated; they move with greater rapidity, and this first marked distinction is accompanied by many others, in the habits and in the internal conformation of the animals. Both, however, have only rudimental clavicles suspended in the muscles. Of the genera whose locomotion is on the toes, some, like the dogs, have their claws unmoveable; others, such as cats, have them retractile; and the seal tribes have the hinder extremities fettered, the feet palmated, and a dentition, not in strict accordance with the general characters of the order. 
Mr. Waterhouse divides the carnivora into six fatmilies, of which the dog, viverra, cat, weasel, bear, and seal, afford familiar examples: of these,

The Canidce have already been the subject of detailed account in two volumes of this work; we shall, therefore, merely state, that the family are distinguished by having six incisors, two canines in each jaw, three false molars above, and four below, and two tubercular teeth belind each of their carnassiers, or incis. $\frac{6}{6}$, can. $\frac{1}{1}-\frac{1}{1}$, pr. mol. $\frac{3}{4}-\frac{3}{4}$, mol. $\frac{1}{1}-\frac{1}{1}$, tuberc. $\frac{2}{2}-\frac{2}{2}=42$. But when connecting this order with the last, by means of the indications in some genera, which attest a partial insectivorous diet, we find it necessary to transpose the arrangement, as it was given in the two volumes of the Canidae, and then we have this partially evinced in the

Sub-genus Agrionus, with its additional teeth in both jaws, and perhaps still more in the first section of Chaon, where we place the Fennecs or Zerdas. We give in this place only an abstract of the classification, and refer the reader, for more detailed information, to Volumes IV. and V. Thus, we find

Genus Canis. - Forms, with the insectivorous propensities, gradually vanishing.

Sub-genus Agriodus, - Sub-genus Chaon,Containing the sections of

Megalotis, the Fennecs or Zerdas.

Cynalopex, Day Foxes.

Saculius, Jackals.

Thuus, Jackal Wolves. 

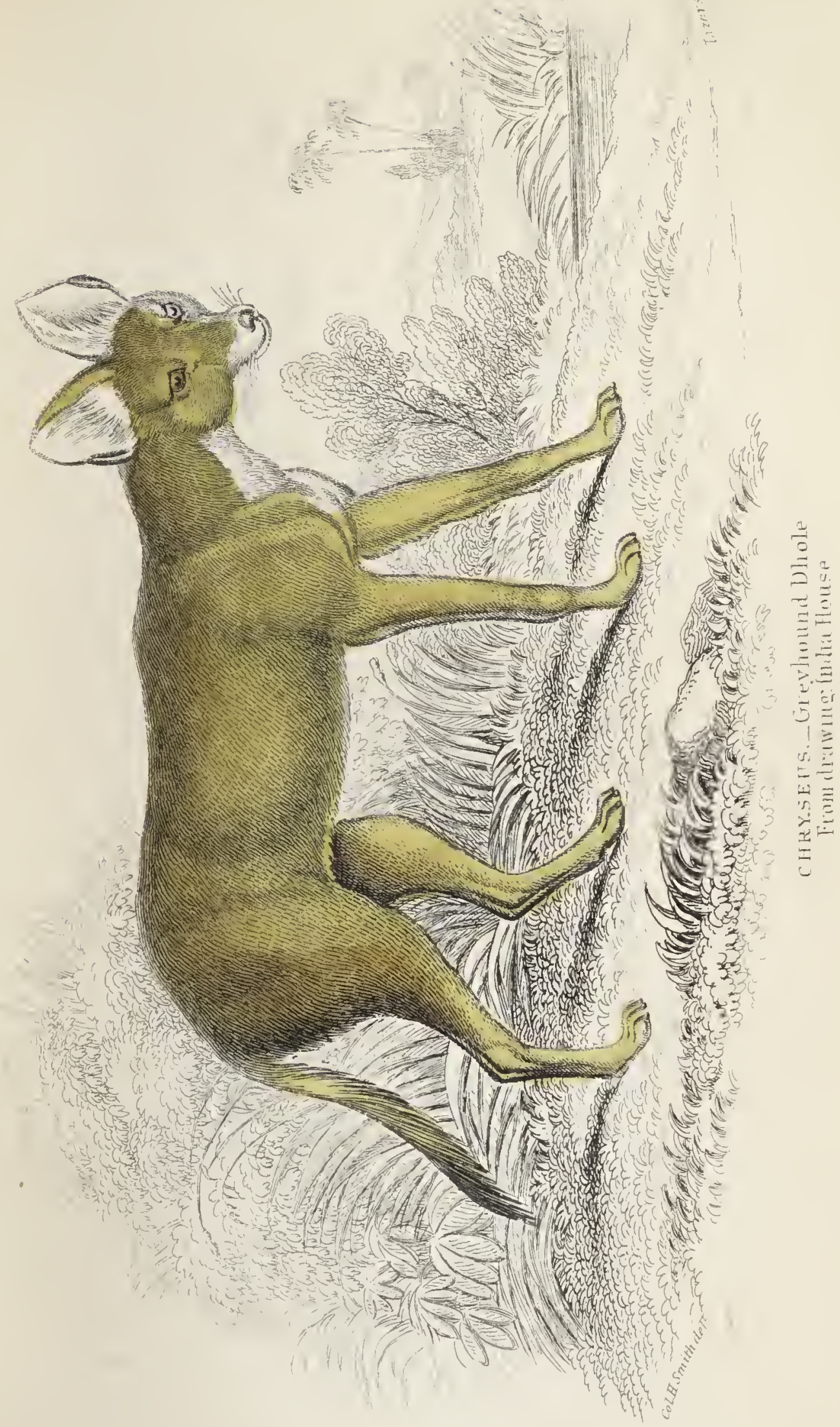

CARNIVORA.

\section{GREYHOU N D D O L E.}

PLATE IJI.

Chryseus, Red Wild Dogs.*

Lyciscus, Dog Wolves.†

Lupus, Wolves.

Sub-genus Canis._Dogs, properly so called, containing the groups of

C. feri, Feral Dogs.

C. lachnei, Wolf Dogs.

C. laniarii, Watch and Cattle Dogs.

$C$. venatici grayii, Greyhounds.

C. sagaces, Hounds.+

C. domestici, Cur Dogs.

C. urcani. Mastiffs.

* Yye give in this volume, a figure of a greyhound dhole, still more lightly made than Chryseus scylax, described in Vol. IV.

+ Canis pallipes, Sykes, appears to be a Lyciscus.

*. To the article of feral dogs in Vol. V., we wish to add, that we have, since the work was written, found, in the library of the India House, a Persian painting, where a couple of the Ictini or Natolian wild dogs are being hunted by the Princes of Feteh Shahs family. A pair of the animals is drawn almost the size of life, and resemble wolves with mutilated or shortened tails. Thers is an error in Vol. V. in naming Plates XXIII. and XXX._XXIII. should be $A$ griodus auritus, and XXX., Proteles Lalandi. 
The domestic races intermix freely with the crepuscular Canidoe of America, which have elliptical pupils.

Sub-genus Chrysucyon, Aguara Wolves.

Sub-genus Dusicyon, Aguara Dogs.

Sub-genus Cerdocyon, Aguara Foxes,-

which again pass imperceptibly into true foxes, with elliptical pupils, that dilate and contract with facility; and, therefore, are more particularly nocturnal.

Sub-genus Vulpes.-Foxes.-The first form, or Arctic Foxes, is still indifferently capacitated to contract the pupils; but the True Foxes of the Old Continent and of the New, possess the faculty completely. They may be divided into two groups in each continent, distinguishable by the tips of the tails being either black or white.

Sub-genus Lycaon, of which only one species is known, externally resembling the hyenas, and at first named Hyona venatica; it is the Lycaon tricolor of Brooks, and has four toes on all the feet.

Genus HyæNA has the same general form of skull as the Canidoe, with the posterior portion more produced; the bony palate prolonged further back, and the small back molar of dogs wanting, there being only five molars on each side above, and four below; four toes on all the feet, and a glandular pouch beneath the tail, which evinces approximations towards the civet group of the next family. There are four or five species known; and fossil hyæna skulls, abundant in cases of the recent tertiary period, attest that there was a time when they 
swarmed in Britain, and over the whole of Europe; being the principal agents that consumed the numerous carcases of huge Pachydermata and Ruminants, whose bones, fractured, and bearing the marks of teeth, are invariably found mixed with them.

Genus Proteles, in form between the hyena and civet, remarkably high on the legs, with a fifth toe high on the joint of the fore foot, but only four on the hind foot. Incis. $\frac{6}{6}$, lan. $\frac{1}{1}-\frac{1}{1}, \mathrm{~mol} \cdot \frac{4}{5}-\frac{4}{5}=30$; but it is still a question if that dentition is complete, all the cheek teeth being simple tubercles.

The Viverrido have the tongue covered with hard sharp pointed papillæ; their claws in walking are somewhat withdrawn, and they have, beneath the tail, a pouch containing glands, which secrete an unctuous, often very odoriferous matter; their form is lengthened and comparatively low. They are active, petulant, and mostly cruel plunderers, destroying for the love of bloodshed; in general, nestling under roots of trees, and in the crevices of rochs. Some approximating the felinæ by the structure of their claws, and others with pads, becoming more and more plantigrade; both more or less arboreal and nocturnal in their habits, feeding on eggs, birds, small mammals, lizards, frogs, and serpents; in the last respect, they have been principally beneficial to mankind, and, no doubt, this quality procured for some species, in Egypt, that high veneration which ranked them with gods.

Genus Herpestes. - The Mangustas. - Eyes 
diurnal, with the bony orbit complete; pad of the hind feet bare.

Sub-genus Ryzena. - The Surecat. - Have the dentition of civets; only four toes on each of ail the feet; a dog-like face, and still rather elevated legs; but the back is arched, and though the tail is sometimes tufted only at the tip, it is, in general, like that of ferrets; the anal pouch opens within the rent, and the hind feet somewhat plantigrade. There is only one species known, it is the

Ryz. tetradactila. - Surecat of the Dutch. Rather less than a domestic cat, still barred across the back with dark markings; a playful and rather gentle animal, producing a not unpleasant sourish smell, whence the Dutch have given it the name of Sure or Sour. It is found in Africa. The Senik of Sonnerat appears to be the same animal.

Sub-genus Cynictis, Ogilby, likewise with the masticatory organs of civets, but the locomotives of dogs. Incis. $\frac{6}{6}$, lan. $\frac{1}{1}-\frac{1}{1}$, mol. $\frac{6}{5}-\frac{6}{5}$, wanting the second tubercular below; their toes are 5-4, and claws long and like the preceding, fit for digging; feet more digitigrade. There are two species known 

3. W3
3

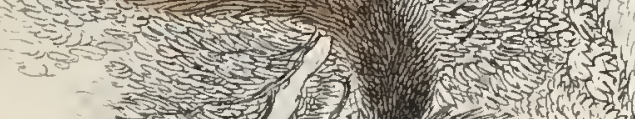

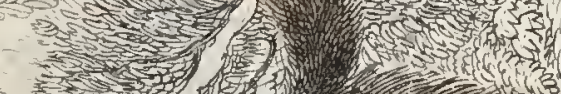

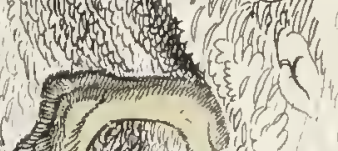

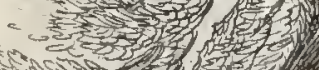

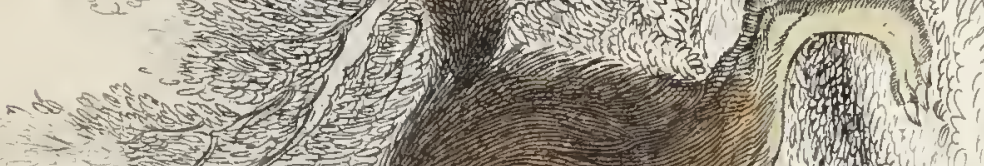

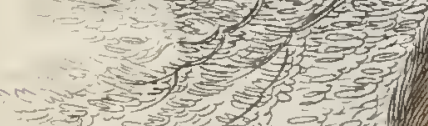
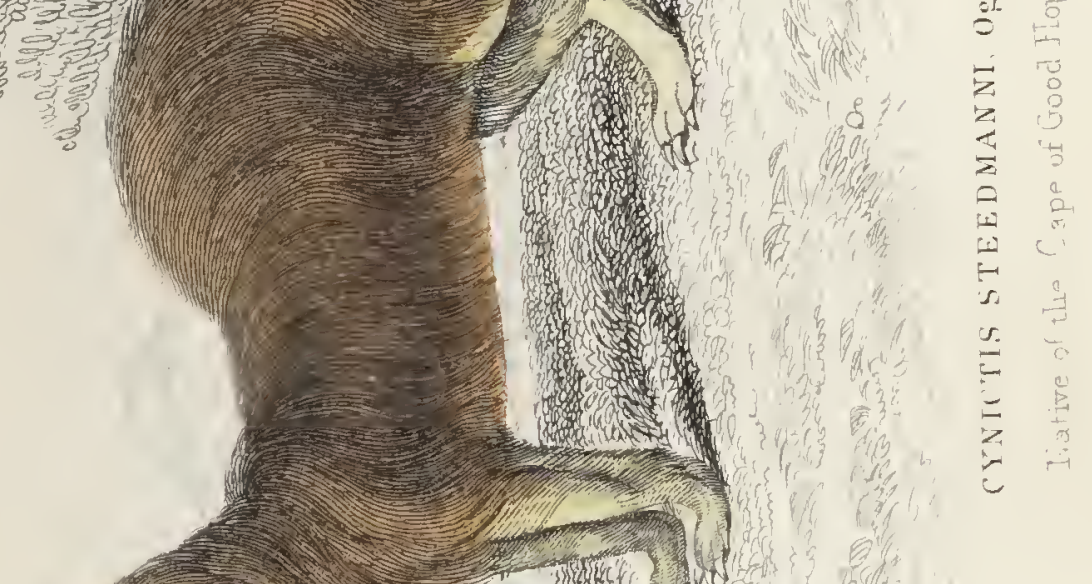

(n)
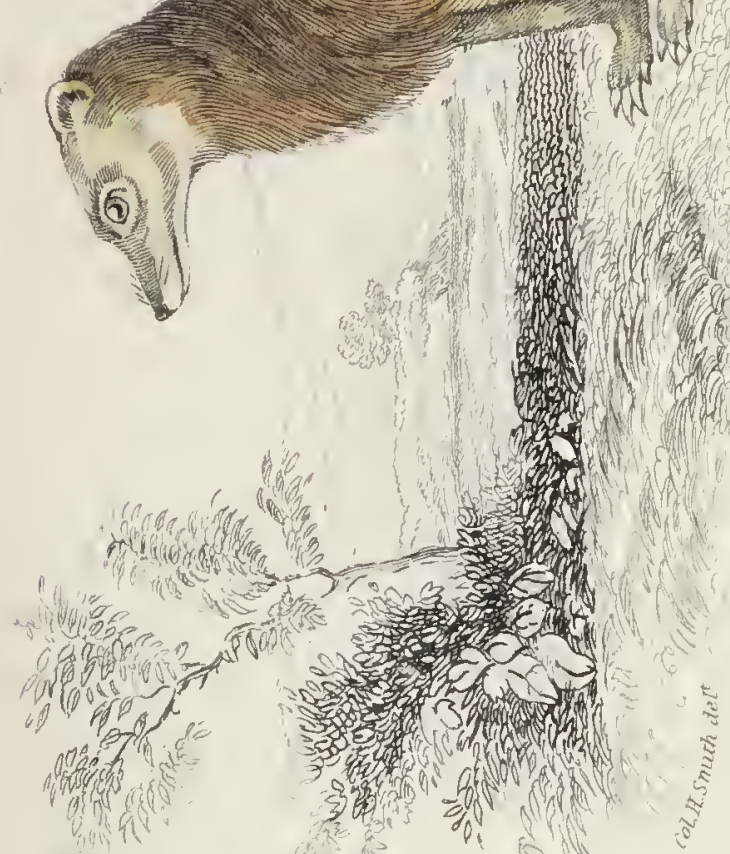

MEERCAT BARROW.

\section{PLATE IV.}

Cynictis Steedmanni, OGILBY.

RUfous-BRown, on cheeks and sides mixed with grey; tip of tail dirty white; length of head and body one foot, tail one foot; appears like a small fox with short limbs. From the Cape.

Cynictis melanurus. - Black-tailed Meercat.Seems to be deficient in tubercular teeth behind the carnassial; darker coloured; tip of tail tufted and black, a trifle smaller, the fur closer. Found at Sierra Leone, and may be the Koheloe of Bosman.

Sub-genus Crossarchus, like the former, intermediate between Ryzoen $a$ and the Ichneumons, having the round head and anal pouch of the first, and the five toes and claws on each foot of the second, but a plantigrade walk; the same number of teeth as Ryzona, but their form is like that of Herpestes Proper. The only species known was brought from Western Africa; it is the

Cross. obscurus, F. Cuvier. - In size similar to Ryzona, with pointed nose, rounded ears, dark grey-brown, paler cheeks, a fuil brush tail, black feet; a gentle and very cleanly animal in captivity. - Sub-genus Herpestes Proper. - The Ichneu- 
mons. - With a simple and voluminous pouch, pierced within the vent; hair ringed alternately with light and dark colours. Teeth $\frac{6}{6}, \frac{1}{1}-\frac{1}{1}, \frac{5}{5}-\frac{5}{5}=$ 36. They are low on the legs, toes 5-5, semipalmated; reside about the borders of rivers and lakes; swim well; do not climb. The most remarkable among them, on account of the misstatements of the ancients, is the

Herp. pharaonis. - The Egyptian Ichneumon, Nems and Got Pharaoon of the Arabs, measures above three feet in length, with the tail included; brown-grey, with coarse hair, and a long vertical bush of black hairs at tip of tail ; keen, mistrustful, yet easily tamed: was once adored by the ancient Egyptians on account of its enmity to crocodiles, of which animal it is probable the Nems has the faculty of discovering the deposits of eggs, and devouring them. Modern Egyptians likewise assert, that they attack serpents. But it is remarked, that the species abounds in lower Egypt, where no crocodiles now exist, and is scarce in the upper country where these reptiles are numerous. Rats, and domestic poultry, have most to fear from them.

Herp. major, H. Urinatrix. - The Great Ichneumon.-Somewhat larger than the last; nearly the same colours.

Herp. griseus. - The Grey Nems. - Likewise from Egypt: somewhat smaller; paler grey.

Herp. fusca.-Black and yellow annulated fur; throat yellowish-brown; tail very hairy; total length 35 inches. Native of India. 

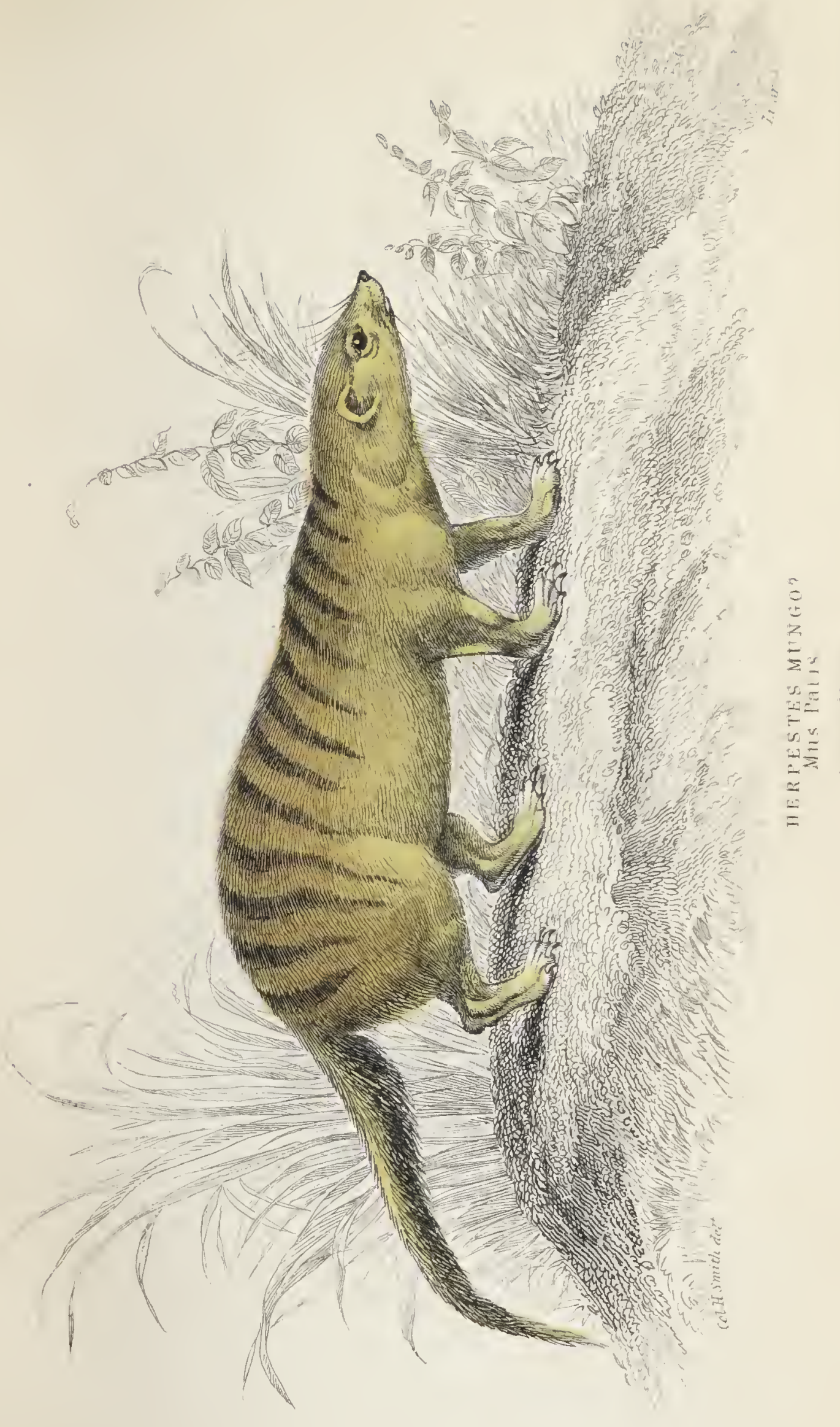

CARNTVORA.

\section{THE ZEBRA ICHNEUMON.}

PLATE V.

Herpestes mungo.

Not above 18 inches in length from nose to end of tail; bright rufous, with twelve or thirteen dark bands : tail pointed. Baron Cuvier does not notice the transverse bands on the back. This species is renowned for victorious conflicts with the most dangerous serpents, and for causing the discovery of that antidote against their poison, known by the name of Ophioriza Mongos.

Herp. vitticollis, Ben. - Grisly, with red back and tail; a black spot from the side of ear to the shoulder; end of tail black; length 22 inches; tail $12 \frac{1}{2}$ inclusive of the hair. From Travancore, East Indies.

Herp. javanicus. - The Java Ichneumon. - Is rufous-grey. Total length 20 inches.

Herp paludinosus, uniform grey-brown; Herp. penicillatus, rufous-grey; Herp. melanurus, and Herp. albicaudatus from Africa, and recently a species discovered in Spain; it is the Herp. Widtringtonii; but Herp. Rufa. Desm., is most likely a species of Cynictis. 
Sub-genus Atrlax.-The Vansire.-Differs from the preceding by the cerebral chamber being proportionably more enlarged, and by the apophyses of the jugal and coronal wanting length to form a complete bony orbit round the eye.

At. galera.-Vohang-shira of Madagascar.-Total length about 20 inches; dark brown, stippled with buff; tail full to the end. Is said to be fond of the water.

Here might be placed the sub-genus Amblionon, of which we have not found the distinguishing characters.

Genus Paranoxurus.*-Instituted by F. Cuvier, on account of the facility most of the species possess of rolling up the tail. They have the same number of teeth as Viverra, $\frac{6}{6}, \frac{1}{1}-\frac{1}{1}, \frac{5}{5}-\frac{5}{5}=36$; but the molars indicate a more frugivorous appetite. The eye is linear; the sub-anal pouch assumes more the form of a fold; the feet are plantigrade, with the toes united by a membrane to near the claws. They are not remarkably agile, and prefer to reside in the crevices of rocks, though, no doubt, they all can climb trees. They appear to be exclusively natives of India, and the great Asiatic islands. Mr. Gray enumerates the species as follows:-

Par. typus, F. Cuvier.-Viverra Nigra Desm.

* The greater number of species of this and the other genera of Viverrids, were discovered by Sir Stamford Raftes and General Hardwicke, who brought them to the notice of Messrs. Diard and Duvaucel, and thus facilitated their being first described in French works. 
-Total length above three feet, whereof the head and body constitute about half; body blackish, with some indistinct darker marks along the flanks; a white spot above the eye, another beneath it; tail entirely black. It may be the musky and musk weasel of Pennant, but there are, under this specific name, several varieties, and probably species concealed. In the Paris Museum, there is a variety with a larger head in proportion, and an additional white spot below the ear.

In a description, with a drawing by Mr. Reynolds Gwatkin, sent from Mussorie in the Himalaya mountains, there is no spot beneath the eye, but a lengthened white streak above it, and a whitishgrey collar round the throat; the general colour is dark badger grey; head, feet, and tail, nearly black; 42 inches total length, and resides in the crevices of rocks, is very shy, but not very agile.

Par. Pennantii.-Pale brownish-ash colour, with indistinct darker lateral bars; nose flesh colour; ears thinly covered with hair; head white about the orbits; limbs, and extreme half of tail black; total length 44 inches. Extremely destructive to poultry and game.

Par. Zondar._Viverra bondar Desm., Musk Cat in Bengal.-Fallow coloured, but with the tips of the longer hairs black, and a black band along the back, and one on each side narrower on the flanks; feet and tip of tail same colour; total length $4 y$ inches.

Par. prehensilis. - Viver. prehensilis Desm.- 
Yellow-grey, with dorsal line; the end of the tail, iegs, two lines of elongated spots near the back, and many small round spots on each flank black; tip of the tail white, spot of the same colour behind each eye, passing round it, and extending on the chaffron to that of the opposite side; another spot at the angle of the lower jaw. It is asserted this species winds the tail round the body.

Par. musanga. - Viver. musanga, Horsf. - V . fasciata Desm. - Clear yellow, with dark brown spots in longitudinal lines; end of the nose, and a transverse band on the forehead above the eyes whitish; lower parts uniform grey.

\section{PLATE VI.}

\section{Paradoxurus dubius.}

Pale yellowish-grey, the longer hairs pointed with brown; below whitish-yellow grey; three dorsal streaks, and fainter spots on the sides brown; ears hairy; feet chestnut; tail at base and point brownblack; a spot on each side the nose, another above the cheeks, and a band between the ears whitish.

It is probable the fur of all the species varies: one caught on a wharf, among timber, at Philadel- 


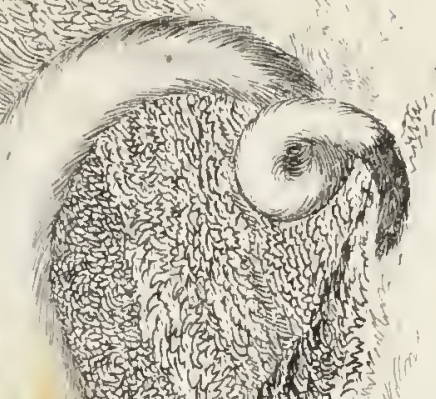
$\left\{\begin{array}{l}3 \\ 2\end{array}\right.$

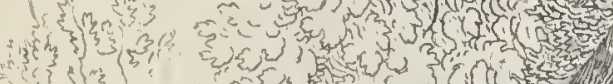

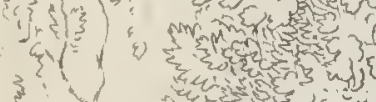

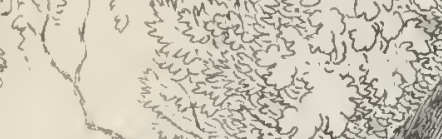

(n)

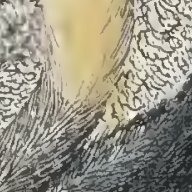

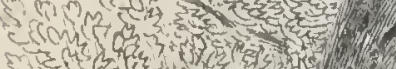

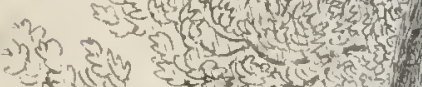

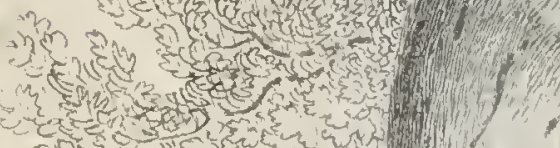
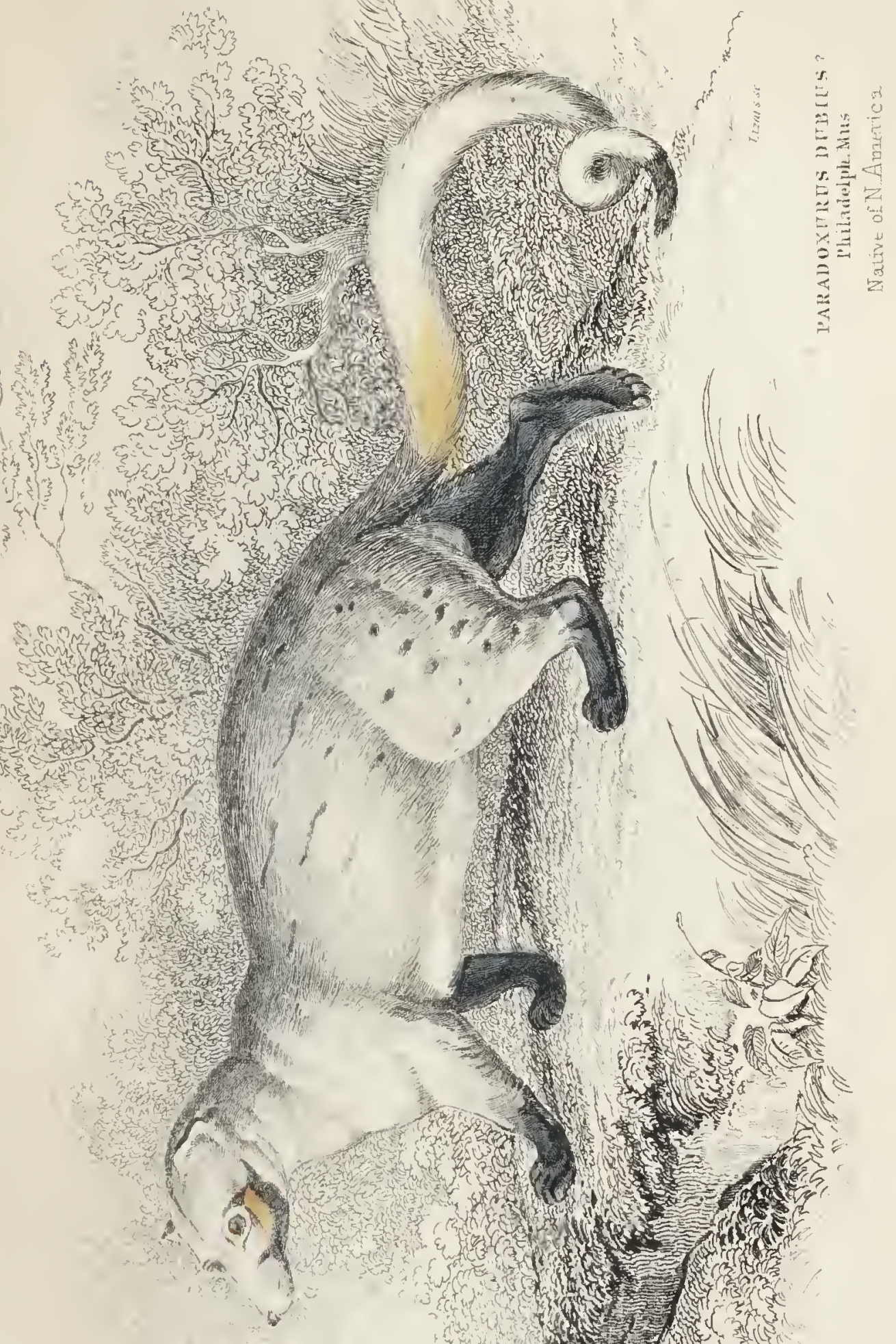

phia, and most nearly allied to the $P$. dubius, had the forehead, region of the temples, sides of neck, throat, nose, and spot beneath the eye, white: the base and summit of tail rust colour, exclusive of the tip, which was with the limbs, outside of the ears, cheeks, and lower jaw, black; the darker streaks, and spots on the yellowish-grey of the back not very distinct. In size equal to Par. typus, but the nose less pointed; under the tail, apparently a large pouch. The native country unknown.

Par. hermaphroditus.-Viver. hermaph., Pallas. - Resembles the last; but is distinguished by the throat being entirely black.

Par. Pallasii.-Blackish-grey, intermixed black and white, below paler; the back with a rather broad streak, and small spots on each side black; limbs, lower parts, and tail, of the same colour; face black, with a spot on each side the nose, another beneath the eyes, and a cross band extending over the forehead and cheeks to the throat, white; ears nearly bare; throat anteriorly blackish-grey, posteriorly whitish; tail longer than the body. Native of India.

Par. crossii. - Abore blackish, the hairs being lead colour, tipped with black; below yellowish, the hairs tipped with white; ears bare at the points; at the base of the ears externally, the face, feet, and three fourths of the terminal portion of tail, brownblack; pale round spots on each side the nose; a smaller of the same beneath the eyes: forehead yellowish. Total length 37 inches. 
Par. Hamiltonii.-With hairy ears; back ashygrey, with six or seven rows of round black spots; dark streak along the back; a narrow stripe between, and one above each eye; on the middle of the neck another black, and on each side a pale, shorter, brown streak; the tail one half longer than the body, brownish rufous, with narrow black rings.

Par. larvatus. - Gulo larvatus, Ham. Smith.Olive-brown grey; tip of tail and feet black; white patches about the face, particularly one running from nose to occiput.

Par. trivirgatus. - Viver. trivirgata, Rein. Blackish-grey; below grey; head darker; no white spots; three black streaks along the spine; feet and tail black, the last mentioned exceeding the body in length. Resides in the Moluccas.

Par. Grayii.-Total length 40 inches, of which the tail measures 20 ; fur woolly; light fulvousbrown above; cinereous beneath; ears and face black with forehead, a stripe down, and spot beneath the eye grey; tail always twisted, cannot be rendered strait in the living animal.

Par? aureus, F. Cuvier.-Smaller than the former species; fur a uniform golden-yellow; hair very long.

Viverra binotata of Reinwart, and Viverra malaccensis of Sonnerat, are probably species belonging to this genus.

Mr. Gray has indicated several other species, but the genus at present seems to be a receptacle for all plantigrade Viverridoe that are not finally classified: 
several are already, and others may be expected to form new sub-divisions.

Sub-genus Cynogale, Gray. - In. $\frac{6}{6}$, can. $\frac{1}{1}-\frac{1}{1}$, mol. $\frac{6}{6}-\frac{6}{6}=40$. Is allied to Paradoxurus, but differs in the length of the face, compressed form of the false molars, the small size and triangular shape of the carnassial tooth : toes $5-5$, half webbed; plantigrade soles, bald nearly to heel; tail long, hairy; fur soft, with longer crisp rigid hair.

Cyn. Bennetii. - Brown, with elongate black hairs; a broad sub-terminal silver band; ears short, rounded: whiskers, upper lip, and chin, white. Inhabits Sumatra.

\section{Here we place, provisionally, the}

Genus Cryptoprocta, Bennet.-Dentition not as yet fully known, but plantigrade feet; toes webbed to near their tips; retractile claws on the fore feet, resembling those of cats; a mephitic pouch under the tail; a close pressed fur and siender tapering tail; all approaching Paradoxurus, but in anatomical structure, allying with Viverva and with Felis.

Of this genus, the type is

Crypt. ferox. $-\Lambda$ young specimen from Madagascar; slept rolled up; was vehemently excited at the sight of flesh.

Genus Galidia.-Incis. $\frac{6}{6}$, can. $\frac{1}{1}-\frac{1}{1}$, mol. $\frac{6}{5}-\frac{6}{5}=$ 38. Though feet and hands are elongated as in digitigrades, the palms are naked, but narrow behind; the number of toes as in Herpestes, yet more 
free; in the upper jaw a false molar is often wanting; tail moderately long.

Gal. elegans is the type.

Genus Galmictis.-Founded on Mustela striata of authors; has the canines more powerful, the true molars broader, more contracted in the antero-posterior direction, $\frac{6}{6}, \frac{1}{1}-\frac{1}{1}, \frac{5}{5}-\frac{5}{5}=36$; in both genera the dentition more blunt and simple, indicates a partial frugivorous habit, that separates it widely from Hemigalea and Prionodon.

Gal. striata, $V$. fasciata? Chat Sauvage à bandes noires, Sonner.-Grey rufous, with six iongitudinal black streaks. Plantigrade. 


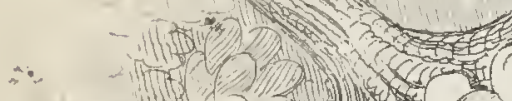

$\therefore \therefore$ - Hit ( )
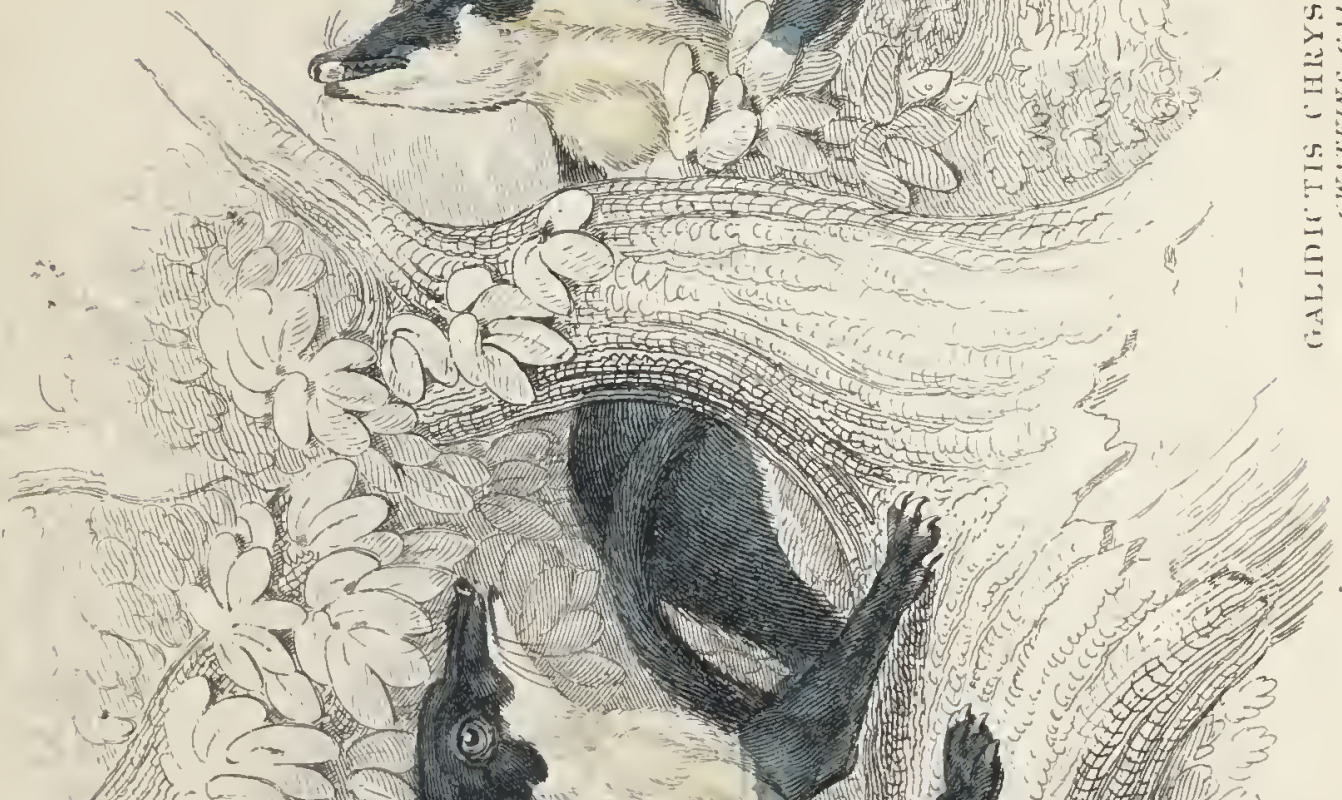

,

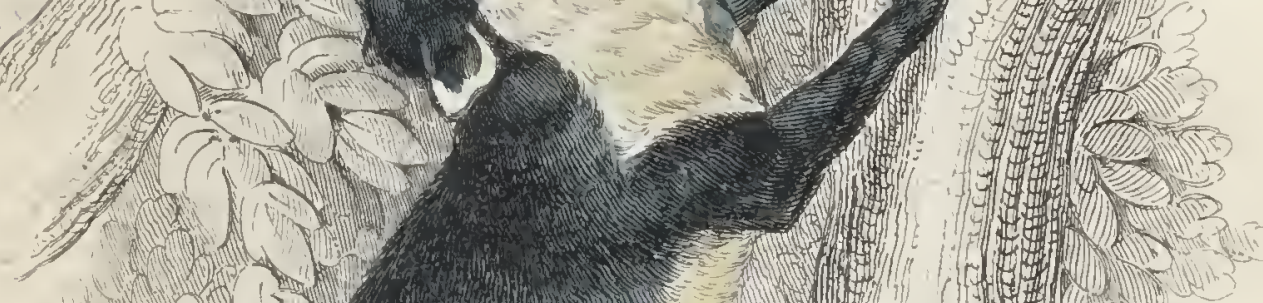

त)

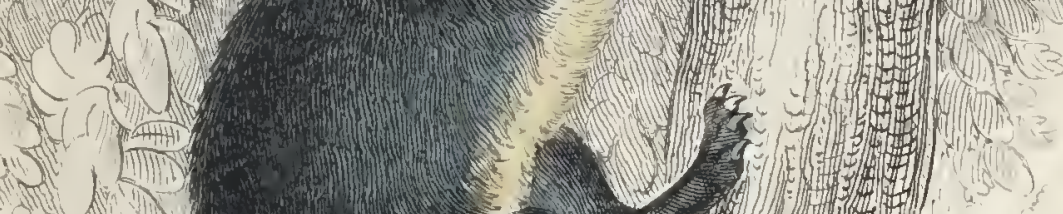

(i) $1=$

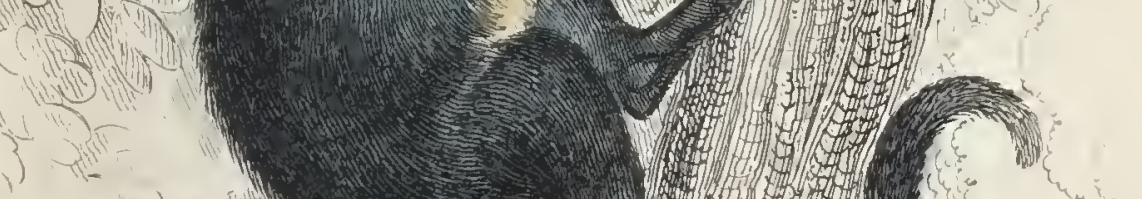



CARNIVORA.

GWATKIN'S GALIDICTIS.

PLATE VII.

Galidictis chrysogaster, Nов.

BACK, shoulders, and legs, black ; body deep brownish, paler on the flanks; the throat white; breast and abdomen orange-tawny; digitigrade; toes cat like; claws white; tail long; total length forty-two inches. Is fetid; sits up erect, gambols actively, ascends trees, and leaps from one to another; barks with a distinct hoarse note. Female exactly like the male. Specimen shot at Mussorie in the Himalayas. From notes of Reynolds Gwatkin, Esq.

Genus Viverra.-The Civets. - We now arrive at the typical genus of the Viverridce, itself constituting a small group of sub-generical forms, several of the species being once held important in the Pharmacopœia of nations, and of great interest to the fashionable world, on account of the so called musk, deemed valuable for scenting clothes, and still esteemed in Asia. The species stands higher on the legs than the other allied genera; their dentition is $\frac{6}{6}, \frac{1}{1}-\frac{1}{1}, \frac{6}{6}-\frac{6}{6}=40$; the nose pointed; eyes linear; feet pentadactylous, digitigrade; tail long, beneath which is the pouch, wherein an odo- 
rous unctuous substance is secreted from two internal follicles, and independent of another secretion of a very offensive matter. It is this double secretion, which, as one or the other prevails, causes the scent to be called offensive or agreeable.

Viverra civetta.-The Civet.-Grey, marked with stripes of black, in general directed downwards, but in some forming curved, and even circular figures; a mane along the back, black, erectile; tail shorter than the body, marked with six or seven black rings, including the tip; cheeks and limbs black. Size of a fox, being nearly four feet in total length.

This animal has been confounded by earlier naturalists with the Genet, Zibet, and other allied species, similarly producing a scenting substance. It is, however, one of the most powerful among the Viverrida, but little known in a wild state, though abundant in Abyssinia, where great numbers are kept in confinement; and some trade is carried on by the natives with the Civet secretion, which they collect. Dr. Shaw relates, in his natural history, how the same substance was formerly obtained at Amsterdam by the Dutch, while it was held valuable in the drug market. In captivity, the Civet is a lazy sluggish animal, sleeping constantly and feeding, seemingly not even roused by the darkness of night, although that period is their time of activity. As the manners of Civets are most likely the same in different species, we may infer the habits of the present by those of the next.

Viv. Bengalensis, Gray.-The Bengal Civet.- We 
take this species to be the Kuttauss of India, well known to sportsmen; a fierce and vigorous animal, equal in size with the former, but differing from it chiefly by the tail being longer, and the black streaks running obliquely from the shoulders to the haunches, at first in four lines on each side, and from the hips in round spots continued to the edge of the buttocks; the tail is black, with ten whitish oval spots, the tenth forming the tip, which, therefore, is white; on the neck and shoulder there are four vertical black stripes on each side, and there are several round spots on the cheek and temple; the abdomen is white.

The Kuttauss does not bear an agreeable musky smell, but one rancid, and so strong, that dogs, in full chase after other game, lose the scent if they rouse one of these animals, and are immediately impelled to worry it to death, remaining unfit to use the nose for the rest of the day. It is a night prowler, dexterous, noiseless, and ferocious, killing for the love of blood, young sheep and pigs, and making great havock in poultry yards; retreating from its depredations to the reedy, brambled, and jungle borders of jeels and water tanks, as near a Mahommedan village as possible, because the people of that creed in India rear poultry, which the Hindoos, reckoning fowls unclean, do not. It is difficult to get at them with dogs, because they escape into trees, or, if they are overtaken, defend themselves by biting, so sharply, as often to break the limb, and refusing to relax the gripe though worried 
by a dozen dogs. See Captain Williamson's Oriental Field Sports.

Viv. fusca, Gray.-Brown Long-nosed Civet.This animal we are only acquainted with through the figure published by Mr. Gray. * It appears that the forehead is very remarkably arched, the nose considerably longer than any other of the genus; and the livery, brownish-buff, is totally without darker streaks or spots, the end of the tail alone appearing to be dusky.

Viv. Zibetha. - The Zibet. - Grey, legs transversely spotted with brown; head long; throat white, with two black bands on each side; no mane; tail with eight or ten semiannuli, black and white. Native of the great Indian Islands, where it is kept in captivity for the sake of collecting the musky secretion.

Viv. Rasse.-The Rasse, Horsf.-Fulvous, with short rounded ears; eight close parallel broad dark lines along the back; numerous small black spots on the flanks in three lines; tail shorter than the body, with eight black annuli; feet brown. Inhabits Java, the woods of the Western Ghauts, India; yields the Dedes of the Javanese, and the Zibet of the Malays.

Viv. Indica.-Buff grey, with erect, more lengthened ears, eight narrow longitudinal dorsal blackish lines, and three rows of sub-continuous spots on each flank. Found in India, on the table land eastward of the Ghauts.

* Illustrations of Indian Zoology. 
Sub-Genus Genetta.-The Genets.-Anal pouch reduced to a mere fold of the skin containing very little secretion; limbs shorter; tail in general long; molars $\frac{6}{6}-\frac{6}{6}$. Resides in Africa and Southern Asia.

Gen. vulgaris-—The Genet.-Grey, with small, round, and elongated spots, forming a kind of longitudinal rows; feet dark; tail with nine or ten black annuli. Resides in France and Spain, probably also in Barbary.

Gen. fossa._The Fossane._Reddish-grey marked with brownish-black spots; tail with ten or eleven annuli ; tip black. Inhabits Madagascar.

Gen. pantherina.-Pantherine Genet.-A large species, having four rows of ocellated spots on each flank, with the middle reddish, while the general colour of the fur is yellowish-grey; tail long, with about eight broad annuli ; tip black.

Gen. Senegalensis. - Senegal Genet. - Smaller than the former. Whitish-yellow grey, with four rows of lengthened oval spots on each flank; feet white; about nine annuli on the tail; tip white. Inhabits Western Africa.

Gen. Barbara.-Barbary Genet. - Still smaller, but with similar coloured fur, with four rows of rounder oval spots on the flanks; feet white; eight rings on the tail, including the tip, which is white. Is found in Barbary.

Gen. pallida, Gray. - Pale Genet. - Likewise small ; rufous and buff; beneath white; a few spots forming two interrupted rows obliquely from shoul- 
der to buttocks; six narrow black rings on the tail ; tip white; feet black. Inhabits China.

Although from the time of Boddaert and Sonnerat, certain species of Viverridoe were occasionally classed with cats, because they had, like them, retractile claws, while their lengthened form, and prolonged jaws, with a different dentition, seemed to deny the justness of the arrangement, systematists persisted in not feeling the necessity of an intermediate genus; latterly, however, Dr. Horsfield's Prionodon led the way, and other forms, likewise with retractile claws, have since been established. The generic names of Hemigalea, which, with the first mentioned, we place after the digitigrade civets, having left, as may have already been remarked, the other cat-toed species, Cryptoprocta, Galidea, and Galidictis, all partially plantigrade, with the Paradoxuri, so that from a genus they now appear to constitute a small family. The greater part bear liveries so exceedingly like Genets, that it may be suspected there are among the last named, some at least which will ultimately pass into the present, if not already so located; and, among others, the Musang of Marsden; the Cape Cat of W. Daniel, figured in his sketches of native tribes, animals, \&c., of Southern Africa ; and the following species, which we leave at present undetermined, because its precise dentition cannot be ascertained. 


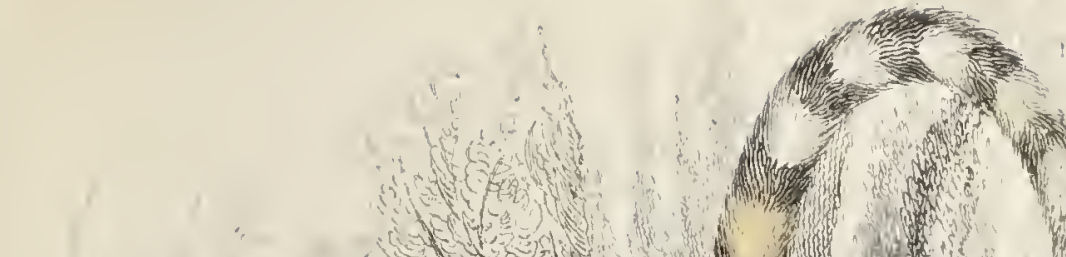
x. $\frac{1}{x+3} \ln 1$ (1)

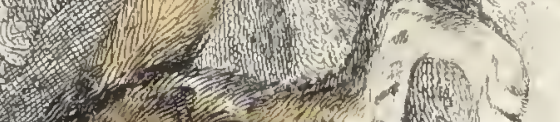
(1)

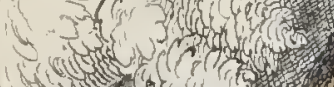

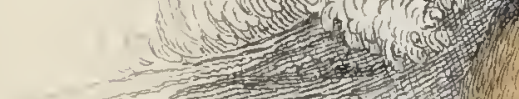

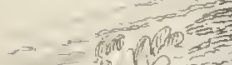

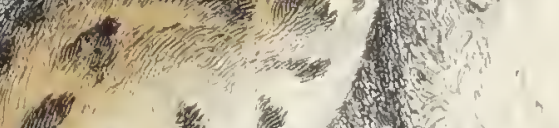

4.

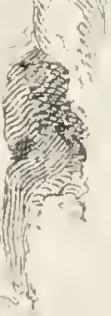

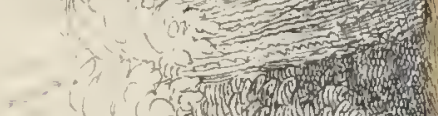

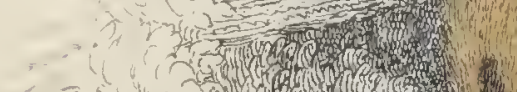

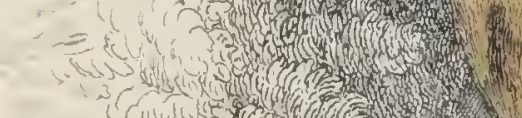

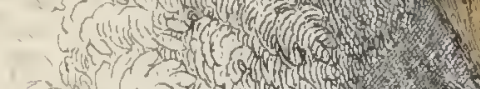

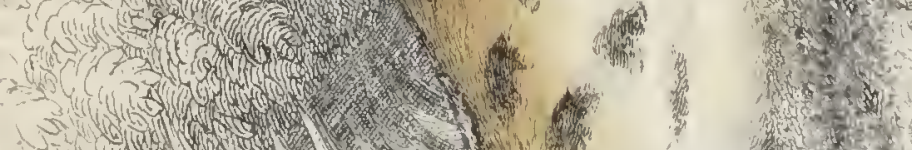
$\rightarrow$ mom (n)
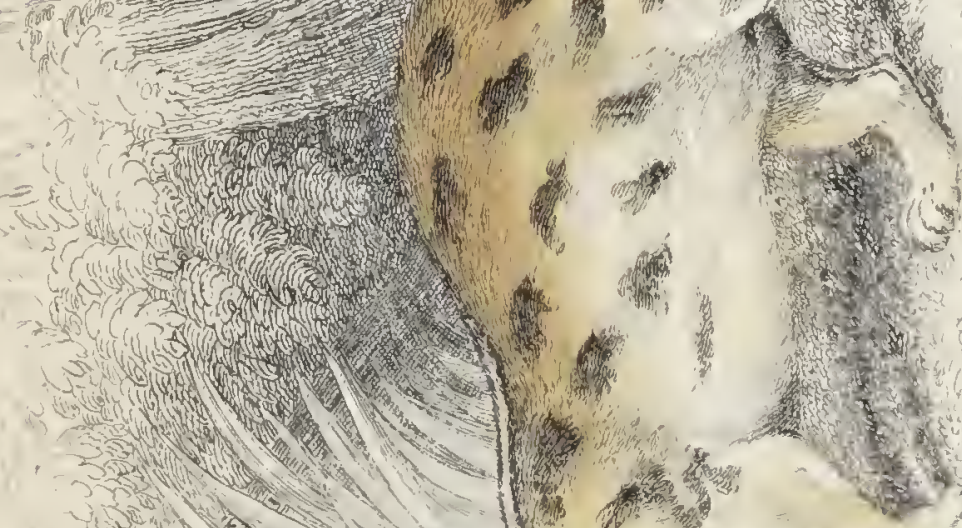

1
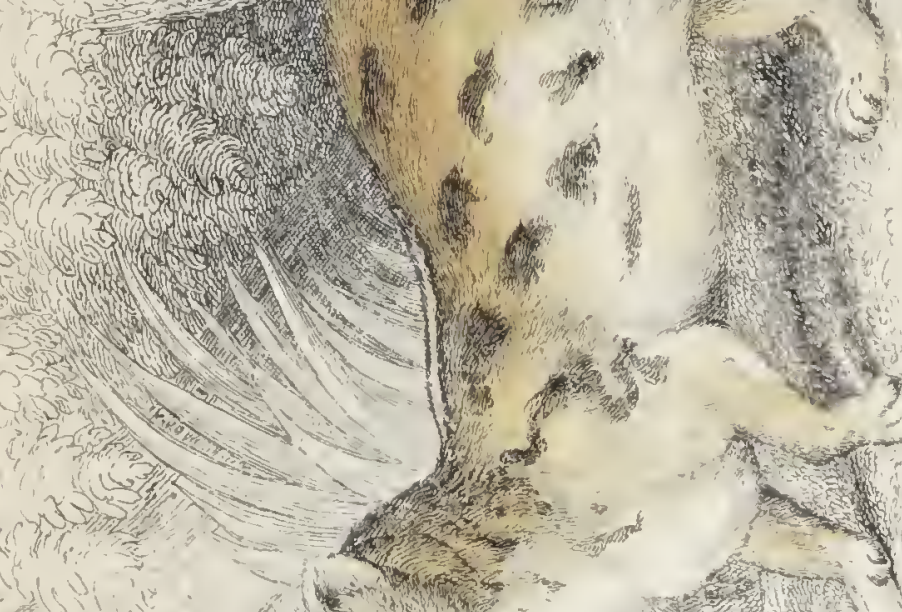

(1)

$$
\text { (1) }
$$

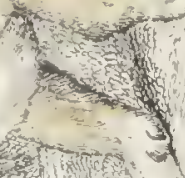



PIATE VITí.

Genetta tigrina?

Size of a domestic cat, equally high on the legs, but longer in the body; legs strong, with the thumb of the fore paws armed and placed as in the cat; head sharper, with black about the eyes; general colour rufous white, clearer below; irregular black har firom ear to shoulder; streak over forehead passing interruptedly along the spine; six irregular large spots forming two oblique rows from withers to flanks; on the loins and thighs large irregular blotches; nine black annuli on the tail, exclusive of tip, which is likewise black. This specimen we found in the Museum of Baltimore, and agrees sufficiently with the figure of Boddaert's Chat Bizaam, to be considered identical. It was brought from one of the great Asiatic Islands.

Gen. villosa, Nobis, Linsang? Horsf._-Size of a polecat, with pointed snout; small round ears; long and slender neck and body; tail equal to the length of the body; legs robust, long; five toes on all the feet, middle toe longest; colour white; an irregular band passing from the ear to the fore leg, another from behind the ear to the withers ; from the shoulder on each side a wavy band, obliquely along the flank, 
inclosing three rows of large oval spots, each row consisting of three; across the loins three broad bars; on the fore legs, lower flanks, and thighs, irregular blotches and specks; tail with six annuli, tip white. Supposed habitat the great Asiatic Islands. Specimen in possession of the late Dr. Leach. The species is nearly allied to, if not absolutely one of, the following genera, which connect the Viverridae with the Feline family. We think both these species or varieties will ultimately be referred to the genus Prionodon.

Genus Hemigalea.-Thoroughly retractile claws; no anal pouch; body elongated, transversely marked. Dent. form. incis $\frac{6}{5}$, can. $\frac{1}{1}-\frac{1}{1}$, mol. $\frac{6}{2}-\frac{6}{5}=40$. All the molars !obate and jagged. 


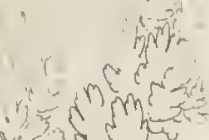

sine

$+2 \cos$

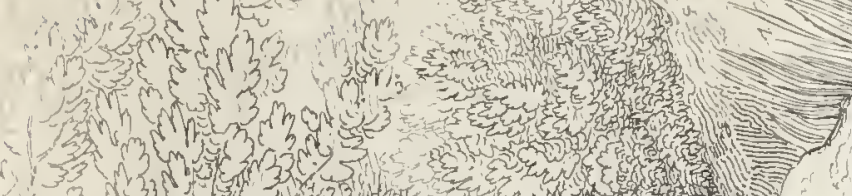

1
3
3

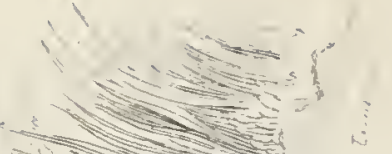

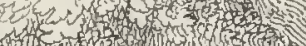

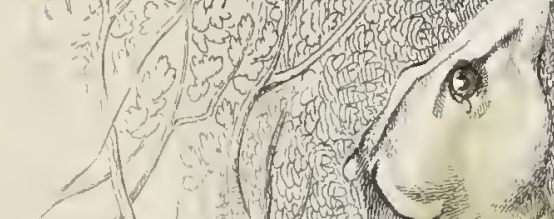
20. m.
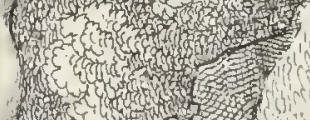
(1) thet
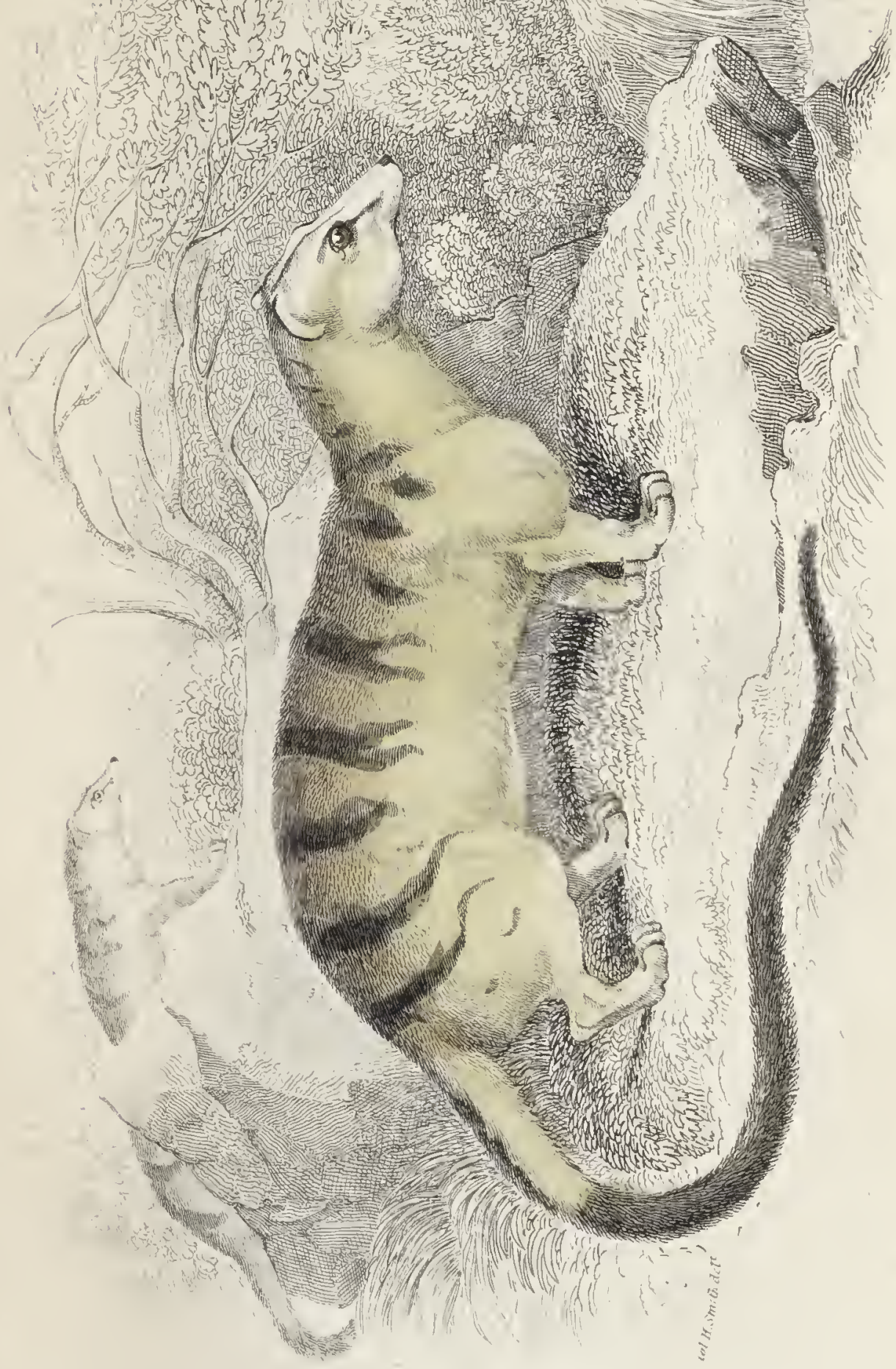

CARNTVORA.

PLATE IX.

Hemigalea Zebra.

First noticed by Mr. Gray under the name of Paradoxurus Derbianus. Viverra, Derbyii, Temm. Low on the legs; robust in make; very pale yellowish-brown, with dark brown marks and broad cross bars. Total length about 30 inches.

Genus Prionodon Delundung, Horsfield.-Anal pouch none? head elongated; muzzle very pointed; body and limbs slender; tail long. Dent. form. incis. $\frac{6}{6}$, can. $\frac{1}{1}-\frac{1}{1}$, mol. $\frac{5}{6}-\frac{5}{6}=38$. All the molars lobate and jagged; toes $5-5$.

Pri. gracilis.-Slender Delundung.-Fur clear yellow, whitish below; three or four irregular large cross bands on the lower part of the back; irregular oblique spots from the ear towards the shoulder; tail with nine annuli, tip whitish. Inhabits India? and Java. It is the Lesang of Hardwicke.

\section{THE FELID压}

are, of all the carnassier order, the most completely organized for subsisting on animal food, and pro- 
vided with arms for subduing their prey. The whole family is cast in the same mould, differing very little except in size, and apparently trivial distinctions; the muzzle is short and round; the jaws short, in which there are two false molars both above and below; the superior carnassial tooth has three lobes, and a blunt heel inwards, and the lower two pointed and sharp edged lobes without a heel; behind there is only a small tubercular tooth in the upper, and none corresponding in the lower jaw. Some Felidæ have vertically contractile pupils, and in others they remain constantly round, yet all have chiefly nocturnal habits. But what offers a marked distinction, and proves to be a most destructive weapon, is the complete power they have of withdrawing the claws by means of ligaments, which, in the usual state of repose, bring the points upwards, and thus keep them always very sharp and ready to be drawn down, giving great efficiency to the stroke of the fore paws, which, particularly in the larger species, are peculiarly heavy. There are many species known, and others, even of the largest size, such as the Wobo of Abyssinia, are still obscurely noticed; but these, and the new continually discovered, with few exceptions, or rather normally considered, all without exception, are spotted, streaked, or harred; the young Lion, the young Puma, and the black species, not being exempted from the general livery. Where so much uniformity of design in their structure exists, it follows, that no characters of real importance can be pointed out, to 


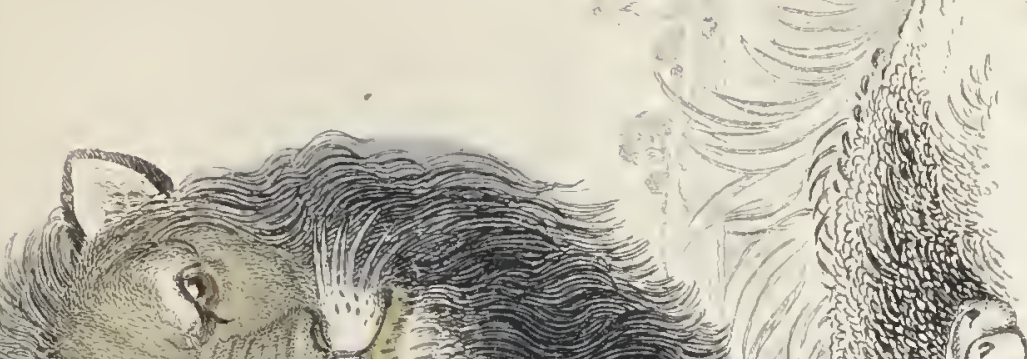

2.
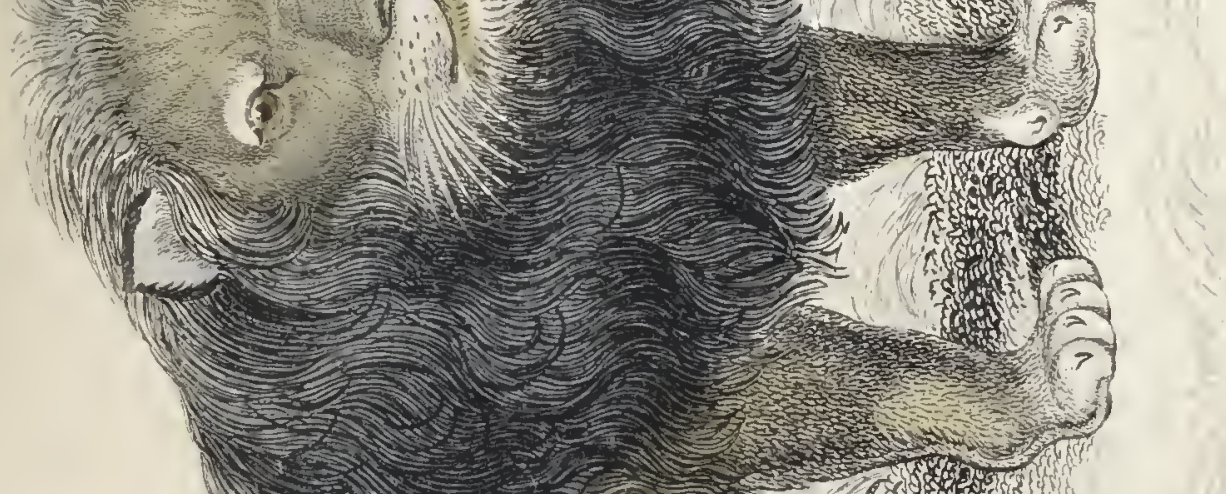

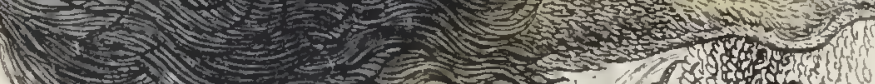

L.

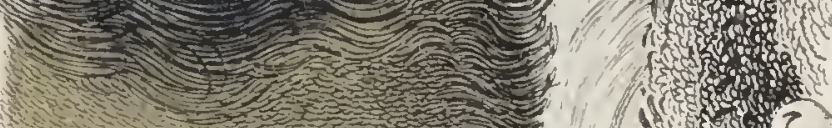
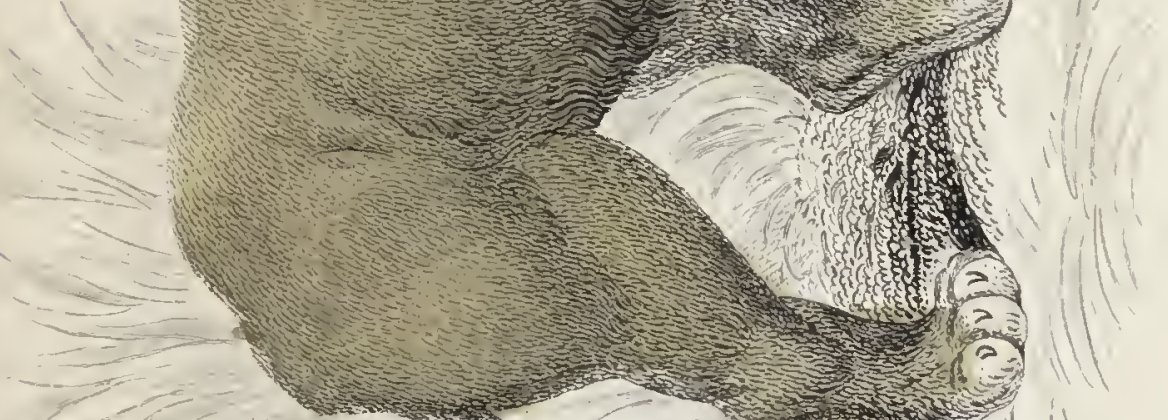

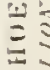

동

ב

?

$4 \equiv$

$3 x$

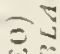

$\stackrel{1}{2}$

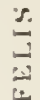



sub-divide the Felidæ into separate genera, though there are distinctions in the markings, and the form of the tail and ears, sufticient to indicate groups. For the particular history and synopsis of the family, we refer to the second volume of the Mammalia of this work, under the title of Felinæ. We notice here only some species which have become known, or clearly distinguished, since that volume was written.

in the Genus Leo, Leach., we figure the

B I A C K M A NED LION.

PLATE $\mathrm{X}$.

Leo melanochaitus, Nов.

The Black Maned Lion of the Cape; a very large variety, not distinctly noticed by late writers, though figured in Griffith's Vertebrated Animals. The species is of the largest size, with a bull dog head; the facial line much depressed between the eyes; large pointed ears edged with black; a great mane of the same colour extending beyond the shoulders; a fringe of black hair under the belly; a very stout saii, and the structure in general proportions lower wan in other Lions. Habitat the Cape. 


\section{THE MANELES LION.}

PLATE XI.

Felis leo gougeratensis.

Somewhat smaller than the African Lion, ${ }^{*}$ destitute of mane, but with a frill of long hairs under the throat, and a large bushy tuft of black hair at the end of the tail. A proud and noble beast, though probably less enterprising than the other species. It may be regarded as a mere variety, even in the case of the double infra orbital foramen, being the common property of all the Asiatic Lions, while it is single in the African. The Maneless Lion is found in Guzzerat, and westward in Southern Persia to the borders of Arabia. $\downarrow$

The second genus, or rather group, is that deno-

* Weighs about 550 pounds, or 50 less than a large Airican Lion. The maned Asiatic species we have examined had the naked part of the nose, and pads of the feet, black; those of Africe flesh colourcd. Both have the spine on the tail.

+ It may be remarked, that this variety is the sacred Lion of the most ancient Egyptian sculptures, and of the earliest Budh representations of the Sing in Ceylon. Unless the Wobo of Abyssinia be a Maneless Lion, it offers a collateral proof of the eastern origin of the religious system of the first mentioned people, for, in Upper Egypt, the Lion is maned. As for the Ceylon Sing, the banks of the Indus alone muld have fumished the type. 


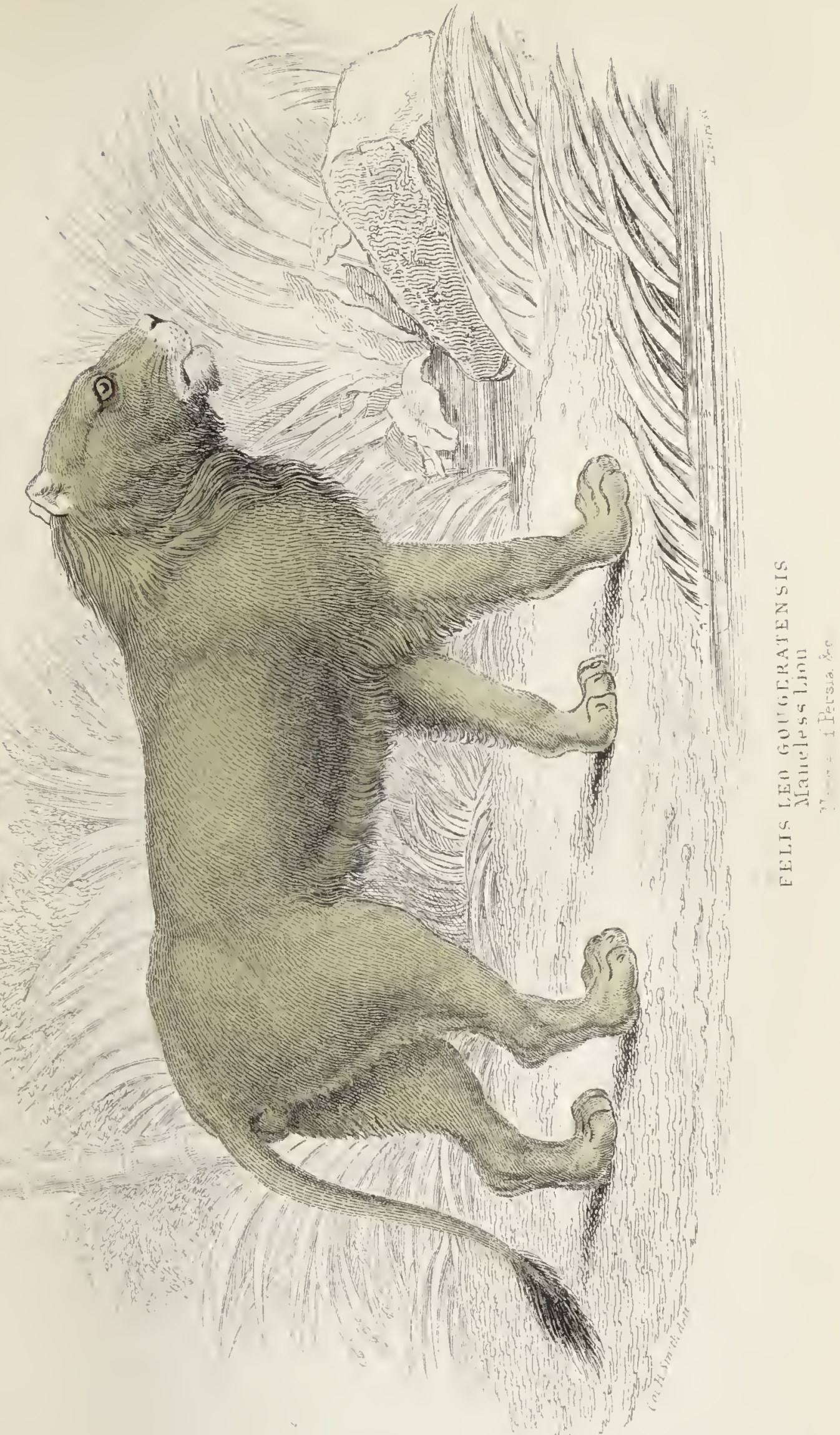



minated Poms, the Couguar of South and North America, distinguished from the rest, because the species are without clear spots, excepting the last, which we formerly discovered in Bullock's Museum. The species of the group are not well defined; in Puma concoler, the South American is distinctly marked with a black streak behind the vibrisse, a white spot on the back of the ear, and is larger than the North American, where all these marks are often missing. But there are, in the South, two others; one, which we measured, was from nose to tail $4^{\prime} 2^{\prime \prime}$, and the tail $2^{\prime} 6^{\prime \prime}$, making a total of 6 feet 8 inches: deep blackish-red, with a few darker specks on the forehead and on the sides; tip of the tail not black, nor any whise on the back of the ear. This is our Proma discolor; from the spots it must be distinct, for in the young Puma the marks are ringed. The second was $2^{\prime} 9^{\prime \prime}$ from nose to tail, $1^{p}$ $3^{\prime \prime}$ the tail, total 4 feet; liver colour, paler beneath, white spot on back of ear; fourteen brown rings, and tip of tail black; numerous dark brown round spots on the body, largest on the rump, inner arm, and abdomen. This we take to be the Jaguarondi. Both were in Bullock's Museum. There remains still the true Black Couguar, Puma atratıs, Nobis, (perhaps Jaguar-ete-pope), already figured by Pennant, and of which we drew a specimen from a living adult. The animal appears larger than the South American Couguar, is of a glossy jet black, excepting the lips, chin, cheek, temple, jowl, throat breast, belly, and knee joint of the hind leg; the 
eyes rivid, greenish; black spot at the angle of the mouth continued on the lower jaw. Compared with the specimen of Black Jaguar in the Museum of the Prince of Wied, the head is much smaller, the stature higher, and the form more slender. The Black Jaguar has, besides, well defined jaguar spots and markings all over the body, still darker than the brownish black of the main colour, and is destitute of any white.

In the genus Felis, Auctorum, or Spotted Cats, we think that a distinct variety of Panther has not received due consideration by naturalists, excepting by Eurenberg. It is the Nimr or Syrian Panther (not Leopard), with little more than three rows of irregular roses or circles of spots, and the lower flanks marked with single, or with sets of open spots; jowl, throat, breast, abdomen, and inside of the limbs, white; the tawny colour of the back much mixed with longer whitish hairs. A reverend friend, well known for his long residence in Asia Minor, informed us, that he was present at the measurement of one recently killed, which, from nose to tip of tail, amounted to the length of thirteen times the heavy shoes of a tall and powerful native shepherd: The animal stands high on the legs, has the tail longer than the body, and the head proportionably smaller than the common panther. It is found in the snowy peaks of Ida, above the plains of Troy, and occupies all the high ranges of Natolia, and southward of Libanus.-We take this to mark the transition to a subordinate group of large Felinæ, of which 
- som

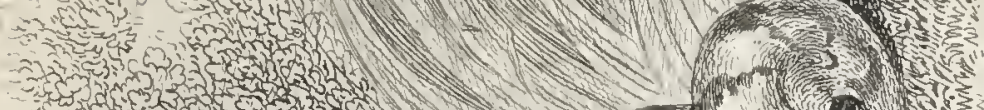

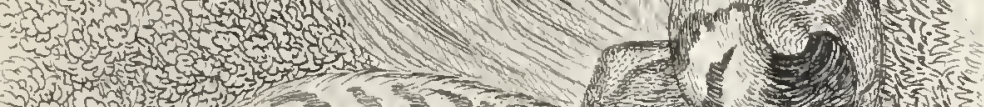

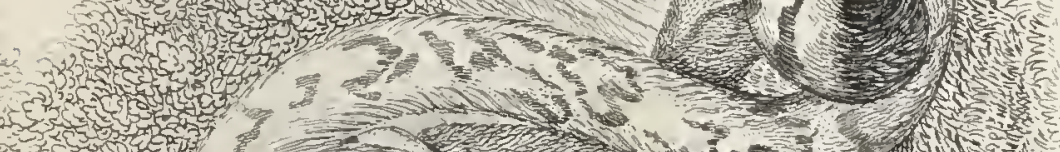

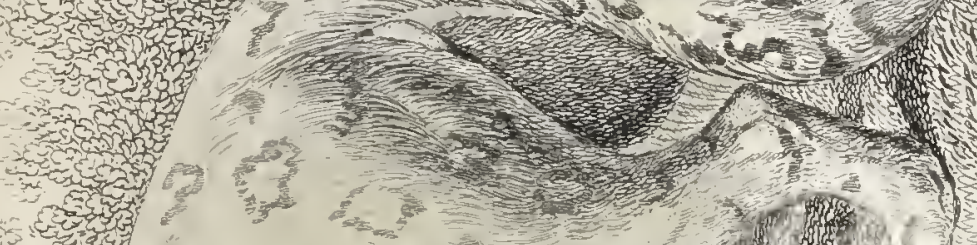

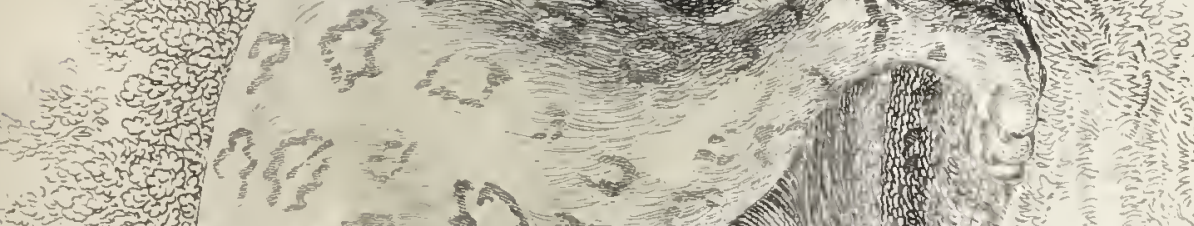

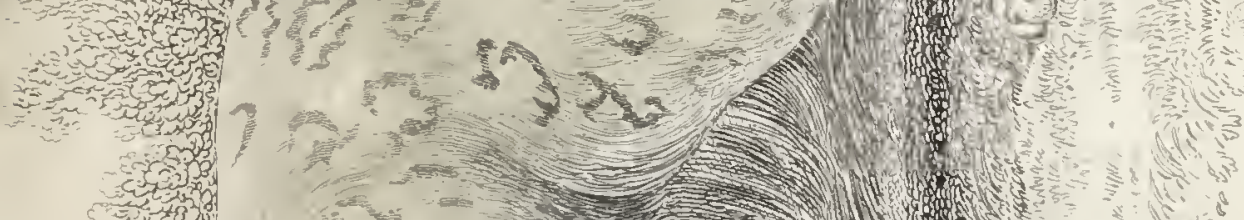

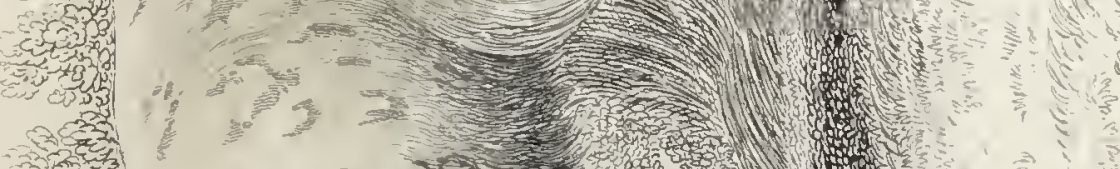

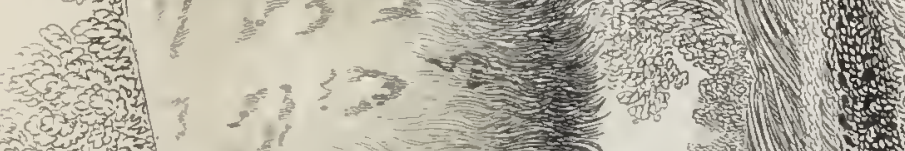

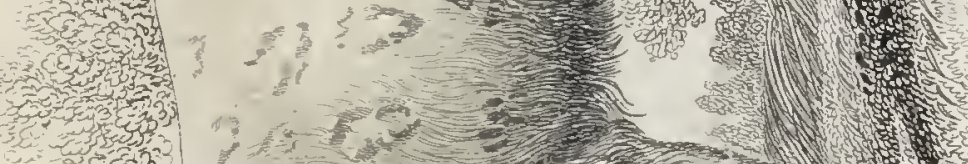

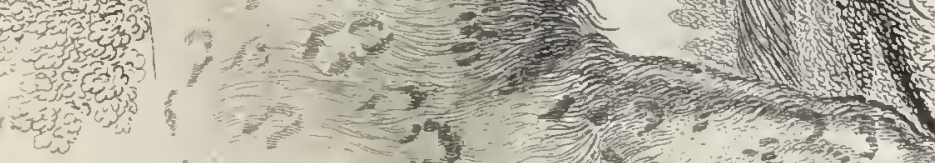

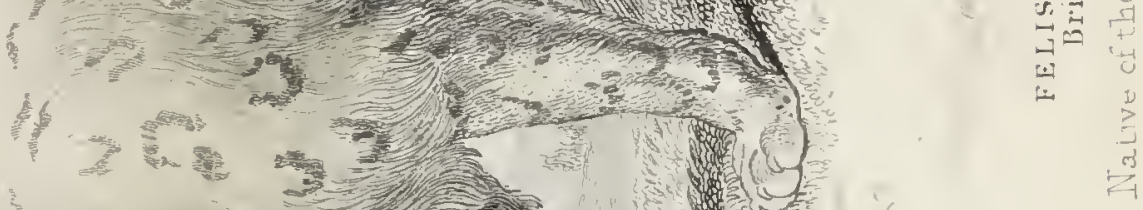

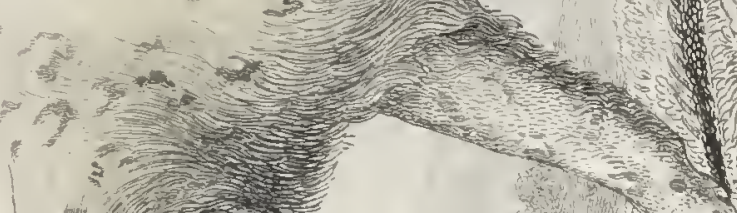

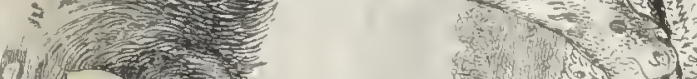

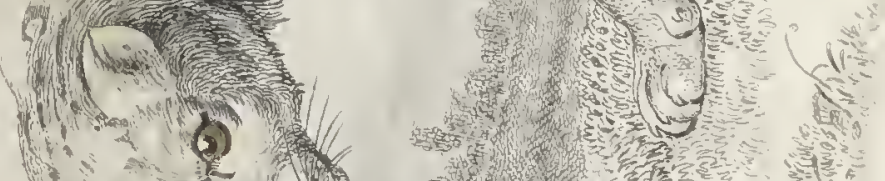
(2) a)

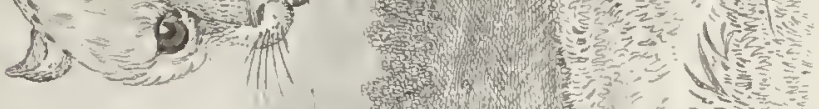
N. (1) 1 (1) H.

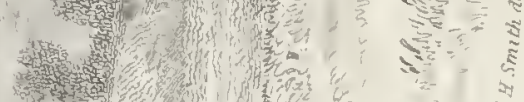
$\leq$ 5 $=8$ 

CARNIVORA.

\section{PLATE III.}

Felis uncica.

Figured by Buffon, and in Griffith's Cuvier, is the type. Although drawn by us from a living specimen in the Tower, and already figured by Buffon, it was by some naturalists not only doubted, but eren denied to exist. There is now, however, a stuffed specimen in the British Museum, to convince the most incredulous. By this the cliaracters common to the group may be fixed; namely, a comparatively small head; short, but powerful limbs; a very long tail, apparently more bushy at the end than at the base, and a system of markings neither striped, nor rose shaped, nor of single spots, but of irregular or angular diagrams, upon a whitish rufous or grey livery.*

Besides the above mentioned, we regard the $R i$ mau dahan, Felis macrocelis, Temm., as a second species, and, probably, Felis nebulosa, Griffith, is a third; we described this before the other was known, from a living specimen in the Menagerie of Exeter

* The figure in Volume II., Felinæ, of this work, is coloured wrong, the fur being white, with very little tawny; that in Griffith's Cuvier was negligently eopied, and the terminal portion of the tail apparently forgotten. 
Change. We have now before us our own and Mr. Howitt's drawing; we have likewise examined the details or separate sketches of the head in different positions; the limbs, and the tail ;* and have noted M. Agassiz's picture, in oils, of that from Sumatra; another we believe by Mr. Landseer; and, finally, that published by Dr. Horsfield; and conclude, unless there be great difference in the size, form, colour, and characteristics of the markings, that they are distinct species.

The Jaguars, of which two very distinct varieties, if not species, have been pointed out, form, we believe, another group, there being a third with irregular or mizzled spots, and a longer face. Buffon's Mexican Jaguar is either the last of this, or the first of the group of Ocelots. The Servals form again one, of which Forster's Cape Cat is a young specimen (not a Viverra); but remarkable for an elevated form of the frontals, and small pointed turned up nose. This is distinguished from the Common Felis Serval, by three virgate streaks on each side the neck, passing upon the shoulder.

Genus Lynchus, Gray.-The Lynxes.-Containing the Short Tailed and Pencilled Eared Cats, which spread furthest north, and are the most robust in structure, and dense in fur, of the whole family. All the species are not as yet clearly distinguished.

* Yet he copied Col. Hamilton Smith's, probably because his own was faulty in the ensemble, as is sufficiently evident in the drawing we liave, where the head is much too darge. 
Genus Cynailurus, Wagler.-The Hunting Leopards are distinguished from all the Felinæ by the imperfect power of withdrawing the claws, which, consequently, are always observed to be worn at the points.

Felis jubata, or the Maned Hunting Leopard, is the type of the group, and occurs wild in Africa, India, and Ceylon; according to Colonel Sykes, Felis vmatica differing in appearance only by being domesticated.*

In a fossil state, the bones of a large feline animal have been discovered in the caverns of Geulenreuth, which Baron Cuvier found to have a greater resemblance to the Jaguars of South America than any other species.

\section{THE MUSTELIDÆ.}

This famil Mr. Waterhouse regards as standing in the same rlation to the Felidce, as do Viverridoe to dogs. "hey have, like the cats, a short obtuse muzzle, bu the skull more elongated, having on either side $n$ each jaw one true molar, the upper being well dveloped, and generally transverse. The

* All the spcimens, whose origin was unquestionable, that we have hithe:o been able to compare, offered a black tip to the tail, and anore silky fur, in those of Asia; a white tip, coarser fur, ad bristly hairs about the neck, in those of Afrita, whose kulls we think comparatively larger. 
false molars in the typical species are $\frac{5}{4}-\frac{5}{4}$, but in some they are reduced to $\frac{1}{3}-\frac{1}{3}$.

Digitigrade mustelidoe, with one tubercular tooth behind the great carnassial of the upper jaw.

Genus Mustela. - Dent. form. $\frac{6}{6}, \frac{1}{1}-\frac{1}{1}, \frac{4}{5}-\frac{4}{5}=34$; muzzle short; animal fetid.

Must. putorius. - The Fitchet, Foumart, or Polecat.-A well known animal. For detailed description, we refer to Mammalia, Volume VII. of the Naturalist's Library.

Must. furo. - The Ferret is considered to be a mere variety of the polecat, for they certairly breed together, and have prolific offspring; the firt, nevertheless, is a native of temperate Europe, and the second was originally introduced from ffrica to Spain, in order to counteract the ravages f rabbits, which, in the time of the Romans, deslated the Peninsula. The Ferret is sufficiently wel known, both in manners and figure, in its pale ellow fur, grizzled with longer black hairs, and in the Allino variety with pink eyes, which we mostcommonly lieep domesticated, or rather captive, fr sporting purposes.

Must. alpina.-The Alpine Foumart - Smaller than the common polecat; head moe elongate, acute; colour sulphur-yellow; chin wite; canine teeth without internal tubercle. Resdes in the Altaic Mountains, and seems to differfrom Must. Altaica only in the length of the tail.

Must. nudipes. - Java Ferret. - Jur brilliant golden-yellow; anterior head and tip od tail white; 
soles of the feet quite naked; total length 16 inclies. Inlabits Java.

Must. Sarmatica.-The Perouasca.-Deep ricli brown; back and flanks mottled with yellow; throat and belly black. Inhabits Poland and southern Russia.

Must. vulgaris. - The Common Weasel. - Reddish-brown above; white beneath; total length $7 \frac{7}{2}$ inches. Inhabits the temperate zone of the northern hemisphere; towards the north it assumes a white livery in winter, and is interesting, on account of the singular boldness of character evinced by them, when roused to fury attacking even man, with a spirit far surpassing the bull dog or the lion, and displaying in quest of their prey a wonderful recklessness, often seizing animals far larger than themselves by the throat, and remaining suspended till their victim drops from exhaustion.

The African variety is double the size; yellowish underneath, with a brown line along the abdomen.

But one of the animals most interesting of this genus, though perhaps not actually distinct, is

Must. erminea.-The Stoat or Ermine.-Yellowish-white in the winter dress, and light brown in summer. In Southern Persia, \&c., the colour never changes; but, towards the north, even in Wales and Scotland, the winter fur is white, with the tip of the tail black. In this state it is the Must. ponticus of Pliny, and is found in the Arctic regions, as far as birch forests extend, spreading over Northern Europe, Kamtschatka, Siberia, the Kurile 
Islands, and the greater part of North America. It is trapped by means of bait placed beneath stones, which drop and crush the animal when attempting to feed; shot with blunt arrows, or in other ways, and is in both hemispheres an article of value in commerce, and important for adorning the dresses of princes, judges, Moslem dignitaries, and chiefs of savages. A century ago the skins were already valued at three pounds sterling per hundred on the spot, in Russia. In Scotland, Norway, Sweden, and Western Russia, the animals are now rare, or much diminished; but from Northern Asia 30,000 skins have been sent in one season, exclusive of what may have been forwarded to Persia and China; and from North America, the Hudson's Bay and the United States fur companies, annually collect at least as many, without reckoning the immense consumption of this peltry by the native Indians, whose chiefs, braves, and even women, adorn themselves profusely with slips of the skin which contain the back and tail, refusing the rest, so that we have reckoned above 200 applied to one single dress. Finally, a considerable traffic in furs, including Ermine skins, is carried on, from the west coast of America, with Japan and China, attesting, notwithstanding the immense numbers of the animal, the importance and value of a commercial article, which the luxury of the ancients did not comprehend, and Western Europe first learned from the Goths.

In severe winters, these animals have been observed to migrate southward in considerable numbers. 
Must. Sibirica.-The Chorock or Siberian Weasel. - Size of a polecat; pale fulvous, darker on the back; muzzle brown; round nose white.

Genus Martes.-Dent. form. incis. $\frac{6}{6}$, can. $\frac{1}{1} \frac{1}{1}$, mol. $\frac{5}{6}-\frac{5}{6}=38$, the additional tooth being one more false molar, and the carnassial, in the lower jaw, has a tubercle on the inner side.

Martes vulgaris. - The Pine Marten. - Total length about 28 inches; tail shorter than the hind legs; brown, with a space of clear yellow under the throat. Inhabits Europe and Great Britain. Does not frequent habitations.

Martes fouina.-Beech Marten. - Total length about 25 inches; 'pale brown, with under part of throat whitish. Infests out-houses; but destroys other vermin. Is found on the continent of Europe.

M. Hardwickii.-Yellowish white; face, ears, cheeks, back of the neck, the fore paws, the whole hind quarter, and tail, brown-black; tail as long as the body. Inhabits the East Indies.

M. Zibelina.-The Sable.-The Sable also of heralds, and Zobal of the Sclavonic nations, is another fur animal of the greatest value in commerce. It is in size about equal to the Marten, with a fine glossy fur in the proper season, and then also deep black, with scarcely any greyish hairs abrut the head, shoulders, and throat; the ears are round; the feet large; the claws white; and the tail bushy. In warmer latitudes it is sometimes of 
a tawny cast, and in Western America of a bright chestnut; in that variety, if it be not distinct, the tail is also shorter, and the ears larger. 'The fur of the animal consists of a downy under-wool, with a dense coat of hair overtopped by another still longer ; this upper covering will lie in any direction, backwards or forwards; and a skin is valued in proportion as this coat is abundant, black, and glossy. They are caught in traps set by hunters, who formerly were convicts or exiles in Siberia, and passed the rigorous winters of that climate in the woods, from before the time the rivers freeze, until they are open to navigation. Their natural habitat is the most northern forests of both the continents, and in the Kurile Islands. Albinism is sometimes observed to affect their colour.

M. huro.-Huron (Weasel) Marten. - Has the paws beneath furred like the sable; is of a light yellow colour ; size of a Marten from Canada.

M. leucotis.—White Eared Marten._First figured by ourselves. Total length about 20 inches; nose rather pointed; ears large, inside pure white, on the outer surface a black edge; lips and cheeks pale brown ; nose, head, throat, and body, deep brown; feet and tail black.

M. lutreola._The Mink.-Total length 17 inches; blackish-brown; upper lip, chin, and beneath the throat, white; feet semipalmate; has been referred to the others, but the teeth are like tlose of Miustelidce: feeds on fish, frogs, \&c., frequenting rapid 
waters in spring, more tranquil rivers in autumn. Is common in Finland, Norway, and Russia to the Black Sea.

M. vison. - The American Mink. - Total length about 2 feet; fur deep brown; under jaw white; feet semipalmate, hairy; tail black.

M. rufa.-Chestnut Mink.-Total length 2 feet 4 inches; bright fulvous chestnut; tail of the same colour; chin white; webs between the toes but little perceptible in preserved specimens. Male and female observed in the museum of New York. Habitat North America.

M. Canadensis. - The Pekan. - Total length about 30 inches: head, shoulder, and upper part of back, grey-brown, clear at first, and darkening, towards the back; the rest of the body, tail, and feet, brown-black; often a white spot on the throat. Frequents the borders of water in Canada and the United States.

We made a drawing of anotlier specimen noted in the Mustelida, without the locality whence we obtained it, but named

M. nigra. - Sable Mink and Fisher Weasel. Having the head and sides of the neck fine grey, and the rest entirely deep black, with a cast of brown; total length about 26 inches. The denomination does not agree with Pennant's Fisher, but mnre with the Sable, excepting that the form of the body, and of the tail, resembles that of a Mink, while the sable is like a Polecat, and the tail is shorter and somewhat tufted. 
M. Pennantii. - Fisher Weasel of Pennant. Fur dark at the base, yellow above, and tipped with black, becoming chestnut instead of yellow on the back; tail shining black; throat brown with a few white hairs; ears short, lighter at tips,

Genus Zorilla.-The name Zorillo, a little fox, was originally given by the Spaniards to the skunk; and Buffon, we believe, applied it to the Cape species, under an impression that it was of the same genus as the American Mepuitis. - Fur barred longitudinally, with two or four irregular black and white streaks; nose short ; two superior false molars, three inferior; claws stout, obtuse.

Zor. Capensis. — Cape Zorillo. - About the size of a polecat; black, with four white bands; head rather round, sometimes with white spot on cheek; tail very bushy; burrows in holes of its own digging. Is found at the Cape of Good Hope.

It appears to be spread over the whole of Africa; and recently specimens, either varieties or distinct, have been sent to England from Trebizond, in Asia Minor.

\section{THE PLANTIGRADES.}

IN classifying the Plantigrade carnassiers, we have felt the anomaly of disconnecting those placed among, the Viverrida, on account of slight modifications of their teeth from the true Plantigrades admitted in 
all modern classification. If, in attempting a natural system, considerations of dentition were alone to be the rigorous elements of construction, no question could be raised on the subject; but the laws of general anatomical structure, although never in real opposition to the dentition of species, in many cases demand and obtain predominant influence, and, we apprehend, should be allowed greater weight than they appear to have, where they are to be viewed solely as confined to locomotion, even in that degree of difference which exists between the Digitigrade and Plantigrade Mammalia; because we find practically, that minor modifications in the teeth, such as occur among the Plantigrade viverrida, keep the several genera so circumstanced, in a location between the Canidae and Felidoe by the side ot Digitigrades with and without retractile claws, even though all the preponderant characteristics of structure assimilate them with the analogues of $U_{r}$ rsida, and yet without disturbing the harmony with the masticatory combinations. The teeth, therefore, to a certain degree, are, in their minor modifications, subordinate to more important organs; and where the predominance is demonstrated, we submit the ordination of systematic connection should be taken from it. Now, appplying this maxim to the three carnassier families of Canida, Felida, and Ursidce, we find that they have each one great and predominant feature of general structure, to which the teeth are subservient rather than sole, or even prin- 
cipal influential organs, since dentitions, with scarce a modification, occur in the intermediate families, and are accommodated to the successive changes of form, till the whole modifying cycle is exhausted; for it takes, within the sphere of combinations, even the retractile claws of Felida, and the nocturnal eyes of Digitigrades, but touches the Plantigrade structure rarely, or not at all, without immediately affecting the whole habit of the species. Thus, all all the Plantigrades can be arboreal, the Digitigrades only so in part: all Plantigrades, however ferocious, even when partially or fully armed with retractile claws, bear evident tokens in their dentition of a more frugivorous habit; thus the influence of general form on character, and even on dentition, is so universal, that in the present instance it appears advisable to give so much more weight to the Plantigrade conformation, as to arrange the whole of the hitherto detached genera from Ryzana to Galidictis, into one connected series with the Ursidce and other groups already admitted in that tribe. But, in the present volume, we find the innovation would require more space than can be spared for the full demonstration of our views; and, therefore, we leave the suggestion to Zoologists in a better position than ourselves for verifying the considerations it involves.

If the transposition were admitted, the Plantrgrade viveridido would form the first family, and might be called Cynarctidie. 
$Y_{\text {Iil }}$ the second, we would propose to include the long-bodied species of Plantigrade mustelida, whose anterior extremities terminate in paws with long non-retractile claws.

\section{THE ARCTOGALID Æ.}

Genus Mephitis.-The Skunks. - Dent. form. incis. $\frac{6}{6}$, can. $\frac{1}{1}-\frac{1}{1}$, mol. $\frac{4}{5}-\frac{4}{5}=34$. The false molars, like those of polecats; the tubercular teeth above nearly equally broad as long; and the carnassial below with two tubercles on the inner side like badgers. Muzzle obtuse; soles of the feet, and fore paws, hairy; claws strong for digging; fur rather coarse, and very long and bushy on the tail; anal glands containing a most fetid liquid, which the animal can eject to some distance. The species are thick-set in form, generally wanting in dexterous activity; occupying holes dug in the earth ; living on birds, eggs, small mammals, honey, frogs, \&c. They enter into human dwellings, penetrate into store rooms and cellars, and, if alarmed by detection, are apt to emit the offensive fluid, which immediately taints bread, meat, vegetables, and even the beer that may be within the walls. We have witnessed the case of a maid servant, seated by the coachman driving his vehicle through a wood, in the State of New York, when a Skunk, crossing the road, failing to spring through a split fence before the horses came up, was alarmed, 
and flung, by what was said to have been a whisk of its rail, the contents of the fetid bag, chiefly upon the clothes of the young woman; and we were assured that the offensive smell could not be entirely removed but by time, although repeated washing and baking in an oven would in a great measure subdue it. Dogs, who have an uncontrollable instinct to worry these animals, no sooner feel the effluvia in their nostrils, than they dig with their snouts like hogs into the ground, and often scratch their noses till they bleed profusely: yet it is said that Skunks, long kept in captivity, are nearly destitute of the offensive faculty. They reside in both Americas, from Canada to Chili.

It is difficult to enumerate the species of this genus, because, like other Carnivora that have the contrasting colours of black and white disposed upon their liveries, the form of the marks, though sufficiently constant in one region, is greatly liable to vary in another, and again in a third; but taking for type, according to Mr. Gray's distribution (a), with tail elongate, hairs sparse, long, and pendant,-

Meplitis (Americana) bivirgata.-The Common Skunk.-We have a species of which we have been enabled to make designs of the adult male and female, and two young; the male about 14 inches long from nose to tail, and the tail, from root to the extremity of long hair, about 10 ; the female somewhat less, and the young little more than five inches, exclusive of about 2 inches of tail. All were pro- 
fusely clothed with jet black hair; but the male had on the forehead a small round space, and on the neck, close behind the ears, a broad one of white, passing backwards to behind the shoulders, where it divided into two, and terminated upon, or just beyond the hips, in the form of the lower limbs of a saltier; the tail, when erect, caused the long hairs to hang gracefully in curves like a military feather, having, in the quantity of black, perhaps a third of white hairs. The female had only two short lengthy patches of white reaching from the neck over each shoulder. The young, a male, had a white spot on the forehead, but on the back there was a short streak half way down, on each shoulder another, and between that and the central one, a small oval of white. The other young was like the mother.

Comparing these with the Chinche of F. Cuvier, we find the same colours similarly distributed on the back, for there the white forms a kind of letter $\mathrm{A}$ or $\mathrm{V}$, according as the animal is viewed. There is no white mark on the forehead, but one beneath the root of the tail, which, further up, is entirely black.

Another Chinche, copied from the Paris Museum, is still the same, but that the white comes over the forehead to the nose, spreads laterally over the thighs, and beneath under the throat, and occupies the whole of the tail. This is like Buffon's figure; thus we find the bivirgate type to pervade most of the descriptions left by travellers, and, practi- 
cally, we have noted no departures from it in any of the museums we have examined, excepting the occurrence of specimens entirely black.* A second species is no doubt to be admitted, consisting of those with more than two longitudinal streaks, which we shall name

Meph. plurilineata, and refer to it the Polecat of Catesby, with nine white stripes; the Conepatl of Buffon, perhaps a made up figure from Catesby's, but marked with six white stripes.

Meph. varians, Gray. - Black, with a narrow white streak on the forehead; large square spot on nape; and two narrow streaks between the blade bones; tail black, base of hairs white. Inhabits Texas.

Meph. Mexicanus. - Fur very soft and silky, black; narrow streak on nose; broad band across the crown; broad vertebral streak, and two narrow dorsal streaks, and small spot on each shoulder white. Inhabits Mexico.

Tail short, bushy, sub-cylindrical, ending with a pencil of hairs.

Meph. bicolor.-Length 15 inches; tail 7 inches; fur soft, short, black; oval spot on nose; larger spot on each temple in front of the ears; broad stripe on each side of the nape and fore part of the back; two narrow stripes between them; two or three cross

* In this species we include the Conepatl of Hernandez, the Chinche of Buffon, the Chinche of Feuillee, Skunk of Kalm, Puant of du Pratz, Zorra of Quito of Humboldt, and probably the Zorillo of Gemelli Carreri. 
rows of small spots on the loins; spot on each side of the tail ; and large pencil at the tip white. Inhabits North America.

Mr. Gray places others, with similar dentitions, under the sub-generical name of

Conepatus. - They have the hind feet large, broad; the bald soles half the length of the feet, oblong, broad, rugose, and warty, rounded behind, scarcely divided into smaller pads; front claws very long; tail short, bushy, sub-cylindrical.

Conep. Humboldtii. - Meph. Conepat. Desm. Black, with some longer shining hairs; broad white band on each side the back, united over the crown; tail very bushy, white, with some of the hairs having long black tips. Var. fur softer, brown, with the white band continued on the base of tail; may be the summer coat. Inhabits the Straits of Magellan.

Sub-genus Marpotias. - Teeth of mephitis; hind feet moderate; bald soles to the heel; front claws elongate; tail rather short; nose acute, produced; fur bristly, close pressed. 


\section{CHIL I SKUNT.}

\section{PLATE XIII.}

Marp. Chilensis, Grar:-Meph. Chilensis, Grofr.

Toral length 1 foot 6 inches; colour deep chestnut brown, with two white streaks on the sides, united on the shoulders, and again connected in the form of a crescent at the back of the head, where it forms a ridge of standing hairs; tail white, mixed with brown, which increases towards the rump, and leaves the white to pass up towards the descending streaks from the shoulders; nose, cheeks, and feet, buff.

Mephitis nasua, of Bennet, and Viverra marputio, Gmel., may belong to this section.

There may be other species in the numerous varieties that are noticed; and even the Coaze of Buffon may be a real Skunk of the brown species, without the white markings, or a large Grison wanting the band on the forehead, such as we have ourselves seen in Guiana.

We form a group of the following genera, which seems to constitute the gluttons of different parts of the world. 


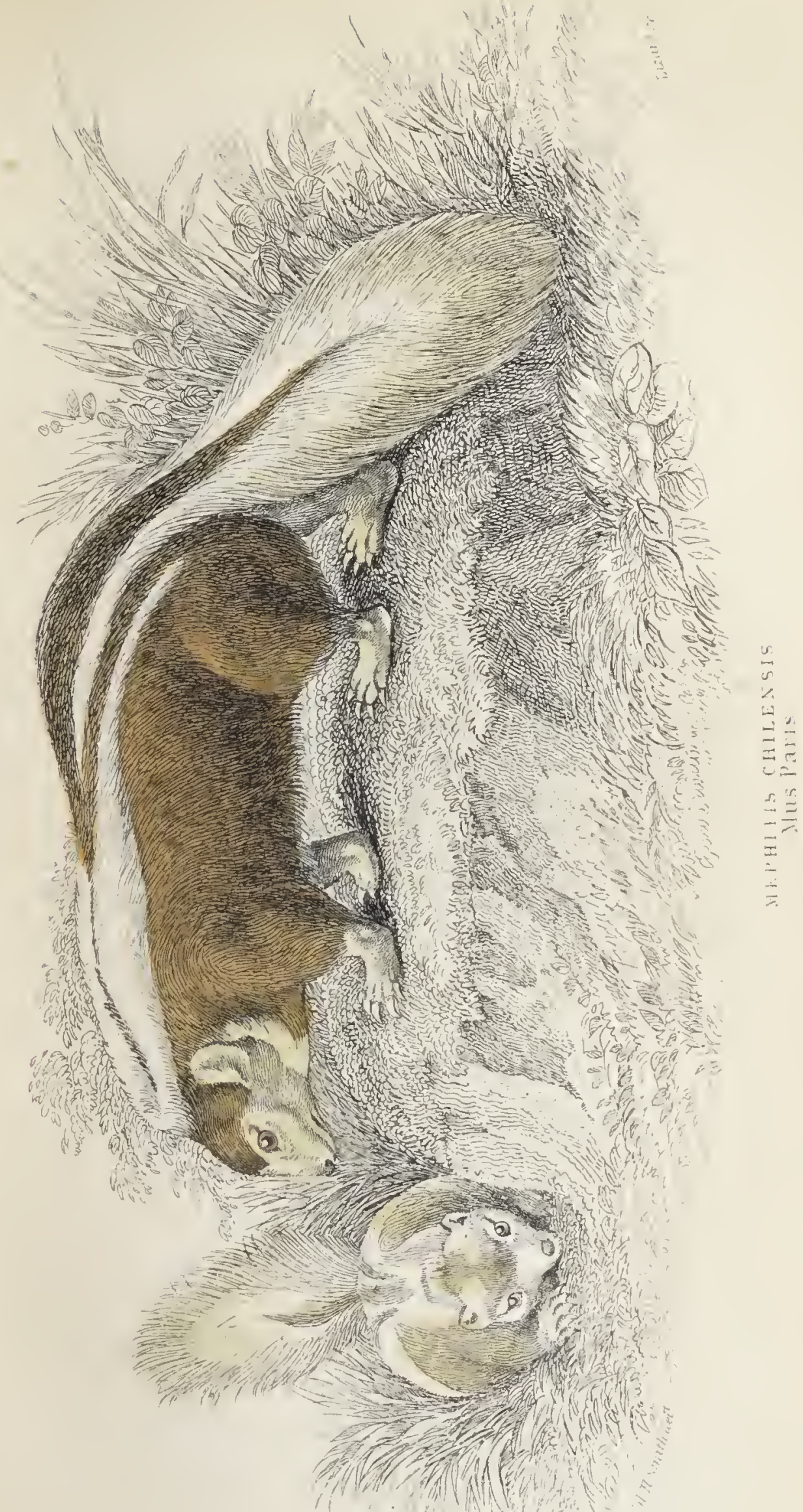



Genus Galictis, Bell.-The Grison._Likewise an inhabitant of the New Hemisphere, and probably of South America only. Dent. form. $\frac{6}{6}, \frac{1}{1}-\frac{1}{1}, \frac{4}{6}-\frac{4}{6}$ $=36$; one tubercular, a carnassial, and two false molars, above; and one tubercular, a carnassial, and four false molars, below; body elongated; ears simple; five toes on all the feet; tail middle sized, not forming a brush; mephitic pouch; hair coars?. 


\section{BANDED GRISON.}

\section{PI, ATE X I V.}

Gaintis vittatu.

A Bout a foot and a half long, and the tail six inclics; the head long, thick, with prominent muzzle ; from forehead to tail grey, by the hairs being annulated deep chocolate and white ; the anterior head, cheeks, sides, limbs, and tail, black; a broad white band passing across the forehead above the eyes and below the ears to the shoulders; the grey on the upper parts of the body increasing in whiteness with age. The species resides in hollow trees, is active in hunting birds and lizards, swims and is remarkably irritable. The white about the forehead we have seen extended over the lips, nose, and around the eyes, but not much beyond the ears. The specimen was not so large (13 inches, tail 7 ) as the first described, with the black less distinctly sepa rated from the liver colour, and another, of the same proportions, was destitute of white, and similar to the young, which are still entirely of a dull chocolate grey, when they have already 8 inches in length. It is the brown variety which may have served for type to the Coaze of Buffon.*

* That is, supposing the fore paws had five toes, otherwise the animal is still doubtful, or unknown. 

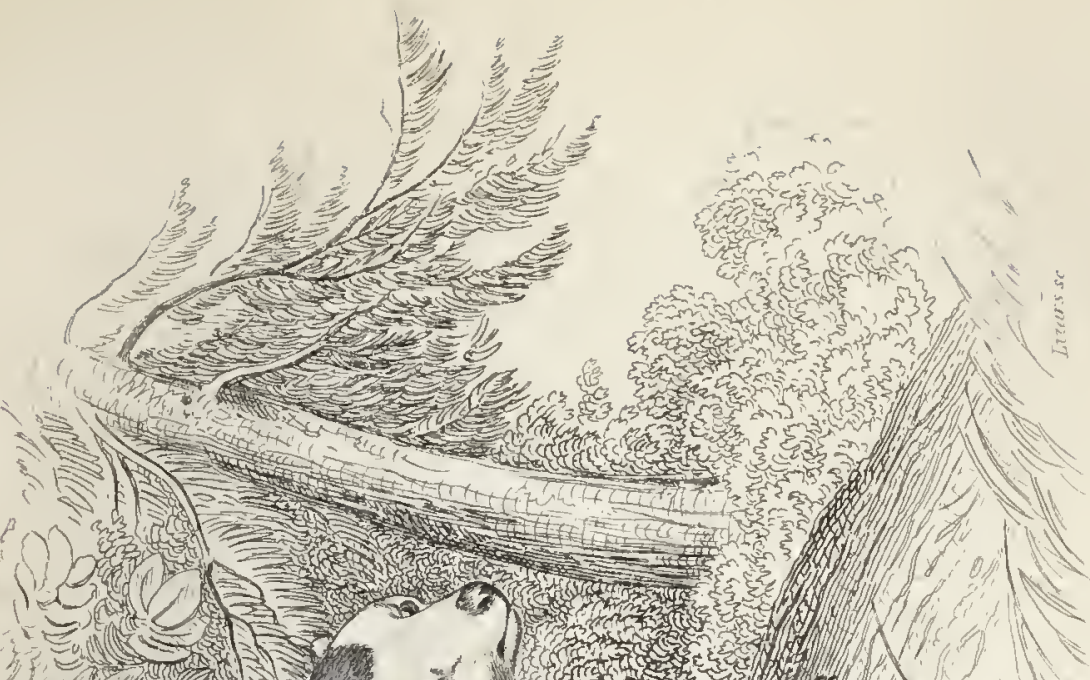

at $=3$

and

Y

x

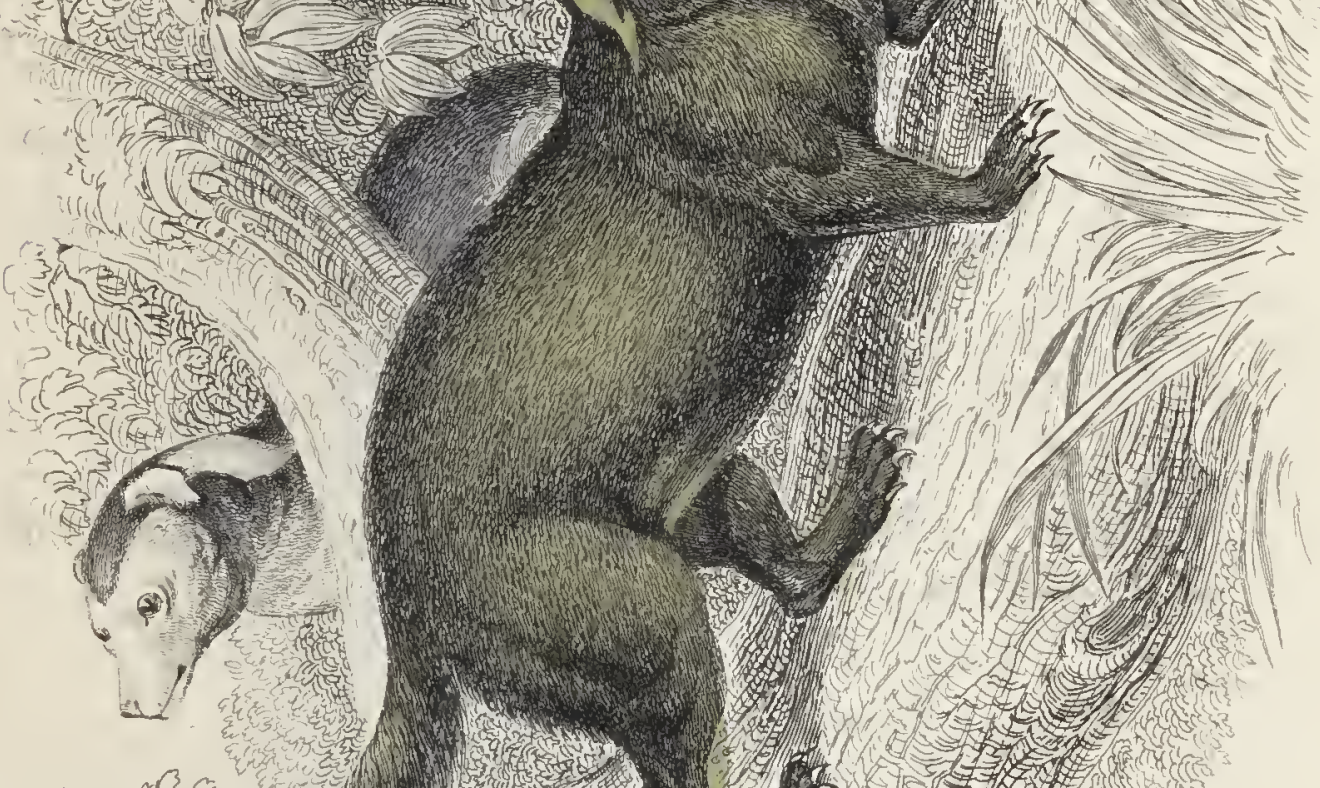

$\begin{cases}3 \\ 3\end{cases}$

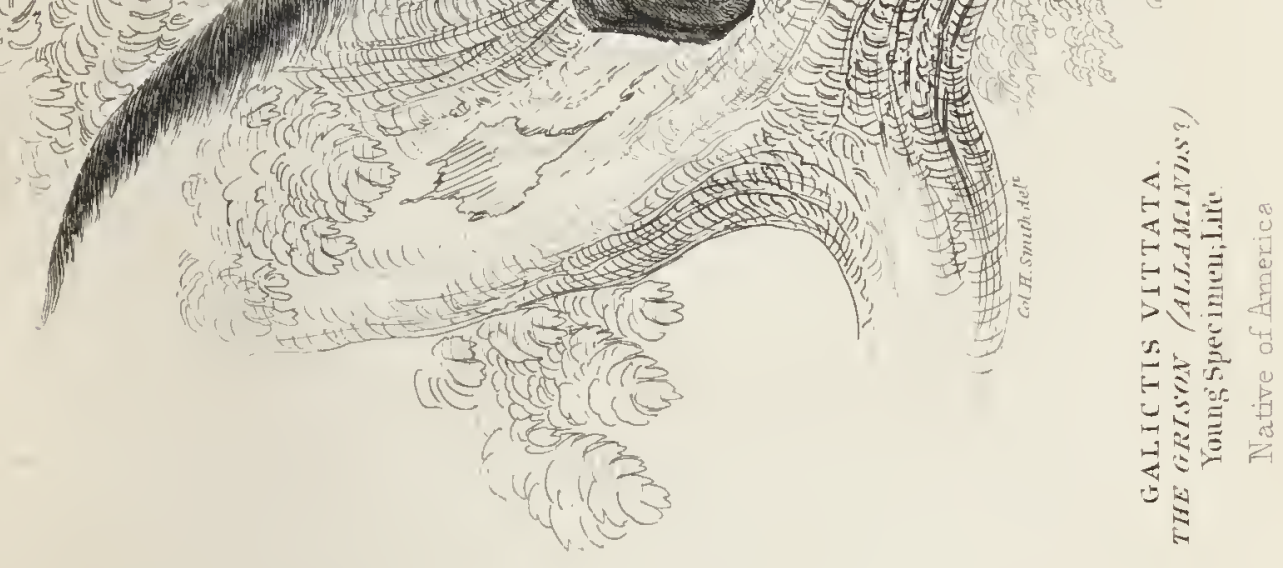



Galic. Allamandi. - Allamand's Grison. - Is a second species, according to Mr. Bell ; but the differences above noted seem to point out mere varieties.

Genus Eira, wherein we intend to include a small group of American Carnassiers, on one side so nearly allied to the Grisons, and on the other to Otters, that they might be referred to that genus, having their lengthened form, and the white heads and throats which are frequent in both genera, and swimming with a facility which is only equalled by their power of climbing trees. The name Eira is itself a generical term, employed for these animals by the Brazilian natives, and has led to considerable uncertainty among Zoologists, because it is not solely used for one species in the country, is not spelt or pronounced alike by different tribes-Taira, Leira, Eyra, Era, being likewise used; and those who have noticed species, have, by inadvertence, or by error in the press, used the name of Guinea as the native country, whereas they should have written Guiana. We believe Mr. Pennant, as well as Brown, fell into the mistake, and so late as 1826 , when Mr. Fred. Cuvier wrote his article Galera, we may still see how much confusion there was remaining on the subject. The dentition is as in the Grisons, incis. $\frac{6}{6}$, can. $\frac{1}{1}-\frac{1}{1}, \mathrm{~mol} \cdot \frac{4}{5}-\frac{4}{5}=34$, whereof in the upper jaw, 1 tubercular, 1 carnassial and 2 false molars on each side; below, 1 tubercular, 1 carnassial and 3 false molars. The toes are always five, armed with strong claws, mostly white; the fingers united to the last phalanx by a membrane; the hind legs 
plantigrade, not equally decided in all; the head is roundish, somewhat Otter like; eyes diurnal; the tongue is rough; the ears small, round; the tail long; there are four abdominal mammæ, but no anal pouch; the fur of two kinds. We doubt whether Mustela lutreola, M. Canadensis, M. vison, and M. rufa, do not, in reality, find a more appropriate location in this genus, they having likewise semipalmate paws, and the rufous mink in particular a plantigrade walk, and in Canadensis the whitish head, which seems to be a distinctive livery of all the true Eiras.

Eira barbara.-Must. barbara, Linn.-The Taira of French writers, Yaguape of the Indians, according to Desmarets not larger than the Marten; similar lengthened form; blackish-brown fur, with a yellowish-white spot on the throat; but there are mixed under this name several species, or at least very distinct varieties. We made sketches and measurements, in the Paris Museum, of a specimen, designated by the name of Taira, which measured from nose to tail, $2^{\prime} 4^{\prime \prime}$, tail $1^{\prime} 8^{\prime \prime}$, making a total of four feet, or double the size of a Marten; it was entirely deep black, with a large rhomboidal spot of pure white upon the throat; the claws strong and crooked; and the sole of the hind feet bare. This species has a strong musky smell.

The so called grey headed civette, Viverra paleocephala, with a grey head, pale buff throat, the colours separated from the dark ashy grey of the neck and body, by a black line, appears to be no, 
other than a variety of the above, and probably identical with the Taira of Bullock's, or London Museum, scarcely differing in figure, and in fur solely that the neck is likewise whitish, but separated by the black line as before. This variety? has been believed to be an Otter, residing in the rivers of Guinea, in Africa, but is South American.

Here we place also the

Eira ilya of Markgrave; Carigueba of the Indians, very correctly, but somewhat coarsely figured in the original drawings of Prince John of Nassau, in the Berlin library. This species, or variety, is entirely blackish-brown, with the head, neck, and throat clear grey; no trace of a black line from the jaw to the shoulder. It is some inches smaller than the first mentioned Taira; burrows, climbs, and was pointed out to us by the Indians of Guiana, swimming, and occasionally diving for prey : at least the grey head, coupled with the foregoing name, was distinctly visible; and no doubt this, or a Taira, was intended by Sonnini, when he mentions the Grey Headed Otters of Guiana.

Comparing these with the Pekan figured in the French Encyclopedie, we take the animal, there represented with a grey head and neck, gradually becoming darker on the shoulders and back, to be the North American variety of the species, badly set up and made digitigrade.

Eira galera, F. Cuv.-.The Galera is in form so like the first ( $E$. barbara), that it may still be only a variety of colour, the head, neck, and throat in 
this being yellowish grey, with a narrow, clear, white line across the throat; the rest of the fur black; length of body $19^{\prime \prime}$, tail $12^{\prime \prime}$, total about 31 inches; height at shoulder nearly $9^{\prime \prime}$.

\section{PLATE XVI.}

Eira ferruginea.*-Gulo castaneus, Griffith's Cuvier.

TiIIs is an aberrant Eira, assuming more the livery of a glutton, but has still the lengthened body and otter head of the genus; is in length at least equal to the Taira; that is, from the nose to the end of the tail about four feet, but in structure much more muscular. With the exception of extremities and tail, which are sepia black, the whole fur is of a fulvous chestnut brown. The specimen was perfectly plantigrade, and the only one we know of existed in the London Museum.

Genus Meldivora.-Ratellus Desm. - There is likewise only one species satisfactorily established of this genus, which represents the gluttons of the north in the southern hemisphere, and in tropical Asia; it is very similar, in compactness of struc-

* Not having been able to examine the dentition of this species, it may still prove distinct from this genus. 

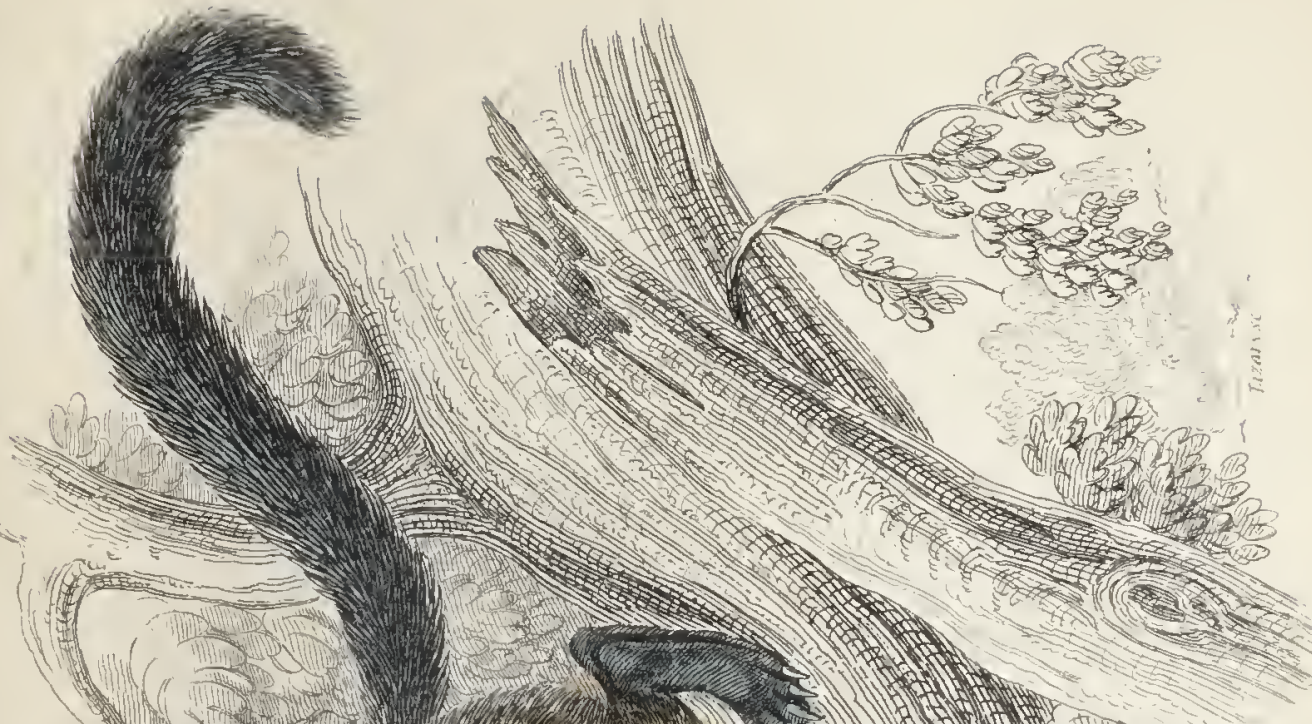

minc $x=2$

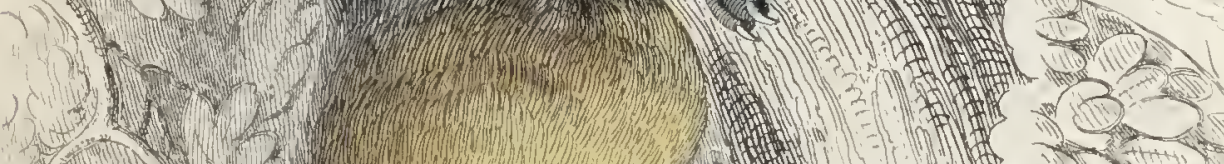

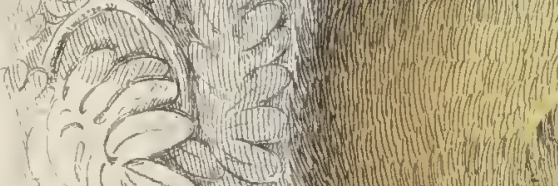 \\ mas}

25

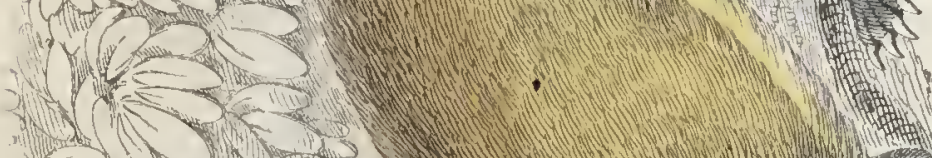
3.1.

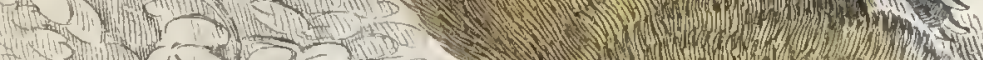

74 H

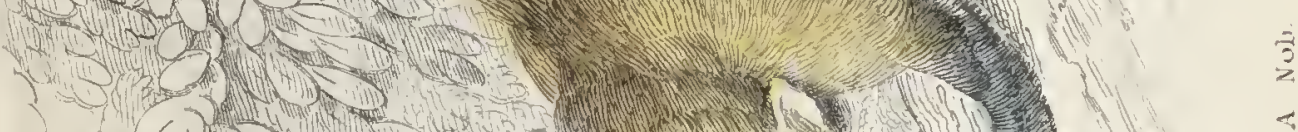

(f mint

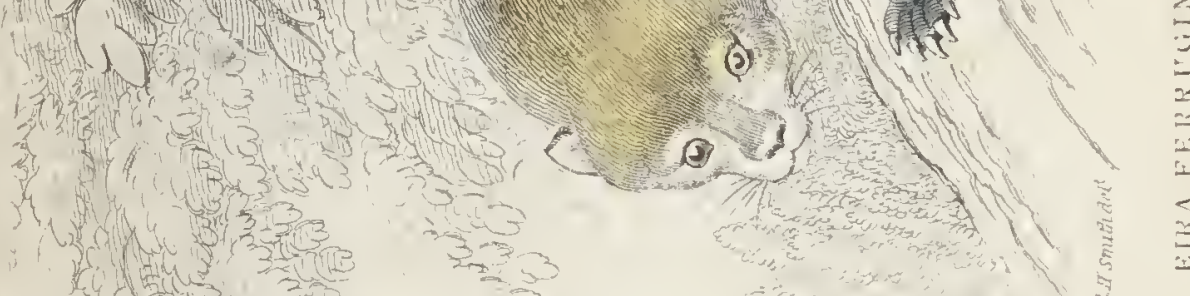

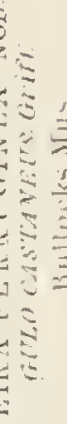



ture: dense and tough skin; but the fur is rather rare, short, and coarse, and the hiảe so loose, that dogs, in biting, can scarcely fasten upon any solid part. It is not a climber, but a most powerful digger in the ground, by means of its strong claws, feeding, it is probable, in South Africa, on all kinds of animal substances and carrion. According to Sparrman, it is a great searcher of honey, and has sufficient instinct to observe the Honey Cuckoo s note, follow his guidance to a nest of bees, and to share the plunder with its feathered partner. In the East Indies, a variety, or perhaps a distinct species, somewhat smaller, is found, and accused of making long and deep subterranean galleries, working its way into the graves of men, and subsisting on the putrid flesh.

Mel. ratel.-The Ratel. - Has the molars $\frac{4}{3}-\frac{4}{5}$, of which two are false on each side in the upper, and three in the lower jaw. Above two feet in length, with the tail one foot; form of a badger, with very small ears; grey on the forehead, neck, back, and tail; beneath all black, with a whitish line separating the two colours, from ears to tail, often forming a patch or band upon the forehead. There appears to be no marked distinction between the Indian variety and the African, and the difference in manners may be merely arising from the observers themselves taking their notices under different aspects and circumstances.

The Ratels offer one more instance of the colours of the fur being light on the upper surface of the 
body, and dark beneath, producing a kind of family livery, alike in this and the Grisons, Taxidea, and Meles, and not obliterated in Eira and Arctonix.

Genus GoLo.-The Glutton.-We retain for the true Gluttons alone the generical name of Gulo, because, notwithstanding the similarity of dentition, they have a more compact and vigorous structure, a short tail, a totally different aspect, different manners, are remote in habitat, and fitted for a very opposite temperature from those we have grouped together under the generical name of Eira. They are, in general form, resembling the badger rather than a marten or an otter, stand higher on the legs, never willingly enter water, and even abandon their prey if it can plunge into a stream while they hang to its neck; though, on all other emergencies, they evince a ferocious tenacity of purpose unsurpassed by any other carnivorous animal. All the Eiras, we believe, are tropical; the Gluttons, probably forming only one species, are nearly Arctic, tenanting, in their greatest state of perfection, in bulk and beauty of fur, the most northern forests of both continents, and becoming rare south of Canada, Sweden, and Poland. Heavy, and rather slow, they have been endowed with considerable intelligence, as is evinced when they are kept in domestication; without it, indeed, although they are by no means select, food for their incessant cravings could not be otherwise supplied. Hunters in both hemispheres agree, that preying on the northern stags and on reindeer of the woods, they can only obtain this quarry 
by carrying in the mouth a quantity of lichen, with which they ascend a tree, crawl on a protruded limo, and drop it, while they lie close and motionless: thus they wait patiently till a deer passes, whicn, stooping to smell at the bait, uncovers its neck from the protection of its horns, and affords time for tine glutton to drop down upon its shoulders, where, fixing the long and formidable claws, the canine teeth are directed at the great blood-vessels of the neck, and there the remorseless brute hangs, regardless of blows from the horns, or of being dashed against trees; and, if no deep water is at hand, he never quits hold, nor fails of destroying his prey in a few minutes. It is said to be but rarely the case that a horned animal is thus caught, because deer do not much frequent woods until their attire is gone; and the elk is said to be protected by the thickness of his mane.* They have an acute sense of smelling, detecting buried food at great depths, and labouring, with prodigious energy and skill, to dig it up, often to the great distress of hunters, who vainly conceal their provisions in what they cali cachés, well fenced with stones, from their depredations. They are no less destructive to the snares of the fur-trappers, whose track they follow, de-

* Although these accounts are discreditcd by recent tra vellers, who have little or no direct knowledge of the manners of these aninals in woody regions, and reason from their condition in the open snowy traets, yet they are the common belief in America, in Sweden, and in Siberia ; and their general sagacity cannot be disputed. 
priving the traps of the bait, by opening it from behind.

Dent. form. $\frac{6}{6}, \frac{1}{1}-\frac{1}{1}, \frac{5}{6}-\frac{5}{6}=38$; characterized like those of Galictis ; the head somewhat dog-like ; ears short, round; body low ; feet pentadactylous, armed with long crooked claws; mephitic pouch under the tail ; fur fine, soft, rather long. Habit not hibernating.

Gulo vulgaris.-The Glutton.-Nearly 2 feet 4 inches from nose to tail; tail, including hair, 8 inches; stature at the shoulder 1 foot; fur iong, brilliant; face dark chestnut; white band across the forehead, spreading on the cheek, and passing down the throat to the breast, marked with black marbling spots; nape and shoulders bright chestnut ; after-body reddish-buff; but the whole breadth of back and loins covered with a deep brown patch; the fore feet and terminal half of tail black. The lighter colours are often replaced by the chestnut, but the white band is seldom wanting.

Gulo luscus.-The Wolverene.-Is probably on 'y a variety, though somewhat larger. A drawing which we made of one in Canada, represents the whole head, neck, shoulders, and a border along the lower part of the sides, uniting at the root of tail, and the basal half, all yellowish-white, leaving a broad space from behind the shoulders backwards, bright bay, darkening to black towards the tail; the feet and terminal part of tail black; toes brown grey; nose grey. This was a female.

Genus Helictis, Gray.-Melogale, Isid Geoff.- 
Dentition $\frac{6}{6}, \frac{1}{1}-\frac{1}{1}, \frac{5}{6}-\frac{5}{6}=38$ : the $\frac{3}{4}-\frac{3}{4}$ anterior molars false, the carnassial above trilobate, with large internal central lobe; tubercular, middle-sized, trans verse, below small ; head elongate; toes 5-5, claws strong, the anterior long, compressed; feet plantigrade, soles naked to near the heel; tail moderate length. The species known belong to Eastern Asia.

Hel. moschata.-Twenty-three inches long, including eight inches of tail; above silvery grey; silvery white at the sides and at tip of tail; head and fore feet brownish-ash; a white streak between and two others near the eyes, with other spots on lips aud near the ears, and the limbs of the same colour. Inhabits China.

Hel. orientalis._Gulo orientalis, Horsf-Eaybrown, a white streak from between the eyes passing over the forehead and neck to the loirs; the orbits; region round ears, lips, throat, and breast, of the same colour.

The next group returns again to the skunks, by the mephitic qualities of Mydaus; but in form, organs of motion, and powers of digging, they associate with badgers.

Genus Meles. - The Badger.—Dentition $\frac{6}{6}, \frac{1}{1}-\frac{1}{1}$, $\frac{5}{6} \cdot \frac{5}{6}=38$; the second incisors placed backwards; first molars above very small, the second and third pointed, the fourth trenchant externally, and the fifth large and tuberculous; below the penultimate the most trenchant; body thick, limbs short, eyes and ears smail ; fetid secretion from a pouch beneath the tail; fur coarse, rather long. 
Mel. vulgaris.-Common Badger.-About $2^{\prime} 5^{\prime \prime}$ from nose to tail, tail $8^{\prime \prime}$, height at shoulder $\mathrm{l}^{\prime}$; head rather long, whitish, with a black streak passing from the nose through the eyes to the ears; colour in general brownish-ash above, black beneath. We have drawn a specimen as red as a fox; white beneath, but with the black bars on the face; five toes, well armed on all the feet; has the manners of a bear; is solitary in the holes which it digs, coming forth only in the night to feed on fruit and animal substances; when young is easily tamed; when attacked, fights obstinately and with great tenacity of life, and therefore is often the miserable victim of the sport of boys, who learn brutality sometimes under the tuition of those whose education and position in life should have taught them better. The species extends over all Europe and the north of Western Asia.

Sub-genus Taxidia. - Is the Badger of North America, separated from Meles by Mr. Waterhouse, on account of the difference in the greater expansion of the occipital region of the skull, which is also the most elevated: the want of the first false molar of the lower jaw, the greater size of the carnassial, \&c. The dentition, therefore, is $\frac{6}{6}, \frac{1}{1}-\frac{1}{1}, \frac{4}{4}-\frac{4}{4}=32$.

Tax. Labradoria.-The Carcajou or American Badger, stands higher on the legs than the common badger. The head is shorter, and the fur being long, full, and rather fine, it appears smaller. In both sexes (we describe from a living pair) the head is white, with a black bar down the jowl from near 
the ear, and two others longitudinal, first encircling the muzzle, passing upwards between the eyes over the nape, and gradually changing to a fine grey, reunite on the middle of the back, having, the whole distance, a broad white space between them, broader and more intense in the male than in the female; the back itself is silvery grey, changing on the sides to pale yellow; the tip of the tail and the four extremities are black, each with five toes, and all armed with powerful long claws. The pair was harmiess to visitors, and had no offensive smell. There is a Californian variety, with darker colours and finer fur, which may be the Tlacoyotl of Hernandes.

Sub-genus Ursitaxus. - Bear Badger.-Formed by Mr. Hodgson, and described by him with teeth $\frac{6}{6}, \frac{1}{1}-\frac{1}{1}, \frac{4}{4}-\frac{4}{4}=32$; the molars strong, broad, low, and furnished on the crowns with obtusely conical processes; the tubercular of the upper jaw transverse, narrow, sub-parallelogrammatic; smalier than the carnassial, and essentially a grinder; no tubercular in the lower jaw. The author indicates a species from the Himalaya mountains, in the 19th volume of the Transactions of the Asiatic Society, and in the Journal of the Asiatic Society of Bengal.

Sub-Genus Arctonyx, F. Cuv. - Balisaur, or Sand Hog. - Has the skull more expanded than Mydaus, and in that character approaches more to Taxidea. Dent. form. $\frac{6}{6}, \frac{1}{1}-\frac{1}{1}, \frac{4}{4}-\frac{4}{4}=32$; the false molars are one less in the lower jaw, and those that remain are smaller; the carnassial and true molar nearly correspond with those of the badger; the 
carnassial above triangular; below long; the molar above large in plane, rhomboidal, below almost tubercular; the canines are much compressed, long, and turned outwards.

Arc. collaris._Collared Sand Hog.-Is classed by Mr. Gray with Mydaus; both have in truth a hog snout and plantigrade walk, with but little difference in dentition; but the present species has a somewhat lengthened tail, beset with a few bristles; does not appear to be mephitic, and is, in aspect, between a small bear and hog; not like a badger. The animal is about 21 inches in length, exclusive of the tail, which measures above 9 inches; there are five toes, terminated by very strong and crooked claws on all the feet; the ears are round; movement rather slow, and habit burrowing; the fur is yellowish-grey, rare and coarse; a dark band passing from the commissure of the mouth through the eyes and ears, then bending down to the middle of the shoulder, and at an acute angle returning upon the breast, where it meets that from the opposite side; within this space the hair is yellowish; the limbs are black. The species eats animal food, but prefers fruit; sits up like a bear in defence, and grunts somewhat like a hog. Is found in the Himalaya range. Mr. Gray figures another specimen, destitute of black marks.

Genus Mrdaus.-Telagon.-Dent. form. in. $\frac{6}{6}$, can. $\frac{1}{1}-\frac{1}{1}$, f. mol. $\frac{2}{3}-\frac{2}{3}$, car. $\frac{1}{1}-\frac{1}{1}$, mol. $\frac{1}{1}-\frac{1}{1}=34$; the incisors in a curved line; the carnassial and true molar sub-quadrangular; snout prolonged, hog-like ; tail very short; ears small; round; claws 5-5. 
$\stackrel{5}{5}$
$\stackrel{5}{5}$

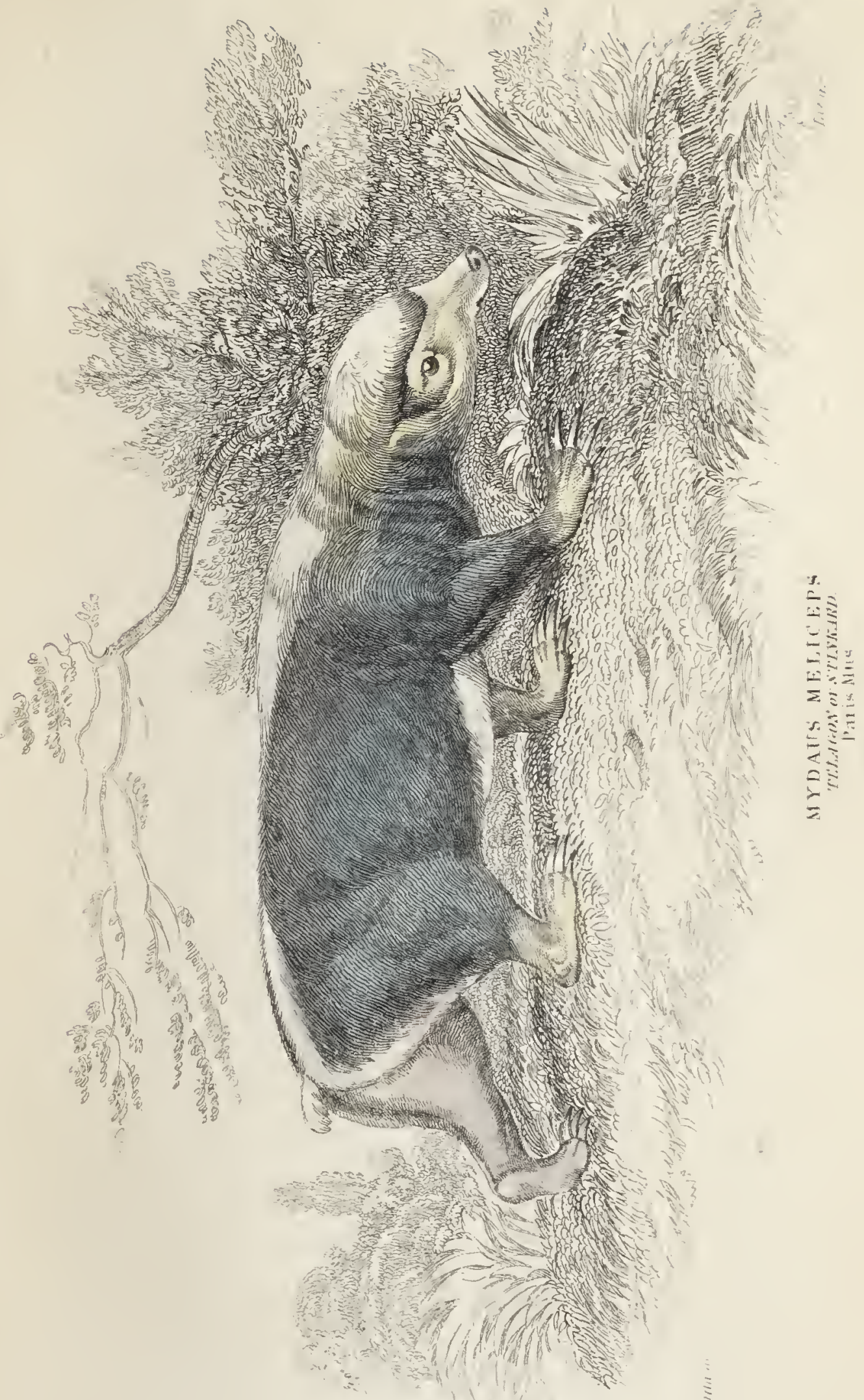



TELAGON OR STINKARD.

PLATE XV.

Mydaus meliceps, Cuv.

Aвоuт 18 inches total length; deep brown, head almost bare and buff; from forehead to croup a broad white streak, sometimes interrupted; tip of tail and claws white. Is found in Java and Sumatra; mephitic; burrowing.

\section{THE URSIDE}

Have the true molars nearly of equal size, remarkably tubercular in structure, the tubercles being more numerous, more elevated and pointed than in the former genera; the limbs are longer, causing the animals to be proportionably much higher at the shoulder; and the fore feet more completely plantigrade, as well as the hinder, are all pentadactylous, and armed with strong claws.

Genus Arctictis.-Ictides of Valenciennes.Dent. form. $\frac{6}{6}, \frac{1}{1}-\frac{1}{2}, \frac{5}{5}-\frac{5}{5}=36$; no anal pouch; feet 
plantigrade; claws semi-retractile; tail prehensile, very strong; eyes nocturnal; ears pencillated; fur long.

Arct. allifrons.-The Benturong, Raffles.-Of the proportions of a large cat; tail longer than the body, very thick at the base; fur long, grey, or mixed white and black; on the head and limbs short; the forehead, nose, and often a great part of the head, white; legs and tail blackish. Native of Bootan and Northern India.

Arct. Niger.-Black Benturong.-Larger than the former; pencils of the ears very long; nose and face flesh colour; some grey on the forehead; the rest all black.

Genus Arlurus.-The Panda.-Dent. form. $\frac{6}{6}$, $\frac{1}{1}-\frac{1}{1}$, f. mol. $\frac{2}{3}-\frac{2}{5}$, car. $\frac{1}{1}-\frac{1}{1}$, true mol. $\frac{2}{2}-\frac{2}{2}=38$. Might be viewed as the racoon of Asia, their canines being similar; but the five claws on each fore paw are slightly retractile. 


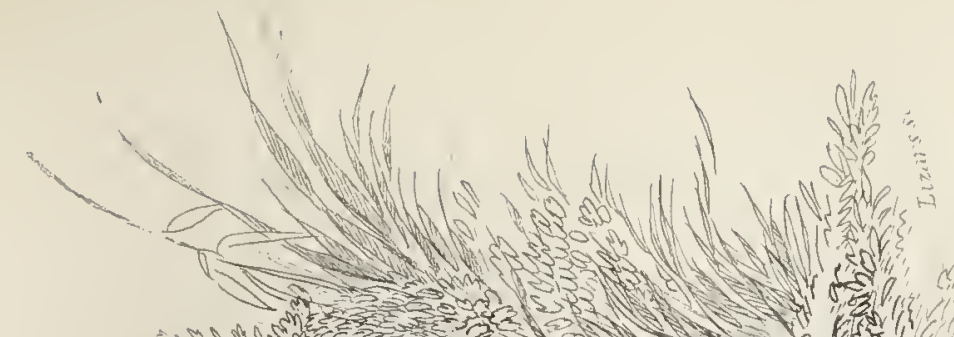

3 MMm

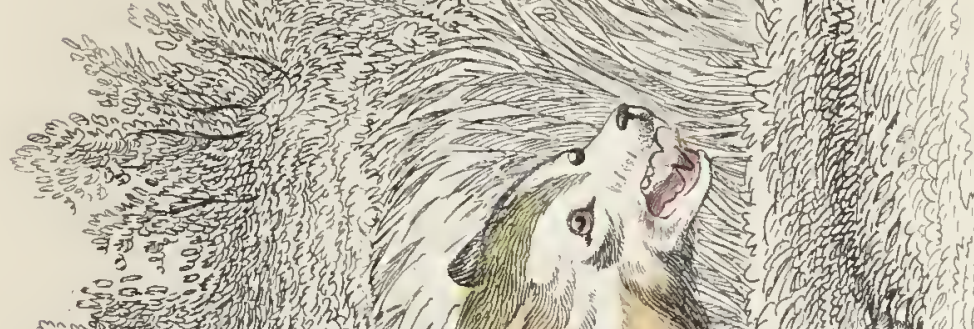

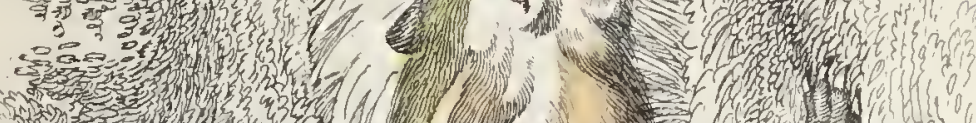

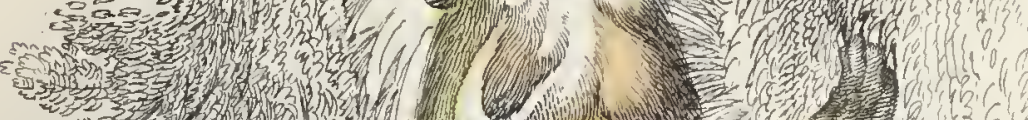

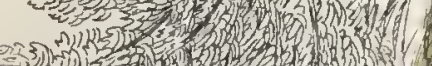

3. -2 z

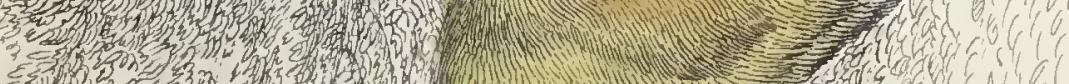

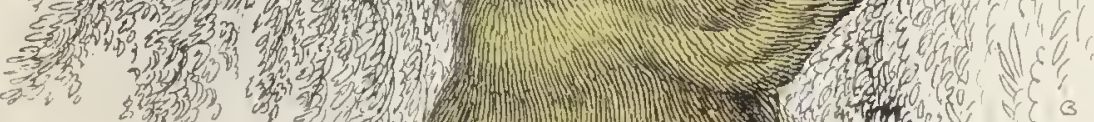

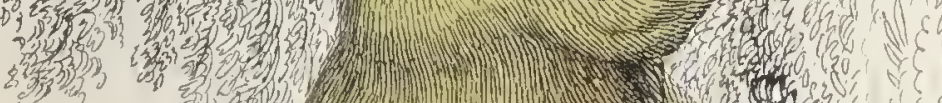

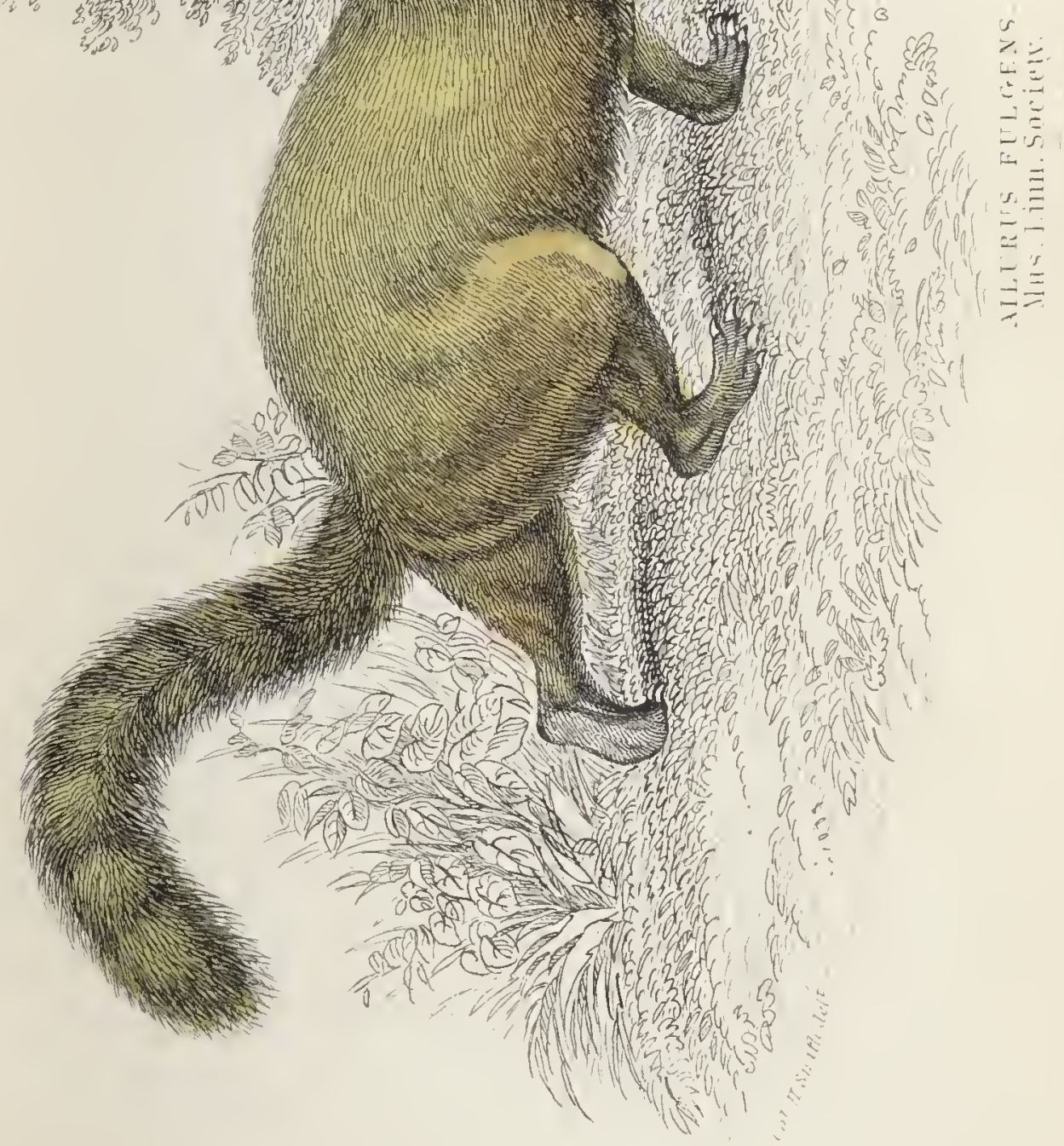



Is in size equal to a large cat, with a dense fur; above golden fulvous, more red on the shoulder, and below dark sepia; the head short, whitish on the sides and forehead; the tail rather long, very bushy and obscurely barred with brown. Inluabits the forests of the lower Himalaya range.

Genus Cercoleptes._-The Poto._The Kinkaiou of Buffon may represent, in the Western World, the Arctictis of the East, both having plantigrade feet and prehensile tails. Dentition $\frac{6}{6}, \frac{1}{1}-\frac{1}{1}, \frac{5}{5}-\frac{5}{5}=36$ : the upper molars with flattened crowns, show a decided preference for vegetable diet, although known also to suck the blood of animals, but scarcely to eat them. Mr. Pennant, under the name of Mexican Weazel or Kinkajou, describes a true Cercoleptes; haring by inadvertence skipped a line in translating Buffon, where the naked flesh-coloured skin applies to the hind feet, and not to the tail, as the English version represents it.*

* Elle est grosse (la queue) à l'origine du trançon et va en diminuant imperceptiblement, et finit en pointe à l'extremité. 
The Potos inhabit tropical America, and are the size of a domestic cat; nocturnal; in confinement gentle, sit on their hams, and use the fore paws like squirrels; with the tail they can draw to them a weight nearly equar to themselves. it is doubtful whether there be more than one species; $M r$. Martin, however, by recent comparisons, establishes two.

Cer. megalotus.-Long-eared Poto.-With ears narrow, elongated, rounded at tip; general colour deep reddish-yellow, with an obscure band of darker colour, almost chestnut along the head, spine, and tail ; sides pale, but throat and abdomen nearly as dark as the back; and similarly marked with a band from breast to croup; tail slender; hair very rigid.

Cer. Brachyotus.-Broad-eared Poto.-Fur full, soft, moderately long, entirely glossy yellowish-grey, clouded with brown, especially over the nose; top of the head, back, and abdomen, dusky straw colour; ears broad, short, and rounded.

Genus Nasua.-The Coatis.-Are a kind of miniature long-tailed bears, of South America, with the nose in form of a snout, much elongated and singularly moveable. Their semi-palmated feet have five toes, and are armed with powerful claws, which serve both for digging and for climbing. Dentition $\frac{6}{6}, \frac{1}{1}-\frac{1}{1}, \frac{6}{6}-\frac{6}{6}=40$. Tail long, bushy, not prehensile; body lengthened. The species are nocturnal, active, Le dessons des pattes, qui est sans poil et couleur de chair vermeille.-Buff. Hist. du Glouton. 
omnivorous, feeding greedily on bird's eggs, which they find in trees, and no less pleased with earth worms, rooted up with the snout; they descend from trees head foremost, by turning the hind feet outwards. The Coatis have a strong disagreeable smell.

Nasua socialis of the Prince of Wied, includes both the following, -

Nas. rufa. - Rufous Coati. — Somewhat less in size than a domestic cat; almost entirely bright rufous; the muzzle greyish-black, with three white spots about each eye, but no white streak down the nose; ears and lower part of limbs black; tail with eight or ten dark brown spots, lips, chin, and throat, white. They live in the deepest forests of Brazil, forming small troops or families, from six to eighteen; and, in danger, caution each other by a shrill warning pipe.

Nas. fusca.-Brown Coati.-This species is properly the Quasji of the Dutch ; in Guiana, the word more properly pronounced quastje, denoting a droll fellow, a pantomime, clown, which, in truth, is not inapplicable to the ludicrously meddling, active, climbing, inquisitive character of the animal, when in captivity. In size. the brown is equal to the former, but the fur on the superior parts of the body is deep brown, dun, grey, or even orange yellow; below orange grey; there are three white spots round each eye, and a white streak passes down the forehead; the nape grey; the extremity of the feet 
black; and the tail annulated with about six rings, having the tip black.

Nas. solitaris, P. of Wied.-The Coati Mondi.Larger than $N$. socialis, measuring from nose to tail $1^{\prime} 11^{\prime \prime} 2^{\prime \prime \prime}$, and the tail $1^{\prime} 9^{\prime \prime}$; total length, 3 feet 8 inches 2 lines; the tail proportionably shorter than in the former, and the snout fuller: the teeth much stronger ; in manners, the greater part of the year entirely solitary; not frequenting the smaller forests, and seldom seen even on the borders of the primeval woods. This species does not dig, but secures one or more places of rest, and hunts by day alone, feeding on fruit, insects, worms, eggs and birds. Whether mice, or other small mammals are objects of prey, is doubtful; but the search after food is undertaken sedately, ascending and descending a tree without the petulant haste of the social; and, in captivity, the character is still evinced in a greater capability of education; more docility, but also confidence in personal powers, and proneness to revenge and resistance. In this respect, a single house dog is no match for him, and even two sporting dogs cannot master a full grown animal in the open wood. Dr. Rengger had one of his dogs killed, by a single bite opening the carotid artery; and in the same moment another, who already endeavoured to escape, had the tendon of the heel cut through.

The face is nearly black, but with the usual three white spots about the eyes; no white streak on the 
nose; the chin black, but the edge of the lower jaws white; ears black, with grey edges; the hair of the head, neck, and back, flanks and extremities, to near the feet, grey at the root, is brown, with a citron yellow tip; and hence, in different lights, the colour is yellowish-brown, or brownish-yellow; on the under parts the colour is more reddish; the tail is marked with seven alternate rings of yellow-brown and brown-black; no great variation of these colours is recoráed. 


\section{PLATE XVIII.}

Nasua monachus.

A specimen, which we drew from life, measured from nose to tail $2^{\prime} 3^{\prime \prime}$, the tail $1^{\prime} 4^{\prime \prime}$, total length 3 feet 7 inches: the nose, lips, and lower jaw, were white, that colour passing upwards to between the eyes; the three usual white spots were present, and the white of the throat passed up the jowl, covered the temples and space round the base of the ears, and hairs within them; it came down the breast, and went round the arm above the elbow : the neck, shoulder, and upper arm dirty ochry-grey; the cheeks, forehead, back, flanks, under parts, thighs, and base of tail, deep sepia-brown; the four legs and paws, with the rest of the tail, pure black. See the Plate. We will designate it by the name of Nasua monachus, to mark its sober monk-like livery, as well as the steady and sedate mode it had of moving and eating, so different from the petulant activity of Nasua fusca. The species is certainly allied to $N$. solitaris; but we doubt the identity, because, in the variations of its fur, we find none to correspond with the above, or with the dimensions here given, the tail being still shorter. 


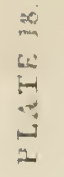



Genus Procyon.-The Racoon.-This constitutes another form of American plantigrades, with manners, locomotive organs, and dentition, not far different from the preceding, but possessed of one characteristic quite peculiar, and that is, the habit of moistening with water whatever it uses for food; the practice must, however, be taken in a restricted sense, since, in a wild condition, Racoons often finding their prey in trees, cannot possibly be believed to descend for the purpose of washing it. Their dentition is $\frac{6}{6}, \frac{1}{1}-\frac{1}{1}, \frac{6}{6}-\frac{6}{6}=40$, whereof the three first molars are pointed, the three following tubercular. They are robust, and in habit nearest approaching true bears, though their limbs are comparatively slender; they have the tail shorter by nearly one half than coatis, still ringed like them, but the cranial part of the head is much wider, and their legs comparatively higher. The native Indians call them by names denoting depressed dogs. In captivity they become tame and playful, but never domesticated nor particularly attached; they ascend trees with the greatest facility, and, in North America, are an object of sport much relished. The species most commonly seen, is the

Procyon lotor. - 'The Common Racoon of North America. - It is a tenant of the woods and plains, abounding in trees. The fur is usually of a deep greyish-ash, produced by the different coloured rings on each hair; below, the colours are lighter, in this respect departing from the common livery of Ursidce, whose limbs are usually dark; the face is 
whitish, with a broad blackish streak or band passing across the forehead, and descending on each side to the angle of the jaw ; the tail has five or six rings of brownish-black, interchanged with as many of a lighter colcur. We have drawn a specimen at New York, which was rufous-grey like a fox, with muzzie, limbs, under surface, and the lighter rings of tail, nearly white. The Californian have often much bright rufous about the limbs and in the rings of the tail, and we have heard of a case of albinism. A full sized Racoon measures, in our notes, about $2^{\prime} 8^{\prime \prime}$, the tail $10^{\prime \prime}$; total length 3 feet 6 , and in height at the shoulder 10 inches. The species is nocturnal, although the pupils of the eyes are round. Like most of the Carnivora of America, it will feed on fish and mollusca.

Procyon gularis. - Black-throated Racoon. - Is described, by Desmarets after M. Beauvoir, as smaller, with a longer tail and narrower head than the common. A specimen which we examined alive in the State of New York, was larger than that whose dimensions are given above, and differed by the colours being in general darker and lighter; the whole throat was black, and the tail, not more than 8 inches long, was equally thick to the end. We were told that the two varieties are never found together. 


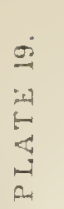

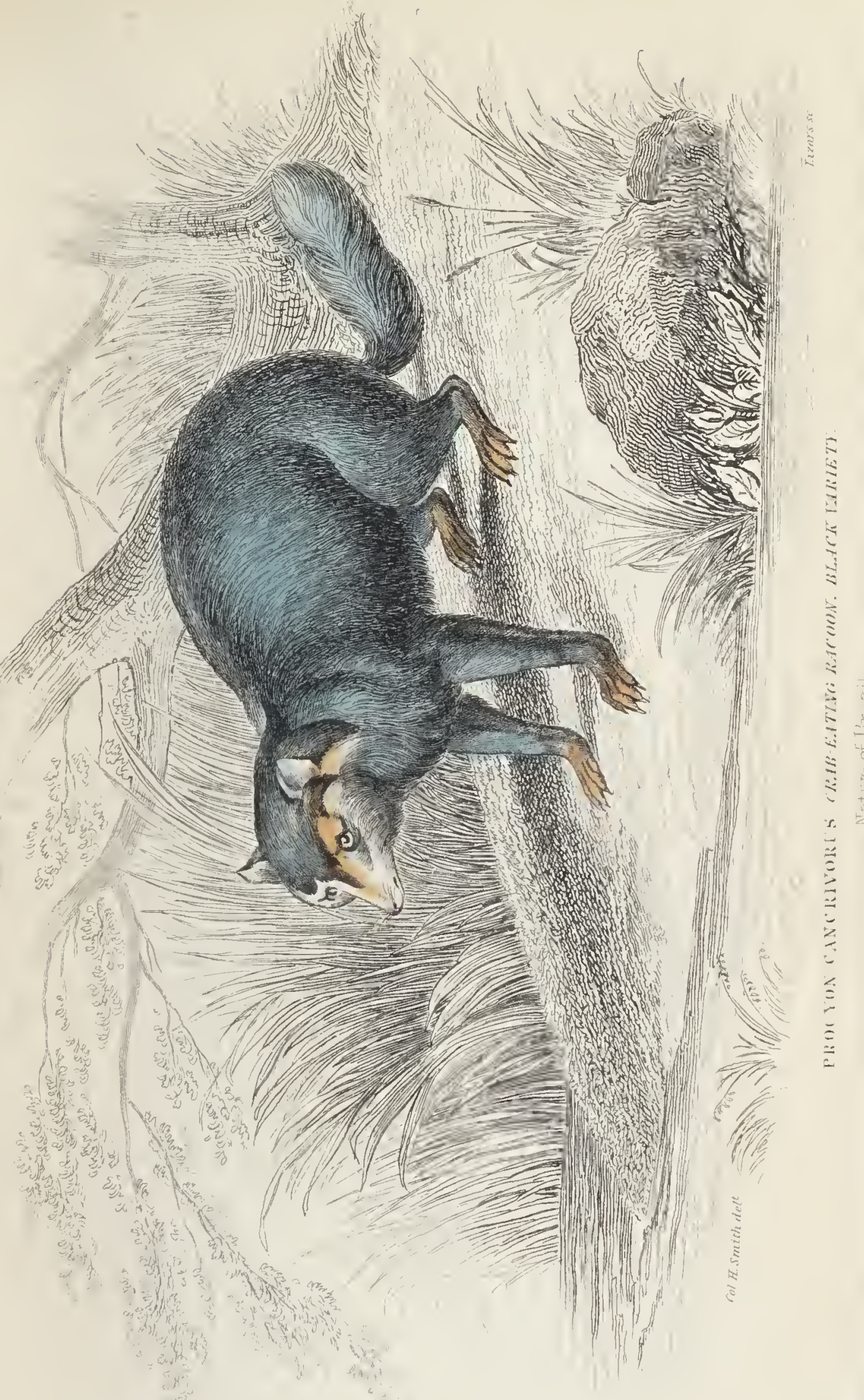





\title{
CRAB-EATING RACOON.
}

\author{
PLATE XIX.
}

\section{Procyon cancrivorus.}

Is the Aguarapope of the Brazilians. The fur is fulvous and grey, with dirty white limbs and face, the same blackish marks on the forehead, and round eyes, and rings on the tail less distinct. We have once met this animal in Guiana, with the fur very short and close, and the tail covered with close hairs; and we have another drawing of one with the hair long, and even undulating like a bear's in winter; the tail very bushy, and the whole pure black, excepting on each side the ridge of the nose, and the fore paws, which were rust colour. This specimen was inferior in size to the adult cancrivorus. The Crab-eater is about $2^{\prime} 6^{\prime \prime}$ from nose to tail, the tail proportionably longer is $\mathrm{l}^{\prime} 3^{\prime \prime}$; total 3 feet 9 inches; and the animal is also taller, being about $l^{\prime} 3^{\prime \prime}$ at the shoulder.

The species occupies all South America east of the Andes, for the mammalogy to the west of that chain is scanty and generally different; it does not frequent high forests, still less the plains, but trees and regions along watery places. His food is pro-- 
bably quite similar to that of $P$. lotor, but that the more abundant rivers in the south, and a peculiar crab very common in all, has made it believed that this object is the principal and most desired prey.

Genus Urisus. - The Bears. - We now come to the most important group of the Plantigrades, claiming attention no less on account of the bulk, the ferocity, intelligence, peculiar manners, and raried extent of habitat of the several species, but also for the economic use to which their flesh and skins are applied, and the mystical and awful faculties rude nations in both hemispheres, and in every climate, have been prone to ascribe to them. The genus Ursus, now divided into four groups, is composed of species, all of which possess considerable sagacity, and, probably, without exception, are omnivorous: in general, flesh and blood are not objects of predilection, but fruit, vegetables, and, in particular, honey. Bears, of all mammalia, are the larges animals still possessed of the facility of climbing trees, only one or two species appearing to be denied the power after their full growth, or not in want of it, because no trees grow in the localities assigned them.

The genus in possession of the whole Northern ITemisphere, from the pole to the tropic of Capricorn, and not even excluded the high mountain regions below and beyond the equatorial line, is represented by a secondary type, particularly appertaining to the dense intertropical vegetation of the low lands in several of the great Australasian 
islands, and thence spreading to the higher peaks of the same latitudes, appears to extend on the continent, through the forests, to the high lands of Indo-China.

In these regions, where the ratiocination and legendary knowledge of the natives is apparently a result of total disconnection with the races of man on the north, the indigenous bears have caused similar mystical impressions to arise with those which we know to exist alike among the red men of America, the yellow Mongole of Tartary, and the ruddy Christian of Arctic Europe. Unquestionably these notions are a consequence of human fear, endeavouring to investigate the real and supposed phenomena observable in bears, such as the power of sitting, and for a few paces walking erect; the propensity of suffocating in their fore paws such of their enemies as attack them; the expressiou of their eyes, evincing thought and a settled purpose more than malignity, but changing to a menacing spectral appearance when the white nictitating membrane is half drawn across the eye ball. Nor is the voice without peculiar power of impression on the imagination, sometimes resembling the ravings uttered by human brutality in the last stage of intoxication, proffering sounds which the ear would fain attempt to catch, as if they might be connected with articulate words in an unearthly language, changing into growls deep and threatening, or forming rapid nasal ejaculations, indicating an anxious but direful intention. If to these we add occasional 
ferocity, and constant tenacity of life, strength that can lift a dead horse into forks of trees, and an unaccountable but universally asserted habit of not attacking a sleeping man, we may infer, though other particularities might be added, that these are sufficient elements of awe and wonder, associated with the idea of bear, to create all the legends and opinions entertained on the subject.

It would be, lesides, a mistaken view of nature, if among the Carnivora, species of such strength, so much sagacity, and among themselves of sociability, species which have not an imperative call to shed blood, but can subsist with satisfaction on vegetables, and, in autumn, are often excessively fat, we should not find occasional traits of forbearance, or even of capricious affection, such as was strongly evinced by the domesticated bear at Nanci in 1709 , which, in a severe winter, took a starving Savoyard boy under his protection, kept him sleeping in his arms, reserved part of his food for him, and, though he allowed him full liberty, was furious when the child was offered to be taken from him. The wild she bear, in more than a single instance, has been known to bestow her forbearance, and even affection, on human beings; and the Indian stories of women having been preserved unhurt, by the caprice of bears, are not without some foundation. Hence, among the red Indians of the west, the bear is often regarded as the original progenitor of the tribe, as still animating the substantial or the shadowy forms of men, as having mysterious powers 
of mischief and of beneficence, which should be deprecated or invoked by offerings, prayers, and ceremonies; such as smoking tobacco over the body, as soon as one is slain in the chase, breathing the smoke into its nostrils, calling upon its spirit aloud, or by whispering into its dead ears, deprecating wrath for having made it a victim, and imploring its good will during the hunting season; dancing in its honour; and, finally, having communication with the invisible power by the intervention of the tribal medicine man, priest, sachem, wizard, and impostor.

Similar superstitions are scarcely less in vogue among several nations of the Mongole race in Northern and Central Asia, and the nummeries of the Pagan Troll of Scandinavia still vibrate with responsive terror in the ears of Christian Northmen of the present time. Heroes and grandees have gloried in the name of Biorn, and two houses, renowned in England and France, still bear the patronymic of Biron, which is generally considered as a mere mutation of the same Biorn, so often in the Latin of the middle ages translated by Ursus.

It is this fear, respect, or interest, which the imagination of mankind confers upon the genus, that caused the denomination to stand, in the north, in similar estimation as the idea of lion is regarded in the south: it made the teeth and claws to be similarly worn in the form of necklaces, and the shaggy skin to be desired for mantles by the brave, as tokens of prowess and victory. To them must 
be referred the selection of bear skins for military ensigns by several nations, or, when they are of unusual colours, such as yellow, pied, or white, they eaused them to be assumed by wizards in their incantations; and, more lately, as donations to churches in the north, where they are even now spread for rugs to warm the feet of the humble pastors during service.

In Southern Asia, where another sub-genus is most common, the natives still have similar ideas of supernatural influence; and something like a sacred character belongs to their Badger-bol (probably the common Prochilus labiatus). Captain Williamson relates a characteristic anecdote of an English ofticer, passing in his palankeen through a forest, being encountered by one, and left to his fate by the bearers, who, during a gallant struggle with the brute, stood aloof, alternately exclaiming as the soldier or the bear rolled uppermost in the conflict, "well done master! well done bear!" and at length coming forward to congratulate "Sahib" on his victory, when the officer was observed to be master. Here the chief cause of admiration may depend upon the histrionical habits of the animals in question, who often appear in the travellers' path, and perform numerous tumbling antics, as if to entertain them, and then depart without attempting mischief.

Bears were long said not to exist in Paleștine, and Pliny, more peremptorily than is usual with him, denies their presence in Africa; yet, that they 
once abounded in Syria, is proved by the existence of a particular species in the country, which shall be noticed in the sequel. Nor are the high lands of Abyssinia, or the range of Atlas without a bear, though neither are as yet described; $*$ and, therefore, the notice of Isybian Bears, recorded to have been exhibited at Rome by Domitius Enobarbus in his edileship, during the consulate of M. Piso and M. Messala, deserves more credit than the negative of Pliny, who was certainly in error respecting stags.

The dentition of this genus consists typically in all, of incis. $\frac{6}{6}$, can. $\frac{1}{1}-\frac{1}{1}$, mol. $\frac{6}{7}-\frac{6}{7}=42$ : the crowns of the molars evince a decided predilection for a frugivorous habit, but little modified in the subgenera, and several incisors and premolars occasionally drop out, or are not evolved. The feet are all pentadactylous, armed with strong claws more or less in line, not much curved, and formed more for digging and climbing than tearing. The limbs are robust and high, compared with other adjoining Carnirora. The ears ample enough, rounder or obtusely pointed; the tail always short, or almost nul; the eyes small; and the fur, in all cold climates, exceedingly abundant and long. In those climates also, the males, and, in some species, all

* Mr. Blyth, from a notice by Mr. Crowther, states an adult female of the Atlas Bear to be inferior to the Ancrican Black Bear, but more robust; the face shorter, broader, muzzle pointed; toes and claws very short; fur slaggy, brownish-black above, below orange-rufous. The spccimen was killed at the foot of the Tetuan Mountains. Does not climb with ease. 
the females, are disposed to hibernate during the prevalence of snow and cold, without taking food, and there produce the young, which are fostered for many days, before the mother rises to break out of her retreat. It appears to be a singular fact, that all the individuals slain during the period of repose, have the excretory passage stopped up, or plugged, by what in Norway is called the tappen, or plug found in the rectum; and, it seems, where hibernation is interrupted by captivity, cub bears so situated, are liable to a temporary blindness. This we have witnessed in the case of a young black bear, brought from Quebec late in the autumn: the nictitating membrane, early during the passage home, spread over both eyes, and became fixed, although the animal was as lively as ever, being permitted to go free about the ship; he could, in in this state, walk over the sides into the chains, climb up the ropes, and was a full match for the tricks the young midshipmen played him, by retorting occasionally with extraordinary quickness and precision, greatly damaging their sea clothes: he trusted entirely to the acuteness of his olfactory sense during the whole period of his blindness, which continued until the last days of February.

Sub-genus Helarctos, Horsf.-The Sun Bears. -First instituted by Dr. Horsfield; and there is a figure engraved by Howitt after our drawing, in 1820, taken from the specimen sent to Lady Banks. The Sun Bears differ from the other sub-genera by being clothed with a short close fur: they have the 
body long in proportion to their height at the shoulder; the ear small and round; the muzzle short and broad; the lips extensile; the tongue very long; a distinct clear or whitish space on the breast, and long crooked claws. Of the sub-genus, the two species known are both equatorial; and if one of these, or a species still undescribed, exists in $\mathrm{Ma}$ laya, it is not probably found beyond the tropic.

Hel. Malcyanus, Horsf. - The Bruang. - Is a species found in Sumatra; about 4 feet long from nose to tail, and 2 feet high at the shoulder; the fur glossy black, close, from the shoulder and throat running forward to the region between the ears, and down the jowl, where that from the head running back, the two together form a ridge: the face to behind the eyes and lower jaw is buff; on the breast, between the arms, a large white crescent, the horns of which point forward; the tail not an inch long. It is the Hel. typus of Leach, Ursus and Prochilus Malayanus of Raffles and Gray, an animal remarkably docile in captivity, feeding chiefly on vegetables, exceedingly fond of plantains and young cocoa plants and fruit; but, above all, greedy of honey, sugar, and similar delicacies. It is inoffensive and sagacious, though possessed of very great strength, and armed with powerful claws; and, no doubt, in its native forests, it may, when excited, be a formidable enemy to man. There is one living in the gardens of the Zoological Society.

Hel. Euryspilus, Horsf.-The Bornean Sun Bear. - Differs chiefly in the form of the mark on the 
breast, which in this species is nearly square, and of a yellowish or orange colour. The only specimen known was brought from Borneo, and had not grown to the size of the Bruang, being 3 feet 9 inches in length. In manners this animal is most likely quite similar to the former. The individual which existed in the Tower of London, stood, however, with more facility on his hind feet, protruded the lips into a kind of funnel. more completely, and the tongue equally or farther than the Malayan. It had the tumbling propensities which are still more characterized in the next species, making, with the head on the ground, antics as if it would stand upon it; and was killed by its own gluttony.

Sub-genus Prochilus. - Labiated or Tumbler Bear.-First noticed in England by the name of Bradipus ursinus, Ursine Sloth, from the circumstance of the individual having no incisor teeth; M. Blainville considered them to have been extracted, and, therefore, named the species a true bear, "Ours Batteleur," or Tumbler Bear; but it appears that there are at any time only four incisors above, and the six below have commonly the two middlemost wanting, while several, and often all the remainder, fall out without being removed by violence: therefore dent. form. incis. $\frac{4}{6}$ or $\frac{4}{4}$ or $\frac{0}{0}$, can. $\frac{1}{1}-\frac{1}{1}$, pr. mol. $\frac{2}{5}-\frac{2}{3}, \mathrm{~mol} \cdot \frac{3}{5}-\frac{3}{3}=36$ or 34 or 26 . The cartilage of the nose is extensile and moveable, and the lips are protrudable. Beside these characters, the ears are narrow, small and pointed, and there is a profusion 
of long semi-erect hair on the nape and sides of the neck, with a white crescent under the throat, but not so low down between the fore-arms as in the sun bears. The only species known, is remarkable for its powers of smell and sagacity. The old blind specimen at Paris, having been removed to a new cell, soon discovered that one of the pannels of the partition would slide upwards; and we have watched him, for a quarter of an hour together, in the act of getting his claws under the edge and raise it up, always with the intention of passing into the next cell, which was empty; and, of course, as soon as he withdrew his paws, to walk forward, the pannel would slide down, still renewing the same manœuvre again and again. It is this species, also, which in India is accused to have occasionally attacked single travellers, and by whole families to have munched the hands and feet of their victim, breaking and crushing the bones, and then sucking the limbs, almost reduced to a pulp, with little laceration of the skin. Captain Williamson attests being witness to an event of this kind* in the vicinity of Dacca, where they were formerly numerous. Colonel Sykes found them in the Deccan, seeming every where to delight in the wildest rocky mountain forests, climbing trees with more activity than true bears, and not unfrequently showing their wild and gamboling antics while they run in the path before the traveller.

Proch. labiatus. - The Bauloo, Sloth Bear, Aswail of the Mahrattas. - This species has also been called * Oriental Field Sports, Vol. II. "The death of the Bear." 
"labiated," and, by the French, Jongleur, \&c. It is a low legged heavy animal, about 3 feet 6 inches from nose to tail, is covered with a great quantity of long black hair, and has a prolonged muzzle, which, with the lips, cheeks, and the crescent, or rather $V$ shaped mark beneath the throat, is white. In captivity its manners are melancholy, but not slothful; and where two or more are kept together, they are sociable. They make a kind of humming noise while a fore paw is kept at the mouth, which by some has been called their song. Although the particular mode of injuring human beings abore noticed is perfectly consonant with their dentition, it may be, that in the notices derived from India relating these facts, more than one species are confounded, and the munching propensity may belong to one of the following species, perhaps that of Thibet.

Sub-genus Ursus. - The Bears Proper. - The Bears, properly so called, are the typical form of the whole genus, and occupy by far the greatest range on the terrestrial surface; they form, consequently, the greater number of species and very distinct varieties; and though the centre of their habitat appears to be in the colder regions of the north, true Bears are found in the Andes of South America. 


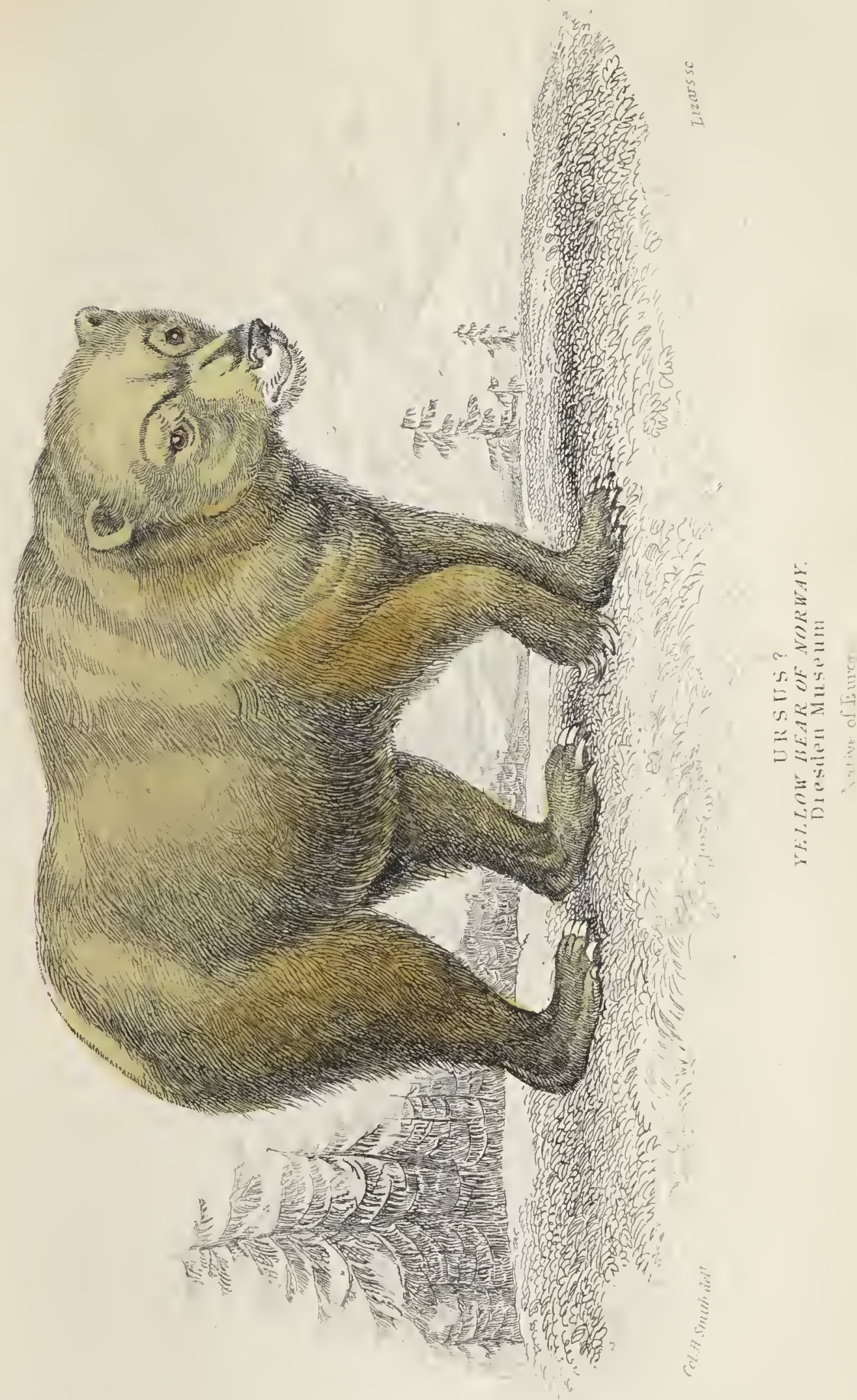



CARNIVORA.

THE BROWN BEAR.

\section{P L A TE XX.}

Ursus Arctos.

THE size of this species, the most commonly seen in Europe, is about 4 feet in length, by two and a half in height at the shoulder; but specimens occur of much larger proportions. It is a square-built powerful animal, with a large head, a prolonged nose terminating in a broad muzzle; the forehead is convex above the eyes; the eyes are small, the ears sub-triangular, more or less hidden in a great quantity of brown shaggy hair, which is more rufous on the back in the summer, and always darker beneath; the soles of the hind feet not very large. We figure Plate XX. (under the name of "The Yellow Bear of Norway"), one copied from a stuffed specimen in the museum of Dresden, which appeared to be a very distinct variety, if not a separate species, measuring 4 feet at the shoulder, 6 feet 8 inches from nose to tail, and 22 inches from muzzle to ear. The colour on the back was brilliant golden fulvous, paler on the shoulder and forehead, bright red on the flanks, and browner below; inside of the ears, lips, and chin, white, and the feet sepia-brown; but the breadth of the forehead, and a very deep 
depression on the plane of the nose between the eyes, gave the head what appeared to us a complete resemblance to that character in fossil skulls of bears, found at Geulenreuth. This animal, it will be observed, was equal in size to the largest Grizzly and Polar Bears, and was sent alive, a present from the King of Denmark to the last Elector of Saxony. It came from Norway.

The Brown Bear assumes an erect posture with facility, walks on the hind feet, and sits on his hams: the same attitude is assumed when the animal is at bay; and it will then suffocate dogs or men that can be clawed within its arms. There are, however, peasants in the north, who will venture single handed to encounter a bear: for this purpose they are armed with a rather long, broad, and very sharp pointed knife, with the blade of great thickness at the back, and the edge very keen, and they wind round the left arm several folds of bear skin fur: thus prepared, they watch the moment of encounter, when the bear rears up, to make two or three quick and repeated stabs, keeping the enemy off as much as possible, in order to guard chiefly against one of his hind feet, which, it is asserted, the animal lifts, if he can grapple with his fore paws, and tears his victim down at one effort. The common practice now is, to shoot them with rifles; but formerly, in Germany and Poland, a bear hunt was reckoned among the most princely of sports. Hunters on horseback, armed with spears, others on foot, with similar weapons, packs of hounds, sustained 
by numerous couples of bear dogs and mastiffs, and whole troops of country people, some bearing nets of great length, others implements to make fires, and all furnished with horns, trumpets, drums, and other kinds of noisy instruments, assemble to drive the game together, and destroy it by open force.

British, or Caledonian Bears, are noticed by the classic writers, and were taken for the purpose of supplying the Roman games; and gladiators, at one time Christian victims, and malefactors always, were exposed to fight, or to be torn by them, and administer to the ferocious taste of the city, so long and so deeply inured to sanguinary pleasures, that eren the efforts of Christian authority could not entirely subdue it, till a foreigner, and that foreigner a Goth, spoke in the language of a conqueror, and was obeyed. Bear baiting in England was likewise a pastime of all classes, from the sovereign to the beggar; and a bear garden is still a proverbial expression, to denote what is emphatically vulgar, if not ferocious.

The Pyrenees and the Asturian mountains still contain a variety of the Alpine Bear, which, in youth more particularly, is clothed in a dirty whitish livery, with only some brown about the head and shoulders.

The Black Bear of Sweden, with a permanently narrow white ring round the neck, if it be only a variety, as Baron Cuvier was latterly inclined to believe, still is one constantly found in the country where the brown species is likewise abundant; but, 
from the specimen of a Bear, figured in Plate XX., it is clear, that the black is not the larger of the two, as he seemed to think. The pair we have seen were little larger than the short legged American Black Bear. In winter, this species has the tips of the hair on the back white, which produces a hoary cast ; and then it may be the Silver Bear of the north of Europe.

Ursus collaris of F. Cuvier.-The Siberian Bear. -Is nearly allied to the last, but distinguished by a large white collar, passing round the neck, and extending upon the anterior part of the shoulders. In form it is more like the Brown Bear of Europe, and is most likely identical with

The Barren Ground Bear of Dr. Richardson, found in the inhospitable regions between the northernmost woods and the Arctic Sea of America. It is larger than the Common Black, with broader soles of the feet, and longer tail and middle sized claws, is allied to the Brown Bear, generally dusky and sometimes yellowish-brown; and the shoulders and flanks covered with long hairs, which, in summer at least, have very pale tips. All these bears still form an article of subsistence to nations in the north, where the oil, fat, hams and skins, are preserved, dressed and exported, or used on the spot, and the rest of the flesh is eaten in a fresh state.

$U$. Thibetanus - The Thibet Bear of F. Cuvier. -Occurs in the mountains of Sylhet and Nepaul. It is distinguished by a large flat head, thick neck, large ears, heavy limbs, and comparatively small 
claws. The colour is black, with a $\mathrm{V}$ shaped spot of white on the breast; the limbs of the spot being more open, and marking not the inside of the breast but the edge of the shoulders. It is this species we suspect to be mistaken, in India, for the Common Bauloo, to which it bears considerable resemblance.

U. Isabellinus, IIorsf.-The Isabella Bear.-Is a variety or species from Nepaul, but little known. Apparently allied to the Brown Bear, with small, obtuse, straight claws, and a fawn coloured fur. One more of these questionable varieties is,

U. Syriacus.-The Syrian Bear.-Mentioned in the Scriptures, noticed in the wars of the Crusades, * and still found, but rarely, in Syria. The animal is of a fulvous white, with large ears, a mane of stiff erect hairs on the shoulders; the rest of the body with woolly fur, above which there is a longer, rather soft coat of hair; the tail, six inches long, the claws small, the stature rather high, and bulk about equal to the common Black Bear; it feeds on flesh, but more commonly on regetables.

Ursus Americanus. - American Black Bear. Head narrow, ears more remote, no depression between the eyes; the muzzle prominent. The species is lower on the limbs, and clothed with glossy black longish fur; the nose and cheeks, to beyond the

* One of these animals had nearly proved fatal to Godfrey of Bouillon, at the siege of Antioch, as related by Math. Puris, for, while riding alone, he encountered the beast, which had attacked a poor wood cutter, and slew it; but not without receiving limself a dangerous wound. 
eyes, are rufous. In character more frugivorous than the brown species; it is consequently less dangerous; is also more active, climbs with greater alacrity, and hibernates regularly about the period when the snows begin to form, remaining concealed until they have disappeared. This bear is somewhat smaller than the Brown, or rather lower on the legs; although it must be observed, that the Indians and hunters recognise two varieties, one of which is taller than the other : it may be, that the last mentioned is identical with the variety before noticed, as the Swedish and Silver Bear.

The Cinnamon and Yellow Bear are considered as varieties of the black. It may, however, be worth mentioning, that a black, and a Carolina yellow, of the same stature, and nearly of the same age, were compared by us: the last mentioned being more slender; less covered in fur; the plane of the nose more convex; the muzzle more pointed; and, in intelligence, more active, for while the black lay down in perfect apathy, and our attention was directed to drawing another object, a familiar breathing over the shoulder made us fancy some unceremonious intruder was looking over our work, but, on turning round, perceived it was the Yellow Bear, carefully raised on his hind feet, not touching our clothes with his fore paws, but having his snout over the shoulder, most curiously intent upon what was doing on the paper.

The Gular Bear.- " Ours gulaire" of Geoffroy.We take aqain to be the High-lesged Black Bear, 
and Silver Kear, hecause the true young Black Bear. has no collar, and is not black, but greyish.

But a very distinct species from all these belongs to South America, and appears to spread from $\mathrm{Ca}$ raccas to Chili ; it is the

Ursus ornatus, F. Cuv. - The Spectacled Bear. -This species is a new discovery made in South America. The fur is smooth, black and shining; the muzzle yellowish, and a semicircle of the same colour, rising from the forehead, nearly encompasses each eye, leaving the orbits themselves black, and there is a light coloured patch on the throat. It is about 3 feet 6 inches in length, and is the handsomest of the ursine genus. The species is found in the Andes of Chili, but the late Sir R. Ker Porter noticed one slightly different in markings, which was found in the Andes, not far from Caraccas, which indicates an extended habitat along the whole chain of the ridge in South America.

There remains yet one more species of land bears to be noticed; one, so remarkable in character, that Mr. Gray has placed it in a distinct sub-genus, which he denominated Danis. It has the muzzle narrowed, lengthened, and flattened; the canine teeth, and the claws of the fore paws very much developed, and scarcely more than a rudiment for tail ; but these characters, including the great proportions of the animal, do not, in our view, amount to more than a specific difference.

Ursus forox, Lewis and Clarke. - The Grizzly Bear.-Is the Meesheh Musquaw of the Cree Indians. 
and Hohhost of the Chopunish ; and, by hunters of the west, familiarly called "Caleb." It äiffers in outward appearance very little from the brown bear, excepting that the colour is of a sepia-black, the back being entirely grizzled with white, and the limbs darkening into positive coal-black; the muzzle is. more or less rust-coloured; and the ears very hairy, appear rather large. The most remarkable character consists in the very great size of the claws, which, on the fore paws, border on 6 inches in length, and are not sufficiently curved for climbing; hence, the adult Grizzly Bear does not ascend trees. This bear, if measurements may be credited, is the largest of the genus; Lewis and Clarke having found one that was 9 feet from nose to tail, and weighed 800 pounds. Of the eight or nine we have seen, none exceeded a common brown bear, nor approached in size the specimen we have figured, nor one that was exhibited in Plymouth some years since, which walked erect without a supporting pole, and, in this posture, was more than seven feet high. But it is in the bulk of the limbs, and the great girth and size of the head, that this bear appears gigantic, and where these characters are coupled with the ferocity and tenacity of life which belong to it, we need not wonder at the capricious characters that it evinces, nor at the mysterious notions which the Indians, and even the Anglo American hunters, entertain of it. $\mathrm{Mr}$. Catlin describes an instance where one of these bears, a female, walked round him and his com- 
panions while asleep, as the track of her paws most clearly demonstrated, and then went to their canoe, which she plundered of all the eatables. It seems to be an understood thing among the backwoodsmen not to meddle with "Caleb," for, on this occasion, when Mr. Catlin was going to fire, although he and his companions had embarked, and were on the water, it was overruled: considering that the species swims exceedingly fast, and that it can bear several bullets through the lungs without arresting its progress, the resolution to depart may have been very proper. In most cases, this bear is not disposed to attack human beings if unmolested; it will rear itself on the hind legs, show its teeth, then turn round to depart, and, perhaps, again repeat the same menace; on other occasions, it may be scared by noise, such as that Mr. Drummond used, by beating a large tin box; still, it is by far the most formidable animal of the American Continent, capable of striking down a bull bison, notwithstanding its enormous strength, and of dragging the carcase to a convenient place, there to bury it, in order to have several meals from the prey, which may weigh from 1000 to 1200 or more pounds. The bears from the eastern side of the rocky mountains, more abundantly supplied with animal food, are much more ferocious than those on the west, where they are in a great measure subsisting on berries. The species extends to the north beyond the latitude of $61^{\circ}$, and to the south into the Mexican territories. 
P ennant, on the authority of Condamine and Ulloa, mentions a brown bear of the Peruvian Andes; but this may be the spectacled bear before mentioned, or is a species still undescribed.

Sub-genus Thalarctos. - Marine Bears. - The North Polar region is frequented by a species of bear, which is sufficiently distinct from the foregoing to be placed in a separate section : it is longer in the body; the head is lengthened and flattened; the ears and mouth comparatively small; the neck very thick and prolonged; the soles of the feet very large and clothed with fur, and the whole coat, dense and long, is silvery white tinged with yellow; the claws black, rather short and stout, not much curved; an additional conic tooth behind the canines. Habits almost amphibious.

Ursus (thalarctos) maritimus. - Polar Bear. Sufficiently described in the foregoing characters, though, we may add, that the species has a very large naked black muzzle, and a keen sense of smelling. It is affectionate to its young, ferocious to all other living beings; feeds chiefly on seals, young whales, and carcasses of dead cetaceæ; and will attack the walrus, who is, nevertheless, able to cope with it: Cartwright saw one dive after a salmon, and catch the prey;-this is a sufficient evidence of the power and agility these bears have in the water: and the distance they can swim was shown to Captain Lyons, who observed one mid way, in Barrow's Straits, twenty miles either way from land. 
The males reside all the winter on ice, and are often carried out to sea to a great distance; sometimes they reach Iceland or Norway, and commit such devastations, that the peasantry assemble to destroy them. The females hibernate, and produce their young under the snow. On land they have a shuffling kind of canter, certainly faster than the best running pace of a man; and, on snow and ice, their hairy feet prevent them from slipping. In size these bears are much longer and broader, though not higher, than the brown. The measurements of French and English zoologists, taken from living specimens in menageries, are necessarily from animals whose growth was checked by captivity and uncongenial climate. A full grown male bear is commonly between 7 and 8 feet in length, and weighs from 1000 to 1200 pounds; and Captain Lyons killed one $8^{\prime} 7 \frac{1^{\prime \prime}}{2}$ in length, which weighed 1600 pounds. In a Dutch narrative, the length of one is given as 23 feet, by the ancient method of measurement, which is an evident misprint for 13; now, measuring Captain Lyons' specimen, from the nose to the extremity of the feet, it would scarcely be less; and, therefore, we see no attempt at wilful misrepresentation.

Fossil bears were long known under various fanciful names, until Blumenbach distinguished among the bones, found in the caverns of Bareuth, and, in particular, at Geulenreuth, the skulls of two species, which he denominates Ursus speleus, and Ursus arctoides; the former in size equal to a horse, and 
the latter smaller, and approaching the existing black bear: a third species Goldfus detected near Muggendorf, and named Ursus priscus. Ursus cultridens, with dentilated edges to the canines, is most likely a misnomer, the teeth not being those of a bear, though we doubt Kaup's opinion of their resembling those of saurians, at least not in the root, which, we think, proves that they belong to a mammal, and not to a saurian.

\section{THE PINNATIPEDES.}

Hitherto Lutra, as a genus, was located among the ill-assorted Digitigrades, between the Plantigrade Mephites, and the Canido, in consequence of an unrestricted subservience to the dentition alone, although the otters show a gradual transition into the amphibious series, by their webbed feet, their lengthened form, prominent seal-like eyes, and the articulations and muscular structure of their hind quarters and tail, which last begins to have the qualities of a skulling oar; and, in one case, even is provided with a kind of fin. The question of location appears to us merely to be, whether the group should close the land carnassiers, or be the first of the Carnivora. that make their constant residence in the water. Undoubtedly, there is great weight in the objection, that they are not strictly Pinnatipedes, and that semi-palmated weasels and martens might as well be transferred to this order, and thus totally derange 
the natural connection which now is observed in the carnassiers of the elongated form. We shall not enter here into the question, whether these semi-palmated animals are in their most natural location, but simply remark, that as otters are neither Digitigrade nor Plantigrade, but swimming Carnivora, some having the soles bald to the heel, others only the palms, and a third class are hairy footed like a polar bear; as the dentition of seals and morses is exceedingly various, without dislocating the connection of the genera that it answered as an order; according to F. Cuvier, a family, or at least a contiguous series; and as these have differently formed anterior extremities, they appear to us, when compared with the sea otter (Enhydra), to be only one remove further in transition towards the fish form, of which Entrydra, the last of the true otters, is the link; on one. side drawing after it the Lutrine genus, and on the other passing into that of seal, which likewise declines towards Cetacea: we conclude, therefore, taking the whole of the conformation together, that it is better to place the several species, more and more approximating towards the marine structure, notwithstanding they have the dentition nearly of Mustelidoe in one series with the Pinnatipedes, than retrograde towards the lengthened land carnassiers, with whom they have less affinity in manner of life, residence, and conformation.

We include, therefore, in the Pinnatipede tribe, the Carnizora with various structures of dentition, having a lengthened form fitted for swimming, web- 
bed feet, eyes constructed for distinct vision under water; habits of residence in, and food derived from the watery element; and these we station in two families, the Otters and Seals.

Family I. The Enhydrida. - Having Musteline forms and dentition; but the four feet distinctly webbed; skull assuming the Phoca character; submarine eyes; constrained movement on land; the articulations in general admitting to form a line with the body; mostly an habitual residence in fresh waters.

Genus Lutra. - The River Otters. - Incis. $\frac{6}{6}$, can. $\frac{1}{1}-\frac{1}{1}, \mathrm{~mol}, \frac{5}{5}-\frac{5}{5}$ or $\frac{5}{6}-\frac{5}{6}=36$ or 38 . A bove the first molar, small, deciduous ; the fourth carnassial middle sized, with two external points and an internal heel; the fifth.with three small external points; in the lower jaw first molar often wanting, the rest similar to the upper; all bearing the pointed characteristics required for the seizing and retaining a slippery fish-form prey. Body very long; legs short; toes 5-5, webbed; tail long, powerful, depressed, tapering; close furred; head depressed; eyes large, plane; ears small; vibrissæ very strong; upper lips covering the lower, and closing it firmly, as in the Phoca; an anal scent bag; under the skin a layer of fat, and other approximations to seals.*

* If we could point out which species have compressed and which depressed tails, and attest the manner of using this organ in swimming, we would have an additional element of distinction. 
They may be divided, according to Mr. J. E. Gray; by the characters of the toes, and the nakedness of the soles. This arrangement we transpose.

A, Toes half webbed, first joints of middle, and next outward finger, united; claws obsolete.

Sub-genus Aonyx, Lesson.

A. Horsfieldii, Gray.-Lutra leptonyx, Horsf.Java Otter.-Head narrower, more lengthened; the neck shorter; fore legs longer; the entire habit slender; the tail likewise shorter and pointed. The fur is brown and soft, with the lips, cheeks, throat, and breast, whitish. This form evidently retains terrestrial habits not in general belonging to the group; it must swim and dive with less power, and reside in shoal waters.

Aonyx Lalandii, Lesson._Lutra Capensis.-Cape Otter.-Fur soft and thick, chestnut-brown, deepest on the upper after parts; brownish-grey on the head; below white. Total length $4^{\prime} 6^{\prime \prime}$. - Resides in the salt lagoons and rivers of the Cape, mostly apt to dry, and leave only holes of deep water.

B, Toes equal, separate, webbed; claws acute.

a, Mufle bald.

* Soles of the hind feet bald to the heel.

Sub-genus Lutra, Lutra vulgaris. - The Common Otter. - Brown; head sometimes coloured whitish; size from 25 to 42 inches total length, and weight from 20 to 40 pounds. Runs on land with difficulty, but swims and dives with great vigour; lurks under banks in sedgy and overgrown watery places, beneath roots of trees, and in holes 
often infected by the remains of putrid fish, upon which it feeds almost exclusively, although larvæ and worms are not refused when pressed by hunger, and young lambs are said to fall sometimes a prey to these marauders, in land excursions; but the otter, it should be remembered, is destructive to fish, and affords excitement to country sportsmen; two causes sufficient for even more serious accusations, and for disregarding the positive utility it can be made of by domestication, which, maugre Buffon's incredulity, is not unfrequently accomplished in North Britain with this species, and largely with an Indian Otter; and, in both cases, rendered available for the most successful fishing.

Otters do not confine their search for prey exclusively to fresh waters, but will, in Great Britain at least, go out to sea : they have been observed, among others by ourselves, above a mile from the land.

L. roensis, Ugilb. - Var.? The Irish Otter. Considered a distinct species, chiefly on account of its salt water habitat and very dark fur' will require not only further investigation, but also a comparison with the otters that fish out at sea on the coasts of Cornwall and Devon, and with the spotted otter, Lutra vulg., Variegata of Desmarets, since a specimen killed in the vicinity of Plymouth, by J. C. Bulteel, Esq. of Fleet, exhibits the sepia-black colour, larger size, and somewhat larger ears of the Irish, and is, moreover, scantily freckled with white specks. 
The common otter occupies the whole of Europe, and extends into Northern Asia eastwards, to an unknown distance.

L. Canadensis.-The Canadian Otter.-Head proportionably larger than the common, size altogether more bulky, being nearly 5 feet total length; lips, chin, and throat, often white; general colour of the fur, which is close, fine, and soft, a rich deep brown. The tail compressed from near the base to the end, shows this species to use it by alternate gyrations from side to side, and to possess inferior powers of diving. It abounds in the lakes and all the affluents of the St. Lawrence, and probably to a considerable distance southward in the United States; but the fur is nowhere so close and fine as in Canada and the northwest.

** With the soles naked anteriorly, but hairy at the heel.

Lutra nair, Indian Otter. - We take this to be the same as the L. Indica; is of a deep chestnut, lightest on the sides; cheeks, lower part of neck, and throat, bright reddish-brown; above the eye a yellowish-white spot. This species is kept by Indian river fishermen, in small packs of ten or twelve, commonly secured, by strings and straw collars, to bamboos at the edge of the water, and used to drive fish into the nets. The otter of Deccan is without spots above the eyes, but it may be of the same species.

L. Chilensis.-A Above, deep vinous-brown; below 
paler; tail darkening to blackish, in length only half the body.

In this division also occur L. Californica, L. Chinensis, and L. Barang.

It is here likewise that several of the seven species, noticed by Mr. Hodgson in Nepaul, will most likely be located, there being at present no further information that we have seen concerning them, than that they vary materially in length, bulk, and proportions, and in colour, one being yellowish-white all over, and the rest brown; and some with the chin and throat, or under surface, pallid or whitishyellow.

*** Soles of the feet covered with hair. Lutra latrix.

b, Without mufle.

Lutra Braziliensis. - Brazilian Otter. - Body and neck long; head comparatively small ; tail compressed near the tip. The specimen we measured was 5 feet 3 inches in length, entirely of a rich brown; this was one of those which frequent the sea coasts, and, we believe, to have been observed near Honduras ; it is said to extend into the Floridas and up the Mississippi. But the species described by Azara, we doubt, is distinct, having more or less white about the head and under surface of the body; smaller dimensions; habits occasionally of wandering on land, and on the rivers and lakes, forming societies of many together, fishing with a common purpose, \&c. We doubt even whether the absence 
of the muffle be alike in both; in our specimen it was small but distinct.

Another species, slighriy described by Mr. Gray from a specimen shown at the meeting of the British Association at Liverpool, came from Demerara; it forms the passage from true otters to the Enhydra or sea otters, differing from both by the size of the tail, which is long, and has two finny edges, and the feet are anteriorly large and webbed beyond the insertion of the claws, and posteriorly rather small.

Sub-genus Enuydra, Flem.-Has 6 incisors above and only 4 below, all very sharp, the molars rather broad and strong; body very long; no anal scent bag; tail shorter than the hind legs when stretched out; hind feet large ; external toes longest, slightly skirted with a web; head rather small, round; ears strait, conical ; eyes large, plane, with a nictitating membrane covering more than the anterior half of the ball ; articulations of the hind quarters resembling Phoca; head of femur without ligamentum teres; and, consequently, the species are reduced to an almost total aquatic life, never visiting further than the rocks bordering on the sea. From the incomplete descriptions extant, we suspect at least two, if not three species, are confounded together. 
Enhydra marina, FLEM.

The species which we take to be the true Enhydra, is that noticed by Captain Cook, and figured by Mr. Webber. We believe it was the same skin, subsequently stuffed, which served for the engraving of the Sea Otter in Pennant's Hist. of Quadrupeds, 4to title page, vol. 2d. Large specimens of this species are above 4 feet in total length; their fur is exceedingly fine and close, of a shining deep sepia, occasionally grizzled with white tipped hairs; or of a rich chestnut-brown; the head, as in other species, is liable to be whitish, and this colour extends sometimes to the abdomen and feet. This animal is the boldest swimmer of the amphibious tribe, for troops of them are met with at three hundred miles from land. They perform many antics in the water, and are occasionally seen balancing themselves in an erect posture, holding a fore paw over their eyes, in order to look about them with more distinctness. * It is found in the Northern Pacific, frequenting the coast of Behring's Island, Kanschatka, the Aleuthian Islands, \&c., all through the latitudes from 49

* Thus balanced, with a " hand" up, they are sea apes. 


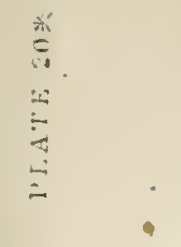

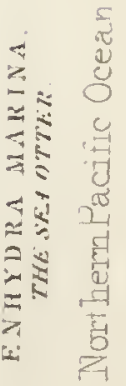



to 60 north, and east longitude 126 and 150 ; affording still a lucrative trade with China, where the skins are much prized.

The second species, of which we gave a figure in Griffith's Cuvier, is a large white-headed animal, with vinous brown fur; but, we think, clearly dis: tinguished by the very short hind legs, terminating in small webbed feet, not so long as the tail, which appears to be depressed considerably, and may act in the water like the flukes of a whale. We take it to be the "varieté $\mathrm{A}$. Loutre marine à tête blanche" of Desmarets. The specimen is in the museum of Paris.

The third appears to have been disregarded by late zoologists, though noticed by Mr. Pennant, Hist. of Quad. vol. ii. p. 85, under the name of Slender Otter. We found two slins of this species in the stores of G. Astor, Esq., at New York, and fancied at first that their extreme slenderness and length were the result of the manner of stripping them off the body. They are about 3 feet from nose to tail, and that organ 12 or 14 inches more. The head is small; apertures of the eyes diminutive; the external ears almost rudimental; girth of the body $13 \frac{1}{2}$ inches; fore legs $3 \frac{1}{2}$ inches; toes palmated; hind legs 4 inches, with the palms wider and fully webbed. The colour is, by Pennant, said to be a rich chestnut-brown; but those we saw were rufous brown, and he assigns them Staten Land, in the Southern Pacific, for habitat, unless there be a mistake, for we understood Mr. Astor's to be brought 
from the Northern Pacific; but, it must be recollected, that his ships necessarily came round by Terra del Fuego.

Family II. The Phocidce.-This family presents a remove further from the terrestrial form, and a complete pinnatipede structure, adapted almost solely to the water. Although they are animals strictly sustained by atmospheric air, they breathe slowly, and can sleep with the head under water. In size some are superior to the elephant, and only second to the larger whales: the fore feet are in all cases approximating to fins, or rather flippers, though there are still some species retaining five fingers, armed with strong claws; but the hinder extremities, peculiarly articulated, have only the power of striking out with the feet, in a direct line backwards, which are always five toed? with very broad membranes; and cannot be brought separately beneath the body; for they are placed so far back, and close together, that they act like the flukes or tail of the whale tribe ; hence their progress on land, though in some cases rather quick, is mostly a painful grovelling, abortive leaping and rolling, never extended beyond the immediate border of the sea, excepting in a season of repose among the males of some of the largest species, who then struggle onward, sometimes to above a mile, where they remain several weeks absolutely without food. None have a tail of sufficient length, or furmed to be serviceable in swimming. They are all totally or partially carnivorous, with incisors va- 
riable in number and structure; six or four above, and four or two below. Their character is passive, in general gregarious and affectionate, willing to aid each other in distress. The species appear to be distributed in three general localities, namely, the Northern Atlantic, the Northern Pacific, and the Southern or Antarctic region. We refer, for details of the genera and species, to Volume VIII. of the Mammalia of the Naturalists' Library, confining our notice, in this place, merely to our arrangement of them, and to point out a few species, which appear to have escaped the notice of the author of that volume. But, before we enter upon them, it is proper to notice the fossil remains of Phocida, which, it appears, Baron Cuvier first mentioned as being found in the marine and shell deposits of Angers, by Professor Renou: there were but few fragments, indicating two species, or perhaps individuals only, of Phoca, of much greater size than the common. Those which Esper described, from the caverns of Franconia, are not of seals, but of terrestrial carnassiers. The Angers specimens were found along with fragments of dolphins and manatees; and it is rather a singular fact, that fossil remains of seals are not more common than they appear to be; for even in England they are rare in the Pliocenes and Miocene strata.

In the first group we place the Phocae proper, which have no external ear; they embrace the genera Calocephalus, which includes the common seai, containirs varieties so constantly distinct in size, 
markings, and even manners, that it is probable two at least, if not three species, are confounded together under that name.

To the species enumerated in the Eighth Volume might be added-

Phoca arcuata of the Paris Museum.-About 4 feet in total length, with the chaffron much arched, the upper lips tumid, provided with strong vibrissæ. The fur is plain dull ochre colour, and the flippers of the fore paws protruding beyond the claws, cut round, and without the appearance of fingers.

In the genus Stenorhincos, we find $S$. Leptonyx, or Small Nailed Seal, from the South Seas, figured very differently from a specimen brought from Brazil, and now in the museum of Brussels, under the name of Ursine Seal? It is about 6 feet long; dark yellow grey; upper lip and abdomen white; the anterior extremities in the form of flippers, have the thumb alone distinct, and armed with a nail, the rest forming four broad festoons, quite black, and without hair. The hind feet have five long, nearly strait claws, beyond which a black, naked, and scollop skin, extends several inches.

On the genus Stemmatopes, or Crowned Seals, we find some remarks in the narrative of Charles Goodridge, wrecked with his companions, and detained two years on one of the desolate islands, named Crozet, in the South Seas*. He says, "the dog

* Nisrative of a Voyage to the South Seas, and Shipwreck, \&.c. : by Charles M. Goodridge, 8vo, p. 180. Exeter, 2d edit. 1838, and personal interviews. 
seals are named by South Sea men Wigs, and the females Clapmatches. The males are larger than it Newfoundland dog; their bark is somewhat similar ; they bite severely, and their skins made clothes. The voice of the females resembles the human.* They bring forth in December on shore, and there also suckle their young, though the sea is their general resort. The young, denominated Pompeys, are excellent food; at first glossy black, and almost without fur: between two and three months old they become silvery grey; but, being no longer fed by their mothers, they become lean, and not choice for eating." We presume this account refers to Lesson's Patagonian Seal, and Mr. Gray's Sub-genus Miourounga.

In the next group we place the Otariae or Eared Seals, with a longer neck, fore paws formed into flippers, and the skin of the hind feet prolonged beyond the claws. The molar teeth more simple and conical.

They form two genera, Platyrhincus, Sea Lions, and Arctocephalus or Sea Bears, described in detail in the Eighth Volume; but, in our collection of drawings, we find one taken by us from a specimen in the museum of Erlangen: it was about 4 feet in length, remarkable for its elongated cylindrical form, with the anterior flippers nearly medial; the nose protruded, making the head somewhat pointed.

* These are, no doubt, the mermaids of the South Seas, noticed by Captains Colnet and Weddell. See Nat. Lib., Vol. Vill. page 290, \&c. 
The general colour an olive-brown above, paler at the side, and turning yellowish-white beneath; the back marked with a number of somewhat semilunate dark-brown spots: on the forehead, which was of the same colour, a broad streak passed across the nose on the cheeks to the ears, leaving the orbits buff. Supposed to be from the South Seas.

Another specimen, formerly in Bullock's Museum, in size nearly equal to the common seal, was there denominated Otaria Australis, and was entirely dull black, though the species figured under that name is larger and rufous.

A third among our drawings, only three feet long, with a velvety black fur, and naked orange-coloured extremities, might be the young of some large species; not the elephant seal, for it has external ears, and cannot be very young, since the bristly piles of the whiskers are long and abundant.

Otaria cinerea of Perron, appears to be the same as the Porcine Seal of Pennant and Molina.

But the most remarkable among the Otarias, in our series of drawings, was obtained in the museum of Philadelphia, and may be O. pusilla of authors, distinguished by an accidental addition in the teeth, for they were incis. $\frac{4}{4}$, can. $\frac{2}{2}-\frac{2}{2}$, molars, not entirely visible, showed $\frac{5}{3}-\frac{5}{5}$, all conical, with a small anterior and posterior lobe. The size was about 4 feet 6 inches to the extremity of the hind feet; the head dog-like, with a full mufle, surrounded with white, and the lips and vibrissæ the same; throat and under surface whitish; all the upper surface brownish- 
olive; the anterior flippers apparently without nails, the posterior rather small, with the inner or undermost toe shortest, the rest increasing in size in regular succession; the claws very small, and all without any prolongation of the skin beyond them. It was brought from the South Seas.

O. favescens, the Yellow Seal of Shaw, may be the young of $O$. molossina of Lesson.

We now pass to the third group, containing the

Trichechi, which forms the genus Trichechos, the Morse or Walrus, whereof not more than one species is yet fully established. Their structure, excepting in the form and position of the tusks, without inferior laniaries, and flat crowned molars, which indicate their food to be more molluscous and vegetable, is very nearly the same as that of seals: receding from the carnivora, they are also more strictly marine, never truly on shore, but resting occasionally on flues of ice, close to the water.

Last of the family, we place the Macrorkine or Proboscidean Seals, whose dentition, consisting entirely of cones, approximates them to cetacea. They have no external ears, large prominent eyes, the males provided with a double folding dilatable skin, forming a kind of proboscis, by the South Sea sealers termed snotters; have the body greatly elongated, and the hinder extremities still more terminal and involved in the skin; their medial digits are little conspicuous, and the external disproportionally longer and robust; their stomachs containing only 
mollusca and algæ, with some stones of considerable weight, seem to show that their aliments require trituration after they are swallowed, and the great bulk of their bodies, together with the aggregate of other characters, constitute them the last genus in the order of carnivora, and next on this side to the true cetacea.

Of the genus Macrorhinus, the species

Mac. proboscidia, or Elephant Seal, is described, as far as yet known, in the Eighth Volume; but it seems that there are other species; one we shall distinguish by the name of

Mac.heminasutus.-Bhort-trunked Elephant Seal. - The mariner Goodridge found this on the Crozet Islands, and during two years it served him and his companions almost entirely for food, raiment, fire, shelter of house, roof, and numerous other purposes; even the blood acting as a detergent much better than soap. The descriptions of Anson and Cook's Sea Lions did not at all answer to the animals he saw, though in colour and manners there appeared no great difference. "The large Sea Elephant is about 25 feet long, and 18 round the body; the blubber often 7 inches thick." The hind feet he described and drew with a pencil, to show in what manner they differed from Lesueurs and Anson's figures, which were shown him; and by that sketch (not ill made) the external toes of both feet gave them, in juxtaposition, the appearance of a Roman $\mathrm{W}$, the three intermediate of each being totally sunk 
in the skin, and externally scarcely perceptible. "The males made their appearance regularly, about the middle of August, and towards the latter end came in great numbers, ranging themselves along the beach, close to the water's edge, and severe contests ensued for possession of a location. In September, the females came up to calve, and suckle the young, for five weeks. At first, the calves are quite black, and their skin is beautifully glossy. By the middle of October all the females return to the water, being by that time quite lean, from want of food and nursing: the old males and young then proceed inland, some to two miles distance, and as many as a nundred in one herd; living together amicably to the middle of December, when both oid and young return to the sea, the old in particular very lean, as they do not make use of any food. While being nursed by their mothers, the calves grow with amazing rapidity, and become a beautiful silver grey, similar to seals. From December to August, yearlings and bull elephants are always to be found on shore." Other particulars are scattered in different pages, and we learned from him, verbally, that the inflatable nasal skin is not a very conspicuous character.

Mac. simus, nobis.-It would seem that there is a third species, almost without the appendage, for, although by no means inferior in size to the former, it is not readily observed even by an artist, as we were informed by Mr. Earle, by whose kind- 
ness we were enabled to copy a finished drawing, on a large scale, made by him of a group he observed on shore at the island of Tristan d'Acunha: it consists of a large male, without a distinct proboscis, two females and a young calf: all the adults pale buff, and the calf black; and we learned from him that the South Sea whalers, in their desire to find fresh meat on deserted islands, have-left pigs on several, and thereby driven off the Sea Elephants, who fear, or rather dislike, the vicinity of animals always prowling along the beach, and unpleasantly noisv, where they seek repose. We suspect this to be the Phoca coxii of the isle of St. Paul, and provisionally name it Mac. simus. 
ORDER VI.

T HE C E T C E A

The Cetacea are divided into two very distinct families, having, in common, the anterior extremities shaped into flippers, and the posterior no longer divided, but forming one horizontal flattened tail. They are destitute of a pelvis, having barely two bones suspended within the muscles, as a rudiment of it. In the first we place the typical or true $\mathrm{Ce}-$ tacea; in the second the herbivorous Cetacea.

The typical Cetacea, or whales, are clearly marked by the nostrils, no longer at the point of the snout, but terminating in one or two fistulous apertures, at the anterior and upper part of the head. The teeth are all conical or wanting, having in lieu a horny substance, called balein or whalebone. We refer for the details of this order to the Sixth Volume of the Naturalists' Library, and repeat here only the general distribution into BALEN ing the genera

Baloena, or Typical Whales.

Rorqualus, Finners or Fin Fish.

Cachalot, Spermaceti Whales.

Narvhalus, Narwhal or Sea Unicorn. 
Diodon, Two Toothed Whales.

Hyperoodon, Bottle Nosed Whales.

Aodon, or Toothless Whale of Harre.

Zipheus, a Fossil Species.

The Delphinice, with teeth in both jaws.

Beluga, White Whale, of which we think the "Poisson Blanc" of the St. Lawrence distinct from the large open sea species.

Delphinapterus, Dolphin without back fin.

Globicephalus, Round Headed Dolphin.

Phocena, The Porpoise.

Delphinus, the Dolphin.

Delphinorhyncus, Long Billed Dolphin.

Soosoo, Gangetic Dolphin.

Inia, Inia of Bolivia.

Oxypterus, Rhinoceros Whale.

The second family contains the herbivorous cetacea already described in the Eighth Volume of this Work. They are distinguished from the true cetacea by the want of blow holes, which, in the skull, indeed, are pierced upwards, but still are nostrils opening in the snout. Their teeth have flat crowns; which circumstance determines their herbivorous character. The head is scarcely separated from the body by a neck, and the body fish-like, having an horizontal tail instead of posterior extrenities. We arrange them in an inverse order from the cetaceous genus Rrtina. The Stelleri, who appear to have only one molar on each side, above and below, a very simple stomach, and are even destitute of the small nails on the anterior flippers. 
Genus Halicone or Dugongus, with teeth resembling two cones united, and incisors that grow out somewhat like the defences of morses; they have no nails on the flippers, and their tail is shaped like the flukes of whales. Of the several species still extant, it may be surmised, that some existed formerly in the Mediterranean, and gave occasion for the narratives of the ancients, which record the tameness and placability of their Delphini.

The third genus, Manatus, makes some slight approaches more towards the great Pachydermata that frequent the water. The flippers have four flat nails on their edges, and the tail is in the form of a spatula.

One of the species, Manatus Americanus, is reported to heave itself up, and bring nearly its whole length out of the water in the rivers of Guiana; and the marks of their presence among the luxuriant herbage, overhanging the borders, near deep holes, at the confluence of two streams, have been pointe.s. out to us, by negro boatmen, who did not fail to throw plantain peels, \&c., overboard, in the manner recorded by Stedman. 
ORDER VII,

\section{THE PACHYDERMATA.}

The Pachydermatous, or thick-skinned order of mammalia, is less uniform in general characters; and owing perhaps to the generally great size of many species, it appears to have constituted, in a more primordial zoology, a great proportion of the inhabitants of the earth; for, not only bones of existing forms are abundantly found in the Pliocene and Eocene strata, but numerous genera, totally extinct, and several affording a considerable number of species, have been discovered, all indicating aquatical habits, and a residence in localities where fresh water lakes and rivers abounded. Those whose structure necessitates a continual resort in the waters, having more the manners, and even conformation of VIanatees, might be placed first in order, but that zeariy all have at least similar propensities; and if the whole structure of the extinct species were known, we would most probably find a series of modifications from the last order passing into the present, of which, for detailed descriptions, we refer to the Fifth Volume of Mammalia of the present work, where the genera and species are described in detail. 
But we arrange their classification somewhat in a contrary order, taking, for leading genus, that which, though extinct, is admitted by physiologists as intermediate between herbivorous cetacea and pachydermata, some referring it to the former, on the supposition that it was not provided with hinder extremities, others as most nearly allied to Tapirus, in consequence of the conformity of their teeth. We include it in

The Proboscidean pachydermata. - Genus DinoTHERIUM.-With tusks projecting from the chin, and turned downwards in the shape of hooks. Of two species indicated,

Dinoth. giganteum was the largest terrestrial animal known, being computed to have measured 18 feet in length.

Here also may be placed other imperfectly known fossil genera, such as Chalicotherium, two species; Lopiricodon, containing no less than fifteen species; Paleotherium, eleven or twelve species, beside several of

Tapirus, among which one nearly equal in stature to the elephant. For the existing species of Asia and America, vide Volume Fifth of the Mammalia, already referred to. All these have a proboscis more or less lengthened; three visible toes of the hind feet, and lacustrine habits.

In the next group we have the true Proboscideans, with tusks, whereof the extinct genera had still the same predilection for water; and even the existing species of elephant evidently delight in it. 
With the exception of the fossil species of the north, their skin was, and is rough, and with little fur ; their molar teeth are composed of vertical laminæ, alternately of bony and of enamel substances. They have five toes to all their feet, huge defensive tusks, and a proboscis of great length and admirable structure. See Volume Fifth, ut supra.

Among these, the lost genus,

Mastodon, chiefly distinguished by the crowns of the molars, consisting of numerous high cones, wearing down in various discs with age. The species Mastodon giganteum, or Great Mastodon, is well known by the enormous skeletons brought from America and exhibited in Europe. Three or four other species have left their debris in Asia, Europe, and South America.

The elephants, properly so called, furnish two well determined existing species; that of India,

Elephas Indicus, with middle sized ears, often with small tusks, and only four nails on the hind feet, ${ }^{*}$ and

E. Afvicanus, with very large ears, large tusks, and often with only three nails on the hind feet.

Fossil elephant bones are also abundant in the tertiary strata of both continents, and from the north Polar Regions to the southern extremities of Asia, Africa, and probably of America: they are very numerous in all the stages of growth in European

* By this is meant the Ceylonese, for the Indian Elephant of the Saul forests, has a larger head, higher hind quarters, and sometimes five toes on the hind feet. 
caverns, and particularly in the Devonshire limestone formations ; molar teeth, \&c., not unfrequently being washed up by the sea in Plymouth sound. At least nine species have been enumerated, and among these Elephas mammonteus, or Primigenius, has been found complete in the ice of Siberia, with hair on the body, and tusks nine feet in length.

Besides these, in a former zoology, there existed in the same habitat with Dinotheria, Tapirs and Mastodons, the nearly allied genera, called Tetrocaulodon and Anthracotherium.

We place next to the Proboscidens, the Pachyderms, with four tusk-like lower incisors.

Genus Hippopotamus, or River Horse, is preeminently aquatic; having the head so shaped that the nostrils, eyes, and ears, can be protruded above the surface without showing any other part of the animal. For description of the living species we refer to Volume Fifth as before, where the probability of the Cape species, H. Capensis, being different from the Senegal, H. Senegalensis, is discussed; and the three known fossil, $H$. major, H. medius, and H. minor, are likewise named.

In the next group the incisors vary, some having four in each jaw, and others none in either; but all have three toes on all the feet.

Genus Rhinoceros, containing the living species of $R$. Indicus, $R$. Sumatranus, $R$. Sondaicus of Tenasserim and Indian Islands, and $R$. Africanus, and $R$. Simus, are described in Volume Fifth; and R. Keitloa. - The White Rhinoceros, another 
large species more recently described by Dr. Smith, possesses two lofty nasal horns, a pale whitish hide, and resides in the interior of Africa, beyond the boundaries of the Cape colony, where it seems two more undescribed species are known, one approximating in character to Keitloa, and the other of much more attenuated form, and bearing one horn, is affirmed to be the true unicorn, a species which Rüppel appears likewise to have heard of on the north side of the equator.

The fossil species are numerous, and much diversified in the structure of the skulls, in the presence or absence of lower incisors, and in the obliquity of the posterior surface of the cranium: some have the bony septum and nasal bones prolonged and firmly attached to the incisive, forming a fitting basis for enormous horns, far surpassing in solidity any of the existing species.

The species enumerated are, $R$. tichorinus, $R$. incisivus, $R$. leptorhinus, $R$. minutus, $R$. elatus, $R$. pachyrhinus, R. hypselorhinus, $R$. Goldfusii, and $R$. leptodon. Of these $R$. minutus, not larger than a hog, shows a reduced size compatible with the next.

Genus Hyrax.-The Proboscideans have several points of approximation to the Rodentia and the Hyrax in size, and part of its structure offers a still nearer similarity, though, in other respects, it may be viewed as a minute rhinoceros without horn, having similar molars, and the incisors may be termed $\frac{4}{4}$, although the upper external are perhaps more pro- 
perly canines. There are two species known, and one as yet insufficiently indicated.

Hyrax Syriacus or Daman, is probably the cony of the English version of the Scriptures, and the Cape species, Hyrax Capensis, or Klipdas of the Dutch, may be the same, both having four toes on the anterior, and three on the hind feet.

Hyrax arboreus may be that with three toes on all the feet, for which we refer to Volume XXIII.

In the next group, we place the solidungular family, which, in its osteology, bears still the rudiments of three toes, and the incisors are $\frac{6}{6}$, usually accompanied by tusks in the male; it embraces the Equidse or Horses, whereof a detailed account is found in Volume XXII. of this work.

in the last of the Pachydermons order, those with cloven feet and two additional false hoofs, we begin to have ruminantial characters of organisation, although there are still incisors in both jaws, the dentition varying in the genera. It includes all the species of Hog described in Volume XXIII., to which we add the fossil

Genus Anoplotherium of Cuvier, with a dentition $\frac{6}{6}, \frac{1}{1}-\frac{1}{1}, \frac{7}{7}-\frac{7}{7}=44$, of which he recognized three species, $A$. commune, of the stature of a pony ; $A$. secundarium, shaped like a roebuck, with no succintorial hoofs to the cloven feet; $A$. minus, not larger than a hare; and $A$. minimum, of the size of a guinea pig, besides several other small, and one large species distinct from the above.

But there were discovered besides debris of $\mathrm{ex}$ - 
tinct wild boars, teeth and bones of an animal, by the Baron considered intermediate between the existing Peccaries and the order Ruminantia, which, with the gazelle-like Anoplotherium, appear to be the links for connecting the Pachydermous order to that of

ORDER VIII.

THE RUMINANTIA,

Like the Felide, an order remarkably homogeneous, and, consequently, most difficult to separate into groups. Notwithstanding the numerous discoveries in zoology, and the vigilant researches of physiologists, little has been added to the stock of our knowledge since the publication of Griffith's Cuvier; and that little of no greater importance towards the determination in question, than other confessedly trivial characters anteriorly used. No doubt, some trifling modifications resulting from the progress of science, might approximate the grouping still more closely to a natural arrangement, but they are not of a nature to deserve the lengthened discussions in this work, which the considerations they involve would demand; and there is, we apprehend, in classification, a paramount importance in 
assisting the human mind to the most obviously natural position of each species, without obscuring the study with fancies which have no truth in nature, and technicalities which substitute conventional phrases, as quasi facts to the true realities of the creation. We, therefore, refer to $V_{0}$ olumes XVIII. and XIX. of the Mammalia, in the Naturalist's Library, for detailed information, restraining our review mostly to the recapitulation of the names of groups, and notices of a few important species, made known since the above named volumes were published.*

\section{THE CAMEIID}

Genus Camelus.-The Camels.

Genus Auchenia. - The Liamas.

Of both these genera fossil remains have been found, and, in particular, of the last mentioned. One of gigantic proportions was discovered by Mir. Darwin, and described in the zoology of the Beagle.

\section{THE CERVID}

In the first group, Mr. Gray has made some modifications and additions to Moschus, by diviaing * "Attachez vous à la connoissance des especes, c'est l'essertiel en histoire naturelle."-Conversation with Baron Cuvier. 
them, under the term Moschids, into three subgenera.

1. Moschus, containing the true musk-bearing musk, and possibly an undescribed species of the central mountains of China, smaller than $\boldsymbol{M}$. moschiferus, paler in fur, and always marked by still paler round spots all over the body.

2. Memina, without musk-bag; a naked space on the outside below the hock.

3. Moschiola, or Tragulus, which embraces the small species of Java and Sumatra.

In this section, the Boryes of Herodotus, probably the Boura, found in Koldagi, a large ruminant, said to be without horns, but having a long black mane, should be placed; but we think it is a Salipede. See the account of Koomrah, in Volume XXII., page 294.

In the next. group, or great genus Cenvus, we have the sub-genus ALCE or Elk, of which we now consider those of the INew Continent as distinct from the Elks of the Old: there still remain some in the forests of Bialowitz in Poland. True Elks have likewise been observed is a fossil state.

In the consideration of distinctive characters, Mr. Gray has pointed out and described the location of the brushes on the hind legs of deer; the Muntjaks, whose horns likewise are not regularly deciduous, being alone without them.

The sub-genus RANGifer appears to have an aberrant form in the mountain forests of High India. It is noticed by Mr. Gray under the name of Cer- 
ous Smithii, and is marked, according to a drawing in the Hardwicke Collection, with white spots like the Axine group. A species of reindeer has been found fossil in France.

Of the sub-genus Dama, only one species, the fallow deer, appears to be at present in existence; but at least three, of very large proportions, are fossil, and among these the Cervus giganteus, or Irish Elk, is supposed to have belonged to the present zoology. Among other evidence, we have been informed of a large deposit of horns, black animal mould, coals and ashes, being found on digging near the Serpent's Head, or the oval part of the serpent temple, at Avesbury, in Wiltshire.

Sub-genus Eraprius, or Stag Proper, contains, beside the species described, one of Africa, C. Barunrus, wanting the bisantler, extending as far east as Syria, and probably the Ail or Hart of Scripture, whose back is always marked with rows of specks, and $C$. elaphoides of Hodgson; Barainsa, which forms the link with the next group, or

Sub-genus Rusa.-The Saumurs or Sauburs of India.-Bishop Heber noticed a species, named by him Goonh, which may have been one of these with the single prickets of the first year, for the beam had no antlers; and, another, Mohr, with horns of such length, that a man could stand between them.

Mr. Blyth has observed an apparent sub-division in both the Rusa and Axine groups, each having species with canines, and species without. Saubur 
and Axis being more equally proportioned; shortbodied as compared with true stags, and more robust; they have short pedicles to the horns, and a very characteristic gait. The other comprises $C$. Moluccensis, equinus of Cuvier, C. nudipalpetra, and the true hog deer, all with long pedicles.

Sub-genus Axis.-C. nudipalpetra, Ogilb., may be a distinct species, retaining the coarse hair and nakedness about the orbits of some Rusce, and the Axine spots indistinct, almost invisible.

Sub-genus Capreolus.-Roebucks.

Sub-genus Mazama.--Here may be added the Cervus humilis of the mountains of Chili.

Sub-genus Suburo.-The Brockets.

Sub-genus Struocerus.-The Muntjaks.

Cervus tunjuc, Vigors, by Mr. Gray considered one of the Rusa group, is evidently intermediate between them.

Cervus ratwa, Hodgson, is a Muntjak we do not find described.

The Styloceri, with elevated bony pedicles, often deprived of horns, connect them with the

\section{GIRAFFID $Æ ;$}

OF which it is not yet proved there is more than one species in existence. A singularity in the organisation of the Giraffe, according to Professor Owen's researches, is the presence of a double gall- 
bladder in one specimen, and the total absence of that organ in two others. We find, also, in the skulls of some males, a central plate of bone between the two frontals, elevated into a boss, like the peduncle of a horn, showing that a bony horn in the forehead of a ruminant is not excluded possibility in the plan of nature. Whether the Merycotherium Sibiricum, a large ruminant found in a fossil state by Bojanus, really belongs to this tribe, is, we believe, still doubtful. For the

\section{CA P R I D E,}

We still refer to Volumes XVIII. and XIX. of the Mammalia of this Work, and maintain in addition, that excepting the tabular view of the inguinal pores and maxillary sinuses of Professor Owen, in themselves not sufficient for a systematic classification, and the additions of interdigital pores, not more important than other trivial characters before adduced, no sensible progress has been made for a more natural distribution of the groups and genera, particularly of Antilopine series, than before shown in Volume XVIII.; nor do we think it likely any other can be adopted, but that which applies the same elements, notwithstanding their unimportance to grouping the species, according as the aggregate of their characters will best indicate analogies and juxtaposition. We have the 
Antilopina, * or great genus Antelope, embracing more species than all the other ruminants taken together, although it is said to have no typical group or species, as if Nature planned her purposes according to the cabalistical interpretation we think fit to bestow upon certain words. We consider every real species as constituting its own type, notwithstanding that it may, or may not have affinities, approximations, similitudes, or analogies with others, which science, for the convenience of generalisation, forms into groups and juxtapositions, but can never so wholly arrange, as to do away with much that is arbitrary. We begin with the

Sub-genus Dicranocerus, or Prong-horned Antelopes of America, which it is now admitted are of two species, A. palmata being ascertained to reside in the mountains of Mexico, and most likely much further to the north, although the local name, $\mathrm{Be}$ renda, as in the case of Mazama, is really applied to other ruminants, such as the Californian Sheep, and $A$. furcifer of the Missouri.

* We regret that in the Synopsis of Ruminantia, in Griffith's Cuvier, we did not note every species of which we had figures, about eight-tenths, as the want of such reference seems to have been since generally felt. We possess at present above one hundred drawings of Antelopes alone, exclusive of details. 
ज)

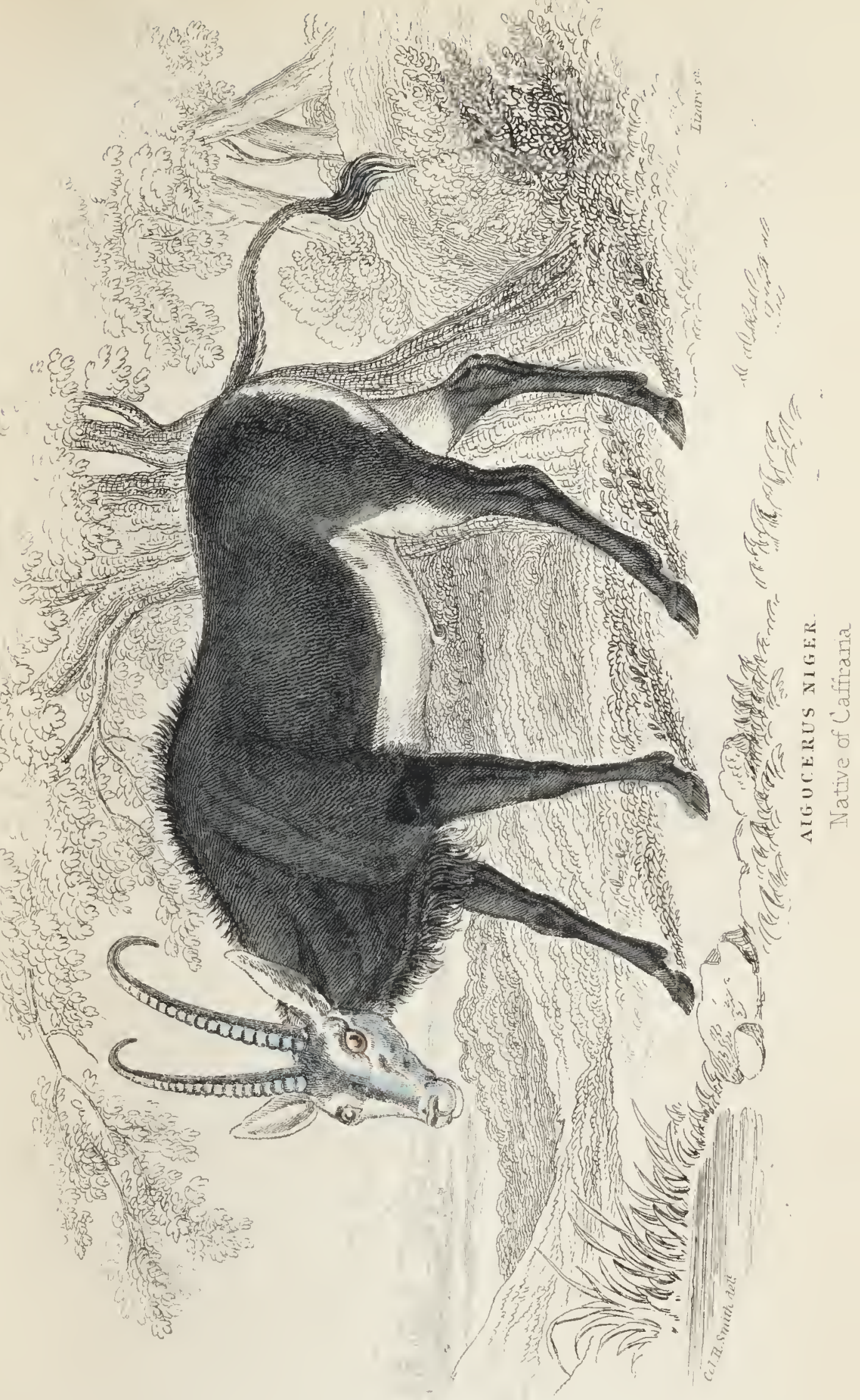





\section{PLATE XXI.}

Aigocerus Niger.

We place after $A$. leucophoea, or Blue Antelope, and A. equina, or Roan Antelope, the magnificent species Aigocerus Niger of Captain Harris. Horns of the male 37 inches over the curve, more slender than in Leucophoea, more regularly curved, annulated three-fourths of their length, with about 30 incomplete rings; head elongated, muzzled, with whitish marks down each side the chaffron; neck and body robust, deep; withers elevated; hoofs short, black, obtuse; hair short, close, intensely black, with gleams of deep chestnut; ears 10 inches, narrow, pointed; black standing mane, pointing rather forward, extending to the middle of the back; belly, buttock, and inside of the thighs, white; tail with hair reaching the hocks; stature, 4 feet 6 inches at the shoulder; 9 feet in length. Resides in the interior of Caffraria, near the tropic of Capricorn, where the species appears in the high lands, forming small families. In the next,

Sub-genus Oryx, Mr. Rüppel seems disposed to place his $A$. beisa, nn account of its similarity to the 
Caffrarian Oryx; but the female being hornless, we suspect, that along with A. ellipsiprimnus, Ogilby, it will be referrible to the reduncine group, or to the genus Damalis. The species, although as yet not completely described, is noticed uncel lLe lame of Baeza by Isenberg and Krapf, who describe it as a fine animal, of the size of a cow, shaped like a deer, with upright, not branching horns; flesh exquisite. Seen near Melkukya.

Another large species, the Damma of the Arabs, with long strait horns in both sexes; white forehead and yellowish general colours. Seen by Rüppel in the great plains of Haraza, and by him taken to be the Dama of Pliny, is no doubt a true Oryx.

Of the sub-genus Gazella it may be proper to observe, that we suspect $A$. cora, Ham. Smith, or $A$. Bennetii, ranges next to $A$. subgutturosa. $A$. Christii we have not yet found described.

In this division, Mr. Bennet has formed a farther section of the Damo, characterized by their slender, very anteriorly uncinated horns and long neck, marked with a white spot on the throat: he enumerates $A$. mhorr, A. nanguer, or Dama (which last name it will be advisable to drop, for reasons assigned under the head of Oryx damma), and $A$. addra; but the three denominations refer evidently to mere varieties produced by geographical separation; although it must be confessed there are differences in the brushes, \&c., of some importance.

In the sub-genus Antilope, the ceruminous substance, secreted in the lachrymal sinus, is in its 
highest development; and Mr. Bennet's conjecture respecting the sexual relations it may bear, is probably correct; but we suspect the animals most largely provided with the organs are precisely those which have least perspiration under exertion, and that the superabundant odours thus generated and cast on the winds, serve these delicate scented species, all with very little voice, to find out each other, and keep together for their common security.

It may perhaps be advisable to detach from this sub-genus, A. Colus or Saiga, and A. gutturosa; both having peculiarities of structure in the nostrils and throat, and sub-lyrate horns, in order to place them in the new

Sub-genus Pantuolops of Hodgson. They may constitute a little group of the temperate and high regions of the Old World, and include A. kemas or Horlgsonii, likewise provided with a peculiar apparatus in the nostrils, sub-lyrate horns, and other assimilating characters.

Sub-genus REDINCA.-Here the recurved horns are generally coincident with a more robust form, longer, coarser fur, dull, or mixed colours, absence of horns in the females, small muzzle, and sub-orbital sinus, \&c.

Oreotragus may form another sub-genus, and is so noticed in Vol. XVIII., page 221, by the name of Saltatrix.

The sub-genera Tragulus, ${ }^{*}$ Raphicerus, Tetra-

* Add to this sul-genus $A$. montana, Rüppel. 
cerus, * Cephalopilus, we pass over with the remark, that $A$. philantomba, of the cephalophine group, was first detected in the British Museum, named and subsequently noticed by ourselves in the synopsis of Griftith's Cuvier, No. 855. $†$

Of sub-genus Neotragus, the Madoka, or Salt's Antelope, is not identical with that figured under the same name in Rüppel's work.

In sub-genus Tragelaphus we place $A$. decula of Rüppel, which, according to him, represents, in Eastern Africa, A. scripta of the west.

In sub-genus NæmorhæuUs, Mr. Hodgson has proposed some modifications of character; but $A$. Duraucelii is more nearly allied to the Cambing ootan and $A$. thar, than to Goral and A. (kemas) hylocrius, Ogilb., or Jungle Sheep, is an additional species. It is to be regretted that we have had no convenient opportunity of publishing the figures of the whole series, such as it is in our possession.

We pass on to two groups having domesticated species, which attest a plural origin, but of which we cannot here subjoin the details.

Genus CaPra.-Beside the species noticed in Vol. XIX.p. 108, of the Naturalist's Library, several have since been added, chiefly through the researches of Mr. Blyth, such as the Himalayan Ibex or Skyn, and the Markbur of Kabul, which, if it be

* Unless the colossal fossil Sivatherium giganteum, found in the Sewallic Hills, belong to it.

+ This is a case for saying, with the Templars: "Non nolis Domine !" 
ferai, appears to be from a species not yet described. Caprit jael, notis, is, we think, identical with $\mathrm{C}$. $\mathrm{Nu}$ biana, 11. Cuvier; Sinaitica of Ehrenberg, Arabica of Rüppel, and Bedan of Wagner. Capra Walie of the snowy peaks of Abyssinia. C. Jharal may turn out to be identical with $C$. Jemlahica. The Neelgherry Ibex is not yet described.

The genus Ovis has been the subject of special investigation by $\mathrm{Mr}$ Blyth, and is divided by him into two sub-genera: Ovis proper containing the species; Ovis Polii, the Rass or Russ of the Pamere table land: O.montana, or our O.pygargus, O.ammon, O. nivicola, Eschscholtz, O. Californica, $O$. Nahoor, O. Burrhel, O. cylindricornis, O. Gmellinii, O. Vignei, O.musimon, O.option, O. aries. Here he places Ixalus probaton, Ogilby, which we consider to be an imperfect Aplocerus mazama, No. 865, Synopsis of Griffith's Cuvier.

In the second sub-genus Ammotragus he places the Tragelaphus aoudad, or Bearded Sheep, Kebsch of the ancient Egyptians? which, according to our arrangement, being intermediate, should form the first, as more nearly allied to Capra than the rest of the genus Ovis*.

Beyond these we continue the classification of the greater ruminants, formerly arranged with an-

* See Zoological Transactions, July, 1840, p. 77. It may be proper to add, that in Griffith's Cuvier, the plate representing Tragelapius is, by mistake, named Capra Jaela, or Abyssinian Ibex. 
telopes, but more or less approximating the bcvine groups.

They constitute the genus Damalis, and it is probable, that when several of the as yet indistinctly described species of Central Africa and of the interior of Arabia, such as the Bahr-el-Wahhash of Burckhardt, having short horns, with the form of Oryx, shall be better known, it will require more sub-genera than we have as yet established.

In the sub-genus Acronotus, additional species will be found, for we possess these several years, a drawing from a young specimen in Frankfort Museum, which indicates an animal like A. bubalis, bu marked like $A$. caama; it appears distinct from A. nigripes of Blyth.

In sub-genus Boselapnus, a species allied to Canna, appears noticed in Riippel's descriptions; and

Sub-genus Strepstceros may claim A. torticornis, A. tendal, and A. Eurycerus of Northern Africa. It seems even that from the notes, drawings, and, we believe, the head of an individual received by General IIardwicke, a true Damalis strepsiceros or Koodoo exists in Eastern Asia ; $*$ and the

* Str. sylhetanus? supposed Buffalo Deer of India. Specimen shot by the late Mr. Lane, collector of the revenue at Dacca; the only one he ever saw: the description was lost, but the head, sent by Captain V to General Hardwicke, is now in the Museum of the India Company: it is a completc head of Strepsiceras, measuring from tip to tip of horns 2 feet 5 inchcs; from tip to base 2 feet 9 inches; circumference at basc of horn $9 \frac{1}{2}$ inches; length on curve 3 feet 
Sub-genus Portax proper, is said to contain two species, the slate coloured Neelghau, and a second, the Ghorangay of Cuttak, never bluish but dark dun. The large new Antilope ellipsiprymnus of Ogilby, and $A$. defassa, the same as Cora, imperfectly described by Rüppel, may form other species, perhaps also a small cow-like hunched animal, brought from Africa, we believe named Ant. Landiana?

Some of these large species might be multiplied, and become valuable additions for domestic consumption. We believe the late Duke of Norfolk at one time endeavoured to propogate the Neelghan in his parks, we having seen at one time five head of them together, all his property, but the experiment failed, it is to be feared from the indifference or secret dislike which park and gamekeepers have to additional trouble.

We now come to

$5 \frac{1}{2}$ inches; skull, from crest of occiput to point of upper jaw, I foot $5 \frac{1}{4}$ inches; across the forelead $5 \frac{1}{4}$ inches; from horn to point of jaw 101 inches; points of horns white, the rest dark. But we still question the reality of the habitat. 


\section{THE BOVID瓜。}

And passing the genera Catollepas* and Ovibos, for which we refer to Vol. XIX. p. 180, and sequence. It may be remarked, that of this family are found abundant fossil remains, in general of larger stature that the present: they consist chiefly of Bos urus, Bos lison, \&c. accompanying the debris of Mastodons, Elephants, Rhinoceroses, Tapirs, and Cervidæ.

The Bovidæ Proper, having since Baron Cuvier wrote, undergone considerable investigation, we think cannot again be strictly divided into three sub-genera, there being intermediate forms of skull sufficiently important, as it would seem, to constitute at least a fourth. Mr. Hodgson, in a detailed paper on this subject, has furnished diagnostics for the addition of one, but it is palpable that in his position, he was not sufficiently conversant with species that are not inhabitants of the ligh central mountain chain of Asia; therefore, we regret, that the extensive collection of materials on Ruminantia, made by Mr. Blyth before his departure for India, remains for the present unpublished. The Subgenera, such as we present them by their consimi-

* From the contents of a letter from Mr. Blyth, Proceedings of Zool. Soc., 10th Aug., 1842, it is evident that Bos pegasus of Griffiths' Cuvier is another Catoblepas. 
larities; and, indeed, in whatever arrangement they may be placed, offer again that peculiar disposition of nature, which Almighty wisdom appears to have impressed on the mammalia destined for domestication, admitting within certain limits species evidently different to commix, and producing a kind of hybrids permanently fertile, but, in general, returning more or less to one or the other forms of the progenitorial stock: thus, the Bison poephagus or Yak, breeds readily with the domestic races of cattle, whether with or without the hunch, and these breed likewise with the domesticated Gayal; and the progeny of all is reported to remain in undiminished vigour: facts applicable to the two species of camel, but not quite in the same degree. We believe these considerations to be the more important, as they evidently support the views which we have endeavoured to advocate, in the history of the Canidce and Equider, in former volumes of this work, and we find again corroborated in the Bovides of Africa.

The Genus Bos, or Bovine tribe, whose general characters are described in Volume XIX. of this work, we apprehend to be best classified by their affinities, in a series which, leaving the Catoblepas or Gnoos, nearest the Acronotine group, most similar in their cervine limbs, commences the $\mathrm{Bo}$ rida, by a structure of forehead, and disposition of the horns, that can be traced onwards through Ovibos (whose ovine nose shows a mere adaptation to his arctic location), and is most remarkable in Bos C'affer, that species in youth exhibiting a black fur, 
sufficiently long and soft to be mistaken for a Bison's.

Sub-genus Bubalus therefore includes Bos Caffer, or Cape Buffalo, but not B. pegasus, Ham. Smith, Griffith's Cuvier; that species having characters which refer it to the Gnoos. But Bos Bornouensis, notis, the Zamouze of Clapperton, with horns only divided by a narrow ridge, on the frontals exceedingly broad, rugged, solid, and black, not turned down or sideways, but directly back and upwards, the two forming a crescent, is a true $B u$ Lalus; it may be the same as

B. corniculatus, Blyth, known by the pair of horns only, which we formerly copied and took to be of a semi-adult $B$. Caffer, but that judgment may have been liasty. Africa contains likewise B. Urachyceros, Gray? remarkable for its large pendant ears, filled with long tufts of hair: in this species the horns, in general, have the same form as those of the Bornou buffido, are considerably smaller, and have a flexure downwards and again upwards. In Eastern Asia and Europe, there are, we think, two species; B. Arnee and the common B. bubalus.

Sub-genus Bison, distinguished from Bubalus, whose frontals form a convex line between the horns, by having that convexity lower and considerably broader, while the horns are set on below the crest and behind the frontal line. In this group we reckon the Bos bison, or Bison antiquorum, Bos Americanus, Bos poephagus, or Yak of Tahtary; and, probably, the Burmese Phain, a small red spe- 
cies, as we are informed, at a distance looking like Devonshire cattle, but with raised withers, showing perhaps the original animal from which the domestic ox, Bos sacer is derived, or a feral race long established in the forests of Indo China. We doubt whether the recently discovered Bos Atlanticus, Blyth, or Sherif-al-Wady of the valleys of Atlas be of the present sub-genus, or one more of the colossal species of the next.

\section{After this group, we place the}

Sub-genus Brbos of Hodgson, wherein we include the giant Bovidae, which surpass in height, at the shoulder, even the largest Bisons and Uri now extant. The Urus of antiquity (not the fossil) may have belonged to the same form, for we include in the group also the Gayals of India, though somewhat inferior in stature, and slightly different in skull; but they have a similar livery and markings, which, to some extent, occurred also in the German Uri of the middle and feudal ages. Bibos, in our arrangement, has the elevated ridge on the shoulders even higher, and, in some species, further prolonged down the spine than Bison. The group is intermediate between the bisontine form and the bovine, having the horns set on very near the frontal crest, which is considerably elevated, and the forehead broader proportionably, and depressed or concave as in the domestic ox, but, towards the centre, rising again, and forming a convexity more or less prominent; the horns rather short, lateral, regularly 
curved, at first obliquely backwards, then up, and the points inclining rather forward are very bulky; at base oval, 15 to 20 inches in circumference, smooth, greenish, with black tips, 24 to 30 inches on the curve; and, internally, the horny sheath is prorided with two strong ridges, ascending from base to tip.

Bos gaurus.-The Gaur.-Eighteen hands and more at the shoulder; several inches lower at the croup; crest of the frontals bluish-grey; general colour rich purple-brown; the four legs dirty white.

The Asl Gayal of Hardwicke, Bibos cavifrons, Hodgson, Great Bison Gaour, Gor, Bison of Dandely, are all names of varieties, or of the same animal, occupying many glens in the mountain forests of India and Indo China.

Bos Sondaicus, B. leucoprymnus.-The Banting. - Little, if at all inferior in size, with horns more spread out laterally, similar colours or reddish, and always with a white oval disk on each buttock. It is an admitted fact, that this giant species will breed with the domestic cattle of Java.

Bos Sylheticus, or Gayal of Sylhet, described in Vol. XVIII. of this work, likewise breeds with the domestic Indian races; and it is doubtful whether

Bos gayceus of Tenasserim, the Ceylonese Wild Bull, that of the Mahabalishwar Hills, and others indicated in the drawings and papers left by the late General Hardwicke, are of one or more distinct species. 
Sub-genus TAURUs, with horns attached to the sides of the summit of the frontal crest, and the forehead plane or slightly concave.

To this group belong the skulls of some enormously large fossil oxen, and, probably, also the more recent Urus or Wizend of the Germans, from which it is supposed strait backed cattle are descended. This domesticated species must have existed in its present perfection, at least these tnree thousand years, since most beautiful and correct representations of it are abundant on the oldest sculptured monuments of Egypt. The cream coloured Bush Cow of Western Africa, shaped like the white variety or Scottish wild bull, but with blue eyes, and a long mane of white hair on the shoulder, and a long succentorial hoof on each foot, may be the species noticed by Pliny, but more likely is a feral race long independent: it might be denominated $B$. taurus Libycus.

We take a second species to be the Bos Indicus or Sacer, the Hunched Ox of India and Egypt, equally figured on the monuments of Egypt of the earliest date, and divided into many races and breeds, but, we believe, always born with teeth protruded through the gums. Both these taurine species intermix freely, and continue a prolific breed with the Gayal, the Banting, and the Yak.

For details we refer to Vol. XVIII., as already stated. 
Hituerto, the succession of orders has shown a gradation of characters, passing without very abrupt transitions into the descending or ascending scales, notwithstanding that several families, exceedingly homogeneous, or constructed with little deviation upon one general plan, seem to forbid all approximation. Where there is thus an hiatus, fossil remains of genera now extinct have occasionally filled up the chasm, and many forms in nature, now missing, may, in the course of time, come to light, and show that the whole circle of combinations, proper for a zoology, adapted to the conditions of existence on the globe, are in being, or may at one time or other have existed, and that such links as are now unknown, may, at a future period, be recovered. In the instance before us, the question arises whether Rodentia or Edentata should follow upon the Ruminantia: the brain and several other organs unquestionably claim precedence for the Rodents, but that in a lineal artificial succession, such as a systematic arrangement ever necessitates; these display a nearer approach to the Marsupials than the Edentata, who, although they are deficient 
in dentition, and even in locomotive activity, still evince characters, such as their huge claws, which approach Ungulata; and the remains of a large extinct edental, at this moment under the inspection of Professor Owen, actually possesses the unexpected combination of both hoofs and claws on the same foot. It is, however, to the pachydermous, rather than the ruminant tribes that the last gigantic forms of Edentata most nearly approximate.

The Edentata are so named, because they are deficient in front teeth, for, in other respects, the order hangs together by almost negative characters which it has in common; such as the great claws which invest the anterior part of the fingers having more or less the form of hoofs, and a deficient activity resulting from the disposition of the members: these, however, are sufficiently different in the species to require separating them into three families. We take, for the reason above indicated,-first, the fossil remains which appear nearly allied to the tribes of Edentata, and are likewise, we believe, connected with the extinct species before mentioned; but of this the description is yet to appear.

The extinct animals we place here are two of very great size, apparently allied to sıths, anteaters, and even to armadillos: they are the Megatherium, above twelve feet long, and the Megalonyx, somewhat less, and not so completely investigated.*

The family of the T'ardigrades, or Sluths, have

* See curious note, in Volume XXII., page 147, of this Work. 
the face short; structure such as to be incapable of active motion.

Genus Bradypus.-The Sloths.-Have cylindrical molars and pointed canines; two pectoral mamme; and the fingers of the paws wrapped within the skin show externally only very large claws; their arms are disproportionably long, and the hind legs short: they feed on leaves, and never quit a tree until it is stripped of verdure.

B. tridactylus.-The Ayei.-Three-toed, and $B$. didectylus, Unau or Two-toed Sloth, are sufficiently well known. They are both from tropical America, and other species named, differ but little in colour and quantity of hair.

The ordinary Edentata have a pointed snout; some have likewise a few molars. We reckon two genera.

Genus Dasypus. - The Armadillos. - Remarkable for the scaly shields, or bony armour, forming a kind of marquetterie of regular patterns upon the defensive plates which cover them; there being a plate on the forehead, a second covering the shoulders, a third forming a succession of segments on the back, and a fourth on the croup; the tail itself being similarly covered by a series of cylinders; and the animal thus entirely protected, by a kind of armour, has, besides, the faculty of rolling itself into a ball, and very often in this state setting itself in motion, bowls down hill without hesitation. They are inoffensive to man, unless the alleged fondness for human flesh, in a state of decomposition, be regarded 
as an offence, for the largest are reported to be avid of animal matter; and the fossil giants of this genus may, in their time, have thus chietly served the end of their creation; while an existing species lately noticed by Mr. Schomburgk, perhaps still, as the Indians assert, feeds in the same manner, it being one that weighed above 110 pounds, was about 3 feet high at the back, and $5 \frac{1}{2}$ feet in length, with the tail 16 inches long, and nearly as thick as a man's thigh at the root; the middle toe of the five on the fore feet was $7 \frac{1}{2}$ inches in length, and armed with claws capable of digging with the greatest rapidity.

No doubt, this species was provided with the same kind of numerous conical teeth which we find in others of the genus.

The Armadillos having seven teeth on each side, above and below, may be divided into sub-genera, taking for one, those with only four toes on the anterior feet, such as Dasypus novemcinctus, or Nine Banded Armadillo; Das. septemcinctus, or Seven Banded Armadillo; and Das. tricinctus, or 'Three Banded Armadilio.

The second division has five toes on all the feet, and contains Das. sexcinctus, ${ }^{*}$ and Octo decimcinctus, or Six and Eighteen Banded Armadillos.

In a third, the toes of the anterior extremities are placed obliquely, the thumb and index being

* Das. sexcinctus, or Weasel Headed Armadillo, shows, in the Genetalia, the first traces of approximation to the oviparous type which particularly characterize the Marsupial Edentata. 
long, and the middle toe bearing a strong sharp edged claw.

This has eight or nine teeth on each side in both jaws, and contains the Das. unicinctus of Linnæus, Twelve Banded Armadillo of Pennant.

Finally, we have the Priodontes of F. Cuvier, Das. gigas, or Giant Armadillo, with long tuberculous tail, very large trenchant claws, and with twenty-two or twenty-four small teeth on both sides and both jaws, making eighty-eight or ninety-six teeth in all. It is to this division the animal above mentioned may belong, but the tail being short, and very bulky at the root, makes it distinct, and approaching in that particular to a fossil species of enormous size. The Giant Armadillo does not weigh more than 70 pounds.

The next genus is that of Chlamypiorus, Harlan, known as yet to possess but one species.

\section{PIATE XXIII.}

Chlamyphorus truncatus.

WITH ten teeth on each side above and below; five toes to all the feet, the claws of the anterior very large, sharp, and compressed; the back covered with a series of transverse scaly pieces, broken in zones or rows, but without separate solid pieces on the shoulders and croup; this covering being simply 
旅

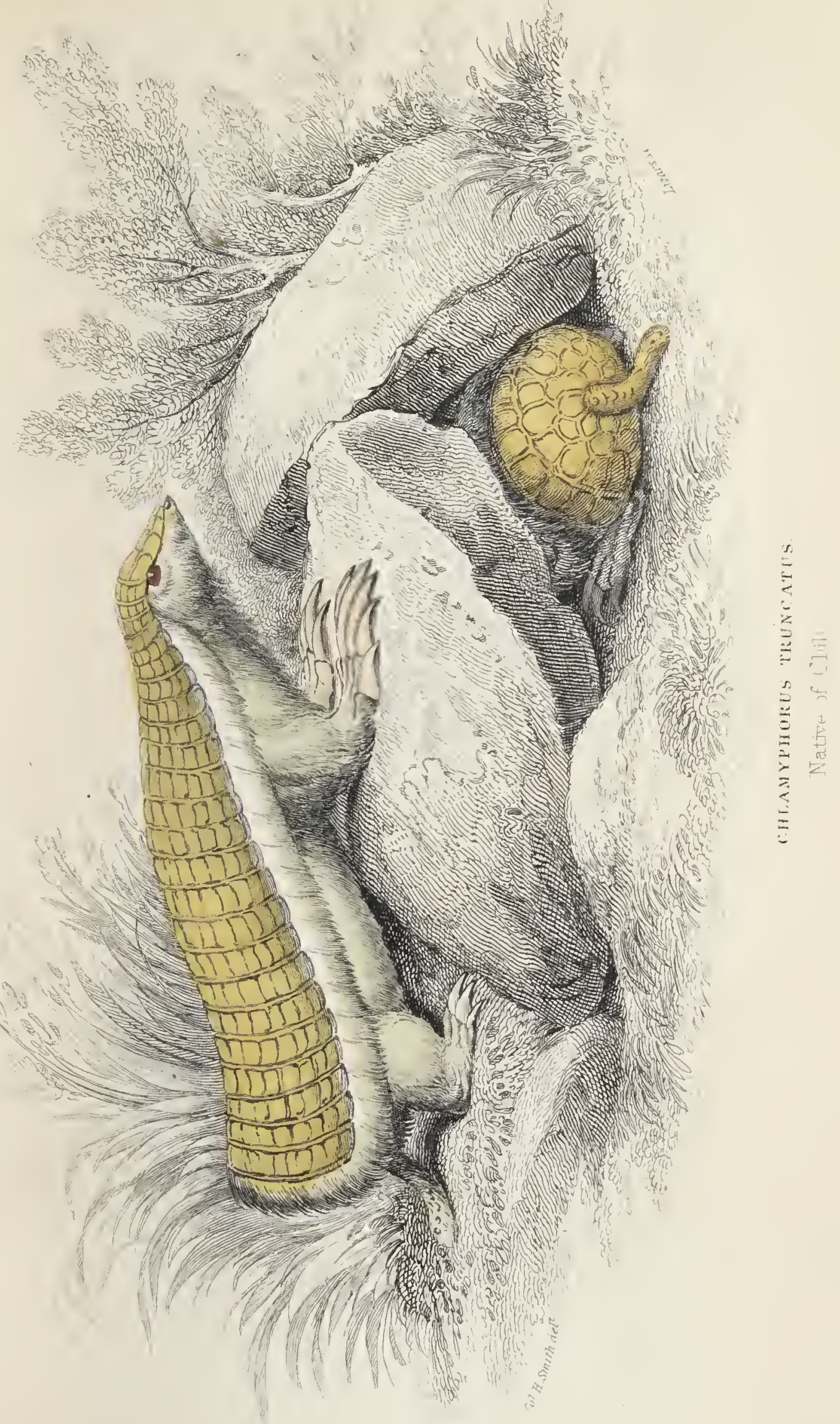



attached to the body on the spine, and the hinder parts protected in a truncated shape, with the tail secured beneath the body. This little animal was discorered in Chili.

The Anteaters, Myrmecophagido. We include in this family the African genus and the American, although the former still possesses a few cheek teeth: both have lengthened and pointed heads, extensile tongues, and feed on ants.

Genus Orycteropus, with flat nails, or claws for digging; their cheek teeth possess the unique structure of being cones, pierced vertically by numerous pores like those of a cane reed.

Oryc. Capensis._Cape Anteater.-Aardtvarken of the Dutch.-In size larger than a badger, bulky, long, low, with a small head and prolonged snout; tail less than the body; colour pale-brownish grey: burrows. The next genus is totally without teeth.

Genus Mrrmecophag..-The Anteaters Proper. -Hard-skinned, hairy, lengthened animals, with tapering long head and snout, small mouth, extensile tongue, for the purpose of protruding into ants' nests and termite hills, to draw out the insects; the anterior claws long, powerful, and cutting, to tear open their retreats, and to serve for defence; the anterior paws usually bent inwards, having a callosity on the outer part of the wrist, upon which their weight presses in walking. All the species belong to tropical America. The smaller have prehensile tails, and all bearing only one young, are in the habit of placing it on their own backs. 
THE TAMANDUA OR GREAT ANTEATER.

\author{
PLATE XXII.
}

\title{
Myrmecophaga jubata.
}

Nearly 5 fcet long, with four toes anteriorly, and five on the hind feet; has a long brushy tail, with vertical hairs above and below, frequently carried in the form of an umbrella: the hair is coarse, longish, grey-brown, with a broad band of black, edged white, passing obliquely from the breast upon the shoulder; the feet dark brown or black. This species is said to be a match for the Jaguar, being protected by its fur and tough hide, and able to use its cutting claws with great force. We have ourselves seen a large and very hard termite nest, which had been torn open a few hours before by one of these animals; giving ample proof of their strength and the power of their claws.

The Myrm.tetrodactyla, commonly called Threetoed Anteater, is much smaller, inhabits trees, and is sooty black, or flaxen white, or party coloured; and the Two-toed Anteater, still smaller, with a soft downy fur, is likewise arboreal ; and, we believe, always whitish.

Genus Manis.-The Manis._These are the Scaly 


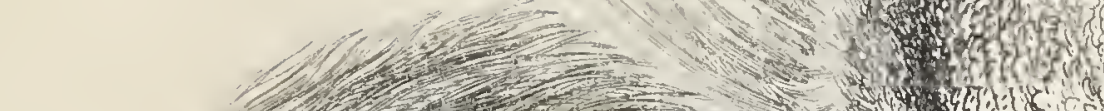

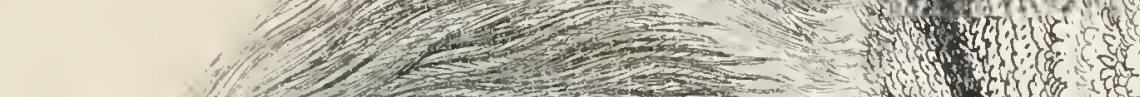

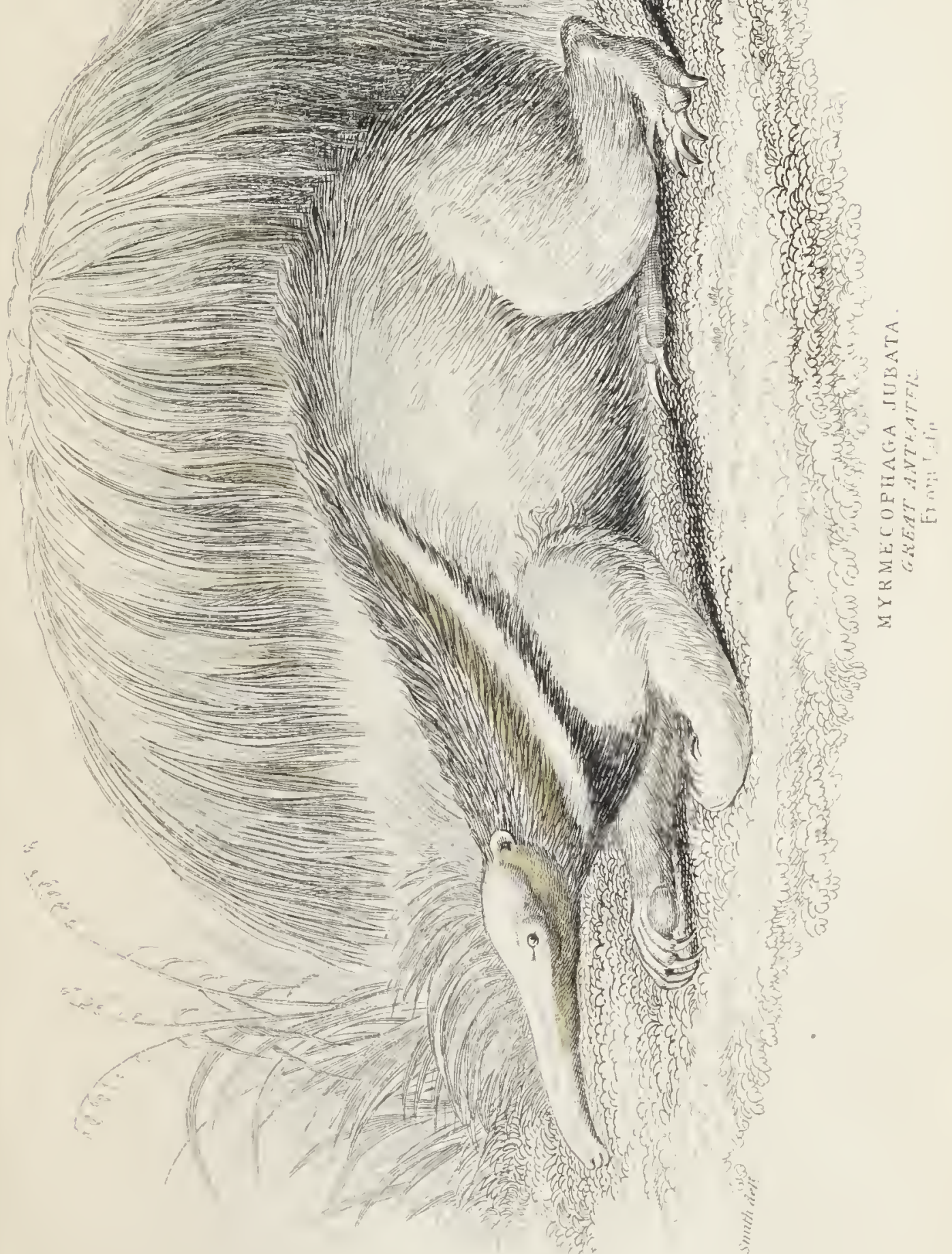



Anteaters of some travellers, being very long, rather slender, low, and long tailed animals, destitute of teeth, covered with several rows of broad horny scales, which they raise when rolled up for their defence. They inhabit Africa, South-eastern Asia, and the Australasian islands. One species was known to the ancients.

There are several species, one, the Short-tailed Manis, or Manis pentadactyla, is the Phatagen of Elian : another, the Long-tailed Manis, or M. tetradactyla, belongs to Senegal, and others have been recently described.

In the Palatinate an ungueal phalanx, or claw joint, has been discovered in the earth, of an extinct Manis, which must have been ahove, 2 i) feet in iength. 
The Rodentia are so named, from the structure of the incisor teeth, which, to the number of two in each jaw, give them the power, and necessitate the practice of gnawing, for they grow up from the roots with such rapidity, that, when not sufficiently used upon hard substances, they rise so that they cannot act upon each. other, and the animal perishes of hunger. Behind the incisors is a void space. there being no canines, and the molars are either with flat crowns, or tuberculated. The cranium is very flat, the orbits not separated by temporal fossæ; the brain almost without convolutions, though rather more complex than in Edentata, approximates the order in more respects to the Marsupials, and, in particular, by the additional character of the teeth, with the genus Phascolomys; the eyes are directed sideways, and their organisation, perhaps with some exception of the Edentata, is in general inferior to the preeeding.

So late as the publication of the "Mammalogie" of Desmarets, 1822, the genera of Rodents were only 24, making 144 species; Mr. Waterhouse, however, in 1839, enumerates no less than 58; and new 
forms being constantly discovered, several additions have been made and others proposed; but, as we have neither in all cases the means of furnishing the characters, nor space left in our volume, and as most of them obtain but a very secondary attention from readers, who are not decidedly attached to the study of Mammalogy, and, moreover, as several species, such as squirrels, hares, rats, and mice, have already obtained a partial review in the Seventh Volume of this Work, where the British Quadrupeds are described, we shall pass over them in rapid notice, dwelling, as on former occasions, only with more detail on a few of the most interesting. In the 58 genera, which, however, do not include Ctenodactylus, Helamys, Otomys of Dr. Smith, Akodon of Meyen; Heteromys of Desmarets, and Saccomys of Fred. Cuvier; there are, nevertheless, enumerated by Mr. Waterhouse, 380 species! So that this order alone will be found to exceed 400 , or more than nearly double the number mentioned in Griffith's Cuvier, published in 1827, for his Synopsis contains only $180 .^{*}$

* We have to notice here the genus Cheiromys, one of those forms in nature whieh baffle systematists in lineal elassifieation, but nevertheless represent the Rodents among Quadrumana, or the Qadrumanous among Rodentia. We think now, that, among the Quadrumana, it should follow immediately after Tarsius, although the dentition offers, as in Rodents, incis. $\frac{2}{2}$, can $\frac{0}{9}, \mathrm{~m} \cdot \frac{4}{5}-\frac{4}{3}=18$ : fore legs short, hinder legs long; tail long, brushy, and the teats, two in number, are inguinal; but the fore hands are eaeh provided with very long 
Although they have been neatly divided into genera with and without clavicles, and that the possession of these bones appears to furnish a greater degree of energy, we nevertheless arrange the Rodentia, according to Mr. Waterhouse's tabular view, into three great tribes, whereof the first embraces the

Murina, all of which possess clavicles.

lst, The Scrunide, or Squirrels, constitute a family of several genera, whereof the Squirrels, properly so called, form the

Genus Scrurus, already described specifically in Volume XV., sufficient for the generalities, which are nearly the same in all the species. Their petulant energy is not without discrimination, and educatable instinct. We have owned a species from South America, which ran at liberty about the house, and, in cases of alarm, would instantly spring on its master's shoulder, and conceal itself in his sleeve. We figure, as a specimen of this form,

and slender fingers, armed with sharp claws, and the hinder have short thumbs with round nails. The Aye-aye of Madagascar, Charomys Madagascariensis, is the only species known. 


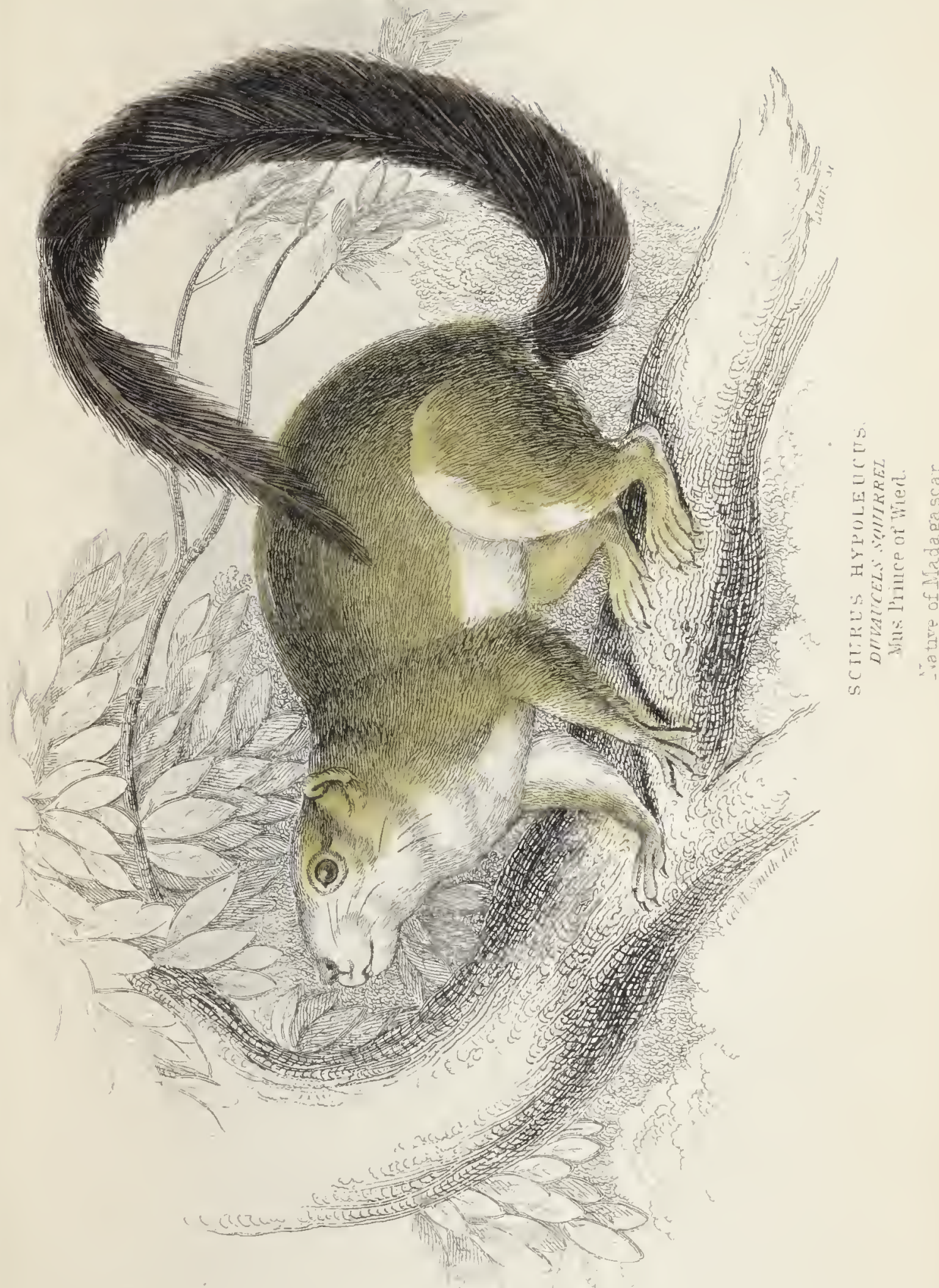



DUVAUCEL'S SQUIRREL.

PLATE XXIV.

Sciurus hypoleucus.

Is size equal to the cat squirrel, with a long flat tail ; the upper parts and outside of the limbs rufous; nose, cheeks, throat, breast, flanks, abdomen, and central under side of tail, white. Native of $\mathrm{Ma}$ dagascar.

We have not space even to name the numerous species known; Mr. Waterhouse enumerating, in Europe and Northern Asia, five species; in North America, twenty; Africa, five; India and Islands, twenty-five; South America and West Indies, five - making sixty. The genus Pтeromys, or Flying Squirrel, whose form is well known, though there be but one species in Europe, we pass without further notice.

The further divisions of the family, which have slight differences in dentition, and are known under the names of the genera Tamias, Xerus, Spermophilus, or Marmots, with cheek pouches; and Arctomys, without cheek pouches, and a new genus? Aplodontia, which terminates the Sciurida, includ- 
ing 107 species;-we think, by no means the whole.

In the next we have the

2d, Muride or Rats, with the molars varying in the different genera from $\frac{3}{3}-\frac{3}{3}$ to $\frac{4}{4}-\frac{4}{4}$, the first of which is Myoxus or the Dormouse, and Graphiurus, not generically different. They are still destitute of anterior thumbs, and have a well furnished brush to the tail.

M. glis, or the Fat Dormouse, described in Volume VII., is one of the best known of the eight or ten species enumerated. The genus Dipus, twelve species, and Merionis, two species, include the graceful Jerboas, or Jumping Mice of Africa, Central Asia, and North America. Here we think may be placed Helamys or Pedetes, the Springhaas of the Cape; and next Mus, the Rats and Mice Proper, sub-divided into Mus hisperomys, Dendromys, Gerbillus, Reithromys, Psammomys, Phlocomys, Sigmodon, Euryotis and Rhizomys, form at least ninety species of every quarter of the world, and in greatest number in South America and the West India Islands; and Cricetus, or the Hamsters, reckon eight more.

3d, The Arvicolide, Voles or Campagnols, with molars $\frac{3}{5}-\frac{3}{5}$, enumerate first, the

Genus Castor, or Beaver, the most important animal to the fur traders; and remarkable for its bulk, trowel-shaped scaly tail, and instinctive habits of building in society, making dams to keep the water up and for the superstitions to which these 
peculiarities give origin. There are two species, one of North America, the other of Europe, more chiefly confined to Poland, under the name of Bolr. Fiber or ONDatra, a second genus, shaped like an enormous rat, with a long and compressed tail, of which the $F$. zilethicus, or Musk Rat of North America, is the only species. Then the genus Arvicola Proper, which includes our Water Rat, Field Mouse, \&c., forming twenty-eight species. The genus Lemmus, the Lemmings, with four or five toes on the anterior feet, eight species; Spalax, or Blind Rats, two; and Geomys, ten species.

Hystricina.-In the second division are placed the Rodents with imperfect clavicles, of which the first family is that of Hystricice, or Porcupines, forming the sub-genera Hystrix, Erethison, Cercolabes, Atherurus, and Synetheres, to include only ten species, of which the Crested Porcupine, $H$. cristata, is the most conspicuous; Erethison Buffonii, or Prehensile Tailed Porcupine, the most common in museums. The Canada Porcupine, E. dorsata, we have seen defending itself by striking with the cluster of spines at the end of its tail, leaving some of them sticking in the hand of the person who gave it offence.

The next group contains the Dasyproctida, the Agoutis. The cheek teeth $\frac{4}{4}-\frac{4}{4}$, four toes and tubercles on the fore feet, three toes on the hinder, sole of the feet callous, naked. They inhabit South America and the West India Islands: three or four species. We have seen D. Acuschy, or Olive Agouti, 
dressed for the table, at Roseau, in Dominica, in 1797.

Genus Ceclogenys, the Pacas, approaches the former species, but is heavier, with very small additional toes on the feet, making them 5-5. The only species is brown or buff, with round white spots.

The Capromyides, or Houtias.-Divided into nine genera, forming twenty-eight species, have molars $\frac{4}{4}-\frac{4}{4}$; resemble very large rats, with four toes and rudiment on the anterior, and five toes on the posterior feet, three species ; Aulacodus one; Orycterus, one; Bathyergus, or Mole Rats, four ; Myopotamus, or Racoonda, one, with fur like the beaver. Echimys, or Spinous Rats, ten species, of which we give

LONG-TOED SPINOUS RAT.

PIATE XXV.

Echimys dactilinus, GEOFF.

TuE back covered with short spines, partly concealed by the hair. This species has the two middle toes of the fore feet very long; the colour is brown. Habitat, South America. Petromys, one; and $\mathrm{Ne}$ lomys, six species.

The Octodontidce, with molars still $\frac{4}{4}-\frac{4}{4}$, and feet $5-5$, are composed of the genera Ctenomys, two 


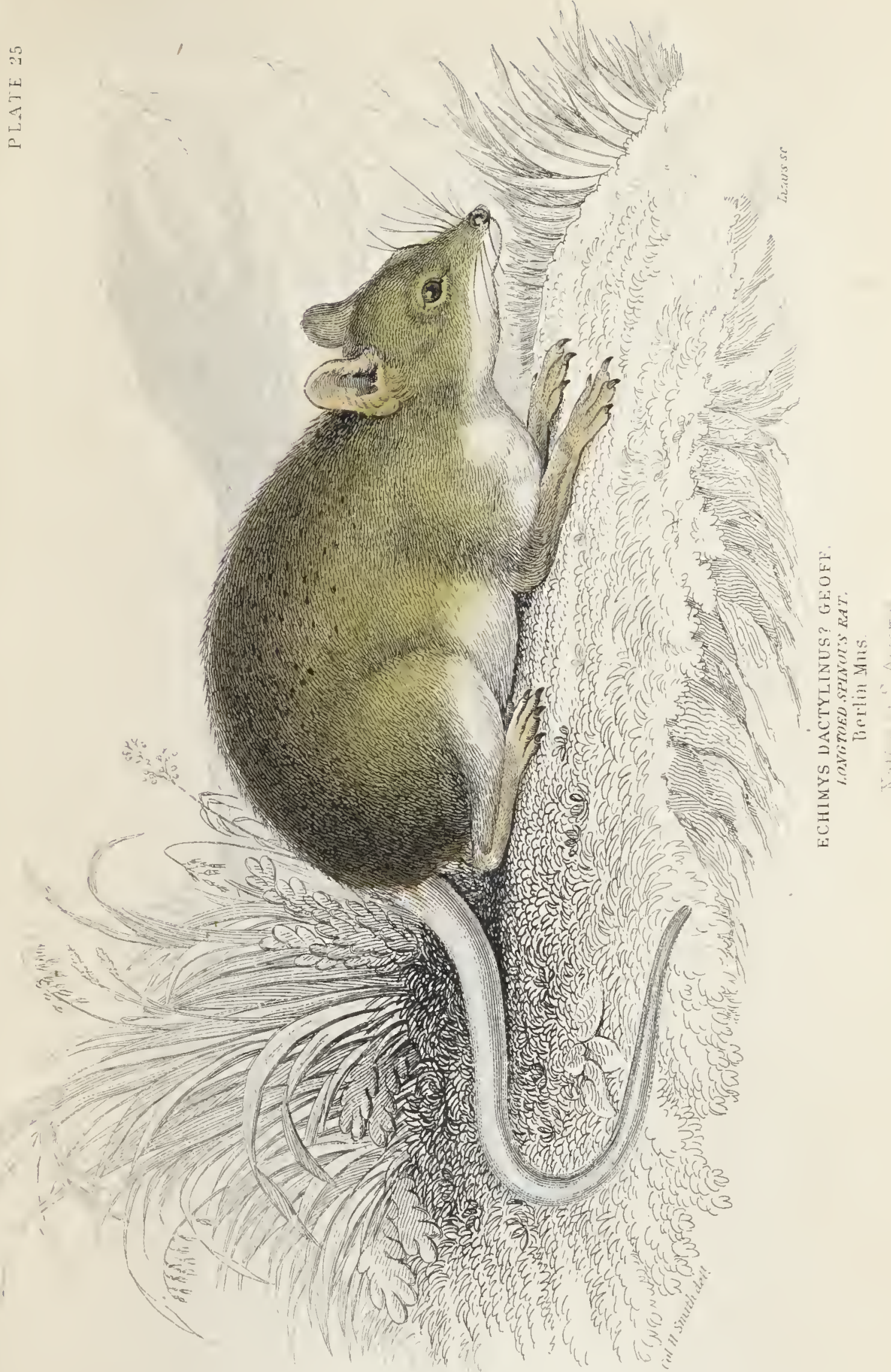





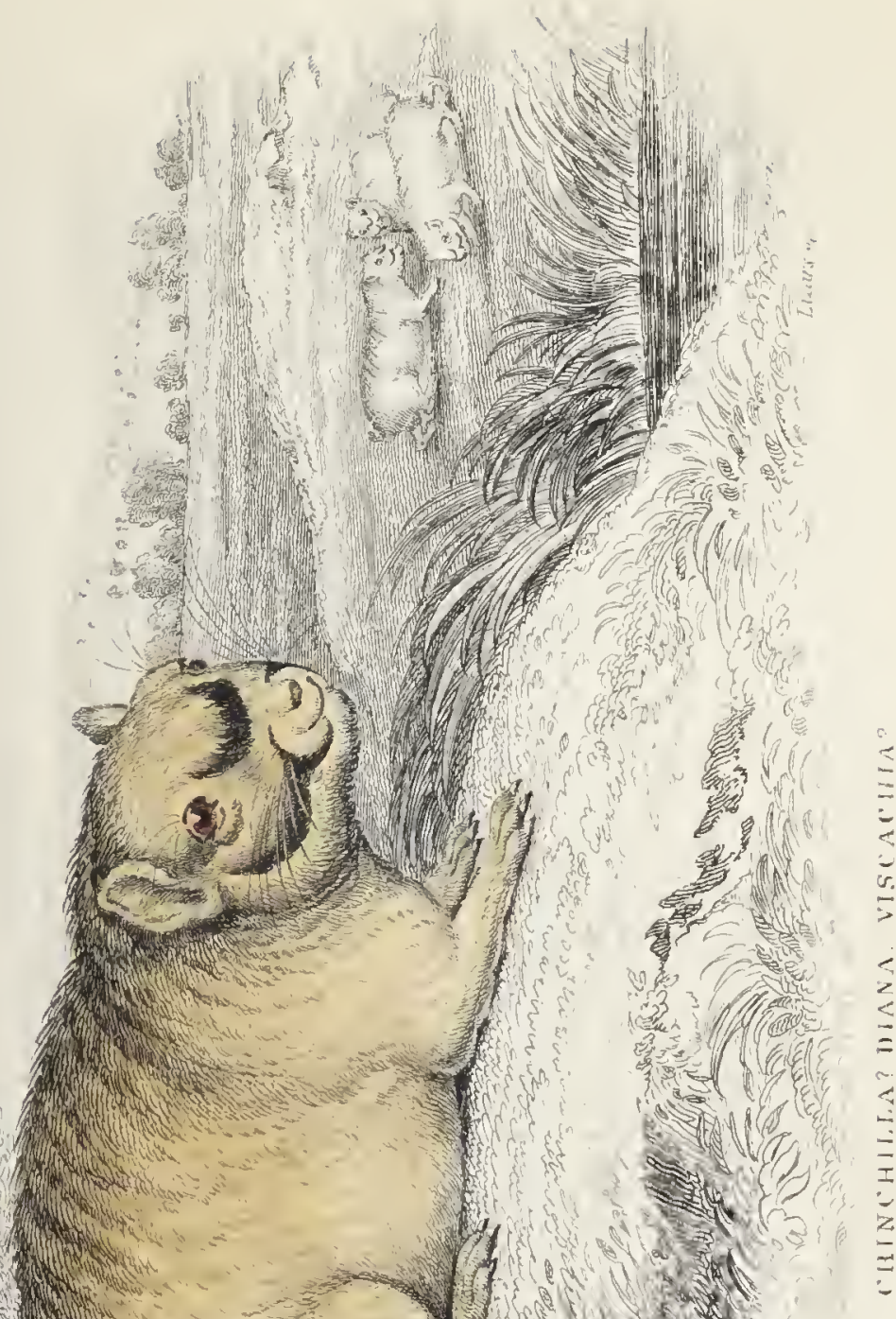

$-30$

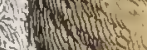

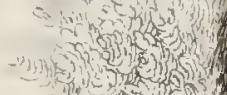



species; Poephagomys, one; Octodon, one; and, Abrocoma, one-all animals externally bearing resemblance to rats. They are natives of South America. We now come to

The Chinchillidce, a small family entirely herbivorous, with a dentition we have not been able to ascertain. They have four toes and a rudiment on the anterior, and only three toes on the posterier extremities. The species known, are, Chinchilla, one; Lagotis, two; and Lagostomus, one. We figure

\section{PLATE XXVI.}

Chinchilla Diana, Viscachia?

A specimen under this name was formerly in the possession of Mr. Cross, already engraved in Griffith's Cuvier. We could not find, at the time, an opportunity of examining the animal, which was inaccessible for that purpose.

\section{THE CAVIIDÆ,}

Alu natives of America, among which the Cavia cobaia, or Guinea Pig, is well known. There are, of this family, the genus Cavia, six species; Kerodon, two; Dolichotis, one; and 
One species, in bulk equal to a Chinese Pig, the largest animal of the Rodentia, having a very deep square head; coarse hair; the feet webbed; no tail; the animal is gregarious in the rivers of Guiana, and very delicate food.

In the 3d division Leporina, forming

The LEPORID 2 or Hares, well known, and having three species described in Volume VII. of this work. There are two genera, Lepus or the Hare, whereof thirty-one species are known, among which we figure

\section{PLATE XXVIII.}

\section{Lepus Brasiliensis, The Tapeti,}

Drawn from life; specimen not larger than a wild rabbit; ashy-brown; yellowish-grey above ; a white half collar on the throat, and a very short tail : inhabits Brazil and the uplands of tropical America.

Genus Lagomys, or Pica, with shorter ears, similar teeth to the former; legs nearly of equal length; no tail.

L. pika, or Alpine Hare, and four other species. 
ii 



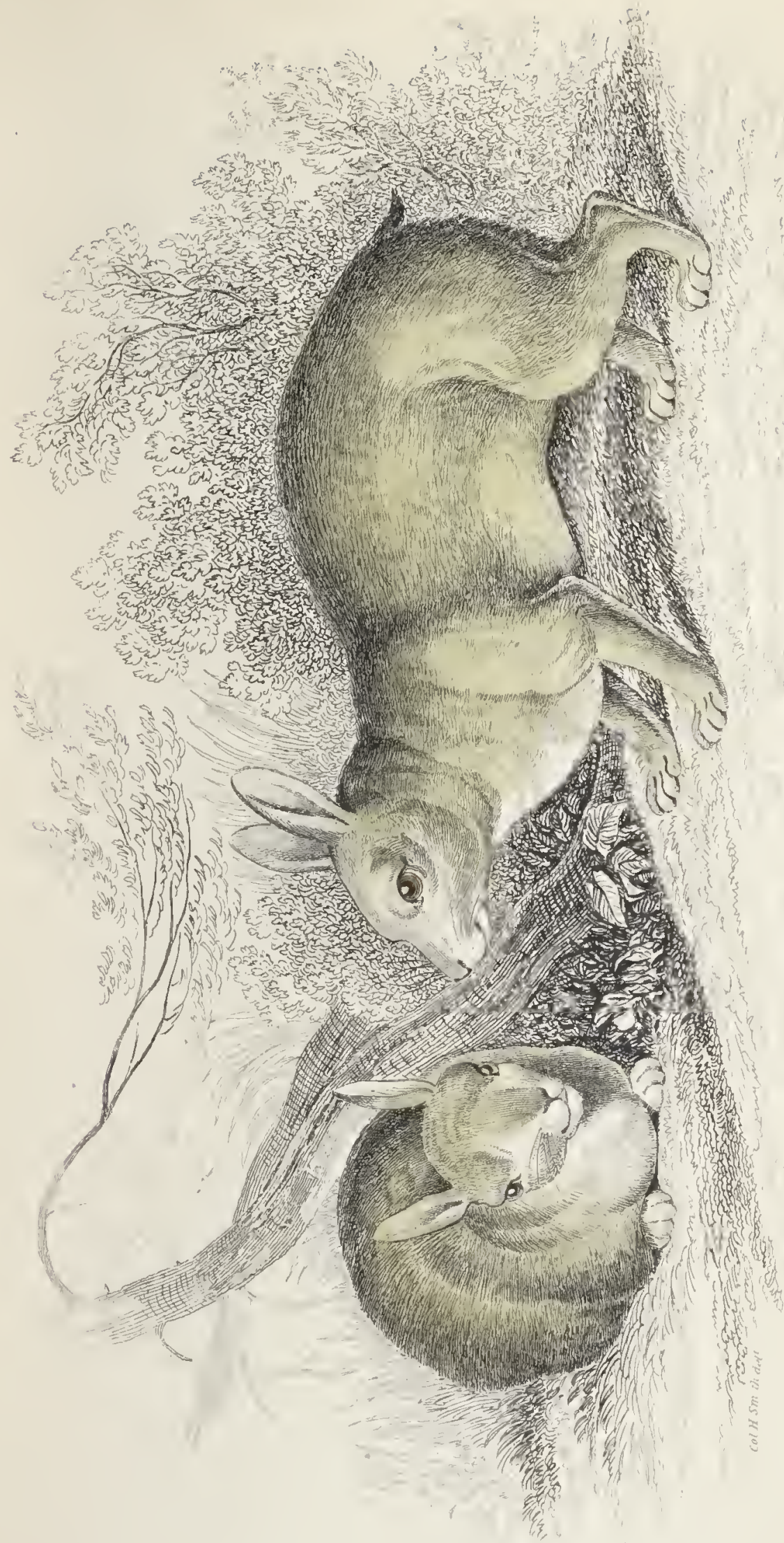

is

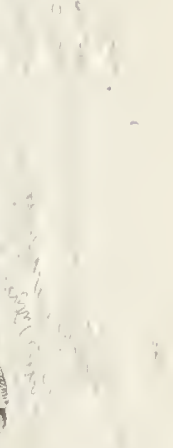





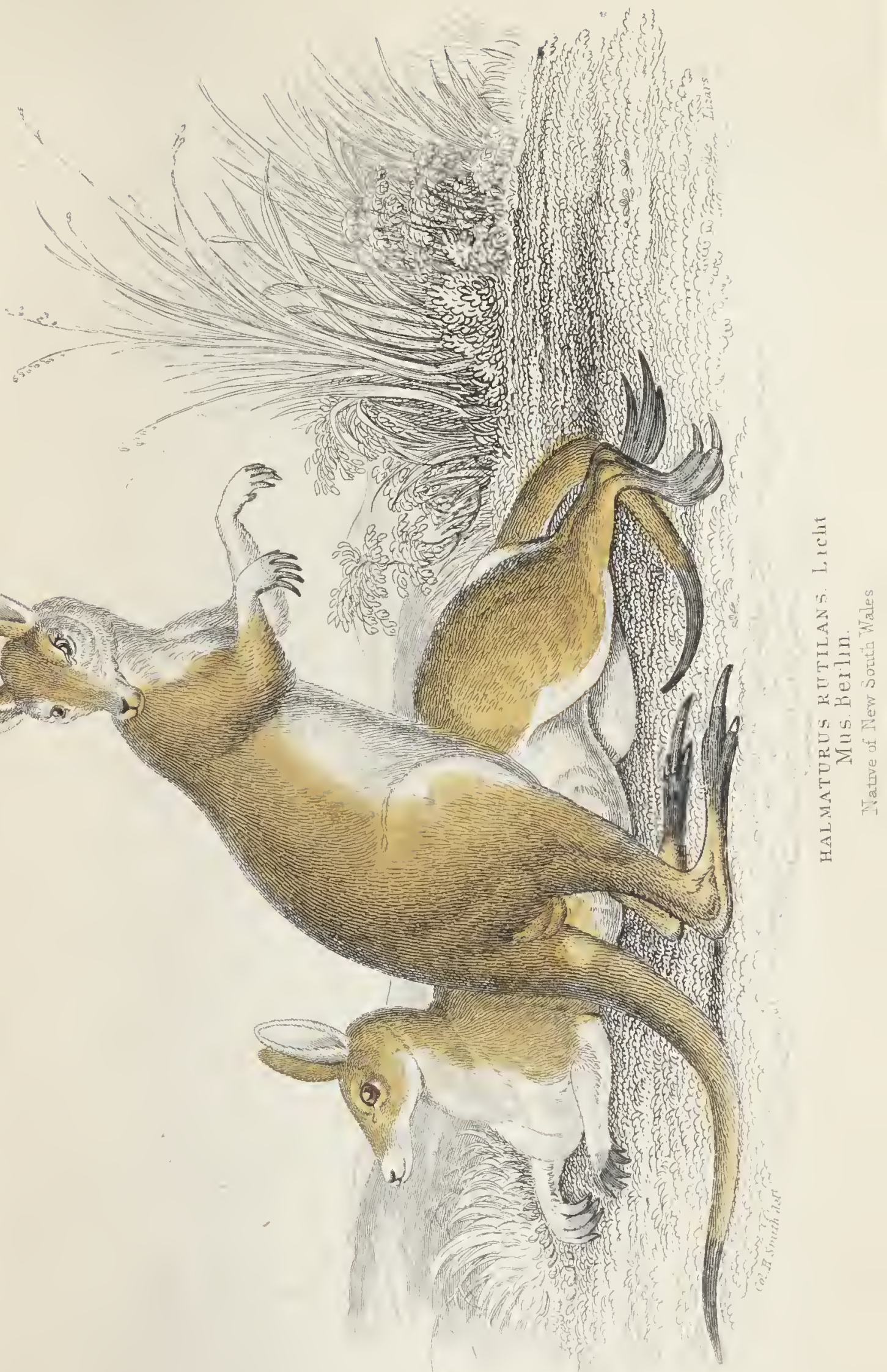





\section{1}

ORDER XI.

THE MARSUPIALIA OR POUCHED ANIMALS.

For this order we refer entirely to the detailed descriptions given in the Eleventh Volume of this work, wishing to add only one species, which appears to have escaped the author, Mr. Waterhouse, and we have not yet found, in the splendid work on this order, now publishing by Mr. Gould. It is

\section{PLATE XXIX}

\section{Halmaturus Rutilans, Lichт.,}

OF which species we found specimens both of male and female in the Museum of Berlin. They are beautiful animals, about three feet high from the head to the ground, in a seated erect posture; the back and upper parts entirely bright reddish; the inferior white, and the feet and tip of tail black. 
ThIS is likewise treated in detail in the Volume already mentioned. We give only the figure of a species, we believe not hitherto published, of

\section{P L A T E X X X}

\section{Echidna setosa.}

ONE nearly allied to Echidna hystrix, but with the snout still more slender, the spines fewer and hid within the fur ; we believe, always destitute of spurs on the hind feet. Ornitnoryncuus forms the only other genus of this order.

THUS we terminate the Introduction to the Mammalia, wherein it has been found necessary to refer to the Volumes of the Naturalist's Library for those orders, genera, and species, which are therein described at length: we have likewise abbreviated, or treated summarily, groups which presented less in- 


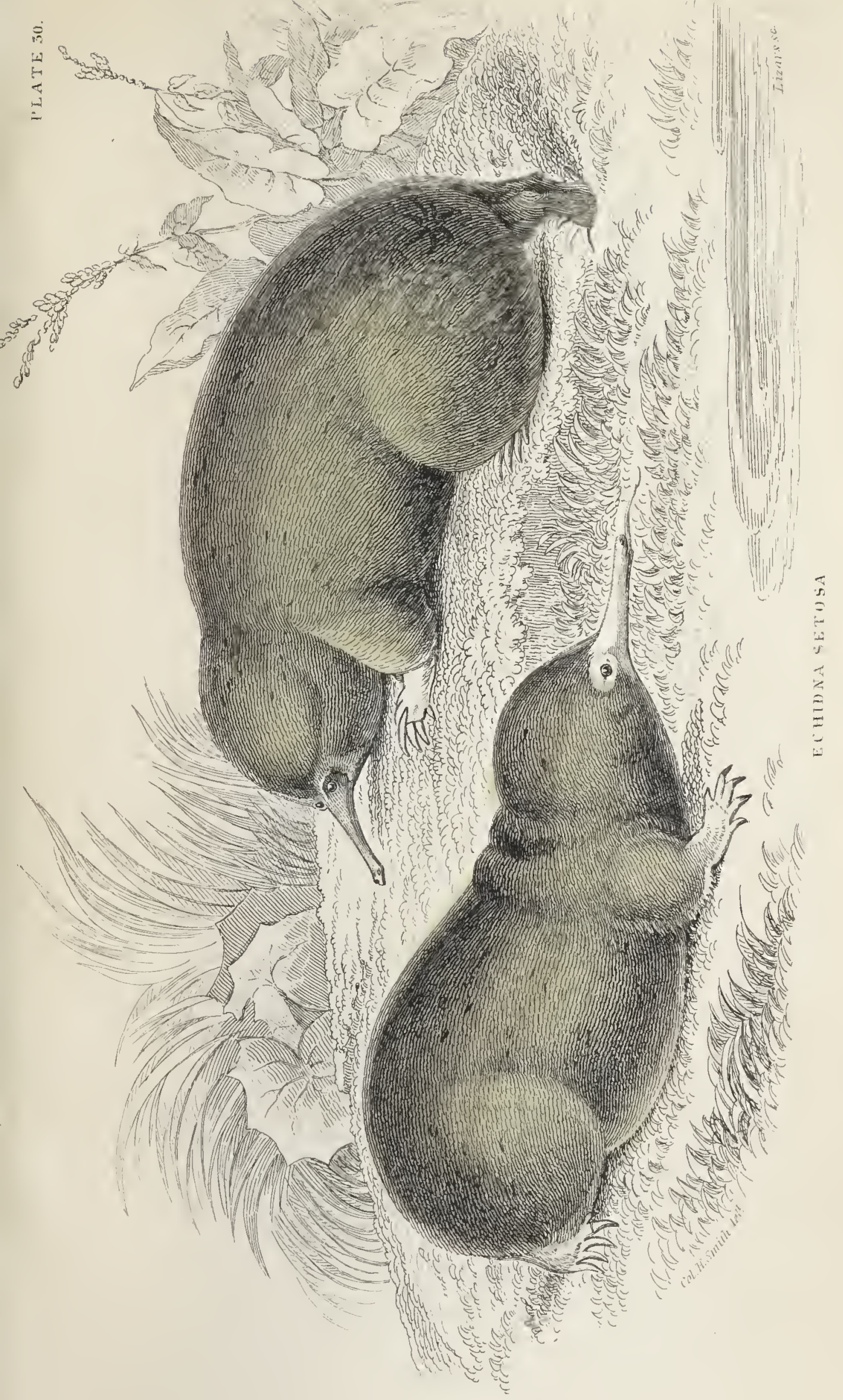



terest to readers who are not professedly students in the science, in order to preserve somewhat more space for genera of greater importance, and close this incomplete Essay, in the hope that a full and detailed Synopsis of the Mammalia may be shortly undertaken, illustrated with abundant Plates, and sufficiently detailed to notice all the discoveries and additions made by the zealous Naturalists of the present time. 

. 



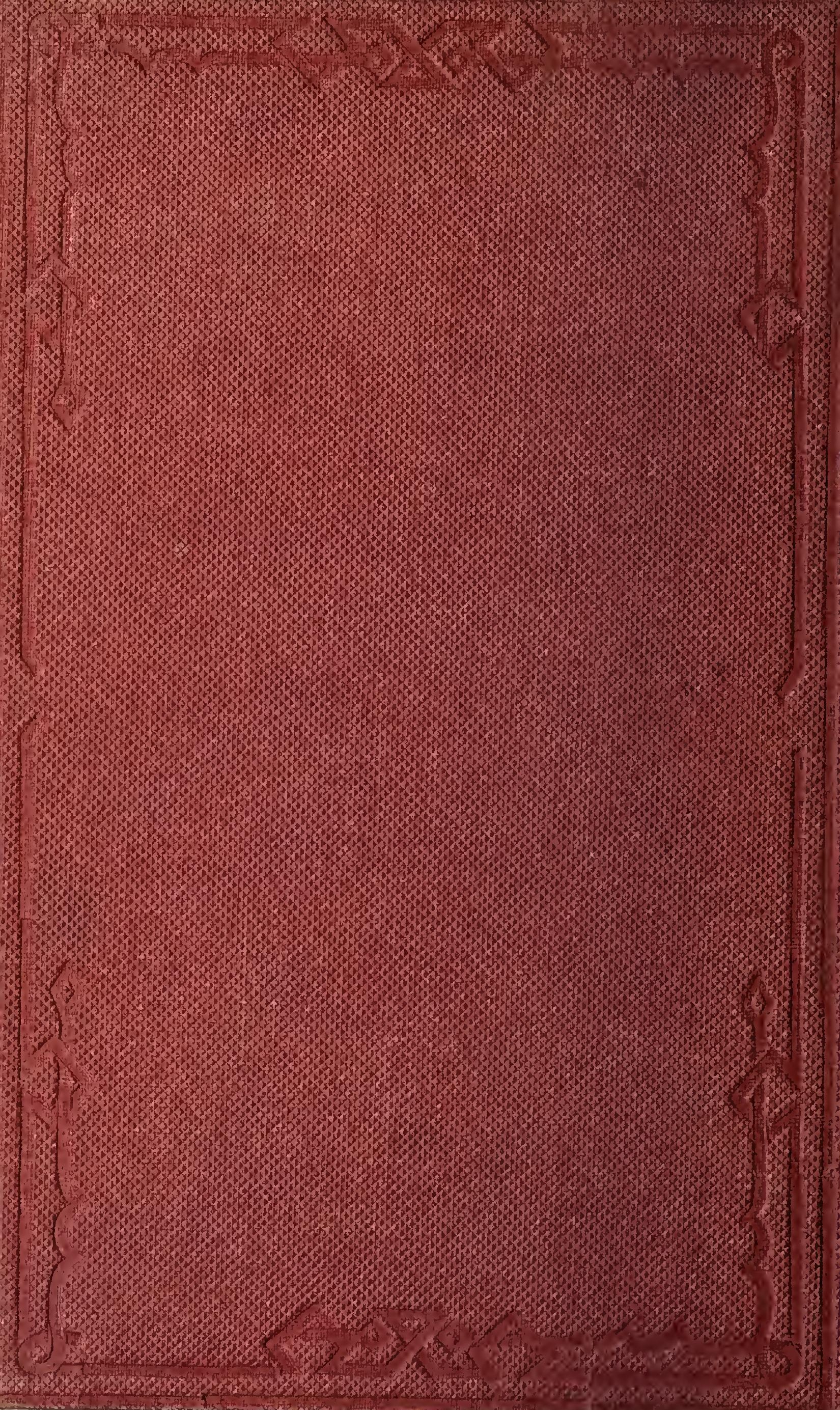

